\title{
THE IMPACTS OF PREDATION AND HABITAT DEGRADATION ON CORAL REEF SPONGE ASSEMBLAGES IN SE SULAWESI, INDONESIA
}

BY

ABIGAIL POWELL

\author{
A thesis \\ submitted to Victoria University of Wellington \\ in fulfilment of the requirements for the degree of \\ Doctor of Philosophy in Science
}

2013

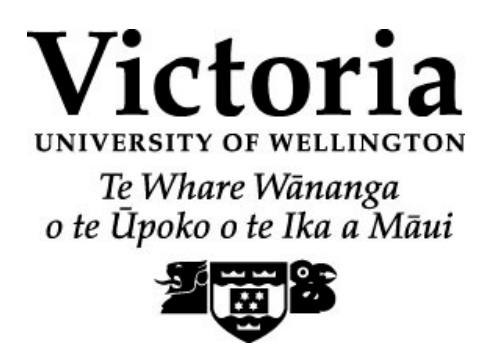




\section{Acknowledgements}

I would like to thank my primary academic supervisor, Dr James Bell, for his unwavering support, insight and guidance throughout this thesis, as well as for his encouragement, honest and helpful feedback on manuscripts and funding applications, and for working with me in the field on a number of occasions. Thanks are also due to Dr David Smith and Dr Leanne Hepburn, my secondary supervisors from the University of Essex in the UK for their advice and feedback during my fieldwork in Indonesia.

I am very grateful to the Commonwealth Scholarship Commission in the UK and Victoria University of Wellington for enabling me to carry out my research in New Zealand on a Commonwealth Scholarship. Thanks are also due to Operation Wallacea for providing funding for my fieldwork in Indonesia. Additional funding for fieldwork and conference attendance were provided by two VUW faculty research grant scholarships and a New Zealand Postgraduate Study Abroad award. I am also grateful to Victoria University of Wellington for a VUW submission scholarship.

I wish to thank the staff of Hoga Island Marine Research Station, and particularly the site manager, Philippa Mansell, who all provided incredible support during my field trips and made my time in Indonesia so special. I would also like to say a big thank you to Jocelyn Curtis Quick, Gabriella Ahmadia, Matthew Fynes, Ian Hendy, Jason Williams, Bridget Tiffany, John Eme, Dan Lazell and the other members of Hoga science staff for diving and field assistance and for keeping me on track during the hectic Hoga seasons.

I am very grateful to the staff and students at the Victoria University Coastal Marine Ecology Laboratory and School of Biological Sciences in New Zealand for their input and encouragement and to Hugo Powell for proof reading assistance. Special thanks go to Ingrid Knapp, my fellow sponge $\mathrm{PhD}$ buddy and officemate for her insights and friendship over the past four years. Thanks also to Patricia Stein at the VUW Science Faculty for her excellent advice and helping me to navigate the university system. 
Finally, I would like to thank my partner Tim for his personal support, perceptive comments and advice, and for keeping me going when things got tough. Lastly, I would like to thank my mother Jan for her emotional, not to mention financial support and her continual encouragement of my work. This thesis is dedicated to her, and in memory of my father Chris, who passed on their love of the sea to me. 


\begin{abstract}
Coral reefs across the globe are in decline due to multiple threats including overexploitation, pollution, coastal development, climate change and ocean acidification. Much research has focused on the effects of these threats on hard corals while their impacts on other important benthic invertebrate groups have been overlooked. Sponges are a diverse and abundant component of coral reef communities in the Indo-Pacific that play important functional roles on reefs including nutrient cycling, linking primary and secondary production, reef bioerosion and spatial competition. Consequently, changes in the abundance and distribution patterns of sponges can affect overall reef ecosystem function. Understanding the factors that control sponge distribution patterns is therefore essential for the successful prediction and mitigation of the effects of current threats to reef systems.
\end{abstract}

Sponge distributions are known to be affected by a number of abiotic factors such as wave action, sedimentation and water flow, but the role of biological factors such as predation and competition is less clear. The primary aim of my thesis was to determine the effects of predation on the distribution and abundance of sponge assemblages in the Wakatobi Marine National Park (WMNP), SE Sulawesi, Indonesia. My first objective (chapter 2) was to identify the major spongivores in the Wakatobi using surveys and behavioural observations of key invertebrate (nudibranchs and starfish) and vertebrate taxa (fish). I then adopted a statistical modelling approach (chapter 3) to examine associations between sponges and a suite of abiotic and biological factors, including spongivore abundance, across nine sites in the WMNP. The results of this analysis showed that although sponge assemblage composition was weakly associated with spongivore abundance, sedimentation is more likely to have a greater impact on sponge abundance and distribution patterns. I found that degraded sites were characterized by low diversity sponge assemblages dominated by a single sediment tolerant species Lamellodysidea herbacea.

In order to explore the relationship between sponges and spongivore abundance further, I used an experimental approach (chapter 4), establishing a caging experiment to examine the effect of excluding predators on reef slope sponge assemblages. The 
caging experiment did not reveal any effects of predator exclusion on sponge abundance or diversity. In the last data chapter (chapter 5), I focus on sub-lethal predation effects on sponges and examine the extent and impact of partial predation on the Indo-Pacific giant barrel sponge Xestospongia testudinaria. Video observations of fish predation and measurements of barrel sponge regeneration rates were used to model the impacts of predation on barrel sponges.

In summary, a combination of observational, modelling and experimental approaches were used in order to determine the impact of fish predation on Indo-Pacific sponge assemblages. Spongivory does not appear to have a major influence on the abundance and distribution of reef sponges but is an important trophic link in reef ecosystems. Ecologically important sponge species, such as the giant barrel sponge $X$. testudinaria, are exposed to intensive partial predation and future changes in predation intensity could have consequences for the fitness of these species. Finally, my work suggests that changes on reefs such as increases in sedimentation could produce a shift from coral dominated to lower diversity sponge dominated communities. 


\section{Table of Contents}

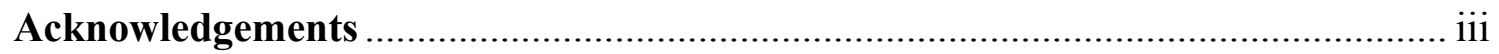

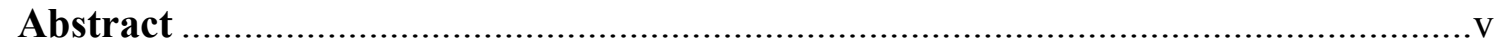

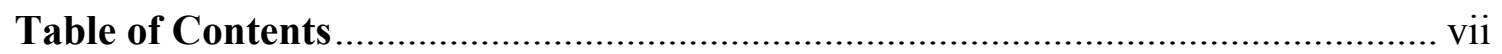

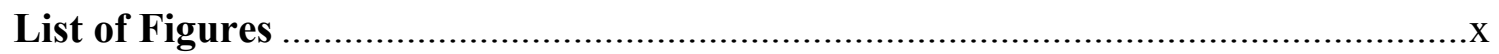

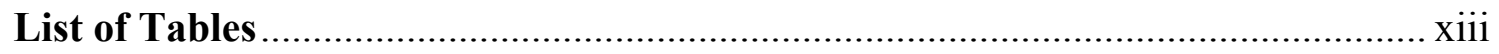

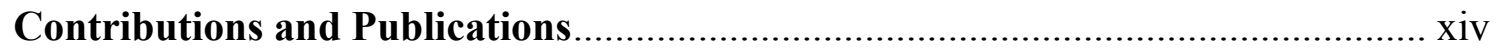

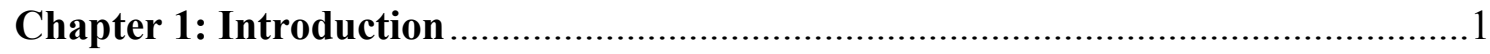

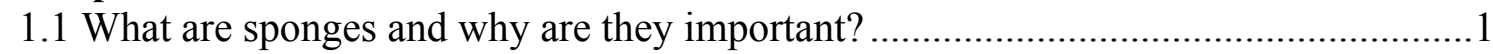

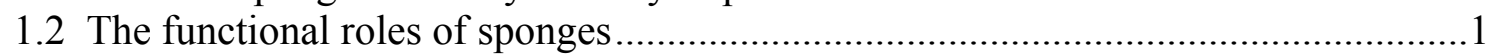

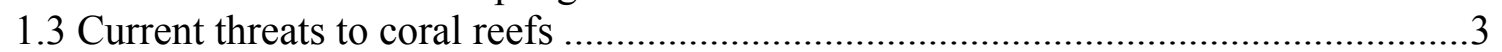

1.3.1 Determining the impacts on sponge assemblages ................................................

1.4 The role of abiotic factors in determining sponge diversity and abundance ..............5

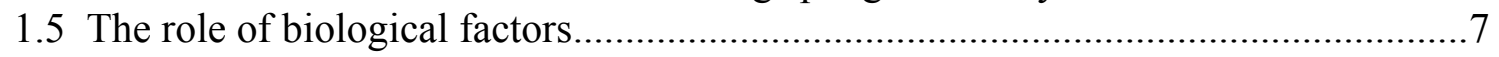

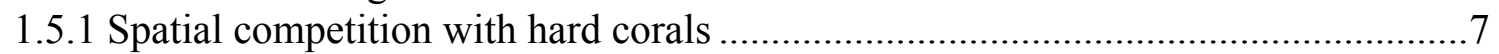

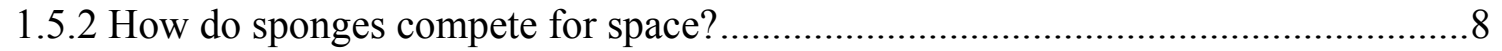

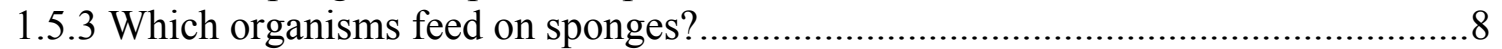

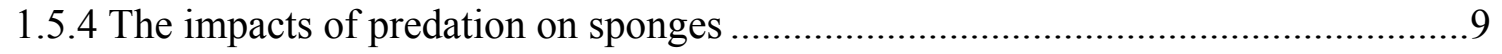

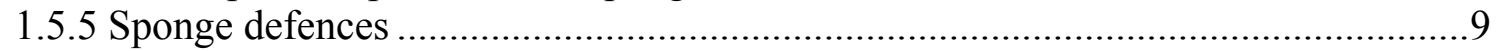

1.5.6 How important is fish predation in determining sponge diversity and abundance

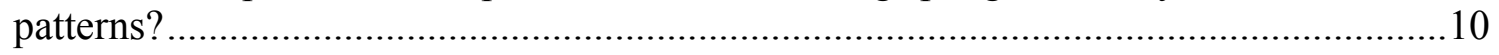

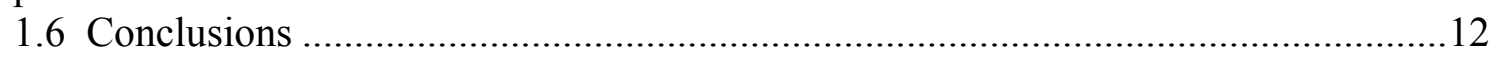

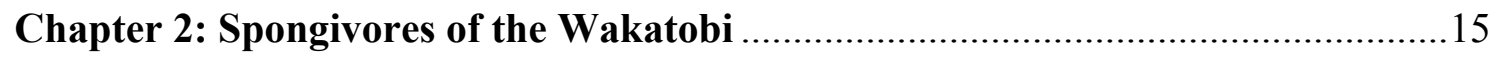

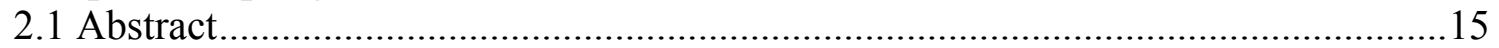

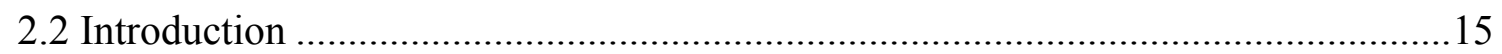

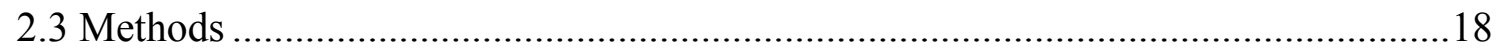

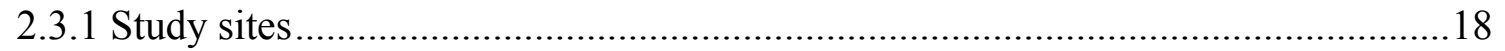

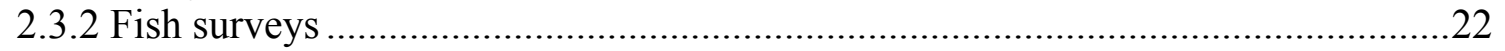

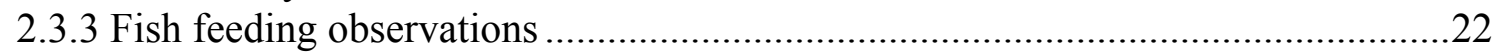

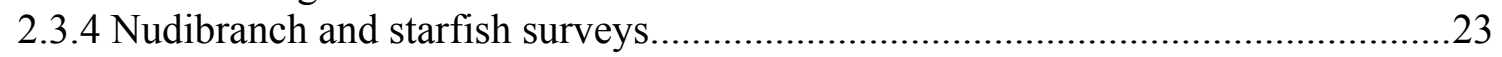

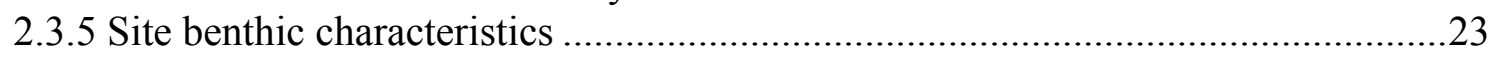

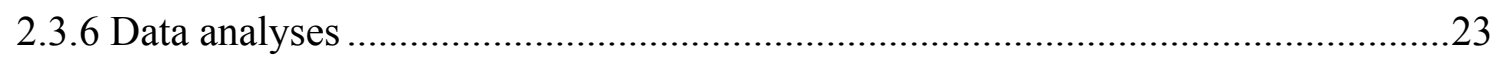

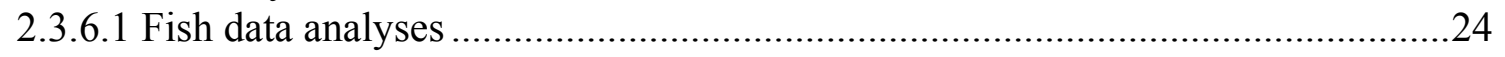

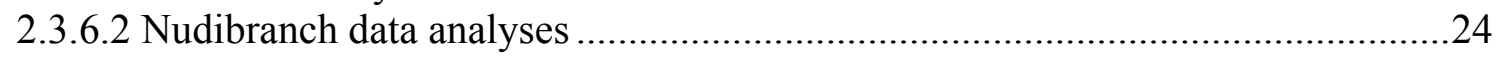

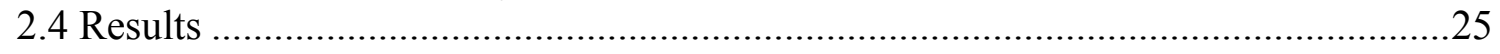

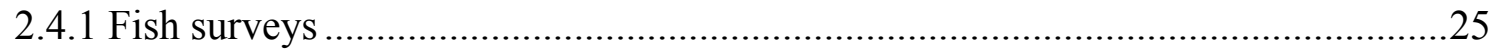

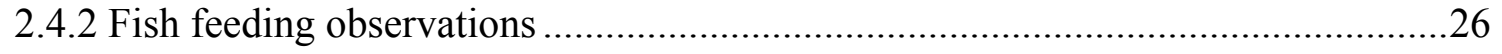

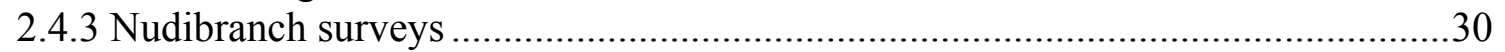

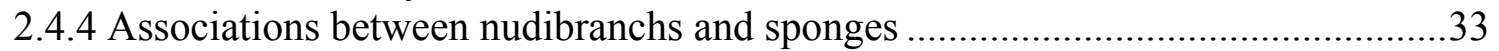

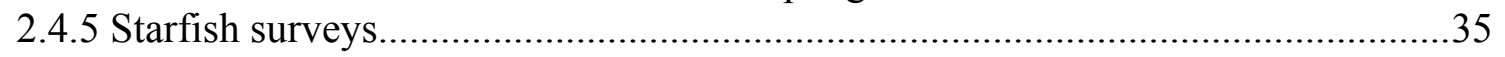

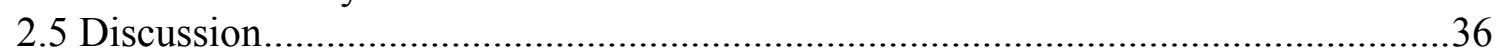


Chapter 3: Identifying biological and environmental factors associated with

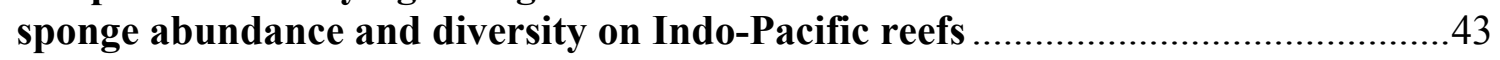

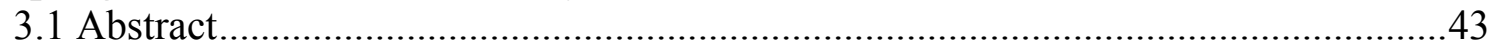

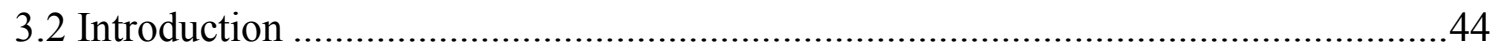

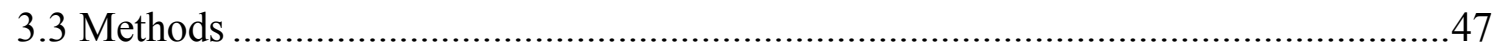

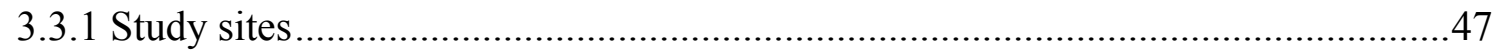

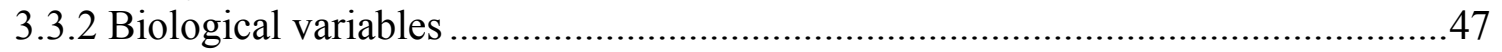

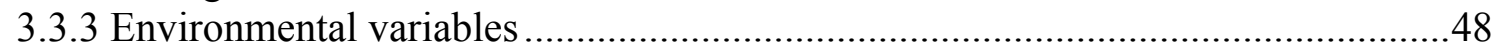

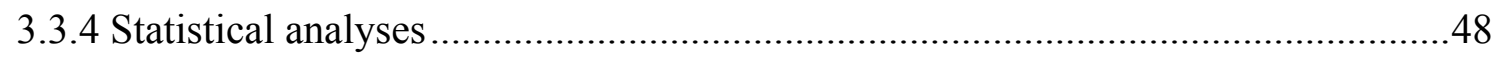

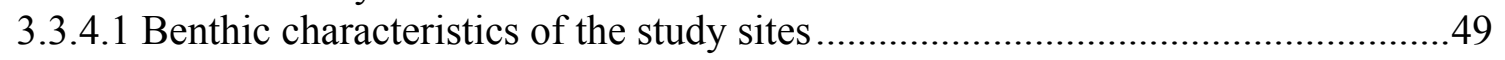

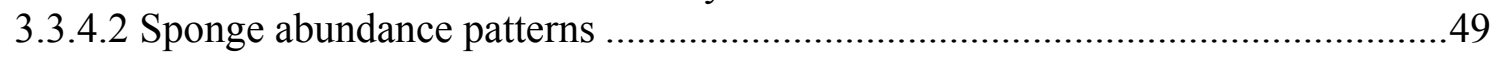

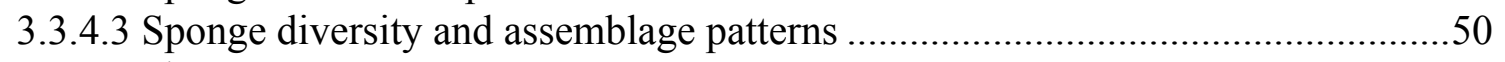

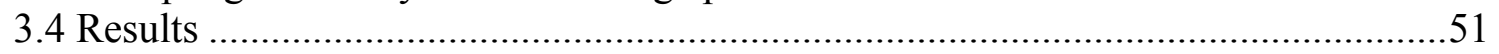

3.4.1 Environmental variables and benthic characteristics of the study sites..................51

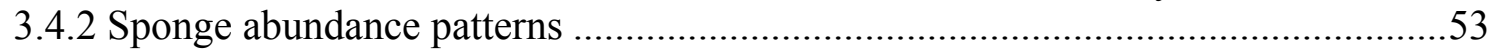

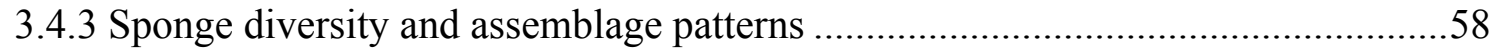

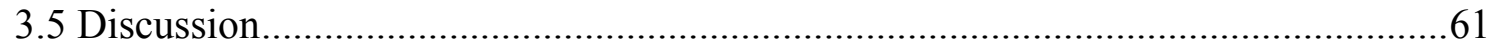

3.5.1 Identification of variables correlated with sponge abundance and their relative

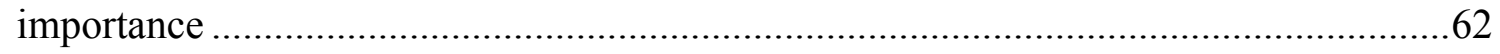

3.5.2 Identification of the variables associated with sponge assemblages and their

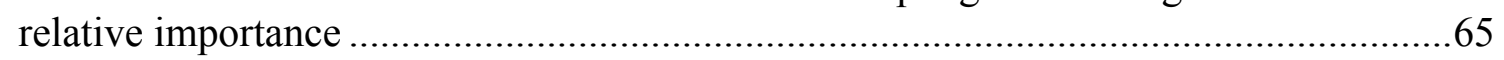

Chapter 4: The effects of predator exclusion on Indo-Pacific sponge assemblages 69

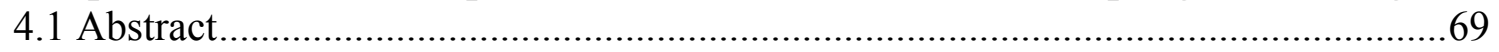

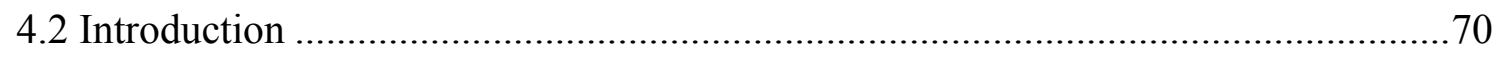

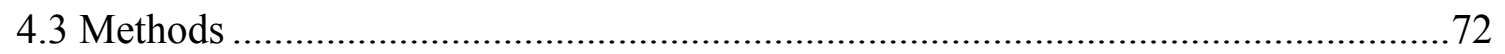

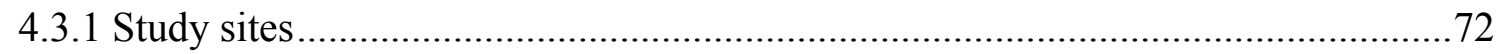

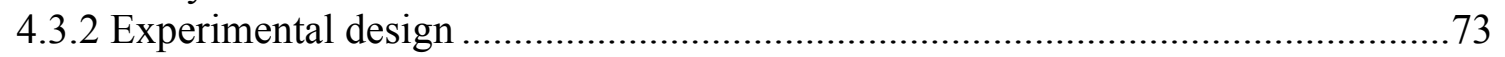

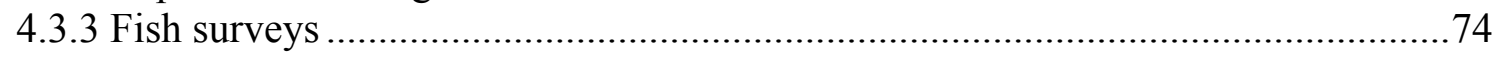

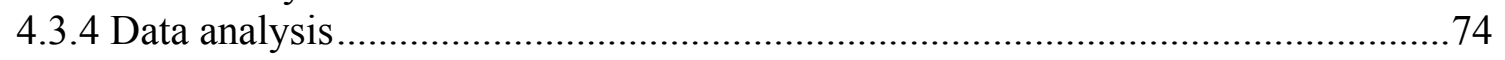

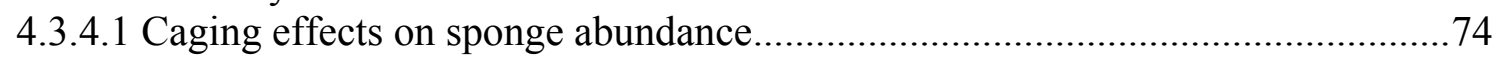

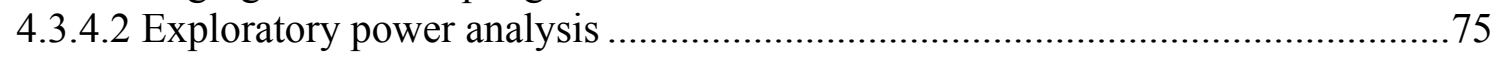

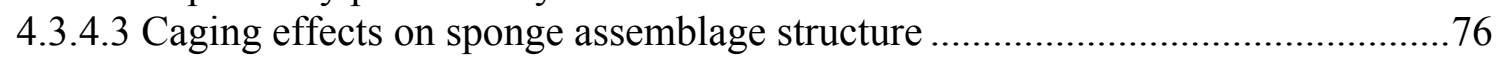

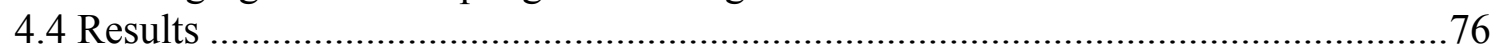

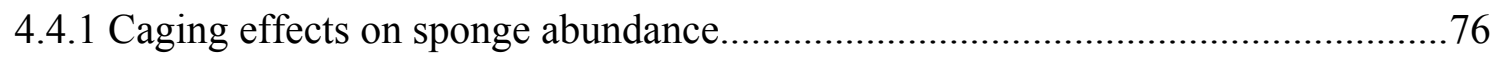

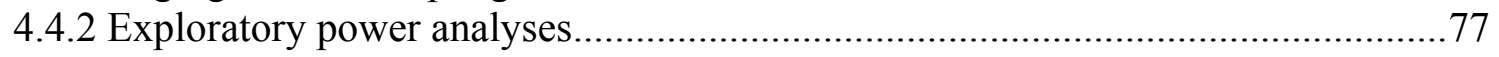

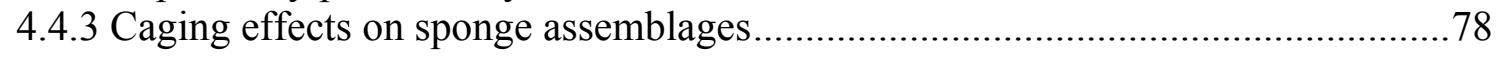

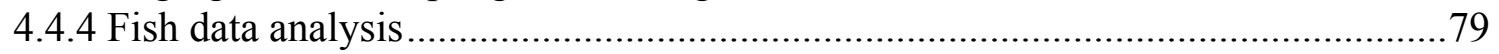

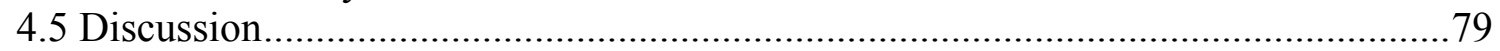

Chapter 5: Fish predation on the Indo-Pacific giant barrel sponge, Xestospongia

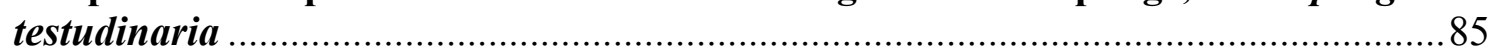

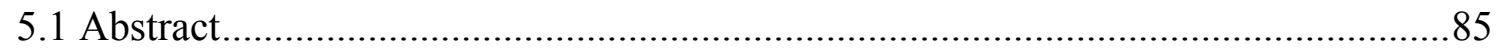

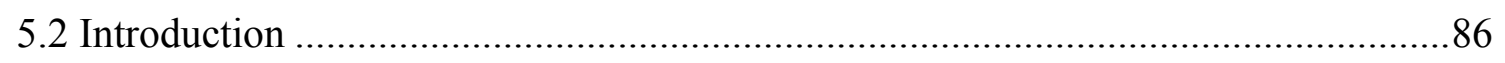

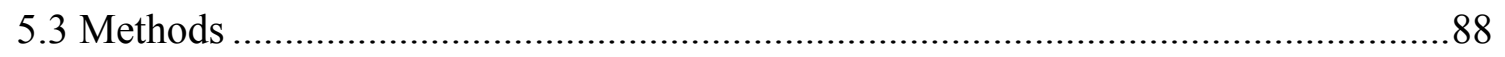

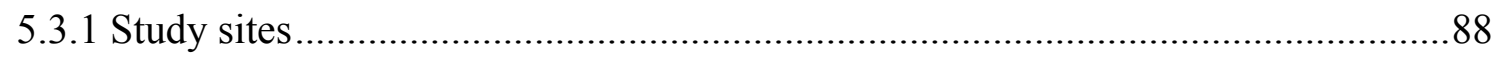

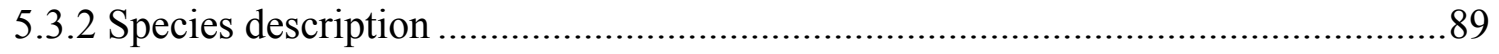




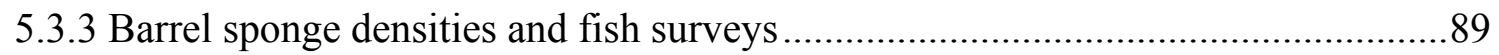

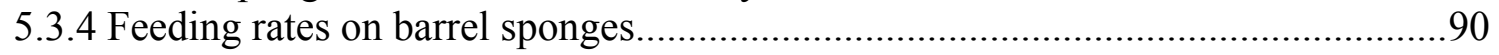

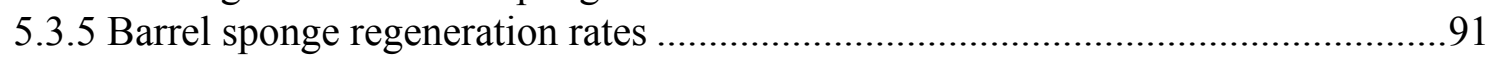

5.3.6 Amount of sponge material consumed by fish ...................................................92

5.3.7 Regression analysis to determine the factors associated with fish predation on

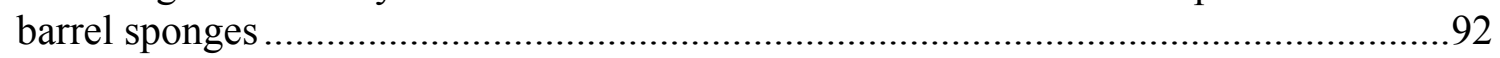

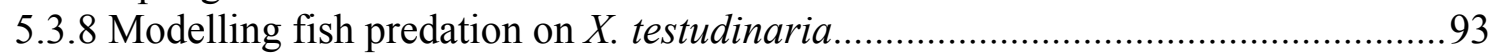

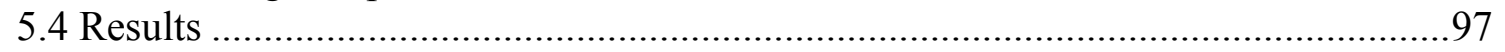

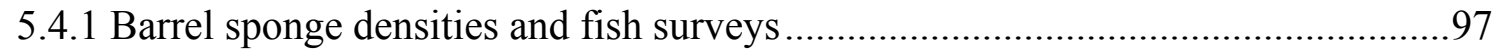

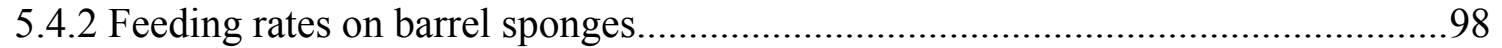

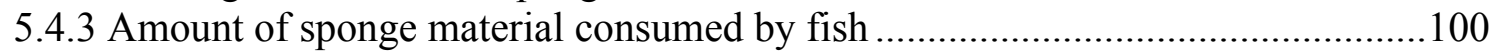

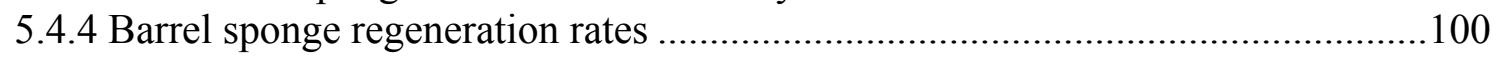

5.4.5 Regression analysis to determine factors associated with fish predation levels on

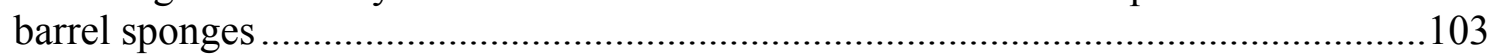

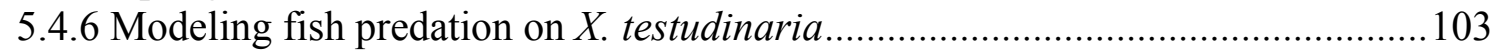

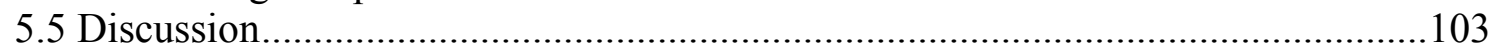

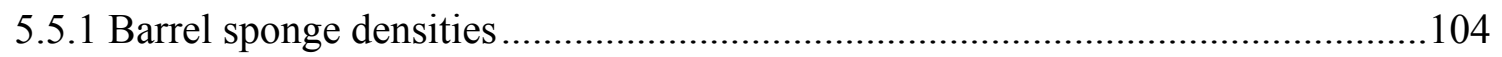

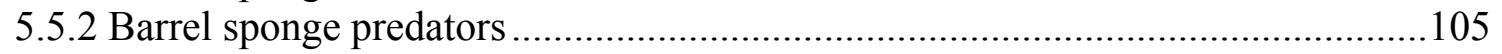

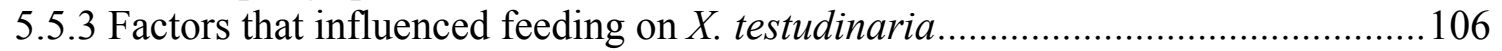

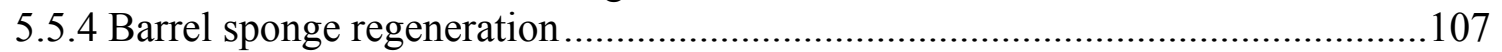

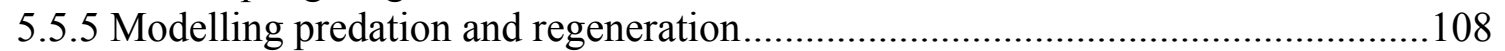

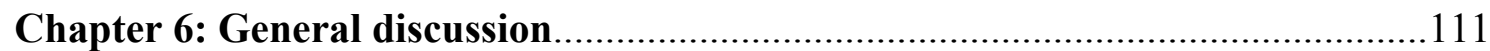

6.1 Which factors control the distribution and abundance of Indo-Pacific sponges? ...111

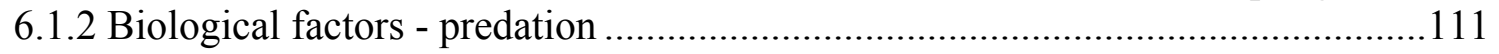

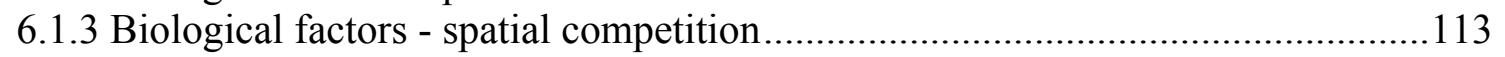

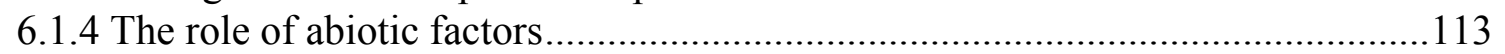

6.2 What are the implications of partial predation on reef sponges? ...........................114

6.3 What are the likely effects of reef ecosystem degradation on sponge assemblages?116

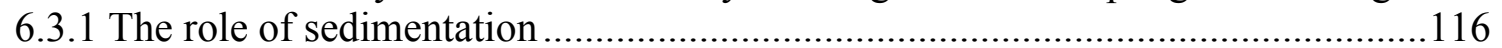

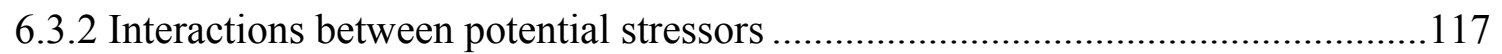

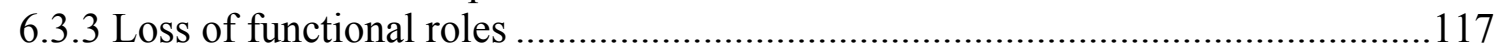

6.4 How can the findings of this thesis inform coral reef management? ......................119

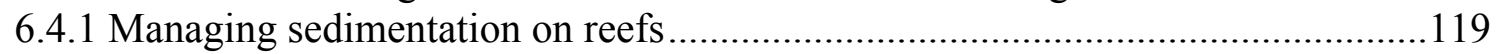

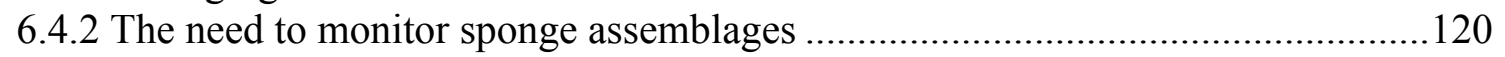

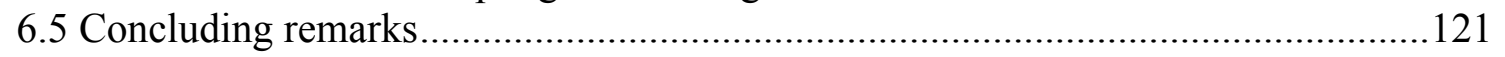

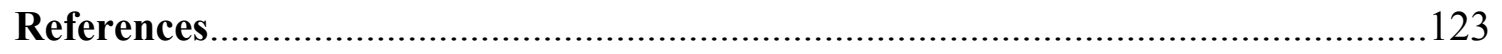

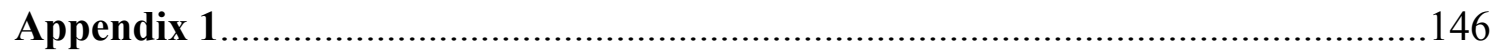

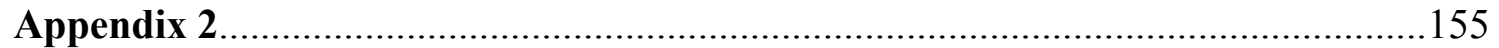

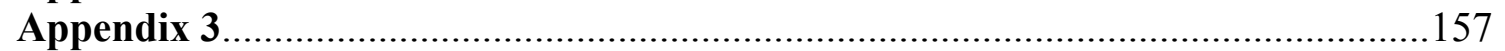

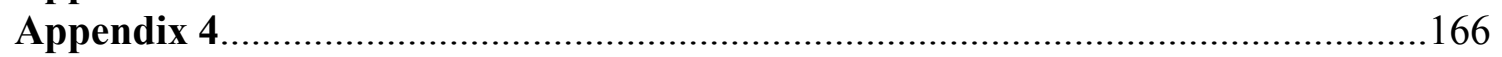

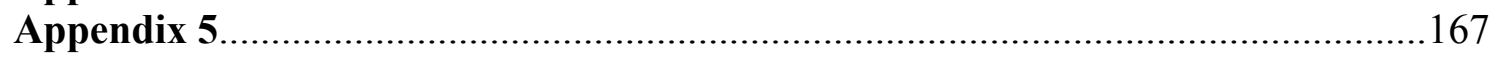

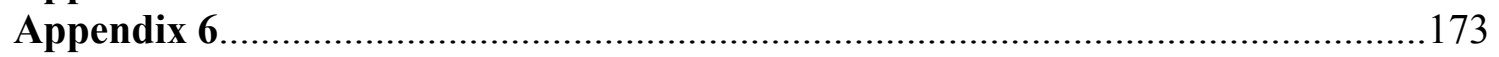

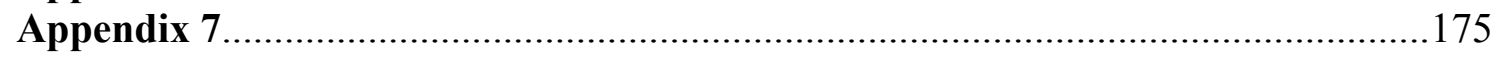




\section{List of Figures}

Figure 2.1 a) Map of Indonesia with the location of SE Sulawesi circled, b) the main Islands of the Tukangbesi archipelago and the location of the Wakatobi Marine National Park boundary, c) the location of the nine study sites and Sampela village.

Figure 2.2 a) Canonical Analysis of Principal Coordinates (CAP) showing differences in fish assemblages across study sites, $b$ ) vectors represent spearman rank correlations of individual fish species with the CAP axes indicating which species are characteristic of the study sites.

Figure 2.3 Unconstrained non-metric Multidimensional Scaling (MDS) plot illustrating differences in the food items fed on by different fish families

Figure 2.4 Mean spongivorous fish densities at the study sites. Error bars represent +1 standard deviation $(\mathrm{SD})$

Figure 2.5 Mean nudibranch densities at the study sites. Error bars represent +1 standard deviation (SD)

Figure 2.6 Canonical Analysis of Principal Coordinates (CAP) showing differences in nudibranch assemblages across study sites.

Figure 2.7 Different nudibranch feeding strategies and characteristic feeding scars on sponge prey. The photographs show a) Phyllidiella pustulosa b) Chromodoris lochi c) Jorunna funebris d) Phyllidia varicosa

Figure 2.8 Starfish species observed a) Acanthaster planci b) Celerina heffernani c) Choriaster granulatus d) Fromia indica e) Fromia milleporella f) Fromia monilis g) Gomophia egeria h) Linckia laevigata i) Linckia multiflora j) Protoreaster nodosus. The two species which may feed on sponge were Celerina heffernani ( 1 individual out of 30 observed on sponge) and Gomophia egeria (1 out of 1 observed on sponge) 36

Figure 2.9 Starfish densities at the study sites. Error bars represent +1 standard deviation (SD)

Figure 3.1 a) Canonical Analysis of Principal Coordinates (CAP) showing differences in benthic composition between study sites, b) The vectors represent Spearman rank correlations between individual benthic components and the resulting CAP axes. These can be used to identify benthic groups characteristic of the study sites.

Figure 3.2 Mean sponge abundance at the nine study sites

Figure 3.3 Distance based redundancy analysis (DbRDA) plots of the model of total sponge abundance with the lowest AICc value of all competing models

Figure 3.4 Dominance plot showing the percentage abundance of the 20 most abundant species. 
Figure 3.5 Distance based redundancy analysis (DbRDA) plots of the best model of sponge abundance when Lamellodysidea herbacea is excluded.

Figure 3.6 Distance based redundancy analysis (DbRDA) plots of the best model of Lamellodysidea herbacea abundance.

Figure 3.7 Species diversity measures at each study site a) total number of species, b) Shannon-Wiener index $\left.\left(\mathrm{H}^{\prime}\right), \mathrm{c}\right)$ Pielou's evenness index $\left(\mathrm{J}^{\prime}\right)$

Figure 3.8 a) Canonical Analysis of Principal Coordinates (CAP) showing differences in sponge assemblages at the study sites, b) Overlaid vectors indicate which sponge species are characteristic of the assemblages at each site

Figure 3.9 Distance based redundancy analysis (DbRDA) plot showing the best model of the multivariate sponge assemblages

Figure 4.1 Map showing the location of the study sites. Two replicate sites, Sampela 1 and Sampela 2, were located on a degraded section of fringing reef off Kaledupa Island and were representative of a degraded reef system. Buoy 3 and Buoy 4 were located in the higher coral cover fringing reef system off Hoga Island

Figure 4.2 Photographs showing the three caging treatments used in the experiment a) full cage b) partial cage c) no cage control

Figure 4.3 Sponge abundance plotted for caging treatments in March and August at the Hoga Sampela study sites

Figure 4.4 Power for rejecting the null hypothesis of no caging effect ( $5 \%$ significance) as a function of hypothetical increases in sponge abundance in caged treatments

Figure 4.5 Unconstrained non-metric Multidimensional Scaling (MDS) plot illustrating differences (as given by Bray-Curtis coefficients) between sponge assemblages within experimental plots at Hoga and Sampela

Figure 5.1 Map of the study sites in the context of the Kaledupa-Hoga reef system

Figure 5.2 Diagram of the idealized barrel sponge used in the regeneration model

Figure 5.3 Schematic representation of the steps involved in the fish predation model. a) Grid representing the surface of the barrel sponge, b) a random number of feeding events is drawn from a negative binomial distribution, c) each feeding event is given a position on the grid, d) each feeding event is assigned a number of bites drawn from a negative binomial distribution, e) each bite is given a location on the grid centred around the point defined in c), but within a certain distance as defined by the extent model parameter, $\mathrm{f}$ ) each bite is assigned a depth which is randomly drawn from a normal distribution which is then subtracted from the thickness for each of the cells that were identified as being bitten in e), g) this step represents somatic growth which is added equally to every cell in the grid, $h$ ) regeneration is added to any cell which has been previously fed on in any previous step (i.e. if thickness is below the 
unwounded thickness of the sponge, some regeneration is applied, even if that cell was wounded many time steps before).

Figure 5.4 Percentage of total bites taken by each species

Figure 5.5 Histogram of the volume of the 29 bites measured

Figure 5.6 Graphs showing the regeneration of the three holes in each sponge. Points represent volume readings taken at each survey. Lines represent the regeneration rate based on a log relationship estimated from the regression analyses.

Figure 5.7 Photographs showing the regeneration progression for hole number 1 of Sponge 5: a) day $0, \mathrm{~b}$ ) day 2 , c) day 5 , d) day 7 , e) day $10, \mathrm{f}$ ) day 15 , g) day 20

Figure 6.1 Schematic illustrating my contribution to our understanding of IndoPacific sponge ecology in terms of the effects of biological and physical factors on sponge assemblages. The top half of the diagram represents what was already known prior to my research. The magnitude of effects is given by the type of arrow, with dashed arrows indicating weak or marginal effects, and full arrows represent stronger structural effects. Grey lines represent what is known from Caribbean reefs and black lines from the Indo-Pacific. Lower case letters refer to the sources of information used a) Aerts \& Soest 1997 b) Pawlik 1998 c) Dunlap \& Pawlik 1996 d) Wulff 2000 e) Bell \& Smith 2004 f) Cleary et al. 2007. In the bottom diagram the red lines represent the findings from this thesis. 


\section{List of Tables}

Table 2.1 General description of study site characteristics

Table 2.2 Number of individuals of each fish species observed and mean \% bites taken on each food item $( \pm 1 \mathrm{SD})$

Table 2.3 Ivlev's Electivity Indices for the fish species observed at Hoga and Sampela29

Table 2.4 Nudibranch species recorded during surveys

Table 2.5 Ivlev's Electivity Indices for the nudibranch species observed at Hoga and Sampela

Table 3.1 Summary table of environmental and biological predictor variables

Table 3.2 Summary table of the results of the DISTLM analysis. Results shown are for the model with the lowest AICc values for each response variable

Table 3.3 Table showing the summed Akaike weights for each parameter for all models within $\triangle \mathrm{AICc}$ of five for each of the response variables

Table 4.1 Results of the 1-way ANOVA tests for differences in sponge abundance between treatments at Hoga.

Table 4.2 Results of the 1-way ANOVA tests for differences in sponge abundance between treatments at Sampela

Table 4.3 Results of the PERMANOVA examining the effects of caging treatment on sponge assemblages at Hoga and Sampela

Table 5.1 Parameters, parameter values and the method used to obtain these values for the numerical barrel sponge simulation model

Table 5.2 List of species observed feeding on the barrel sponges in the videos

Table 5.3 Results of the PERMANOVA to test whether bite rates differed between sites

Table 5.4 Comparison of the summed Akaike weights for the regeneration rate models tested

Table 5.5 Reported densities for Xestospongia muta and Xestospongia testudinaria 


\section{Contributions and Publications:}

The data chapters that make up this thesis are based on a series of manuscripts that are in the review process or shortly to be submitted for publication. All fieldwork, analyses and writing were carried out by the author with the following exceptions:

\section{Chapter 2}

Study design: Author with guidance from Dr. James Bell

Data collection: Author

Analyses: Author

Writing and editing: Author with editing by Dr. James Bell

\section{Chapter 3}

Study design: Author with guidance from Dr. James Bell

Data collection: Author

Sponge taxonomy: Sample identification was carried out by Dr. Jade Berman with Dr. John Hooper and Patricia Sutcliffe at the Queensland Museum.

Analyses: Author

Writing and editing: Author with editing by Dr. James Bell

Publication: Powell A, Smith DJ, Hepburn LJ, Jones T, Jompa J, Bell JJ (2012)

Possible phase shift of an Indo-Pacific coral reef system to a low diversity spongedominated reef community. To be submitted to Marine Ecology Progress Series.

\section{Chapter 4}

Study design: Author with guidance from Dr. James Bell

Data collection: Author and Dr. James Bell

Analyses: Author

Writing and editing: Author with editing by Dr. James Bell

Publication: Powell A, Smith DJ, Hepburn LJ, Jompa J, Bell JJ (2012) Investigating the effects of fish predation on sponge assemblages: an exclusion experiment. In prep.

\section{Chapter 5}

Study design: Author with guidance from Dr. James Bell 
Data collection: Author

Analyses: Analyses were carried out by the author except for the code for the barrel sponge predation model that was written in R by Timothy Jones.

Writing and editing: Author with editing by Dr. James Bell

Publication: Powell A, Jones T, Smith DJ, Hepburn LJ, Jompa J, Bell JJ (2012) Fish predation on the Indo-Pacific giant barrel sponge, Xestospongia testudinaria. In prep.

Publication: Powell AL, Hepburn LJ, Smith DJ, Bell JJ (2010) Patterns of sponge abundance across a gradient of habitat quality in the Wakatobi Marine National Park, Indonesia. The Open Marine Biology Journal, 4: 31-38. 


\section{Introduction}

\subsection{What are sponges and why are they important?}

Sponges were among the first multicellular animals to evolve some 580 million years ago ( $\mathrm{Li}$ et al. 1998). They were responsible for building the first reefs before the appearance of hard corals and their basic, but successful, body plan has remained virtually unchanged since they first evolved (Wood 1995). They are an extremely widespread group of sessile invertebrates occurring in marine environments from polar to tropical regions (Barthel et al. 1991; Bell \& Barnes 2000a; Diaz \& Rützler 2001). They are suspension feeders and have an internal system of canals termed the aquiferous system through which water is pumped by flagellated cells, choanocytes, which create a unidirectional current through the sponge (De Vos et al. 1991). Water enters the sponge through inhalent pores or ostia and leaves the sponge through larger exhalent oscula. Food and oxygen are removed from the water by a number of cell types including the choanocytes (Reiswig 1971).

The classification of sponges has traditionally been a contentious field of study. In early descriptions, sponges were placed in either the animal or plant kingdoms and Pliny described them as 'intermediates' between the two kingdoms (Holland 1634). Indeed, sponges do possess certain characteristics more typical of plants than animals. Their cells are totipotent so even differentiated cells retain the ability to become different cell types (Ganguly 1960). This contributes to the exceptional ability of sponges to regenerate from physical damage (Ayling 1983; Hoppe 1988; Duckworth 2003). Many sponges are also able to reproduce asexually via fragmentation as well as sexually through the production of larvae (Kelly-Borges \& Berquist 1988; Wulff 1991; Tsurumi \& Reiswig 1997; Zilberberg et al. 2006). It was not until 1826 that the debate was settled and sponges were finally classified as animals (Grant 1826). There are currently 7000 extant sponge species in the phylum Porifera, which is divided into three extant classes, the Demospongidae, Hexactinellida, Calcarea and the extinct Archaeocyatha.

\subsection{The functional roles of sponges}

Porifera are integral components of tropical coral reef systems and have many functional roles. Sponges provide a key link between the benthos and the water 


\section{Chapter 1}

column termed bentho-pelagic coupling (Gili \& Coma 1998; Lesser 2006; Bell 2008). As they filter large quantities of water, they remove food particles (e.g. ultraplankton and picoplankton) and nutrients (e.g. silicon and nitrogen) from the water column. These nutrients and carbon from the food particles then become available to higher trophic levels through predation on the sponges. The ability of sponges to efficiently remove plankton and bacteria from the water column means sponges may also play an important role in the aftermath of disturbance events such as hurricanes. For instance, Wulff (2001) observed that after Hurricane Allen damaged Jamaican reefs in 1980, many sponges appeared to have stopped pumping and that the water column contained high levels of particulate organic matter. However, as the sponges began to pump again the water column cleared rapidly, removing potentially harmful decomposing organic matter (Wulff 2001). Sponges are also thought to impact the water column through oxygen depletion, however, so far this has only been measured in the field in cave dwelling sponges in the Red Sea (Richter et al. 2001).

Another important functional role played by sponges on coral reefs is their impact on the reef substrate through the process of bioerosion (Bell 2008). Bioeroding sponges are diverse, widely distributed and among the most important bioeroders on coral reefs (Hutchings 1986). They bore into the calcium carbonate skeleton of hard corals and weaken their structure making them more likely to become detached from the reef (Sammarco \& Risk 1990; Macdonald \& Perry 2003). The structure and form of coral reefs is determined by the interaction between reef growth and reef erosion; if bioerosion consistently exceeds reef growth then the reef framework will gradually be destroyed (Stearn \& Scoffin 1977). As a result, changes to the number of bioeroding sponges may impact the long term future of coral reefs. One of the negative impacts of increased nutrient input on reefs has been documented increases in the number of bioeroding sponges with a concurrent increase in excavation rates (Holmes 2000). In contrast, other sponges have been shown to impact the reef substrate in a more positive way. For example, Wulff and Buss (1979) found that sponges on reefs in Panama play a key role in binding corals to the reef substrate when the bases of the corals have been eroded. In the same study, experimental removal of sponges from areas of reef resulted in the loss of $40 \%$ of the live coral colonies within six months. 


\section{Chapter 1}

Some of the first research on the ecological interactions of sponges revealed a remarkable number of associations between sponges and other organisms (Pearse 1934, 1950). Their internal structure provides microhabitats for a myriad of organisms including crustaceans, polychaetes, opiuroids, cnidarians, molluses and fishes (Wulff 2006a). For example, Ribeiro et al. (2003) studied the encrusting sponge Mycale (Carmia) microsigmatosa in southeastern Brazil and found that 19 specimens contained 75 invertebrate species with a total of 2235 individual symbionts. Recent research has uncovered many different types of associations between these symbionts and their sponge hosts ranging from specialists that only occur in association with one sponge species to opportunists, which may also occupy other habitats. The nature of these associations ranges from mutualism to parasitism. For example, the relationship between the brittle star Ophiothrix lineata and the Caribbean sponge Callyspongia vaginalis appears to be mutually beneficial. The brittle stars clean the inhalent surfaces of the sponges and in turn gain protection from predators who avoid the inedible sponges (Hendler 1984). In contrast, polychaete worms that are commonly found in sponges may be parasitic, feeding on the tissue of their hosts (Pawlik 2008).

Finally, sponges play an important role in coral reef food webs. In addition to filtering out food particles from the water column many sponges have also been found to contain photosynthetic cyanobacteria (de Laubenfels 1950; Wilkinson 1978). These sponges facilitate primary production and provide a link between primary and secondary production on coral reefs (Bell 2008). Sponges are fed on by a variety of organisms including opistobranchs, crustaceans, molluscs, echinoderms and fish (Wulff 2006a). It is interesting to note that despite the abundance of sponges only a relatively small number of species feed on them. Sponge predation and its role in determining patterns of sponge diversity and abundance are discussed in more detail in the final section of this review.

\subsection{Current threats to coral reefs}

In addition to their exceptional biodiversity, coral reefs contribute to coastal protection, and are a vital source of income and food for nearly 500 million people worldwide (Wilkinson 2004). Coral reefs across the globe are currently declining as a result of many threats including overexploitation, habitat destruction, increased 


\section{Chapter 1}

sedimentation and nutrient levels due to poor land management, and face the potential future threats of ocean acidification, raised sea temperatures and climate change (Rogers 1985; Hughes 1994; Pandolfi et al. 2003; Hoegh-Guldberg et al. 2007). The Indo-Pacific region is a centre of global marine diversity for several major taxa (Roberts et al. 2002) and encompasses 75\% of the world's coral reefs but this region is also facing the widespread degradation. A recent meta-analysis of 2667 Indopacific coral reefs between 1968 and 2004 estimated that an average of $1 \%$ or 1,500 $\mathrm{km}^{2}$ hard coral cover was lost per year over this period. These authors found that average hard coral cover declined from $42.5 \%$ during the early 1980 s to $22.1 \%$ in 2003. In addition only 7 out of the 390 reefs surveyed in 2003 had coral cover greater than $60 \%$ (Bruno \& Selig 2007).

\subsubsection{Determining the impacts on sponge assemblages}

Currently, much research focuses on investigating and mitigating the impacts of habitat degradation and overexploitation of coral reefs (Fitt et al. 2001; Lesser 2007; Tkachenko et al. 2007), however, the vast majority of this research does not take into account the effects on sponge assemblages. Given the numerous functional roles fulfilled by sponges on reefs, changes in sponge diversity and abundance could have a major impact on the function of the reef ecosystem as a whole. For example, a decline in the abundance of Acroporid corals on reefs in southwestern Puerto Rico due to the combined effects of disease, siltation, eutrophication and hurricanes led to dramatic increases in the abundance and percentage cover of the bioeroding sponge Cliona langae (Williams et al. 1999). As a result coral recovery was prevented and these reefs have undergone a phase shift from coral dominated to sponge dominated ecosystems (Norström et al. 2009).

In order to ascertain the impacts of habitat degradation and overexploitation on sponge assemblages, a key step is to determine the relative importance of biological and physical factors in controlling sponge biodiversity and abundance. If physical factors are more important than biological factors, then declining abundance of corals and fish are unlikely to have significant effects on sponge assemblages; if the reverse is true then significant changes to sponge assemblages may occur, with subsequent ecosystem functioning effects. In the following sections I review what is known about 
Chapter 1

the role of physical and biological factors in driving sponge abundance patterns on coral reefs.

\subsection{The role of abiotic factors in determining sponge diversity and abundance}

The influence of physical factors on sponge assemblages has been investigated in both temperate and tropical regions (see Ginn et al. 2000; Bell \& Barnes 2000b; Bell \& Smith 2004; Pawlik et al. 2007a; Cleary \& de Voogd 2007; de Voogd \& Cleary 2007). A number of different approaches have been used ranging from in-situ observations of sponge assemblages in different environments to laboratory-based manipulations. An important factor known to influence sponge assemblages is water flow. For example, in Canada, Ginn et al. (2000) found that sponge coverage increased with increasing depth and current velocity, and that current affected sponge orientation. High water flow can increase the growth and final size of some sponge species by increasing food availability and the internal flow through the sponge, however, some studies have shown that other species grow better in low-flow areas (Duckworth et al. 1997). In a temperate sea lough in Ireland, Bell and Barnes (2003) found that water flow affected sponge distributions, but found the extent of its effect varied between habitats and was also related to sedimentation regime, since water flow and sedimentation regimes are often linked.

At a local-scale, the abundance and species composition of sponges can be influenced by substrate type and inclination of the substrate they are growing on. In Lough Hyne Marine Reserve, Bell and Barnes (2003) found significant differences in the sponge assemblages occurring on rocks and cliffs, which they attributed partly to differences in the stability of these two substrates. In Indonesia, Bell \& Smith (2004) found that substrate surface angle was correlated with differences in sponge species richness with the highest species richness occurring on vertical surfaces. These authors suggested that rather than being a direct effect of the substrate angle, this difference was caused by lower levels of sedimentation on vertical surfaces.

Sedimentation is known to have a major effect on a number of reef organisms (Amesbury 1982; Rogers 1990; Riegl \& Branch 1995; Harrington et al. 2005). Its effects on corals have been particularly well-documented with increased 


\section{Chapter 1}

sedimentation being associated with lower coral species diversity, decreased live coral cover, slower growth rates, decreased calcification rates and lower levels of recruitment (Rogers 1990). A number of studies on Indonesian reefs have shown that changes in sponge assemblages are also associated with different levels of sedimentation. For example, Bell and Smith (2004) found significant differences in the species composition of sponge assemblages on a reef impacted by high sedimentation rates versus a reef with lower levels of sedimentation in south-east Sulawesi, Indonesia. In the Spearmonde Archipelago, also in Sulawesi, de Voogd and Cleary (2007) found that differences in suspended sediment loads were correlated with differences in the sponges present along an onshore-offshore gradient.

Some of the effects of sedimentation on the physiology of sponges have been investigated in manipulative experiments. Gerrodette and Flechsig (1979) exposed the tropical sponge Verongia lacunosa to different levels of sediment in aquaria and measured its effect on sponge pumping rates. They found that sediment detrimentally affected the pumping rates of this sponge and that low levels of sediment $\left(11.1 \mathrm{mg}^{-1}\right)$ were sufficient to cause a reduction in pumping rate. They also observed that pumping rates decreased in proportion to the amount of sediment rather than in response to a critical level of sediment. More recently, Roberts et al. (2006a), artificially increased the ambient sediment levels around individuals of Cymbastela concentrica which occur on temperate Australian reefs and found that increased sediment negatively affected the growth rates and reproductive status of $C$. concentrica. These results indicate that sedimentation has major effects on sponge growth and physiology but there is generally very little information available.

Most of the research into the effects of physical factors on tropical sponges to date has focused on local factors such as substrate type, sedimentation or local patterns of water flow. However, new research is revealing the existence of large-scale structuring factors that drive seasonal and annual changes in sponge assemblages. Carballo et al. (2008) monitored sponge assemblages off the coast of Mexico for six years and found that the sponge assemblages were very diverse and stable during the dry season whereas during the wet season the sponge assemblages were less diverse. This short-term pattern was correlated to seasonal changes in the local winds driving changes in sedimentation regimes on interannual timescales. In addition to this 


\section{Chapter 1}

regular seasonal fluctuation they observed large scale annual patterns related to the Southern Oscillation (SOI) and Multivariate El Niño-Southern Oscillation (MEI) indexes.

\subsection{The role of biological factors}

Until recently, biological factors were thought to play a relatively minor role in determining sponge diversity and abundance patterns, but transplantation experiments in the Caribbean have shown that fish predation can have a major influence on the distribution and abundance of certain species of sponges (Wulff 2005). In Indonesia, as discussed above, a number of studies have shown that various physical factors influence sponge assemblages (Bell \& Smith 2004; de Voogd \& Cleary 2007), but very few studies have focused on the role of biotic factors. Here I review the current state of our knowledge on two of the most important biological factors affecting sponge assemblages on coral reefs; competition with hard corals and fish predation.

\subsubsection{Spatial competition with hard corals}

Previous studies have shown that sponges are important spatial competitors in temperate and tropical benthic communities (Suchanek et al. 1983; Aerts 1998; Bell $\&$ Barnes 2003; Bell 2008). In temperate regions, the competitive ability of sponges may be related to seasonal changes in sponge growth rates. A study of sponge competition in Lough Hyne Marine Nature Reserve found that sponges are able to overgrow most other organisms during growth periods but the new space occupied by the sponges is released when they retract during winter months (Bell \& Barnes 2003). As a result they can play an important role in stimulating changes in benthic community composition (Bell 2008). Most information regarding sponges as spatial competitors on coral reefs comes from the Caribbean. The first studies of sponge coral competition were based on one-off observations of interactions as it was assumed that the relatively constant tropical environmental conditions would mean seasonal impacts on benthic communities were minimal (e.g. Suchanek et al. 1983; Aerts \& Soest 1997). However, subsequent research showing that tropical sponge assemblages are much more dynamic than previously thought has prompted more recent studies to monitor sponge coral interactions over time. The results of these 


\section{Chapter 1}

studies have revealed that these interactions are indeed dynamic. In the Caribbean, Aerts (2000) examined the dynamics of 'standoff' interactions for three sponge species and found that in most cases competitors lost and gained space alternately over the 15-month study. They also found that damaged corals were more susceptible to overgrowth by sponges. These findings are significant in the context of habitat degradation as they indicate that coral damage on the reef could favour the overgrowth of corals by sponges thus contributing to the further deterioration of corals.

\subsubsection{How do sponges compete for space?}

Many sponge species produce toxic secondary metabolites and have been targeted as a source of bioactive compounds for the development of pharmaceutical drugs (Thomas et al. 2010). These metabolites are thought to play a number of ecological roles including anti-fouling and predator deterrence but are also important in competition with other spatial competitors (Becerro et al. 1997; Clavico et al. 2006). A study of the effects of four bioactive sponges on their neighbours in Sulawesi showed that coral overgrowth by sponges caused necrosis in more than $85 \%$ of the interactions (de Voogd et al. 2004). In situ experiments in the Bahamas using pulse amplitude modulated (PAM) fluorometry have demonstrated that sponge secondary metabolites have rapid allelopathic effects on coral zooxanthellae resulting in impaired photosynthesis and occasionally leading to coral bleaching (Pawlik et al. $2007 \mathrm{~b}$ ). In addition to the production of toxic metabolites, sponge species may also use a number of other strategies to compete for space including rapid growth rates enabling them to overgrow slower growing competitors (Suchanek et al. 1983).

\subsubsection{Which organisms feed on sponges?}

One of the important functional roles played by sponges is acting as a link between primary and secondary production (Bell 2008). Sponges are fed on by a variety of different organisms including opistobranchs, crustaceans, molluscs, echinoderms, sea turtles and fish. The type of sponge predators and the extent to which they affect sponge community structure varies between tropical, temperate and polar regions. In polar and temperate regions, the main sponge predators are invertebrates (Dayton et 
al. 1974; Wägele 1989). Predation by a number of starfish and a nudibranch species is thought to play a key role in structuring Antarctic sponge assemblages (McClintock et al. 2005). In temperate regions predation is not thought to be a major determinant of sponge community structure as typically only portions of adult sponges are consumed, resulting in limited damage (Wulff 2006a). In the tropics, in addition to invertebrate predators a number of fish species also feed on sponges.

\subsubsection{The impacts of predation on sponges}

In a review of the ecological interactions of sponges, Wulff (2006a), suggests that there are three major types of sponge predators on coral reefs. Firstly, smorgasbordfeeding sponge predators such as some species of angelfish. These are species that take only a few bites of any given sponge before moving on to a different species. The second group consists of sponge specialists, species that feed on particular sponge species. Examples of sponge specialists include hawksbill turtles that feed almost exclusively on sponges in the Caribbean (Meylan 1988), and small crustaceans that inhabit and consume their host sponges. The final group consists of opportunistic sponge feeders that do not usually feed on sponges but will feed on certain sponges if they become available. For example, some fish will feed on sponges living on the undersides of boulders that have been overturned. The Caribbean starfish Oreaster reticulates, which inhabits seagrass beds was observed to feed on a number of reef sponge species that were washed into the seagrass as a result of a hurricane (Wulff 1995). These observations suggest that predation on sponges by opportunistic feeders could increase in the future if changes to reefs mean that the availability of other food sources is reduced.

\subsubsection{Sponge defences}

Although they lack visible defences, sponges possess a number of means of protecting themselves against predation. The presence of large numbers of spicules in many species is thought to deter some predators from feeding on sponges (Jones et al. 2005). In addition, predator deterrence is thought to be one of the important ecological functions of the toxic secondary metabolites produced by sponges (Pawlik et al. 1995). A number of studies have used feeding experiments to determine the 


\section{Chapter 1}

deterrent activity of sponge extracts contained in pellets (Pawlik et al. 1995; Swearingen III \& Pawlik 1998; Becerro et al. 2003; Ruzicka \& Gleason 2008) These experiments have enabled a number of sponge species to be ranked according to palatability and in addition have been used to investigate broad geographical trends in sponge predator deterrence. Interestingly, the results of these studies indicate that chemical defences in sponges do not follow the same biogeographical pattern as other taxa, which tend to show increasing chemical defences towards the tropics. Temperate sponges seem to be as well defended as tropical sponges and the chemicals produced by sponges seem to be as effective against allopatric and sympatric predators (Bercerro et al. 2003). While they have provided useful information, pellet experiments have some limitations. They may provide an incomplete picture of sponge deterrence. For instance some sponge species are palatable to angelfish but are not consumed by starfish and vice versa (Wulff 1994, 1995). In a recent review of the ecological interactions of marine sponges Wulff (2006a) stressed the ongoing need for, and the value of, experimental manipulations and field observations of predation on living sponges.

\subsubsection{How important is fish predation in determining sponge diversity and abundance patterns?}

Most of the work on sponge predation in the tropics has been carried out in the Caribbean. Randall and Hartman (1968) analysed the gut contents of 212 species of West Indian reef and inshore fishes. They found sponge remains in 21 species and that the proportion of sponge contained in the gut contents of most of these species was low. Only 11 species had gut contents comprising of $6 \%$ or more of sponge. This led the authors to conclude that fish predation was unlikely to be a significant factor in limiting sponge distribution patterns in the West Indian Region. These authors were also the first to propose that fish exhibited a smorgasbord approach to sponge feeding thus minimising the risk of depleting a particular food source and the risk of consuming large quantities of a toxic or low nutritional value sponge. Since this study, more recent work has challenged the view that fish predation has a negligible impact on sponge distributions. Studies using additional methods to gut content analysis have led to the discovery that predation plays an important role in 


\section{Chapter 1}

determining the distribution of certain sponge species, however, the extent of its influence is still debated (Dunlap \& Pawlik 1998; Wulff 2000; Pawlik et al. 2007a).

A number of studies have attempted to determine the factors driving differences between sponge assemblages in mangrove and reef habitats. Transplantation experiments have shown that mangrove sponges are readily consumed by reef fish (Dunlap \& Pawlik 1996). Dunlap and Pawlik (1996) fixed pieces of sponge on reefs and recorded fish feeding behaviour on the sponges using underwater video. They observed intense feeding by a number of fish families including, angelfish, cowfish, parrotfish and filefish. They found that the colour of the sponge made no difference to fish feeding behaviour. The spongivores in this study did not display a smorgasbord approach to feeding as they concentrated on preferred species until they were consumed.

More recently, Wulff (2005) found that fish predation and competition maintain distinct sponge faunas on mangrove roots in the Pelican Cays and Twin Cays in Belize. The sponges found on roots in Twin Cays were typical mangrove species but the sponges on roots in Pelican Cays were unusual as they were predominantly reef species, perhaps attributable to the proximity of these mangroves to coral reefs. Transplantation, predator exclusion (caging) and competitor exclusion (artificial substrata) were used to determine the factors responsible for differences in the reef and mangrove faunas. The conclusions of the study were that mangrove sponges were excluded from reef habitats by spongivores and that, surprisingly, the reef sponges were excluded from mangrove habitats because they were outcompeted by faster growing mangrove sponges rather than by the abiotic conditions in the mangroves. The generality of these finding have subsequently been challenged by Pawlik et al. (2007a) who argue the results obtained in the Belize study are the product of the unusual nature of these mangrove systems and that in most cases it is the extreme abiotic conditions in the mangroves that exclude reef species rather than competition. It is probable that the relative importance of biological and physical factors vary between locations and between different spatial scales. However, these studies do provide clear evidence that predation can restrict the distribution of some sponge species. 


\subsection{Conclusions}

Sponges are important components of coral reefs and are involved in many key processes. As a result, changes to sponge diversity and abundance can have subsequent effects on the ecosystem function of coral reefs. However most research into the factors driving sponge distributions on coral reefs has been undertaken in the Caribbean, and there is a paucity of information for Indo-Pacific reefs. Past studies have found that local physical factors, such as sedimentation, can influence both sponge diversity and abundance. In addition, an increasing number of studies are finding that biological factors, such as competition for space with hard coral and fish predation, can also affect sponge assemblages. This is significant as both coral cover and fish populations are declining on many reefs worldwide. Currently there is a need to expand this research to other regions with different coral reef communities, such as the Indo-Pacific, as findings from the Caribbean may not be generally applicable. This will enable us to better understand and maintain the processes currently maintaining Indo-Pacific reef diversity.

The primary aim of my study was to determine the influence of biological factors in determining sponge distributions and abundances in the Wakatobi Marine National Park in south-east Sulawesi, Indonesia. My research focused on the influence of fish predation as my preliminary results suggested that there was only a weak relationship between hard coral cover and sponge abundance (see Appendix 1: Powell et al. 2010). I used a combination of in situ observations of spongivore feeding behaviour, caging experiments and further observations of the effects of sub-lethal partial predation to determine the extent of fish predation on sponge assemblages and explore how declining fish populations will affect sponge distributions and abundance. The specific objectives of the study were:

1. To identify the main spongivorous species in the Wakatobi Marine National Park.

2. To examine the impact of fish predation in the wider context of other potential physical (sedimentation, water flow etc.) and biological (relationship with hard coral 


\section{Chapter 1}

cover) variables to uncover the factors that are most correlated with sponge diversity and abundance.

3. To examine the effects of predator exclusion on WMNP sponge assemblages.

4. To measure the extent and impacts of fish predation on the Indo-Pacific giant barrel sponge, Xestospongia testudinaria.

The four data chapters of this thesis address these objectives and in the final chapter, I discuss my findings in the wider context of sponge ecology. 
Chapter 1 


\section{Spongivores of the Wakatobi}

\subsection{Abstract}

Predation has a major influence on the abundance and distribution of benthic reef invertebrates at local scales. The effects of predation on algae and hard corals have been the focus of much research, but predation also has the potential to affect other functionally important groups of reef invertebrates such as sponges. Currently, there is a lack of information regarding the abundance of spongivores and potential impacts of spongivory in the Indo-Pacific. The aim of this study was to identify species that may be particularly important in controlling sponge abundances, either through their numerical abundance, or prevalence of sponges in their diets in the Wakatobi Marine National Park. The most abundant spongivorous invertebrates were nudibranchs with eight species associated with sponges; however, their low densities mean that they are unlikely to have a major influence on sponge distribution patterns. The most abundant vertebrate spongivores were fish and in total 16 species were observed feeding on sponges, which included species in the families Zanclidae, Acanthuridae, Chaetodontidae, Pomacantidae, Blennidae and Tetradontidae. In contrast to the Caribbean, no Scaridae were observed feeding on sponges. Based on their abundance and feeding on sponges, the fish with the greatest potential to influence sponge distribution patterns and abundance in the WMNP appear to be Zanclus cornutus, Chaetodon kleini, Pygoplites diacanthus, and Pomacanthus sexstriatus. Only one sea turtle was observed throughout the survey period so it seems unlikely that turtles currently have a large effect on sponge distributions in the WMNP.

\subsection{Introduction}

The abundance and distribution of species is affected by a number of abiotic and biological factors operating on a range of spatial and temporal scales (Levin 1992). One of the most important biological factors is predation, which can be broadly defined as any interaction between two organisms that results in a flow of energy between them (Paine 1969; Holt 1984; Sih et al. 1985; Chase et al. 2002). The effects of predation can be both direct, by affecting prey densities or indirect by affecting the outcomes of other processes, such as competition (Chase et al. 2002). Predation has 


\section{Chapter 2}

been shown to have profound effects on coral reef benthic assemblages. In extreme cases, changes in predator abundance can lead to phase shifts where the dominant benthic assemblage is replaced by another group, leading to major changes in ecosystem functioning (Hughes 1994). Most research into the effects of predation on reefs has focused on the impact of fish predation on algae and hard corals (Hughes 1994; Lirman 2001; Lefevre \& Bellwood 2011). Currently, there is a lack of information on the effects of predation on other groups of functionally important benthic reef invertebrates, such as sponges.

Sponges are fed on by a number of vertebrate and invertebrate species, with the most important vertebrate sponge predators being sea turtles and fish (Wulff 2006a). Sponges are a major component of the diet of hawksbill turtles (Eretmochelys imbricata) in the Caribbean (Meylan 1988; Leon \& Bjorndal 2002) and are also consumed to a lesser extent by green turtles (Chelonia mydas) (Bjorndal 1996). Observational and gut content surveys have shown that fish species from a number of families feed on sponges including angelfish (Pomacanthidae), filefish (Monacanthidae), parrotfish (Scaridae) and boxfish (Ostraciidae) (Randall \& Hartmann 1968; Dunlap \& Pawlik 1996; Pawlik 1998). The most comprehensive survey of spongivorous fish species was carried out in the Caribbean by Randall and Hartmann (1968), who examined the gut contents of 212 fish species in the West Indies and found sponge remains in the gut contents of 21 species. Reef sponges are also fed on by an array of invertebrate groups including nudibranchs and starfish (Yasman 2003; Wulff 2006a).

It was initially thought that predation by these species had little effect on sponges but research in the Caribbean suggests that its importance may have been underestimated (Dunlap \& Pawlik 1996; Dunlap \& Pawlik 1998; Pawlik 1998; Wulff 2000).

Observational and experimental work in the Caribbean has shown that fish spongivory on coral reefs can affect the distribution of sponges, restricting some species to lagoon or mangrove habitats or to cryptic locations within the reef framework (Wulff 1997; Pawlik 1998; Hill \& Hill 2002). Fish predation has also been shown to reduce the capacity of some sponges to overgrow corals (Hill 1998). These findings have potentially important implications for reef management. Coral reef sponges fulfil numerous functional roles in reef ecosystems, such as nutrient cycling, 


\section{Chapter 2}

bentho-pelagic coupling, eroding and consolidating the reef matrix, facilitating primary production, contributing to habitat complexity and providing microhabitats and food for other organisms (Bell 2008). If top down processes play an important role in controlling sponge populations then a decline in spongivores could lead to an increase in sponges with subsequent ecosystem effects.

Despite the fact that Indonesia is a global centre for marine biodiversity with over $51000 \mathrm{~km}^{2}$ of coral reefs (Allen \& Adrim 2003; Allen 2008) and exceptionally high sponge species richness (Van Soest 1989; Bell \& Smith 2004), to date no studies have examined the impact of spongivory on Indonesian reefs. The need to understand the drivers of sponge abundance and diversity in the Indo-Pacific is particularly important given the rapid changes that are taking place on reefs in this region. Indonesian reefs currently face multiple threats including overexploitation, coastal development and pollution (Edinger et al. 1998; Mous et al. 2005; Bruno \& Selig 2007). These threats can have major impacts on reef organisms including potential spongivores. For example, it is estimated that numbers of nesting hawksbill turtles in Indonesia have declined by $80 \%$ over the past 100 years due to exploitation (Meylan \& Donnelly 1999). In addition, fishing has the potential to change spongivorous fish abundance both directly through the removal of spongivorous species or indirectly due to cascading effects following the removal of large piscivorous fish (Scheffer et al. 2005). Given the numerous functional roles of sponges, changes in the abundance or distribution patterns of sponges could affect processes such as nutrient cycling and bioerosion on Indo-Pacific reefs.

A pre-requisite to determining the role of predation in controlling sponge distributions and abundance on Indo-Pacific reefs is to identify which species are feeding on sponges. To date no studies have focused specifically on the diet of spongivorous fish but a number of surveys from around the Pacific provide an insight into which species are likely to feed on sponges. The most comprehensive of these studies include Hiatt and Strasburg (1960), Hobson (1974) and Sano et al. (1984) who examined the gut contents of fishes from the Marshall Islands, Hawaii and Japan, respectively. These studies have highlighted certain groups and species that feed on sponges in the Pacific. The largest consumers of sponge appear to be in the families Zanclidae (moorish idol), Tetradontidae (pufferfish), Ostraciontidae (boxfish), Pomacanthidae (angelfish), Siganidae (rabbitfish), Monacanthidae (filefish) and Pomacentridae 


\section{Chapter 2}

(damselfish). However, there appears to be considerable variation in the extent to which Pacific reef fish species in the same family feed on sponges. For example, sponge on average contributed $72 \%$ of the gut contents of the rabbitfish, Siganus chrysospilos, but less than $1 \%$ in two of the other species of rabbitfish examined in a Japanese study (Sano et al. 1984). There also appears to be considerable variation in feeding habits between locations. For example, Chaetodon kleini (Klein's butterflyfish) fed on zooplankton in Hawaii (Hobson 1974) but feeds on benthic invertebrates in other locations (Sano 1989; Nagelkerken et al. 2009). The plasticity of fish feeding behaviour means that there is a need for more comprehensive studies to identify those species that contribute to spongivory in Indonesia.

The primary aim of this chapter was to identify species that may be particularly important in controlling sponge abundances in the Wakatobi Marine National Park (WMNP), SE Sulawesi, Indonesia. Given the potential future changes to coral reefs due to direct anthropogenic effects within the WMNP (i.e. blast fishing, local fish depletion) and global climate change (increased bleaching and disease outbreaks), it is vital to understand the processes that govern sponge abundance. By identifying important spongivore species it could be possible to predict how changes in their abundance may affect ecosystem function, which may have future management and conservation consequences. My objectives were: i) to identify spongivorous fish using timed in situ observations of feeding behaviour; ii) to identify potential spongivorous invertebrates by carrying out nudibranch and starfish surveys and recording signs of spongivory, and also by examining associations between invertebrates and the substrates where they were found; iii) to evaluate the potential impact of spongivory by these species by surveying their abundance across nine study sites; and iv) to examine the potential impacts of anthropogenic activities on spongivore populations by comparing spongivore assemblages across a gradient of habitat degradation.

\subsection{Methods}

\subsubsection{Study Sites}

Fish, nudibranch and starfish abundance and diversity surveys were carried out on reef slopes at nine sites in the Wakatobi Marine National Park (WMNP) in SE Sulawesi, Indonesia. The WMNP was gazetted in 1996 and is the third largest marine 


\section{Chapter 2}

national park in Indonesia (Clifton \& Unsworth 2010). It is located in the coral triangle and supports highly biodiverse marine communities, but is also inhabited by over 90,000 people and local communities are highly dependent on reef resources for food and income (Cullen 2010). Declines in hard coral cover have been documented in the park since 2002 (McMellor \& Smith 2010) and there is also evidence that a number of nearshore fisheries are currently being exploited at unsustainable levels (Exton 2010). Four sites, Kaledupa Double Spur, Kaledupa, Sampela 2 and Sampela 1 were located on the fringing reef that surrounds Kaledupa Island. Another four sites, Buoy 1, Buoy 3, Bouy 4 and Pak Kasim's were situated on the fringing reef that surrounds Hoga Island and the final site Ridge 1 is located on a ridge approximately 1 $\mathrm{km}$ offshore from Hoga Island (see Figure 2.1). These sites were selected as they encompass a range of environmental and biological conditions. Site characteristics are summarised in Table 2.1. Surveys were carried out during daylight hours between 07:00 and 17:00 from June-August 2009. 


\section{Chapter 2}

C.
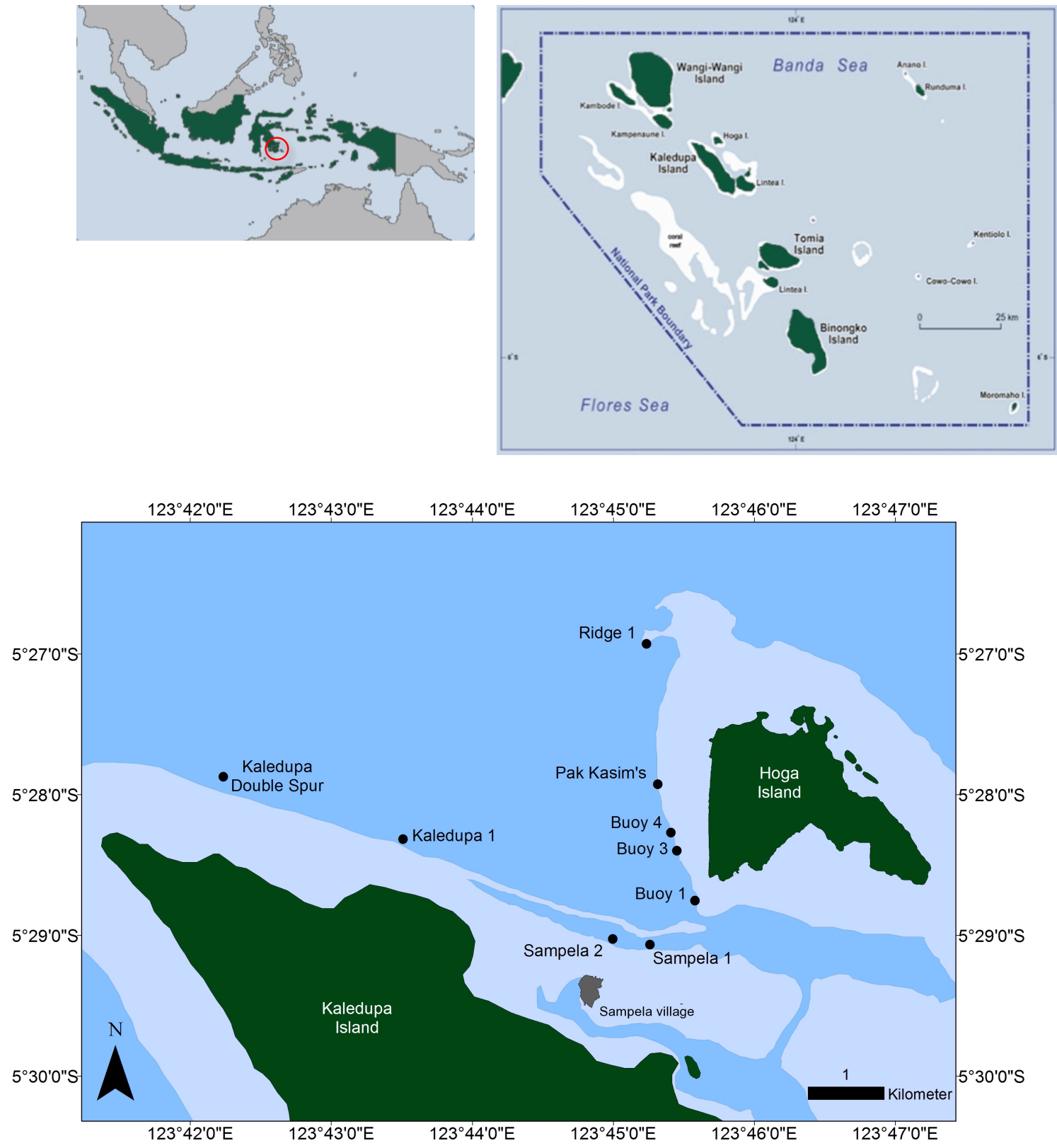

Figure 2.1 a) Map of Indonesia with the location of SE Sulawesi circled. b) The main islands of the Tukangbesi archipelago and the location of the Wakatobi Marine National Park boundary c) The location of the nine study sites and Sampela village. 


\section{Chapter 2}

Table 2.1 Description of study site characteristics

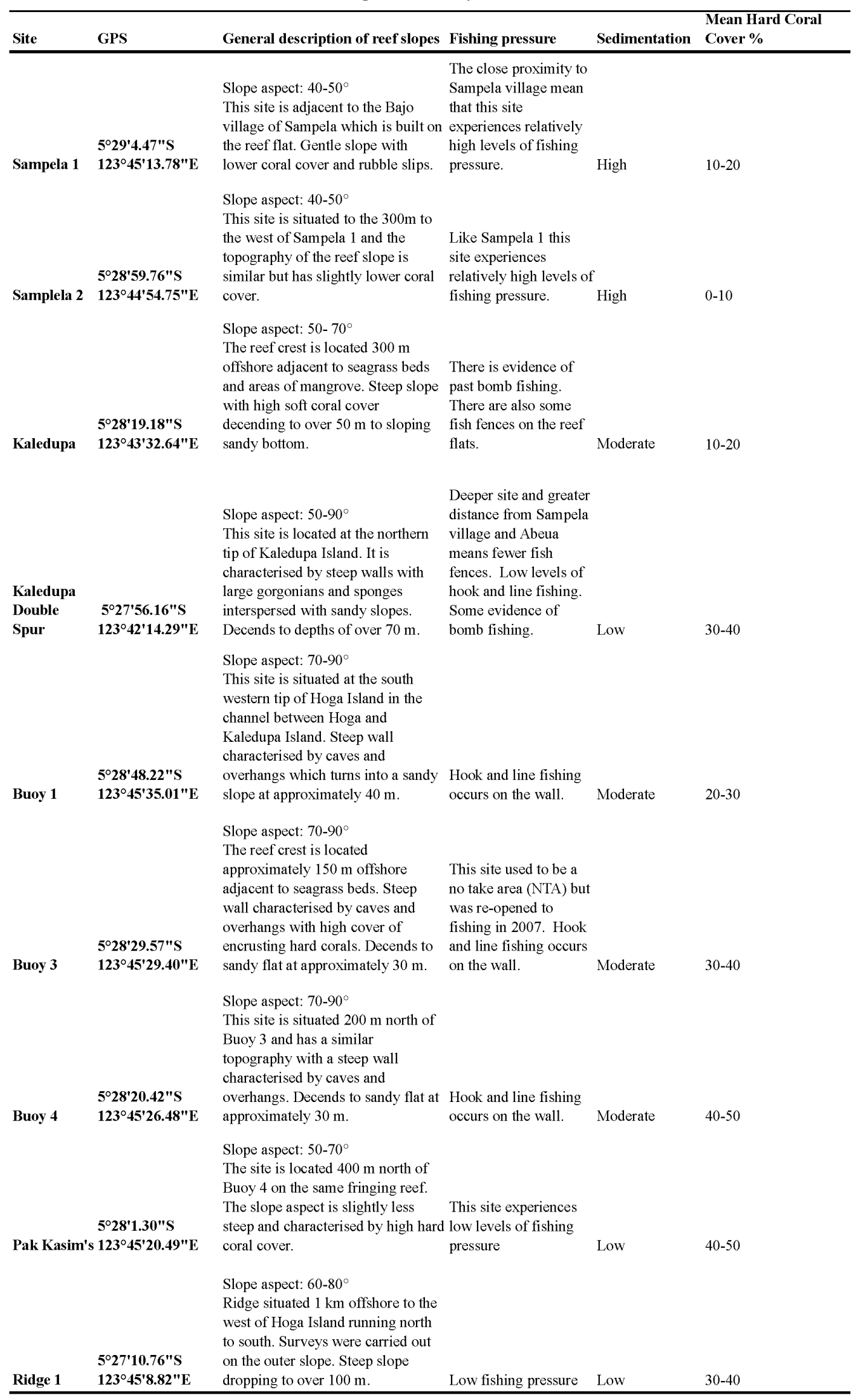




\subsubsection{Fish Surveys}

Fish surveys were carried out by divers using SCUBA on reef slopes at a depth of approximately $10 \mathrm{~m}$ at the nine study sites. Only one depth was surveyed due to logistical constraints. A $50 \mathrm{~m}$ transect was laid on the reef slope following a $10 \mathrm{~m}$ depth contour. Divers waited ten minutes before surveys began to allow fish to resume normal behaviour prior to starting surveys. Divers then swam back along the transect recording all fish present to species level in a virtual 'tunnel' extending $2.5 \mathrm{~m}$ either side of the transect tape and $2.5 \mathrm{~m}$ above the substrate. Three transects were surveyed at each site. A $10 \mathrm{~m}$ gap was left between the end of one transect and the start of the next.

\subsubsection{Fish feeding observations}

Observations of fish feeding behaviour were limited to two sites, Sampela 1 and Buoy 3 due to logistical constraints. These sites were selected in order to maximise the total number of species that could be observed as the fish survey data showed that they had very different fish assemblages. These sites also represent different levels of habitat degradation with Sampela having lower levels of coral cover and higher sedimentation rates. Fish observations were carried out within three $150 \mathrm{~m}^{2}$ plots marked out with flagging tape at each site. The habitat within the plots was surveyed with photoquadrats (method described further below and in Appendix 2) so that the number of bites taken by fish on sponges could be compared to the proportion of sponge in the environment. Once an individual of a target species was located it was followed for three minutes. Pilot trials showed that this was the optimum time that fish could be continuously observed with a small chance of them leaving the observation area on the reef slope. Every bite taken by fish and the food item that was fed on was recorded. Food categories recorded included: sponge, hard coral, soft coral, coralline algae, other algae, dead coral (structure of coral skeleton still visible), dead coral covered in algae, rock, rubble, sand and 'other' (ascidians, anemones and gorgonians). The proportion of each food item available at each site was determined from photoquadrats (described in more detail below). At least three individuals of each targeted species were observed. Observations were limited to adult fishes that 


\section{Chapter 2}

were identified on the basis of size, colouration and other morphological characteristics.

\subsubsection{Nudibranch and starfish surveys}

Nudibranch and starfish surveys were carried out by divers using SCUBA on reef slopes at a depth of approximately $10 \mathrm{~m}$ at the nine study sites. All nudibranchs and starfish present $2.5 \mathrm{~m}$ each side of a $30 \mathrm{~m}$ transect were identified and recorded. Three transects were completed at each study site. Photographs were taken of each nudibranch and starfish in order to confirm identifications. Divers also recorded the substrate that the nudibranchs and starfish were on and any signs of feeding behaviour such as the presence of feeding scars on the surface of sponges. In order to avoid bias in search effort each survey was limited to 25 minutes.

\subsubsection{Site benthic characteristics}

Photoquadrats were used to measure site benthic characteristics at Sampela 1, Sampela 2, Buoy 3 and Buoy 4. This information was used to examine whether invertebrates were more frequently associated with sponges than would be expected by chance given the proportion of sponge at these study sites. The photoquadrats from Buoy 3 and Sampela 1 were used to determine whether the fish whose feeding behaviour was observed were actively selecting or avoiding sponges. Ten 1 X $1 \mathrm{~m}$ quadrats were photographed at pre-selected random positions along the transects that were used for the invertebrate surveys and in the fish feeding observation plots. To assist with subsequent image analysis the quadrat was subdivided into nine sections and close up images were taken of these squares in addition to the photograph of the overall quadrat. Images were analysed using the programme Coral Point Count with Excel extensions (CPCe) (Kohler \& Gill 2006). Twenty points were randomly overlaid on each quadrat image and the substrate type under each point was recorded. Substrate types included were: sponge, hard coral, soft coral, coralline algae, other algae, dead coral (structure of coral skeleton still visible), dead coral covered in algae, rock, rubble, sand and other (ascidians, anemones and gorgonians). The close up images were used as a reference to aid with identification.

\subsubsection{Data analysis}




\section{Chapter 2}

Statistical analyses were carried out using PRIMER-E v6 (Plymouth Routines in Multivariate Ecological Research) and based on distance matrices calculated using Bray-Curtis coefficients.

\subsubsection{Fish data analyses}

Permutational multivariate analysis of variance (PERMANOVA) with site as a fixed factor with nine levels was used to test the null hypothesis that there was no difference in fish abundance between the study sites. The same PERMANOVA design was also used to test the null hypothesis that there was no difference in the fish assemblages between the study sites. Unconstrained multidimensional scaling (MDS) and constrained canonical analysis of principal coordinates (CAP) were used to visualise differences in the fish assemblages between the study sites. Vectors representing Pearson correlations with the resulting CAP axes were used to identify the species that characterised the differences in multivariate fish assemblages between sites. An unconstrained MDS plot was also used to visualise differences in the food items fed on by fish in different families.

Ivlev's (1961) electivity index was used to test whether fish fed more often on sponges than would be expected given the proportion of sponge in the environment.

$$
E=\frac{r i-p i}{r i+p i}
$$

Where $E$ is the electivity measure, $r i$ is the percentage of bites taken of sponge and $p i$ is the percentage cover of sponge in the environment. The value of the index ranges between -1 to +1 where negative values indicate avoidance of sponges and positive values represent active selection of sponges.

\subsubsection{Nudibranch data analyses}

I also used a univariate PERMANOVA with site as a fixed factor with nine levels to test the null hypothesis that there was no difference in nudibranch abundance between study sites. The same PERMANOVA design was also used on the multivariate 


\section{Chapter 2}

nudibranch assemblage data to test the null hypothesis that there was no difference in nudibranch assemblages among the study sites. MDS and CAP plots were used to visualise site differences. Ivlev's electivity index was used to test whether nudibranchs were found more often on sponges than would be expected given the proportion of sponge in the environment where $E$ is the electivity measure, $r i$ is the percentage of nudibranchs observed on sponge and $p i$ is the percentage cover of sponge in the environment.

Sea turtle distributions and abundance were not analysed as only one hawksbill turtle was observed throughout this study.

\subsection{Results}

\subsubsection{Fish surveys}

In total 188 species of fish representing 30 families were recorded on the 27 reef slope transects (see Appendix 3 for fish abundance data). The total number of fish recorded was 10,400 with a mean number of fish per transect of $385( \pm 141)$. Fish assemblages were significantly different between the study sites (PERMANOVA) and Figure 2.2 illustrates these differences, with the vectors giving an indication of the fish species that were characteristic of the study sites. Buoy 1, Buoy 3 and Buoy 4, which are steep reef walls with caves and overhangs, were characterised by Cephalopholis spiloparea (strawberry groupers), Pomacentrus nigromarginatus (black margin damselfish) and Pseudochromis paccagnellae (royal dottybacks). Pak Kasim's, Ridge 1, Kaledupa 1 and Kaledupa Double Spur were characterised by Chrysiptera talboti (Tabot's damselfish), Chromis atripes (darkfin chromis) and Neogliphidodon nigroris (Behn's damselfish). The last two sites, Sampela 1 and Sampela 2, were characterised by a number of species including Sufflamen bursa (scythe triggerfish), Centropyge bicolor (bicolor angelfish), Scolopsis bilineata (bridled monocle bream), Dascyllus trimaculatus (threespot dascyllus), Pomacentrus amboinensis (Ambon damselfish) and Pomacentrus alexandrae (Alexander's Damselfish). 
a.

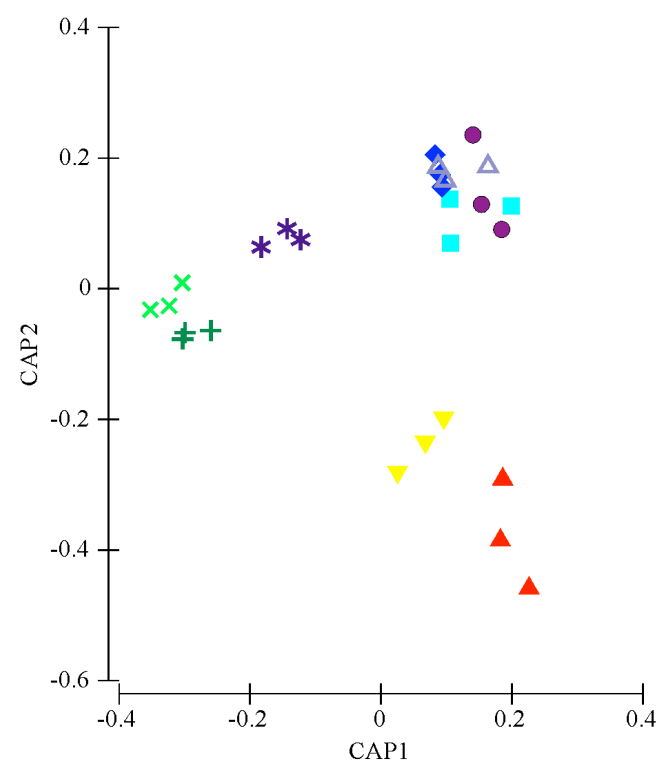

b.

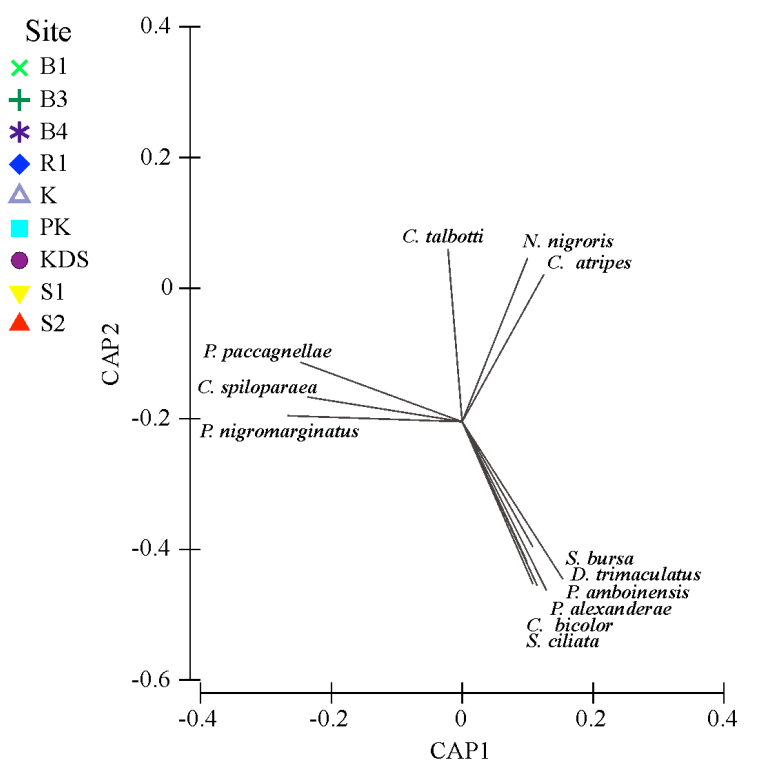

Figure 2.2 a) Canonical Analysis of Principal Coordinates (CAP) showing differences in fish assemblages across study sites. b) Vectors represent Spearman rank correlations of individual fish species with the CAP axes indicating which species are characteristic of the study sites.

\subsubsection{Fish feeding observations}

In total, the feeding behaviour of 45 species in 12 families was observed. The proportion of bites that each species took on each food item is summarised in Table 2.2 Some food items, such as dead coral covered in algae and coralline algae, were fed on by a large proportion of the species observed ( $>50 \%)$ whereas others were only fed on by a few species. 


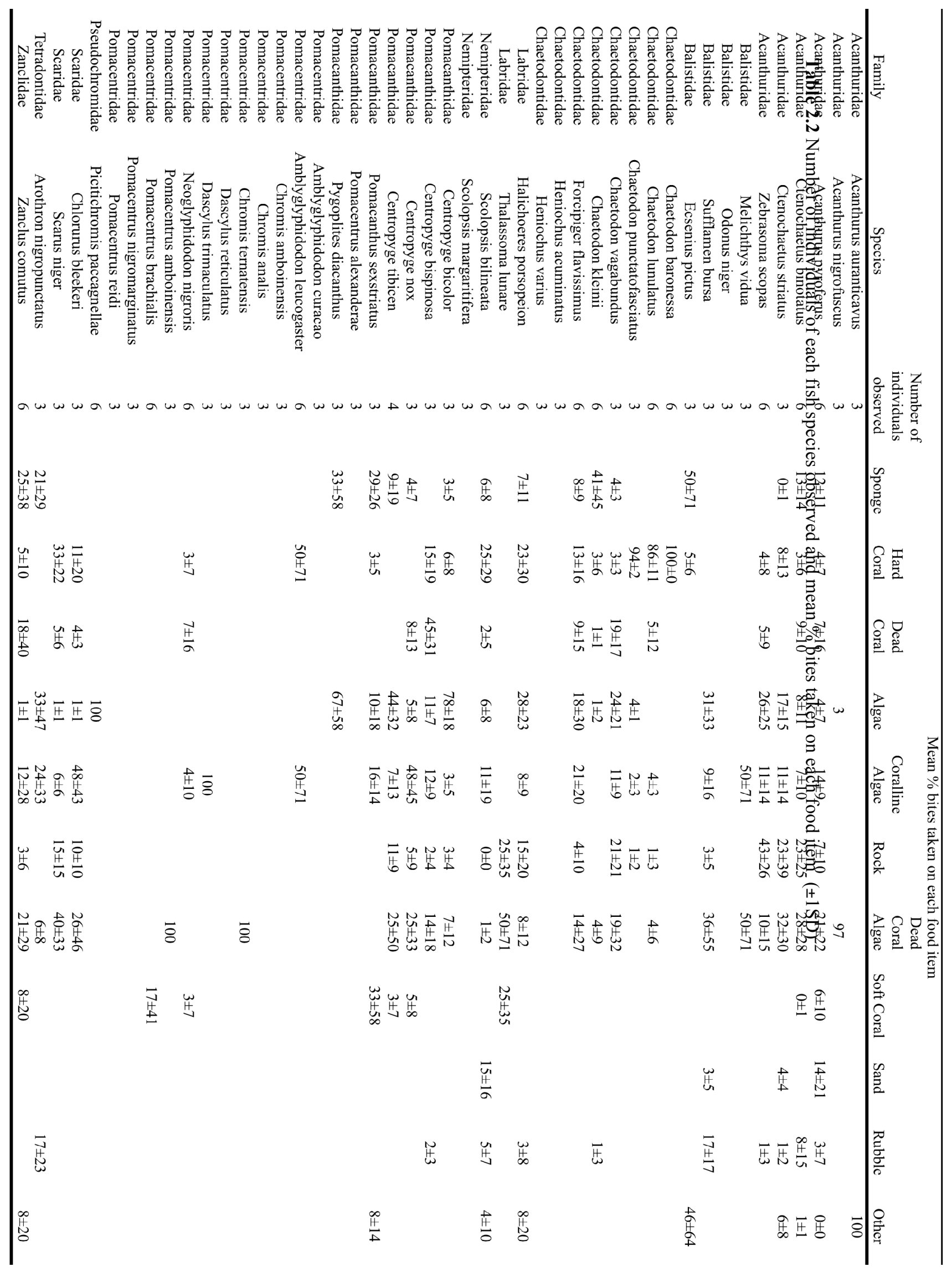


In total, 16 species in 8 families took bites of sponge (Table 2.3). The highest mean number of bites $(17 \pm 24)$ was taken by a surgeonfish, Ctenochaetus binotatus (twospot surgeonfish). Two other surgeonfish Acanthurus pyroferus (mimic surgeonfish) and Ctenochaetus striatus (lined Bristletooth) also took bites of sponge, however, only one bite was taken by one individual of $C$. striatus so it seems unlikely that sponge is a major food source for this species. The species that took the second highest mean number of bites ( $14 \pm 25$ ) was Escenius pictus (pictus blenny). Of the three individuals observed of this species, the first fed solely on Xestospongia testudinaria (giant barrel sponge), the second took bites of an ascidian and the last individual was not observed feeding. Three species of butterflyfish were observed feeding on sponges. Cheatodon kleini (Klein's butterflyfish) took a mean of $11 \pm 12$ bites of sponge. A large proportion of the total bites taken by this species were taken on sponge (82\%). Forcipiger flavissimus (longnose butterflyfish) and Chaetodontus vagabundus (vagabond butterflyfish) only took on average $2 \pm 4$ and $1 \pm 1$ bites respectively. The angelfish that were observed taking bites of sponge included Pygoplites diacanthus (regal angelfish), Pomacanthus sexstriatus (six banded angelfish) and three species of pygmy angelfish. Pomacanthus sexstriatus is a large angelfish that fed on a variety of sponges. The three individuals of $P$. sexstriatus that were observed only took a mean of 7 bites on sponge but this accounted for an average of $39 \%$ of the total bites of this species. The three species of pygmy angelfish, Centropyge bicolor (bicolor angelfish), Centropyge nox (midnight angelfish) and Centropyge tibicen (keyhole angelfish) took fewer bites of sponge and fed on coralline algae, dead coral covered in algae and other algae to a greater extent. Half of the Zanclus cornutus (moorish idol) individuals were observed taking bites of X. testudinaria. 
Table 2.3 Ivlev's Electivity Indices for the fish species observed at Hoga and Sampela

\begin{tabular}{|c|c|c|c|c|c|}
\hline Site & Family & Species & $\begin{array}{l}\text { Number of } \\
\text { fish } \\
\text { observed }\end{array}$ & $\begin{array}{l}\text { Total } \\
\text { number of } \\
\text { bites on } \\
\text { sponge }\end{array}$ & $\begin{array}{l}\text { Ivlev's } \\
\text { Electivity } \\
\text { Index }\end{array}$ \\
\hline \multirow[t]{12}{*}{ Sampela } & Acanthuridae & Acanthurus pyroferus & 3 & 22 & 0.48 \\
\hline & Acanthuridae & Ctenochaetus binotatus & 3 & 13 & 0.27 \\
\hline & Acanthuridae & Ctenochaetus striatus & 3 & 1 & -0.7 \\
\hline & Chaetodontidae & Cheatodon kleini & 3 & 19 & 0.89 \\
\hline & Chaetodontidae & Forcipiger flavissimus & 3 & 1 & 0.26 \\
\hline & Labridae & Halichoeres porsopeion & 3 & 1 & 0.4 \\
\hline & Nemipteridae & Scolopsis bilineata & 3 & 1 & 0.28 \\
\hline & Pomacanthidae & Centropyge bicolor & 3 & 2 & -0.45 \\
\hline & Pomacanthidae & Centropyge tibicen & 3 & 3 & 0.09 \\
\hline & Pomacanthidae & Pygoplites diacanthus & 3 & 7 & 0.86 \\
\hline & Teradontidae & Arothron nigropunctatus & 3 & 7 & 0.8 \\
\hline & Zanclidae & Zanclus cornutus & 3 & 47 & 0.9 \\
\hline \multirow[t]{10}{*}{ Hoga } & Acanthuridae & Acanthurus pyroferus & 3 & 31 & 0.72 \\
\hline & Acanthuridae & Ctenochaetus binotatus & 3 & 90 & 0.82 \\
\hline & Blennidae & Ecsenius pictus & 3 & 43 & 0.92 \\
\hline & Chaetodontidae & Chaetodon vagabundus & 3 & 2 & 0.14 \\
\hline & Chaetodontidae & Cheatodon kleini & 3 & 46 & 0.95 \\
\hline & Chaetodontidae & Forcipiger flavissimus & 3 & 13 & 0.71 \\
\hline & Labridae & Halichoeres porsopeion & 3 & 1 & 0.42 \\
\hline & Nemipteridae & Scolopsis bilineata & 3 & 1 & 0.28 \\
\hline & Pomacanthidae & Centropyge nox & 3 & 3 & 0.46 \\
\hline & Pomacanthidae & Pomacanthus sexstriatus & 3 & 7 & 0.88 \\
\hline
\end{tabular}

The difference in food items fed on by fish in different families is shown in Figure 2.3. On average Chaetodontidae (butterflyfish) fed on large amounts of hard coral, the Pomacanthidae (angelfish) and the one species of Pseudochromidae (dottyback) that was observed fed on algae, while the Acanthuridae (surgeonfish) and Scaridae (parrotfish) species generally fed on dead coral covered in algae. Sponges accounted 


\section{Chapter 2}

for a large amount of the diets of the three families, Zanclidae (moorish idol),

Tetraodontidae (pufferfish) and Blennidae (blennies).

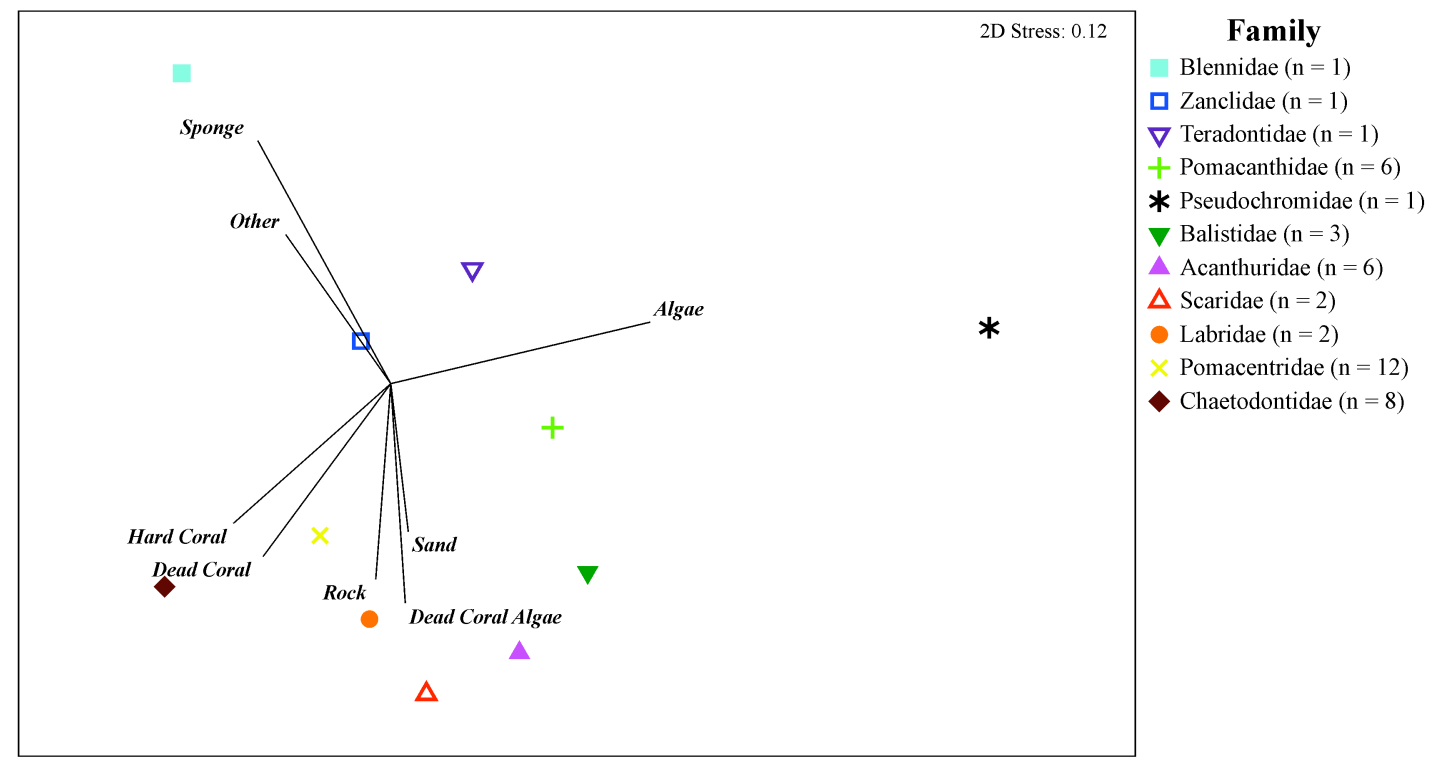

Figure 2.3 Unconstrained non-metric Multi Dimensional Scaling (MDS) plot illustrating differences in the food items fed on by different fish families.

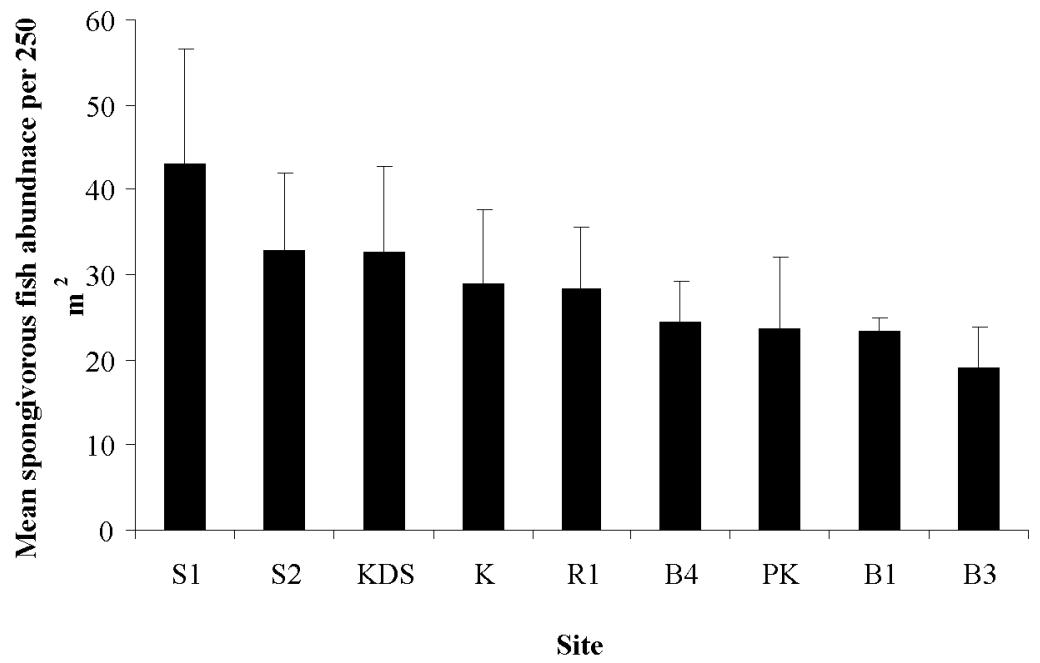

Figure 2.4 Mean spongivorous fish densities at the study sites. Error bars represent +1 standard deviation (SD).

\subsubsection{Nudibranch Surveys}




\section{Chapter 2}

In total 132 individual nudibranchs were recorded on the transects belonging to 26 species and nine different genera (see Table 2.4). It was found that nudibranch abundance was significantly different between study sites (PERMANOVA, $\mathrm{df}=8$, pseudo- $\mathrm{F}=2.671, \mathrm{P}=0.019$ ). Figure 2.5 shows the variation in mean nudibranch densities across sites. Mean abundance was highest at Sampela 1 and Ridge 1, but there was high variability between transects at Sampela indicating that nudibranch abundance was patchy at this site. The lowest mean abundances were recorded at Pak Kasim's and Kaledupa Double Spur.

Table 2.4 Nudibranch species recorded during surveys

\begin{tabular}{lc}
\hline & Total number observed \\
Species & $\left(27\right.$ transects $\left.=4050 \mathrm{~m}^{2}\right)$ \\
\hline Chromodoris annae & 8 \\
Chromodoris coi & 1 \\
Chromodoris dianae & 6 \\
Chromodoris elisabethina & 1 \\
Chromodoris geometrica & 2 \\
Chromodoris kunei & 1 \\
Chromodoris leopardus & 1 \\
Chromodoris lochi & 19 \\
Chromodoris cf. dianae & 9 \\
Chromodoris willani & 4 \\
Flabellina exoptata & 1 \\
Hypsolodoris apolegma & 1 \\
Jorunna funebris & 1 \\
Phyllidia coelestis & 1 \\
Phyllidia elegans & 11 \\
Phyllidia ocellata & 4 \\
Phyllidia pustulosa & 40 \\
Phyllidia varicosa & 6 \\
Phyllidiella lizae & 4 \\
Phyllidiella rudmani & 1 \\
Phyllidiopsis krempfi & 1 \\
Phyllidiopsis pipeki & 2 \\
Phyllidiopsis shrineenae & 1 \\
Phyllidiopsis striata & 2 \\
Pterraealidia ianthina & 1 \\
Risbecia tyroni & \\
\hline
\end{tabular}




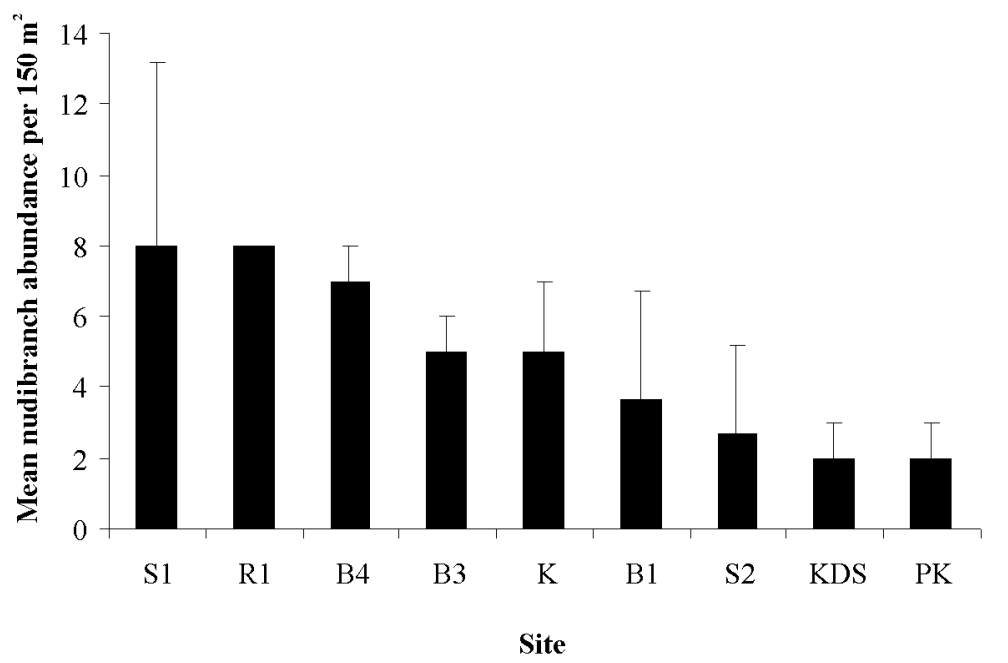

Figure 2.5 Mean nudibranch densities at the study sites. Error bars represent +1 standard deviation (SD).

In addition to differences in nudibranch abundance, there were significant differences in the species present at each site (PERMANOVA, $\mathrm{df}=8$, pseudo-F=1.7684, $\mathrm{P}=0.0044$; Figure 2.6). The vectors in Figure 2.6 represent Pearson correlations $(>0.5)$ of individual benthic components with the resulting CAP axes and can be used to identify which nudibranch species are characteristic of each study site. The results show that Chromodoris lochi appears to be restricted to sites with steep walls and overhangs such as at Buoy 1, Buoy 3 and Buoy 4. Ridge 1, Kaledupa and Sampela were characterised by a number of sponge feeding nudibranchs in the family Phillidae. 

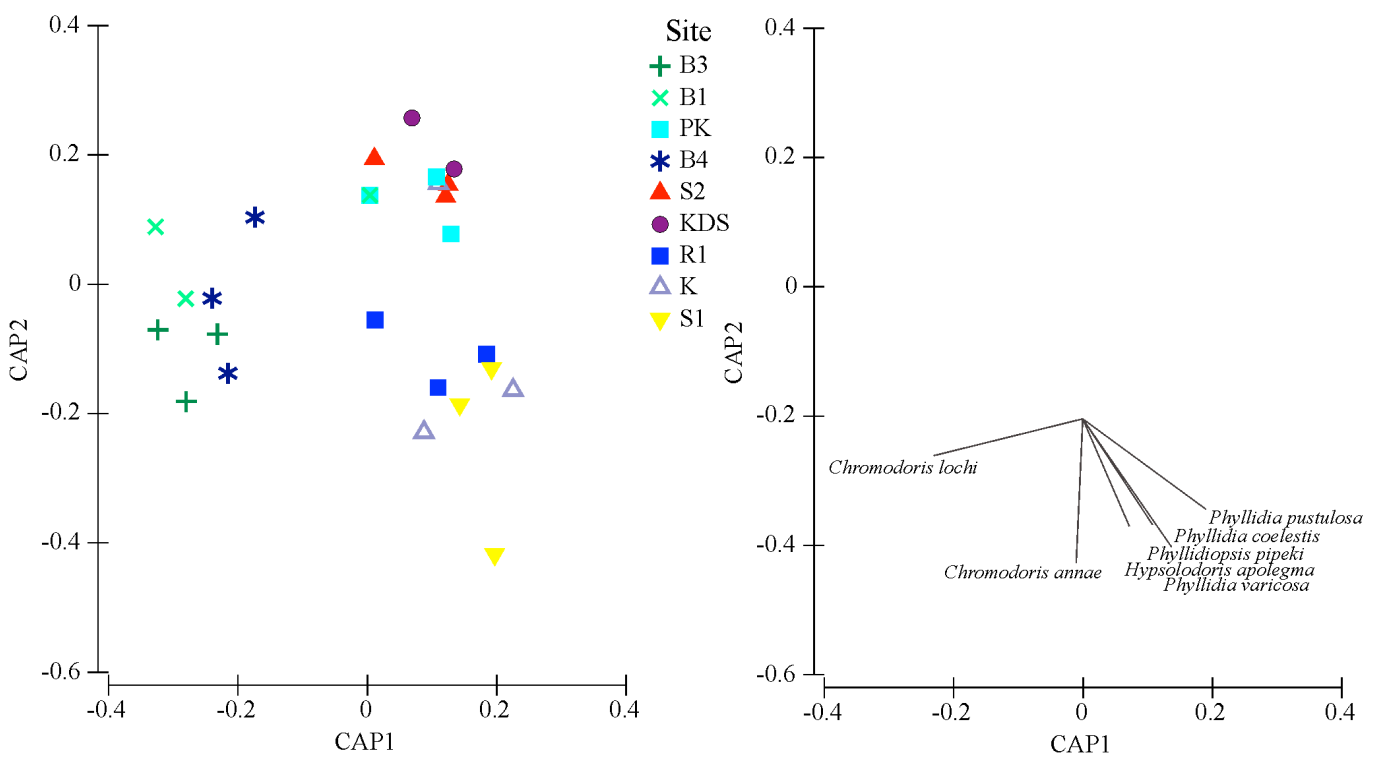

Figure 2.6 Canonical Analysis of Principal Coordinates (CAP) plot showing the differences in nudibranch assemblages at the study sites.

\subsubsection{Associations between nudibranchs and sponges}

At Sampela, Phyllidia varicosa, Phyllidiella pustulosa, Chromodoris annae, Phyllidia elegans were all found on sponges more frequently than would be expected by chance based on Ivlevs electivity index (Table 2.5). On Hoga reef slopes, Chromodoris willani, Chromodoris geometrica, Phyllidiella pustulosa, Chromodoris cf. dianae, Chromodoris lochi were also associated with sponges. None of the nudibranch species observed was found to be actively avoiding sponges (i.e. having a negative Ivlev electivity index). 
Chapter 2

Table 2.5 Ivlev's Electivity indices for the nudibranch species observed at Sampela and Hoga

\begin{tabular}{llcc}
\hline \multirow{2}{*}{ Site } & Species & $\begin{array}{l}\text { Number of individuals } \\
\text { observed }\end{array}$ & Ivlev's Electivity Index \\
\hline Sampela & Phyllidia varicosa & 4 & 0.90 \\
& Phyllidia pustulosa & 12 & 0.87 \\
& Chromodoris annae & 2 & 0.85 \\
& Phyllidia elegans & 6 & 0.62 \\
& Chromodoris leopardus & 1 & 0.00 \\
& Hypsolodoris apolegma & 1 & 0.00 \\
& Phyllidia coelestis & 1 & 0.00 \\
& Phyllidia ocellata & 2 & 0.00 \\
& Phyllidiopsis pipeki & 1 & 0.00 \\
& Risbecia tyroni & 2 & 0.00 \\
Hoga & & \\
& Chromodoris willani & 1 & 1.00 \\
& Chromodoris geometrica & 2 & 0.91 \\
Phyllidia pustulosa & 3 & 0.86 \\
Chromodoris cf. dianae & 7 & 0.71 \\
Chromodoris lochi & 15 & 0.69 \\
Chromodoris annae & 3 & 0.00 \\
Phyllidiopsis striata & 1 & 0.00 \\
Phyllidia elegans & 1 & 0.00 \\
Chromodoris elisabethina & 1 & 0.00 \\
Phyllidiopsis krempfi & 1 & 0.00 \\
Chromodoris dianae & 1 & 0.00 \\
\hline
\end{tabular}

Figure 2.7 illustrates some of the observed feeding methods adopted by nudibranchs. Two species, Phyllidia varicosa and Phyllidiella pustulosa from the family Phillidiidae are specialised sectorial feeders. They do not have hard mouthparts and feed by excreting enzymes onto the sponge surface and then consume the sponge once it has been softened leaving behind characteristic feeding scars. The other two species Chromodoris lochi and Jorunna funebris have rasping radula, which they use to scrape sponge tissue. Chromodoris lochi appears to feed by scraping off the surface layer of the sponge while Jorunna funebris consumes the whole sponge. 

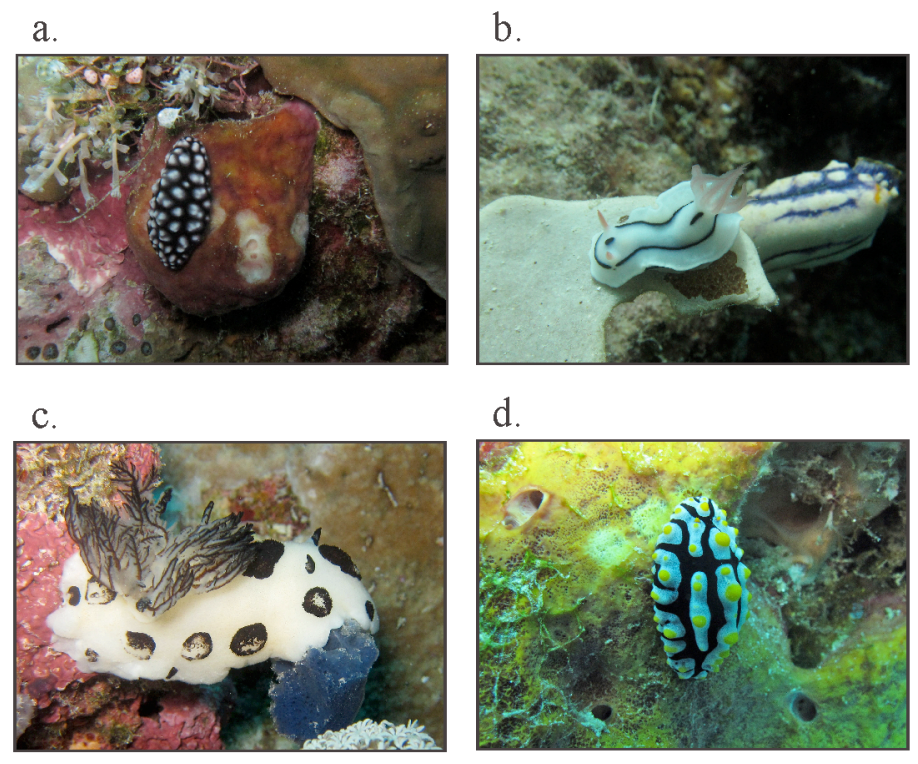

Figure 2.7 Different nudibranch feeding strategies and characteristic feeding scars on sponge prey. The photographs show a) Phyllidiella pustulosa b) Chromodoris lochi c) Jorunna funebris d) Phyllidia varicosa.

\subsubsection{Starfish surveys}

Ten species of starfish (Figure 2.8) representing 117 individuals were recorded. The three most abundant starfish species were Linkia laevigata $(\mathrm{n}=62)$, Choriaster granulata $(\mathrm{n}=20)$ and Celerina heffernani $(\mathrm{n}=19)$. The other species each accounted for less than $5 \%$ of the total starfish species observed. Starfish abundance was highest at Sampela 1 and lowest at Buoy 3 (Figure 2.8). Of all the starfish recorded only two individuals were found on sponges. The first was one of the 19 Celerina heffernani specimens recorded and the second was the only Gomophia egeria that was observed. 

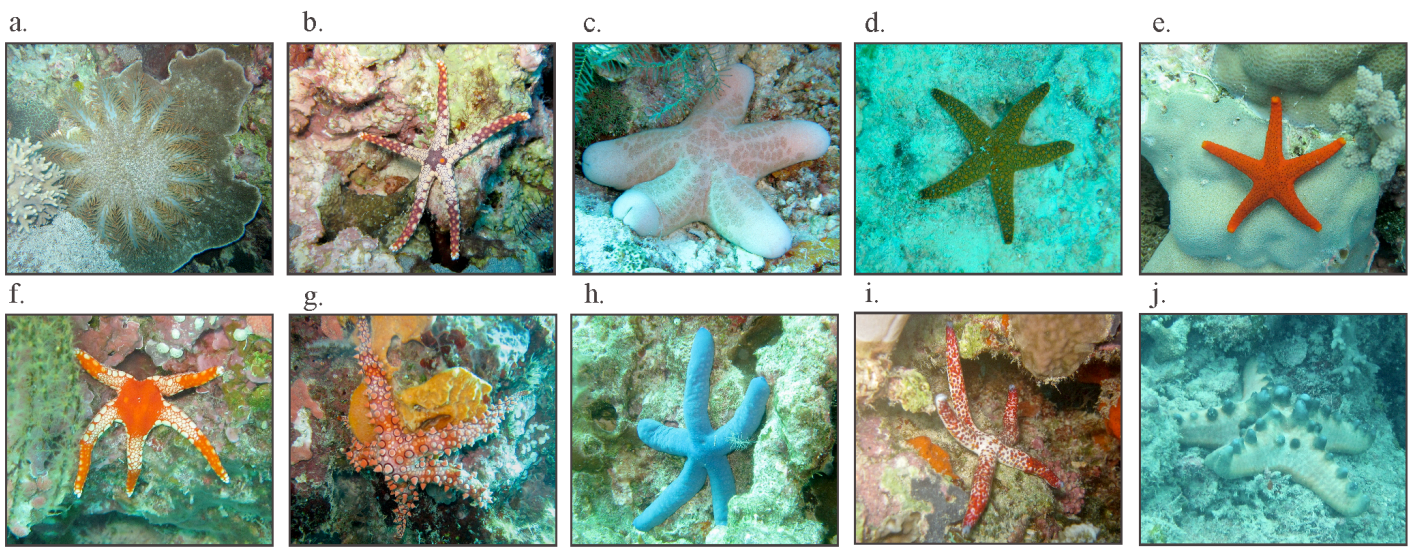

Figure 2.8 Starfish species observed a) Acanthaster planci b) Celerina heffernani c) Choriaster granulatus d) Fromia indica e) Fromia milleporella f) Fromia monilis g)

Gomophia egeria h) Linckia laevigata i) Linckia multiflora j) Protoreaster nodosus. The two species which may feed on sponge were Celerina heffernani ( 1 individual out of 30 observed on sponge) and Gomophia egeria (1 out of 1 observed on sponge).

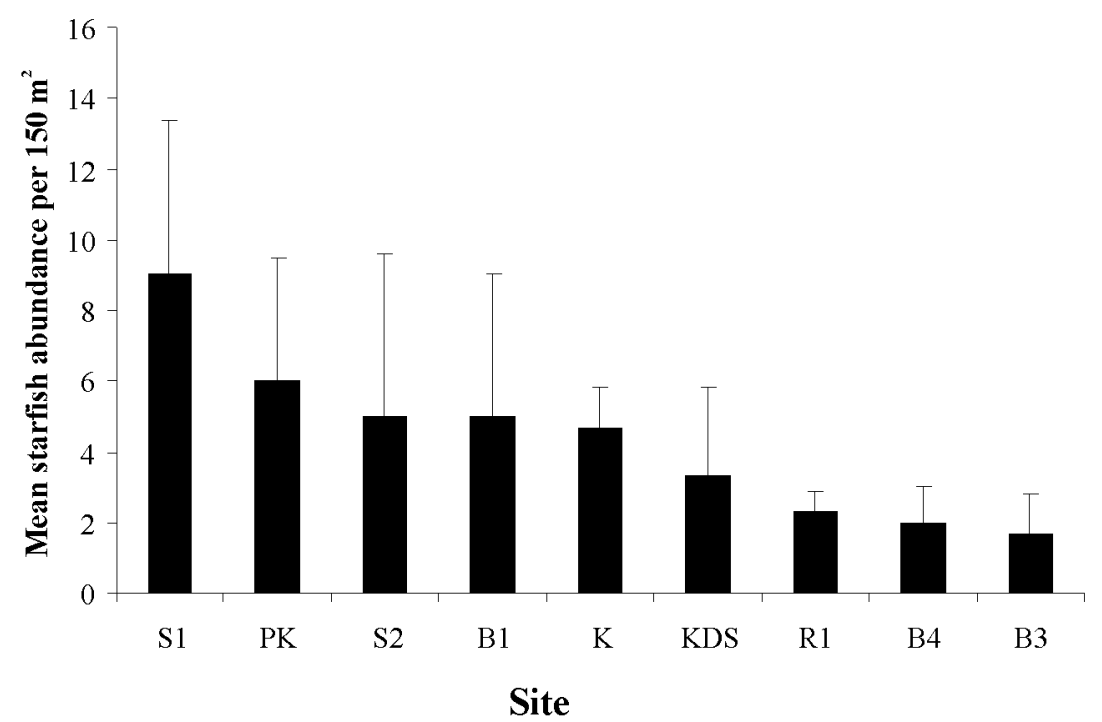

Figure 2.9 Starfish densities at the study sites. Error bars represent +1 standard deviation (SD).

\subsection{Discussion}

The main aim of this chapter was to identify spongivorous vertebrates and invertebrates in the Wakatobi Marine National Park (WMNP). The main vertebrate 


\section{Chapter 2}

spongivores on reef slopes in the WMNP were fish and the principal invertebrates were nudibranchs. In total 14 fish species were identified to be selectively feeding on sponges, while nine species of nudibranch were positively associated with sponges. In terms of overall abundance, spongivorous fish outnumbered nudibranchs and thus appear to have greater potential to affect sponge distribution patterns. Spongivorous fish abundance was highest at degraded sites and lower at higher quality sites. It is currently unclear whether this is due to the impacts of fishing or variation in site habitat characteristics. In contrast nudibranch abundance did not vary consistently with habitat degradation.

\subsubsection{Vertebrate spongivores}

In total 16 species of fish were observed feeding on sponges. Two of the fish that fed selectively on sponges (Ivlev's Electivity Index $>0.80$ ) were the angelfish Pygoplites diacanthus and Pomacanthus sexstriatus. This is consistent with studies of fish feeding behaviour and gut content analyses from the Caribbean that show sponges are a major part of the diets of a number of angelfish species (Hourigan et al. 1989;

Dunlap \& Pawlik 1996). Randall and Hartmann (1968) found that four angelfish species were among the largest consumers of sponge in the West Indies with sponges making up over $95 \%$ of the gut contents of angelfish in the genus Holacanthus and over $70 \%$ in the genus Pomacanthus. Of the three species of pygmy angelfish I observed only Centropyge nox fed more on sponge than would be expected given the percentage cover of sponge at Buoy 3 (Ivlev's Electivity Index $>0.40$ ), however sponges do not appear to constitute a large proportion of the diets of Centropyge bicolor or Centropyge tibicen. My results indicate that pygmy angelfish do not feed on sponges as much as angelfish in other genera and also highlight the fact that there can be considerable variation in the feeding habits of species within the same genus indicating the need for higher taxonomic resolution when assessing the feeding behaviour and potential impacts of spongivory on coral reefs.

Zanclus cornutus, commonly known as the moorish idol and the only member of the family Zanclidae, has been reported to feed on sponges in a number of areas throughout the Pacific. Sponge remains made up on average $84.5 \%$ of the gut contents of 12 individuals in Hawaii (Hobson 1974) and 86\% of 30 individuals in Japan (Sano 


\section{Chapter 2}

et al. 1984). In this study Z. cornutus was observed feeding on sponges (Ivlev's Electivity Index $=0.90$ ) but interestingly only the individuals at the degraded site, Sampela, fed on sponges and particularly on the giant barrel sponge Xestospongia testudinaria. At the higher coral cover site Buoy 3, Z. cornutus fed mostly on coralline algae (60\% of all bites) but also on hard coral, ascidians and algae. One possible explanation for this difference is that at Buoy 3 moorish idols are able to feed on a wider range of food items whereas at Sampela hard coral and coralline algae cover are much lower (see Chapter 3) and therefore their diets are predominantly sponge based due to the lack of alternative food sources.

Two species of butterflyfish were documented feeding on sponge, Chaetodon kleini and Forcipiger flavissimus. These widespread and abundant species also appear to feed selectively on sponges (Ivlev's Electivity Index > 0.70). Although C. kleini has been previously described as a zooplanktivore (Hobson 1974), my results suggest that in the WMNP this species also feeds on sponge and to a lesser extent on hard coral and algae. Nagelkerken et al. (2009) also found that C. kleini feeds on sponges on the Great Barrier Reef where $28 \%$ of bites taken by C. kleini $(\mathrm{n}=8)$ were on sponges and that sponges accounted for $8 \%$ of the gut contents of five other individuals. The abundance of this species and its relatively high feeding rate on sponges $(11 \pm 12$ bites per 3 min observation period) mean that it could potentially affect sponge populations.

An unexpected finding of this study was that two species of surgeonfish, Ctenochaetus binotatus and Acanthurus pyroferus fed on sponges. There is limited information available on the feeding behavior and diet of $C$. binotatus that appeared to take the greatest number of bites of sponge in this study. Rather than actively cropping algae surgeonfish in this genus are thought to use their sectorial mouths and soft comb-like teeth to scrape detritus and sediment from the substrate (Randall 1955, 1980). Consequently, it is possible that $C$. binotatus was feeding on detritus on the surface of the sponge. However, the fact that this species was observed to interact with sponges more than expected given the percentage cover of sponge in the environment (Ivlev's Electivity Index $>0.80$ ) suggests that this species derives a particular benefit from scraping the surfaces of sponges. A. pyroferus also fed predominantly on sponges (Ivlev's Electivity Index $>0.70$ ), which is surprising given 
that earlier gut content analyses indicated that this species feeds on algae and detritus (Eagle \& Jones 2004). In terms of overall abundance and feeding rates, these species could potentially impact sponge distributions and abundance, however, the fact that they do not appear to remove large amounts of tissue means that their impact is likely to be small.

One of the greatest differences that I found between the spongivorous fish of the WNMP and those reported from the Caribbean was that I did not observe any spongivory by parrotfish. This was in contrast to the Florida Keys were Dunlap and Pawlik (1998) found that Sparisoma aurofrenatum and particularly schools of juvenile Scarus croicensis or Scarus taeniopterus fed on Xestospongia muta. The two species of parrotfish that I observed Scarus niger and Chlorurus bleekeri fed mainly on hard coral, algae and coralline algae. One possible explanation for this is that all of the parrotfish that I observed were adults and Dunlap and Pawlik (1998) found that spongivory was particularly common among juvenile parrotfish. Consequently, it is possible that juvenile parrotfish also feed on sponges in the WMNP.

Overall spongivorous fish abundance was highest at the degraded sites Sampela 1 and Sampela 2. The high abundance of spongivorous fish at these sites could be due to the cascading effects of overfishing on these reefs. Fishing pressure on reefs tend to be highest in close proximity to fisher access points (Stuart-Smith et al. 2008) so it is likely that fishing pressure at these sites is higher than at the other study areas due to their close proximity to the villages of Sampela and Ambeua. Artisanal reef fisheries tend to target large carnivorous fish species such as grouper (Russ \& Alcala 1996; Unsworth et al. 2007), which can lead to increases in the abundance of smaller species as they are released from predation. This could include spongivorous fish such as angelfish and butterflyfish which are not typically targeted by fisherman.

\subsubsection{Invertebrate spongivores}

Twenty-six species of nudibranchs were recorded during the invertebrate surveys. The vast majority of these were in the nudibranch sub-order Doridina. Of these, 21 species were in the sponge feeding families Chromodoridae and Phyllidiidae including the three most abundant species, Phyllidiella pustulosa $(\mathrm{n}=40)$, Chromodoris lochi $(\mathrm{n}=$ 19) and Phyllidia elegans $(\mathrm{n}=11)$. The results of the analysis of nudibranch habitat 
selectivity are consistent with observations from other regions that Chromodorid and Phyllidiid nudibranchs feed on sponges (McDonald \& Nybakken 1997).

The extent to which predation by nudibranchs regulates sponge abundance is currently unclear. A number of studies in tropical, temperate and polar systems suggest that in most cases nudibranchs only partially consume their sponge prey (Dayton et al. 1974; Gemballa \& Schermutzki 2004; Yasman, 2003). This evidence combined with the fact that many sponges show rapid regeneration rates (see Chapter 5) suggests that in many cases nudibranch predation is unlikely to have a major impact on sponge populations. A study in Alaska found that a large recruitment event of a dorid nudibranch, Archidoris montereyensis, resulted in the complete disappearance of the sponge, Halichondria panacea, in an area where it had previously occupied up to $40 \%$ of the substratum but this appears to be an unusual situation. In the present study the most abundant nudibranch Phyllidiella pustulosa (n $=40$ ) only occurred at densities of $2.11 \pm 1.59$ per $150 \mathrm{~m}^{2}$ so it seems unlikely that at such low densities nudibranchs could have an impact on sponge abundance.

This study is the first to focus on spongivores in the WMNP and as such provides new information on the extent and potential impacts of spongivory in SE Sulawesi. However, a number of logistical and methodolgical limitations need to be taken into account when considering the results. Logistical constraints limited the number of fish species that were observed and the number of sites where feeding observations were carried out. The present study includes feeding observations for many of the most abudant reef slope fish species off Hoga and Kaledupa but less common potential spongivorous fish may have been missed. For instance, three species of large angelfish, Pomacanthus imperator, Pomacanthus navarchus and Pomacanthus xanthomepoton were observed at very low densities during the fish surveys (see Appendix 3) but not observed within fish observation plots. Another limitation of the methodological approach is that it was not possible to identify which sponges fish were feeding on during the in-situ observations of feeding behaviour. This information would have been very useful but could only be recorded for relatively large sponge species that are easily recognisable in the field. Prior to conducting this study a small pilot study was carried out to examine whether analysing fish gut contents would be preferable to in-situ observations of feeding behaviour (discussed 


\section{Chapter 2}

in Appendix 4), however, identifying sponges in gut contents was as extremely difficult. In addition, quantifying how much sponge tissue was removed per bite by different species would have provided a more accurate estimate of the impact of each species rather than relying on number of bites alone. However, it was not possible to measure bites in-situ without losing track of the target fish or potentially missing bites. Finally, the fact that the spongivore surveys were all carried out the same year in the dry season means that potential annual and seasonal variation in feeding behaviour and spongivore abundance would not have been captured.

To conclude, these results indicate that fish were the most significant vertebrate spongivores and nudibranchs the most significant invertebrates in the WMNP. Overall the number of spongivorous fish species was relatively low which is in agreement with the findings of previous studies in the Caribbean and the Pacific. The fish species with the greatest potential to influence the distributions and abundance of sponges are those which have high feeding rates on sponges and also those that are abundant. In the present study Cheatodon kleini, Pygoplites diacanthus, Pomacanthus sextriatus and Zanclus cornutus appear to have the greatest potential to influence sponge populations. 
Chapter 2 


\section{Identifying biological and environmental factors associated with sponge abundance and diversity on Indo-Pacific reefs}

\subsection{Abstract}

The aim of this chapter was to determine how much of the observed variation in sponge assemblages in the Wakatobi Marine National Park (WMNP) could be explained by variation in spongivorous fish abundance relative to other biotic and abiotic factors. Sponges were surveyed across a range of reef slopes in the WMNP and sponge abundance and assemblage composition patterns were examined. Distance based multiple linear regression (DISTIM) coupled with an information theoretic approach to model selection was used to identify the potential drivers of sponge variation by examining associations between sponges and ten environmental and biological variables. Sponge assemblages were significantly different across the study sites and were dominated by one species Lamellodysidea herbacea, which accounted for $42 \%$ of the total sponges observed. When modelling total sponge abundance as a function of the abiotic and biotic factors only a small proportion of the variability in observed sponge abundance was explained (13\%). When Lamellodysidea herbacea was excluded from the analysis, $34 \%$ of the variation in sponge abundance was explained and it was found that sedimentation explained more of the variation than any other factor ( $19 \%$ of the total variation). Contrasting patterns of sponge abundance with increasing sedimentation levels were observed where Lamellodysidea herbacea abundance was positively associated with sedimentation whereas total sponge abundance excluding Lamellodysidea herbacea was negatively associated with sedimentation. Multivariate analyses of overall sponge assemblages revealed that assemblage structure was associated with a number of abiotic and biotic factors with no dominant factor. These results have implications for reef conservation in the WMNP and potentially other coral reefs, suggesting that while overall sponge abundance might stay relatively constant with increased sedimentation levels, sponge assemblages are likely to be less diverse and dominated by a few sediment tolerant species. Spongivorous fish abundance does not appear to be strongly associated with sponge abundance or assemblage compostition in the WMNP. 


\subsection{Introduction}

Coral reefs are among the most biodiverse ecosystems in the world but it is estimated globally that $60 \%$ of reefs are threatened by human activities, including coastal development, overexploitation, invasive species and pollution (Burke et al. 2011). The Indo-Pacific region is a hotspot of global marine diversity for most major taxa (Roberts et al. 2002) and encompasses $75 \%$ of the world's coral reefs; however, this region is also facing the widespread degradation of its reefs (Edinger 1998). An analysis of 2667 surveys of Indo-pacific coral reefs between 1968 and 2004 suggest that an average of $1 \%$ or $1,500 \mathrm{~km}^{2}$ of hard coral cover has been lost per year over this period (Bruno \& Selig 2007). Currently, the vast majority of coral reef research in this region has investigated the effects of overexploitation and degradation on scleractinian corals and fish, while the impacts on other important groups of reef organisms have been relatively poorly studied (highlighted by Przeslawski et al. 2008).

Sponges fulfil many functional roles in reef ecosystems and are involved in processes including bentho-pelagic coupling, nutrient cycling, reef consolidation and bioerosion (Bell 2008). The high abundance of sponges on many reefs and their diverse functional roles mean changes in their distributions and abundance have the potential to affect the overall reef ecosystem functioning. Norström et al. (2009) highlighted two cases where reefs have undergone phase shifts from coral to sponge dominance. On coral reefs in Puerto Rico large increases in the bioeroding sponge Cliona langae were observed following declines in hard coral cover due to the combined effects of disease, hurricane damage, siltation and eutrophication (Williams et al. 1999). The long-term consequences of these phase-shifts are currently unknown, but increasing numbers of bioeroding sponges could adversely affect reef growth by increasing the rates of reef bioerosion relative to reef accretion (Nava \& Carballo 2008). The second example is from reefs in Belize where large increases in the sponge Chondrilla nucula were observed following mass coral mortality after a bleaching event. Aronson et al. (2002) warn that the rapid growth of this species has reduced the available substrate for coral recruitment, which may result in slower vertical reef accretion. Therefore in order to predict how anthropogenic changes will affect sponge assemblages on reefs it is important to understand which factors influence sponge distributions and abundance. 


\section{Chapter 3}

Evidence from observational studies in polar, temperate and tropical marine systems has shown that a number of abiotic factors can influence sponge assemblages. For example, sedimentation is known to affect many reef invertebrates (Rogers 1990) and a number of authors have found differences in sponge diversity and abundance in areas experiencing different sedimentation regimes (Bell \& Barnes 2000b; Bell \& Smith 2004; Cleary \& de Voogd 2007). Sponge species distributions and abundances have been previously correlated with water flow (Ginn et al. 2000; Bell \& Barnes $2000 \mathrm{~b} ; 2003$ ) and differences in sponge assemblages have also been observed in areas exposed to varying degrees of wave action and turbulence (Schmahl 1985; Schubauer et al. 1985; Bell \& Smith 2004; Roberts et al. 2006b; Bannister et al. 2007). Substrate type also appears to affect sponge assemblages with a number of studies concluding that sponge abundance is higher on hard fixed substrates like bedrock than on loose habitats such as gravel, cobble or boulders (Ginn et al. 2000; Carballo \& Nava 2007). Another abiotic factor that has the potential to affect sponge assemblages is temperature. Field and laboratory experiments have shown that raised sea temperatures can result in fatal bleaching of Xestospongia muta in the Caribbean (López-Legentil et al. 2008).

In addition to abiotic factors, biological factors such as predation and spatial competition can also influence the diversity and abundance of coral reef sponges (Suchanek et al. 1983; Wulff 1995, 2000, 2005, 2006a; Dunlap \& Pawlik 1996, 1998; Aerts \& Soest 1997; Pawlik 1998; Aerts 1998, 2000; Bell \& Barnes 2003). Predation can have a major impact on marine communities both directly through its effects on prey densities and behaviour and indirectly by mediating the outcomes of competitive interactions between prey (Chase et al. 2002). In tropical ecosystems, fish, turtles and invertebrates, such as starfish and nudibranchs, feed on sponges and there is evidence to suggest that this predation can have significant effects on sponge assemblages (Randall \& Hartman 1968; Wulff 1995; McDonald \& Nybakken 1997). For example, in the Caribbean some sponges are thought to be restricted to cryptic habitats on coral reefs by fish predation (Dunlap \& Pawlik 1996).

In order to ascertain the effects of anthropogenic impacts on sponge assemblages it is important to identify the relative importance of the different factors that influence their spatial distribution. For example, if a biological process, such as predation, plays a major role then declines in spongivorous fish (e.g. due to overfishing) could result 


\section{Chapter 3}

in increases in sponges as they are released from predation with subsequent ecosystem effects. Alternatively, if abiotic factors such as sedimentation levels or water flow are more important, then sponge assemblages may be more affected by factors that affect these processes, such as coastal development (Hodgeson \& Dixon 1988; Edinger et al. 1998). Multiple studies have found correlations between one or two abiotic factors and sponge abundance. However, few studies consider multiple potential drivers of sponge abundance and diversity meaning that it can be difficult to determine the most important factors within a given system. In addition, studies that do examine multiple variables often include 'composite' factors such as 'depth' and 'offshore distance' which often reflect changes in multiple variables such as sedimentation, light intensity and wave exposure (e.g. Zea 2001; Cleary \& de Voogd 2007; de Voogd et al. 2009).

The aim of this study was to identify associations between a suite of biological/environmental factors and the abundance and composition of sponge assemblages on reef slopes in the Wakatobi Marine National Park in Indonesia. Sponge abundance and diversity was surveyed in conjunction with a suite of biological and environmental variables at nine reef slope sites. The study sites were selected because they are subject to a range of environmental conditions. The biological and environmental variables were selected on the basis that they had been previously identified in the literature as affecting sponge distributions and/or abundance. A model selection approach was adopted to determine how much of the variation in the observed sponge assemblage patterns between sites could be explained by these variables and the relative importance of each variable. Given previous studies investigating the effects of biological and environmental factors on sponge abundance I hypothesise that: i) sponge abundance will be negatively correlated with sedimentation, turbidity, spongivorous fish abundance and hard coral cover; ii) sponge abundance will be positively correlated with substrate angle, water flow, Chlorophyll- $a$, salinity, algal cover and temperature; and iii) that the factors that explain the greatest amount of variation observed in sponge abundance are likely to be abiotic factors such as sedimentation and water flow. 


\subsection{Methods}

\subsubsection{Study sites}

This study was conducted in the Wakatobi Marine National Park (WMNP) in Southeast Sulawesi in Indonesia in June-August 2010. Environmental and biological variables were quantified on reef slopes at a depth of approximately $10 \mathrm{~m}$ at nine study sites: Sampela 1, Sampela 2, Kaledupa, Kaledupa Double Spur, Buoy 1, Buoy 3, Buoy 4, Pak Kasim's and Ridge 1. The study sites were located on reefs in close proximity to Kaledupa and Hoga Islands (for map see Figure 2.1 in Chaper 2). These study sites were chosen as they represent a range of abiotic conditions and biological variation with respect to benthic assemblage composition and fish assemblages (please see Table 2.1 in Chapter 2 for site characteristics).

\subsubsection{Biological variables}

The abundance and diversity of sponges was surveyed in situ using SCUBA in six $1 \times 1 \mathrm{~m}^{2}$ divided quadrats at each site (total $\mathrm{n}=54$ ). The size and number of quadrats was based on species accumulation curves. Sponge patches were counted if any part of the sponge was in the quadrat. Quadrats were placed at random locations (using a random number generator) along a $30 \mathrm{~m}$ transect tape, which was laid out at $10 \mathrm{~m}$ depth on the reef slope. Any sponges that could not be identified in situ were assigned an ID code that was used for all the individuals with the same external morphological characteristics. These were referred to as operational taxonomic units for the purposes of this study. Photographs of each operational taxonomic unit were taken in situ. Small samples were also taken and photographed back at the research base. Bleach spicule preps were made from a number of different individuals of each operational taxonomic unit to confirm that they shared internal as well as external characteristics. The percentage cover of other major organisms and substrate types present in quadrats were calculated from photographs analysed using the image analysis software Coral Point Count (Kohler \& Gill 2006). The substrate present below 100 points randomly superimposed on each quadrat image was assigned to one of the following categories: hard coral, coralline algae, other algae (turf or macro), soft coral, sponge, rock, rubble, sand, other (e.g. ascidians, bryozoans). Fish surveys were carried out along three transects on the reef slope at each site using the underwater visual census method (English et al. 1997). A $50 \mathrm{~m}$ transect line was laid on the reef 


\section{Chapter 3}

slope following a $10 \mathrm{~m}$ depth contour. Ten minutes were then allowed to elapse before the commencement of surveys to allow fishes to resume normal behavior (Fowler 1987). The abundance and identity of all fish were recorded by one diver in a virtual 'tunnel' $50 \mathrm{~m}$ long, $5 \mathrm{~m}$ wide and $5 \mathrm{~m}$ above the substrate. Spongivorous fish were classified as those that have been identified in the literature as having being found with more than $5 \%$ of sponge in their gut contents and also included those fish that were observed feeding on sponges during the fish surveys (Hiatt \& Strasburg 1960; Hobson 1974; Woodland \& Randall 1979; Eagle \& Jones 2004; Kavanagh \& Olney 2006; Disalvo et al. 2007; Nagelkerken et al. 2009; Chapter 2 of this thesis).

\subsubsection{Environmental variables}

Turbidity, temperature and chlorophyll-a were recorded using an RBR XR-420 data logger set to record every minute with no averaging. The data logger was deployed on reef slopes at a depth of $10 \mathrm{~m}$ for a minimum of three 24 hour periods at each study site. To quantify sedimentation levels, four sediment traps were deployed on the reef slope at each site at a depth of $10 \mathrm{~m}$ and placed approximately $5 \mathrm{~m}$ apart from each other. Sediment traps were constructed as described by English et al. (1997). After 10 days the traps were sealed and collected. The sediment was extracted using filter paper and dried in an oven at $100^{\circ} \mathrm{C}$ for a minimum of 24 hours. The sediment samples were then weighed to obtain mean dry weight of sediment at each site. The angle of each quadrat was also measured in situ using a protractor mounted on a spirit level. The protractor was attached to the spirit level in such a way that it could be rotated $360^{\circ}$. The spirit level was first used to determine $0^{\circ}$ so that the protractor could be held in this position while the spirit level was pivoted so that it was parallel with the edge of the quadrat. The angle of the spirit level was then recorded from the protractor. Water flow was measured with an impeller current meter (Valeport Model 106), which was deployed on reef slopes at a depth of $10 \mathrm{~m}$ for a minimum of three 24 hour periods at each study site.

\subsubsection{Statistical analyses}




\section{Chapter 3}

Statistical analyses were carried out in the PRIMER-E v6 environment (Plymouth Routines In Multivariate Ecological Research). Analyses were based on similarity matrices calculated using Bray-Curtis coefficients.

\subsubsection{Benthic characteristics of the study sites}

A one-factor permutational multivariate analysis of variance (PERMANOVA) was used to test for differences in the benthic characteristics of the study sites with site as a fixed factor with nine levels. PERMANOVA was used as it is a permutation-based method and therefore makes no assumption about the distribution of the data. Site differences were represented graphically using unconstrained non-metric Multi Dimensional Scaling (MDS) and constrained Canonical Analysis of Principal Coordinates (CAP). Spearman rank correlations between individual benthic components and the resulting CAP axes were used to identify benthic groups that were characteristic of particular study sites.

\subsubsection{Sponge abundance patterns:}

A one-factor univariate PERMANOVA was used to test for differences in sponge abundance at the study sites with site as a fixed factor with nine levels. The associations between sponge abundance and biotic/environmental variables were investigated using distance-based multivariate multiple linear regression (DISTLM). DISTLM is a routine that can be used to model the relationship between a multivariate dataset, as described by a resemblance matrix, and a set of predictor variables (Anderson et al. 2008). Draftsman plots were used to check for skewness and multi-collinearity in the predictor variables. Factors that were highly correlated with other variables were removed in order to maximize the parsimony of the models. Turbidity was left out of the analysis as it was highly correlated $\left(\mathrm{R}^{2}>0.9\right)$ with sediment levels. The following 10 variables were considered in the DISTLM analysis: substrate angle, temperature, sediment, flow rate, chlorophyll-a, hard coral cover, coralline algae, other non-coralline algae, soft coral and spongivorous fish abundance. Models incorporating all possible combinations of predictor variables were generated using the Best procedure within DISTLM. An information theoretic approach based 


\section{Chapter 3}

on modified Akaike's Information Criterion (AICc) was used to identify the best model. AICc values indicate the goodness of a model fit to the data, penalised for increasing the number of factors (Symonds \& Moussalli 2011). Models with the lowest AICc are considered the most parsimonious. In addition to identifying the model with the lowest AICc value, the Akaike weights of all models with $\triangle \mathrm{AICc}$ (measured relative to the model with the lowest AICc) less than five was quantified in order to account for uncertainty in model selection. The Akaike weights of a given model can be interpreted as the probability of that model being the best model for the observed data and can therefore be used to assess the uncertainty associated with model selection (Johnson \& Omland 2004). Akaike weights were also used to estimate the relative importance of each predictor variable (Symonds \& Moussalli 2011). For each predictor, the Akaike weights of all the models (with $\triangle \mathrm{AICc}$ less than 5) that contained that predictor were summed. The summed Akaike weights for each predictor can be interpreted as the relative importance of that predictor with predictors that consistently occur in the most likely models having an Akaike weight close to 1 whereas variables that are absent from all models or are only present in poorly fitting models (high AICc values) have an Akaike weight close to 0 (Symonds \& Moussalli 2011).

\subsubsection{Sponge diversity and assemblage patterns:}

Species diversity indices consisting of the total number of species (S) present, Shannon's index (H') and Pielou's evenness index (J') were calculated for each study site.

The same PERMANOVA design as used in the analysis of sponge abundance data was used to test for differences in the multivariate sponge assemblages at the study sites, but a dispersion weighting transformation was applied prior to the analysis. This transformation was considered appropriate as some sponges, particularly Lamellodysidea herbacea, were highly abundant and also showed evidence of spatial clustering (Clarke et al. 2006). Constrained analysis of principal coordinates (CAP) was used to visualise the differences in the sponge assemblages and to identify species that were characteristic of the various study sites. Spearman rank correlations 
Chapter 3

$(>0.4)$ of individual species abundances with the CAP axes were used to determine which species were most characteristic of the study sites. The associations between sponge assemblage structure and the other variables were investigated using the same approach as for the analysis of sponge abundance using distance-based multivariate multiple linear regression (DISTLM).

\subsection{Results}

\subsubsection{Environmental variables and benthic characteristic of the study sites}

Site means for the environmental and biological parameters are summarized in Table 3.1. Mean quadrat angle ranged from $78^{\circ} \pm 5.66( \pm$ indicates 1 standard deviation of the mean) at Buoy 4 to $46.67^{\circ} \pm 31.09$ at Sampela 1. Chlorophyll- $a$ also varied between sites with the highest mean value being found at Kaledupa $(0.42 \mu \mathrm{g} / 1 \pm 0.19)$ and the lowest at Pak Kasim's $(0.14 \mu \mathrm{g} / 1 \pm 0.06)$. There was little variation in the mean water temperatures recorded at the reef slopes at the study sites. Temperatures ranged from $28.12^{\circ} \mathrm{C} \pm 0.18$ at Kaledupa to $27.37^{\circ} \mathrm{C} \pm 0.69$ at Buoy 1. The highest mean flow rate was recorded at Sampela $1(0.063 \mathrm{~m} / \mathrm{s} \pm 0.044)$ and the lowest was recorded at Buoy $1(0.002 \mathrm{~m} / \mathrm{s} \pm 0.0084)$. Mean spongivore abundance varied between $48 \pm 11.36$ per $125 \mathrm{~m}^{2}$ transect at Sampela 1 to $19 \pm 4.16$ on reef slopes at Buoy 3 . 
Chapter 3

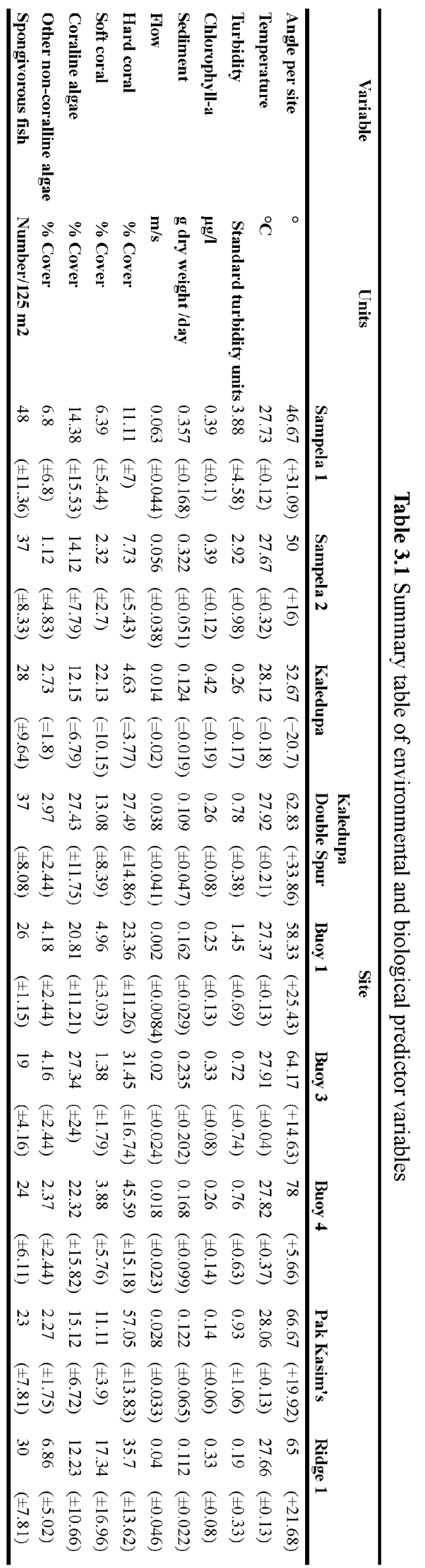


Overall allocation success of the CAP analysis was $40.74 \%$. The results of the CAP analysis of benthic characteristics (Figure 3.1) show that Sampela 1 and Sampela 2 were characterised by sponges, sand and rubble. Kaledupa 1 was characterised by rock and soft corals. Ridge 1, Pak Kasim's, Buoy 1, Buoy 3, Buoy 4 and Kaledupa Double Spur were all characterised by hard coral cover.

a

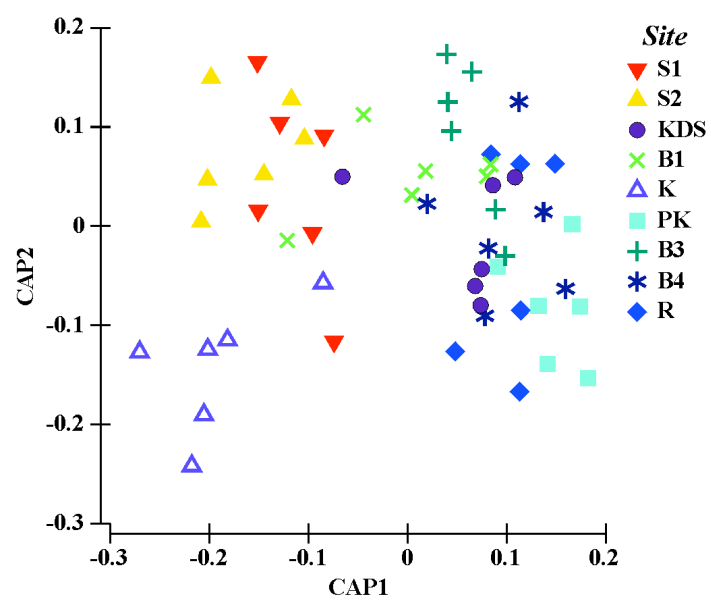

b.

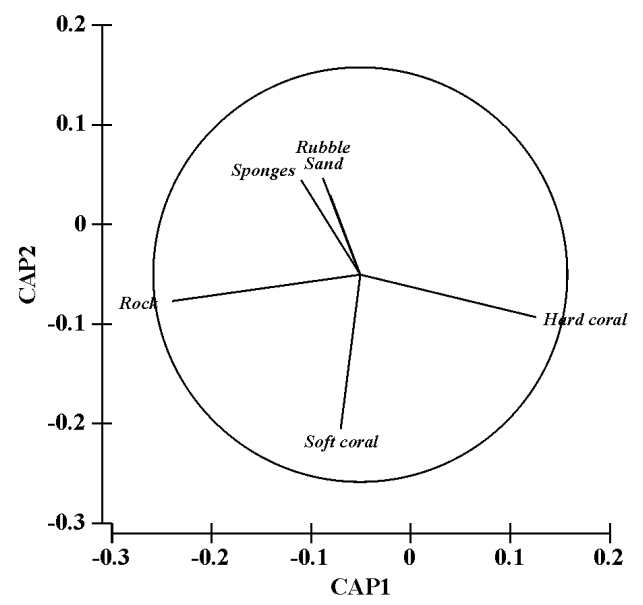

Figure 3.1 Canonical Analysis of Principal Coordinates (CAP) plot showing differences in benthic composition between study sites. The vectors represent Spearman rank correlations between individual benthic components and the resulting CAP axes. These can be used to identify benthic groups characteristic of the study sites.

\subsubsection{Sponge abundance patterns}

In total, 3856 sponges were observed across all the study sites with a mean density of 71 ( \pm 1 SD 38$)$ sponges per $\mathrm{m}^{2}$. Mean sponge abundance per $\mathrm{m}^{2}$ was highest at Sampela $1(103.67 \pm 69.68)$ and lowest at Kaledupa Double Spur (47 \pm 11.93$)$ (Figure 3.2), and PERMANOVA results revealed that there were significant differences in sponge abundance among sites $(\mathrm{df}=8, \mathrm{pseudo}-\mathrm{F}=2.6566, \mathrm{p}=0.0073)$. 


\section{Chapter 3}

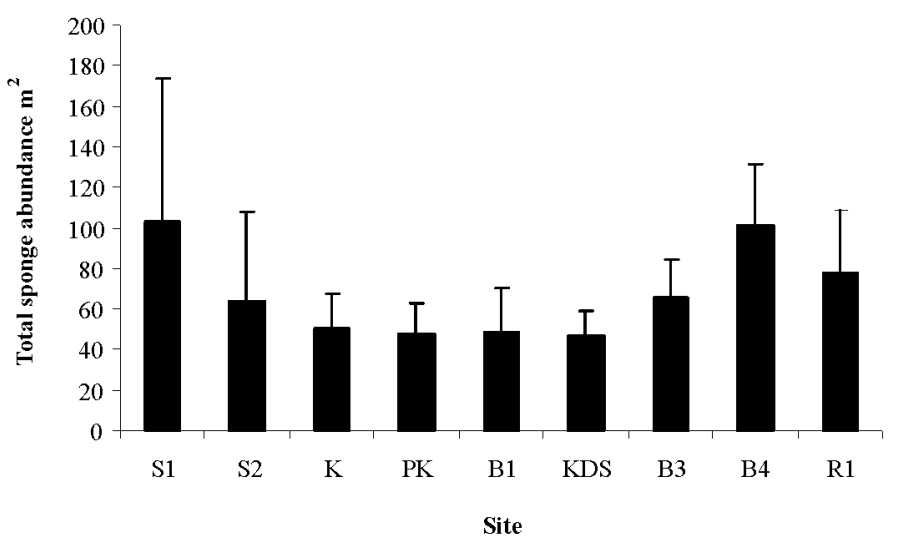

Figure 3.2 Mean sponge abundance at the nine study sites.

The results of the DISTLM analysis on total sponge abundance showed that the best model for sponge abundance contained three predictor variables but only explained a small amount of the total observed variation (13\%) (see Figure 3.3 and Table 3.2). The predictor variables were hard coral cover ( $8 \%$ of total variation explained), sediment (4\%) and chlorophyll- $a(1 \%)$.

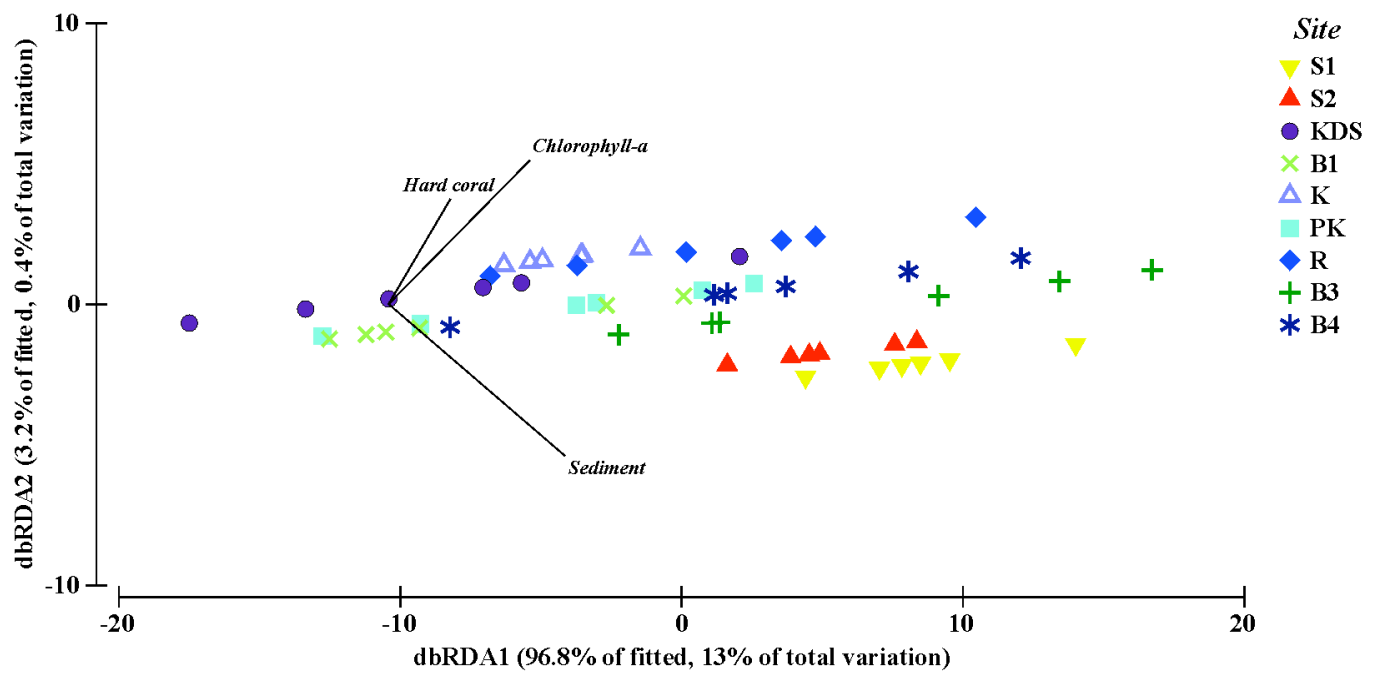

Figure 3.3 Distance based redundancy analysis (DbRDA) plots of the model of total sponge abundance with the lowest AICc value of all competing models 


\section{Chapter 3}

Further analysis of the abundance data showed that one species Lamellodysidea herbacea accounted for $42 \%$ of the total sponges observed (1613 sponges in total; Figure 3.4). Therefore, the data was split into Lamellodysidea herbacea abundance and remaining sponge abundance to examine the factors influencing each of these separately.

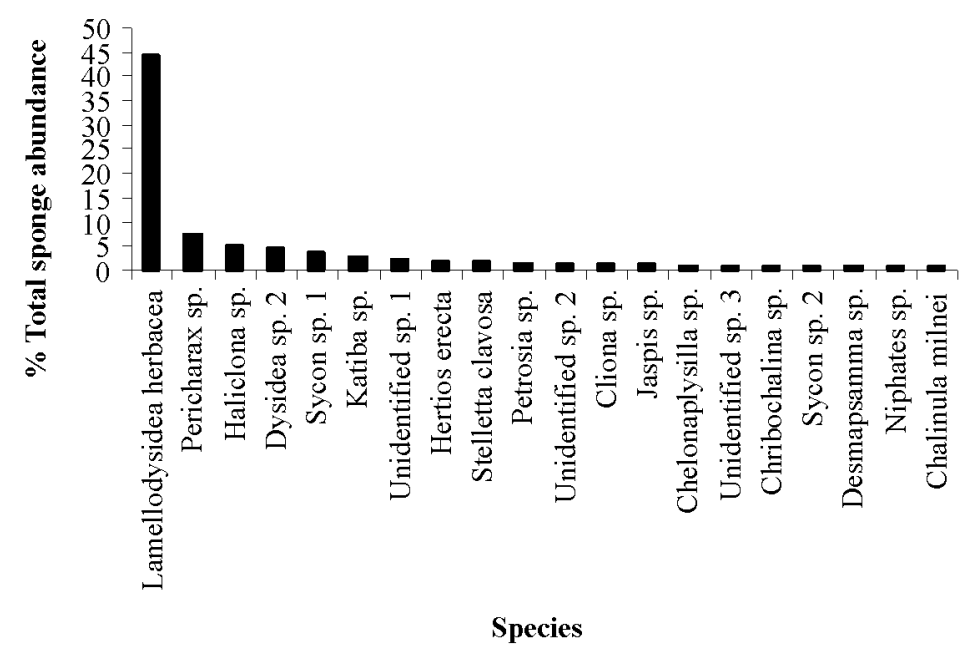

Figure 3.4 Dominance plot showing the percentage abundance of the 20 most abundant species.

When modelling sponge abundance excluding Lamellodysidea herbacea, the best model, based on AICc, contained four predictor variables that together explained 34\% of the variation in sponge abundance between quadrats (Figure 3.5 and Table 3.2). The variables were sediment (18\% of total variation explained), quadrat angle (12\%), Chlorophyll-a (4\%) and hard coral cover (1\%) (see Table 3.2). Examination of the relationship between sponge abundance and sedimentation showed that mean sponge abundance was negatively correlated with mean sedimentation rates at the study sites (Table 3.2), with the highest sponge abundance at sites with the lowest sedimentation rates, Ridge 1 and Buoy 4, and lowest at the highly sedimented sites Sampela 1 and Sampela 2. 


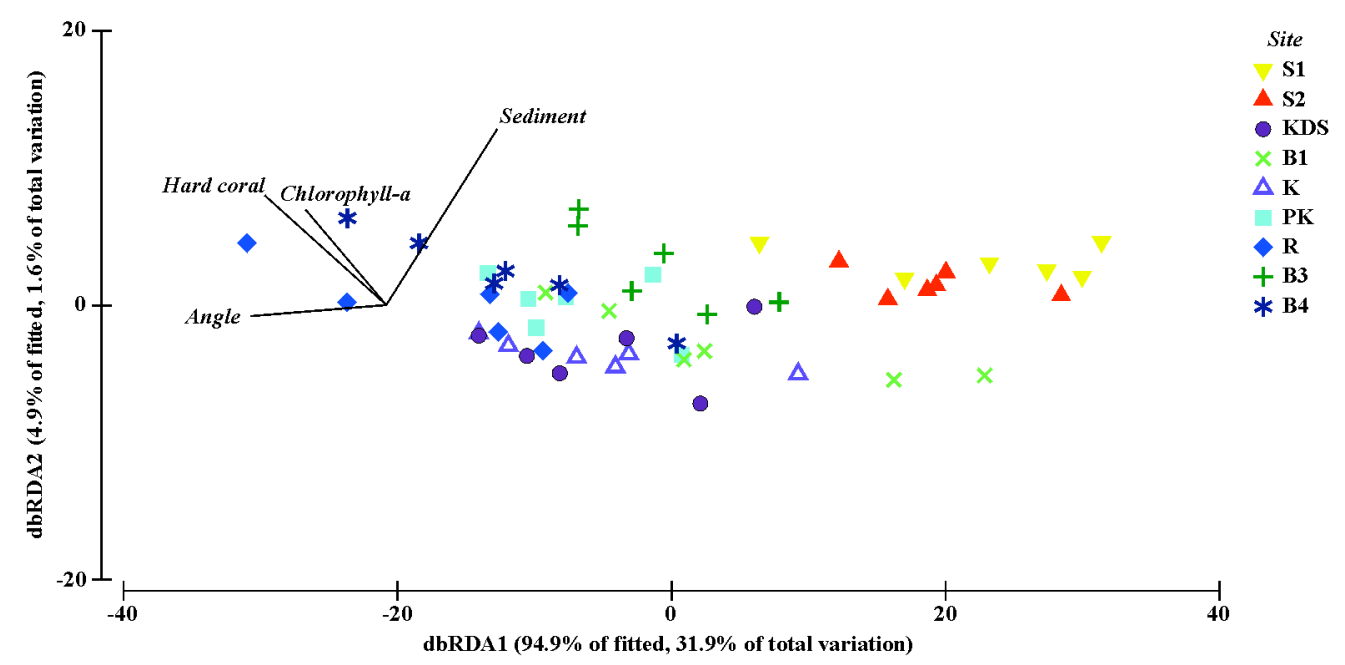

Figure 3.5 Distance based redundancy analysis (DbRDA) plots of the best model of sponge abundance when Lamellodysidea herbacea is excluded.

The results of the summed Akaike weights for each parameter ranged from 0.92 to 0.16 (see Table 3.3). Sedimentation had a summed Akaike weight of 0.92 indicating that it was found in the vast majority of likely models, as did quadrat angle (0.73) meaning that this parameter was also consistently in the top models. There is less evidence to support the hypothesis that the other parameters in the best model, hard coral cover and chlorophyll- $a$, were associated with sponge abundance as these had Akaike weights of 0.62 and 0.53 , respectively. Spongivorous fish was not included in the best model but had a summed Akaike weight of 0.61 over all models with $\triangle \mathrm{AICc}$ less than 5. This indicates that although it wasn't in the best overall model there is some support for this factor affecting sponge abundance. All of the other parameters had Akaike weights of less than 0.5 suggesting they are not associated with sponge abundance (Table 3.3).

Sedimentation also explained some of the variation observed for the most abundant species Lamellodysidea herbacea. The DISTLM analysis for just Lamellodysidea herbacea showed that the best model contained only one variable, sediment, explaining $15 \%$ of the variation in Lamellodysidea herbacea abundance between quadrats (Figure 3.6). Unlike the rest of the sponge assemblage mean Lamellodysidea herbacea abundance was positively correlated with mean sedimentation at the study sites (Table 3.2). This species was most abundant at the sites with the lowest numbers 


\section{Chapter 3}

of other types of sponges, Sampela 1 and Sampela 2. The abundance of Lamellodysidea herbacea was also highly variable between quadrats (high SD) as they tended to be found in large aggregations in some quadrats but were absent from others.

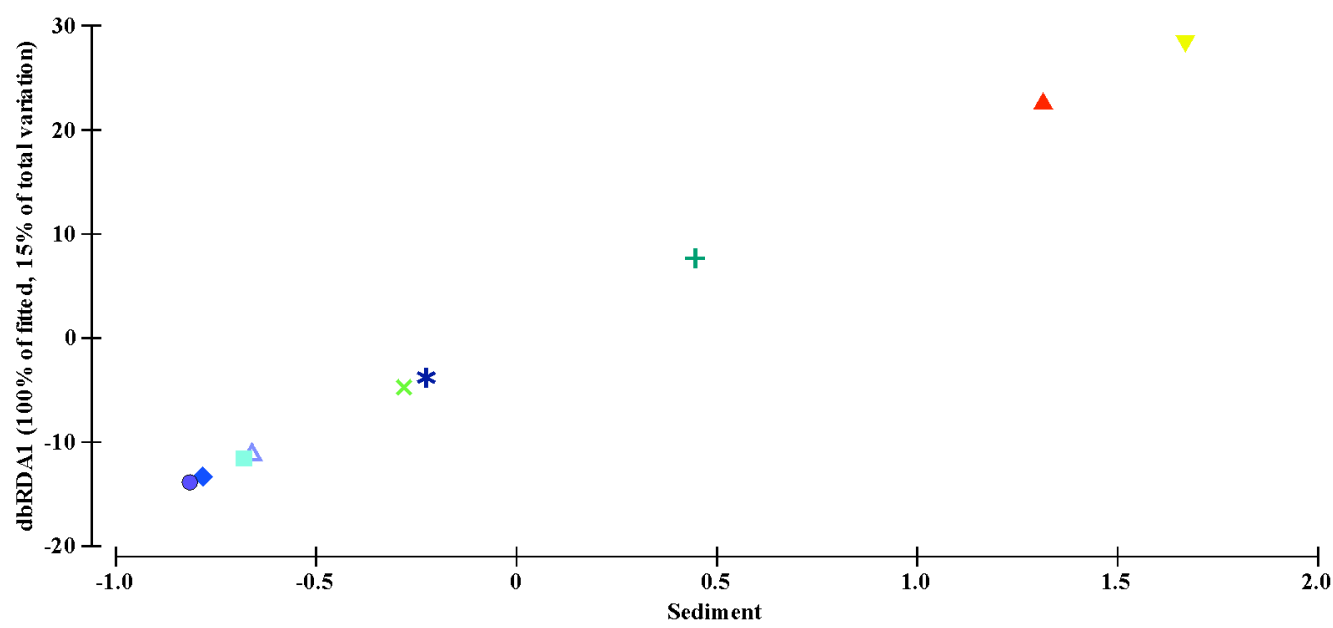

Figure 3.6 Distance based redundancy analysis (DbRDA) plots of the best model of Lamellodysidea herbacea abundance.

The results of the summed Akaike weights for each parameter ranged from 0.98 to 0.19 (see Table 3.3). Sedimentation had a much higher summed Akaike weight than any other factor $(0.98)$. The next highest summed weight was coralline algae with a summed weight of 0.42 . 
Chapter 3

Table 3.2 Summary table of the results of the DISTLM analysis. Results shown are for the model with the lowest AICc values for each response variable.

\begin{tabular}{|c|c|c|c|c|c|c|c|}
\hline Response & AICc & $\begin{array}{l}\text { \% Total variability } \\
\text { explained }\end{array}$ & Predictors & $\begin{array}{l}\% \text { Variability explained by } \\
\text { each predictor }\end{array}$ & Pseudo-F & P-value & Relationship \\
\hline \multirow[t]{3}{*}{ Total sponge abundance } & 333.08 & 13 & Hard coral cover & 8 & 0.47 & 0.57 & positive \\
\hline & & & Sediment & 4 & 2.67 & 0.092 & positive \\
\hline & & & Chlorophyll-a & 1 & 0.96 & 0.34 & positive \\
\hline \multirow{4}{*}{$\begin{array}{l}\text { Sponge abundance excluding } \\
\text { Lamellodysidea herbacea }\end{array}$} & 340.71 & 34 & Sediment & 18 & 12.1 & 0.0004 & negative \\
\hline & & & Quadrat Angle & 12 & 7.64 & 0.0029 & positive \\
\hline & & & Hard coral cover & 1 & 6.58 & 0.0064 & positive \\
\hline & & & Chlorophyll-a & 4 & 2.38 & 0.12 & unclear \\
\hline Abundance of Lamellodysidea herbacea & 390.85 & 15 & Sediment & 15 & 9.2 & 0.0001 & positive \\
\hline \multirow[t]{5}{*}{ Multivariate sponge assemblage } & 426.74 & 26 & Sediment & 8 & 5.06 & 0.0001 & $\mathrm{NA}$ \\
\hline & & & Chlorophyll-a & 6 & 3.64 & 0.0001 & NA \\
\hline & & & Spongivorous fish & 6 & 3.45 & 0.0001 & NA \\
\hline & & & Flow & 5 & 2.84 & 0.0001 & NA \\
\hline & & & Temperature & 4 & 2.2014 & 0.001 & $\mathrm{NA}$ \\
\hline
\end{tabular}

Table 3.3 Table showing the summed Akaike weights for each parameter for all models within $\triangle \mathrm{AICc}$ of five for each of the response variables.

\begin{tabular}{lcccc}
\hline & \multicolumn{2}{c}{ Summed parameter Aikaike weights for each response variable } \\
& \multicolumn{2}{c}{$\begin{array}{c}\text { Sponge abundance excluding } \\
\text { Predictors }\end{array}$} & Total sponge abundance & Multivariate sponge \\
\hline Sediment & 0.47 & 0.92 & 0.98 & 0.72 \\
Spongivorous fish & 0.2 & 0.61 & 0.31 & 0.53 \\
Chlorophyll- $a$ & 0.53 & 0.53 & 0.22 & 0.52 \\
Temperature & 0.2 & 0.42 & 0.23 & 0.52 \\
Flow & 0.26 & 0.35 & 0.25 & 0.49 \\
Hard coral & 0.65 & 0.62 & 0.19 & 0.44 \\
Quadrat angle & 0.19 & 0.73 & 0.21 & 0.38 \\
Coraline algae & 0.28 & 0.29 & 0.42 & 0.37 \\
Soft coral & 0.19 & 0.23 & 0.29 & 0.34 \\
Other algae & 0.27 & 0.16 & 0.29 & 0.23 \\
\hline
\end{tabular}

\subsubsection{Sponge diversity and assemblage patterns}

Analysis of the three measures of species diversity gave similar results (Figure 3.7).

The three sites with the highest total species richness were Ridge 1 ( $S=43$ ), Buoy 1 $(\mathrm{S}=41)$ and Kaledupa Double Spur $(\mathrm{S}=40)$. These sites also had the highest Shannon diversity and Pielou's evenness. The sites with the lowest species richness were Sampela $1(S=19)$, Sampela $2(S=28)$ and Buoy $4(S=32)$ and again these sites had the lowest observed species diversity and evenness. When examining Pielou's evenness index it was evident that Sampela 1 and to a lesser extent Sampela 2 were dominated by relatively few species. 
Chapter 3
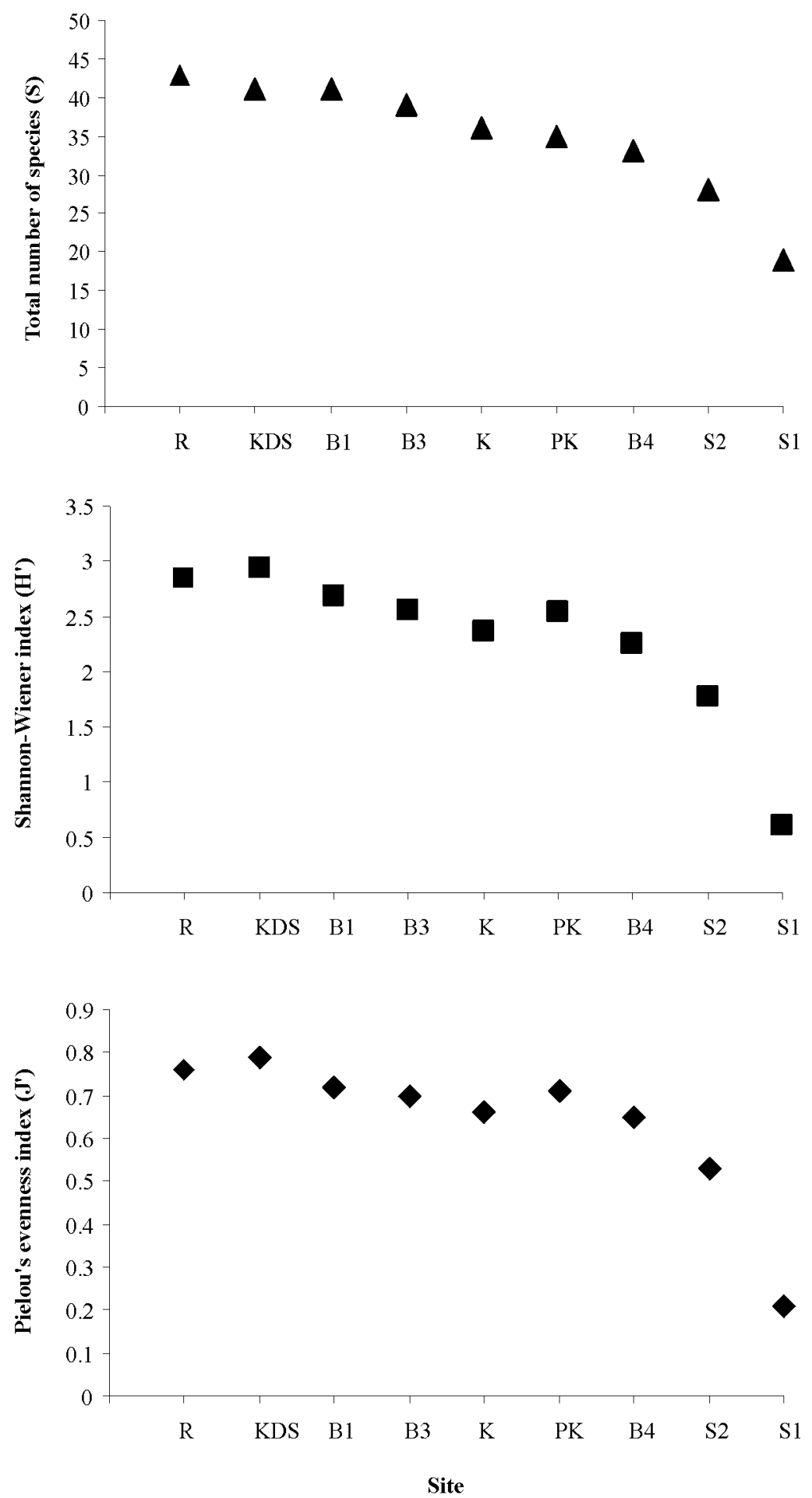

Figure 3.7 Species diversity measures at each study site. a) total number of species, b) Shannon-Wiener index (H'), c) Pielou's evenness index (J'). 


\section{Chapter 3}

PERMANOVA tests revealed that there was a significant difference between the sponge assemblages at the study sites (pseudo- $F=3.12, p<0.001$ ). Sponge assemblages at Sampela 1 and Sampela 2 were similar and characterised by high abundance of Lamellodysidea herbacea (Figure 3.8). Sponge assemblages at Kaledupa, Buoy 1 and Ridge 1 were characterised by Callyspongia (Euplacella) biru, Niphates sp. c.f.4514, Stelletta clavosa, Cinachyrella c.f. australiansis and Chalinula sp. 50. Pak Kasims and Kaledupa Double Spur, were characterised by Clathria mima, Dysidea sp. 17, Haplosclerina Sub order sp. undet. and one unidentified species. Finally, Buoy 3 and Buoy 4 were characterised by Chelonaplysilla sp 5 and another unidentified species OTU 3 (see Appendix 5 for full species list).
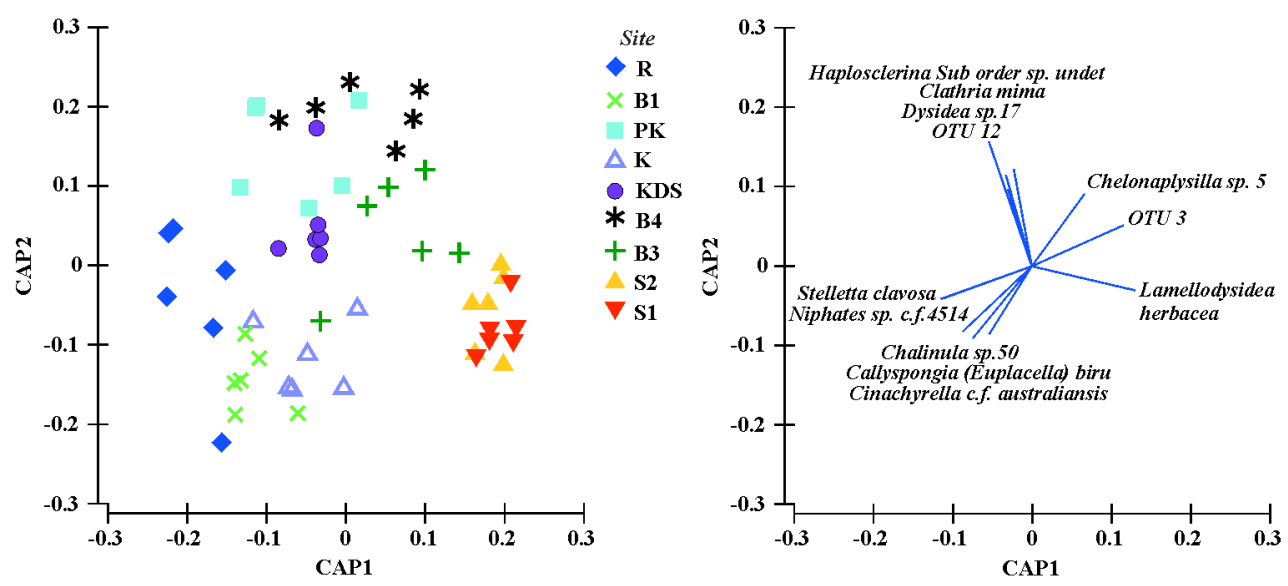

Figure 3.8 Canonical Analysis of Principal Coordinates (CAP) plot showing the differences in sponge assemblages at the study sites. Overlaid vectors visualise which sponge species are characteristic of the sponge assemblages at each site.

The best model identified using the DISTLM routine explained $26 \%$ of the variation in sponge assemblages between quadrats. It contained five variables; sediment (8\%), chlorophyll-a (6\%), spongivorous fish (6\%), flow (5\%), and temperature (4\%) (Figure 3.9). The Akaike weights of all the predictor variables ranged from 0.72 to 0.23 (Table 3.3). Spongivorous fish abundance, chlorophyll-a and temperature had Akaike weights greater than 0.5 indicating some support for these factors influencing sponge 
assemblage structure, but the major contributor was sediment with an Akaike weight of 0.72 .

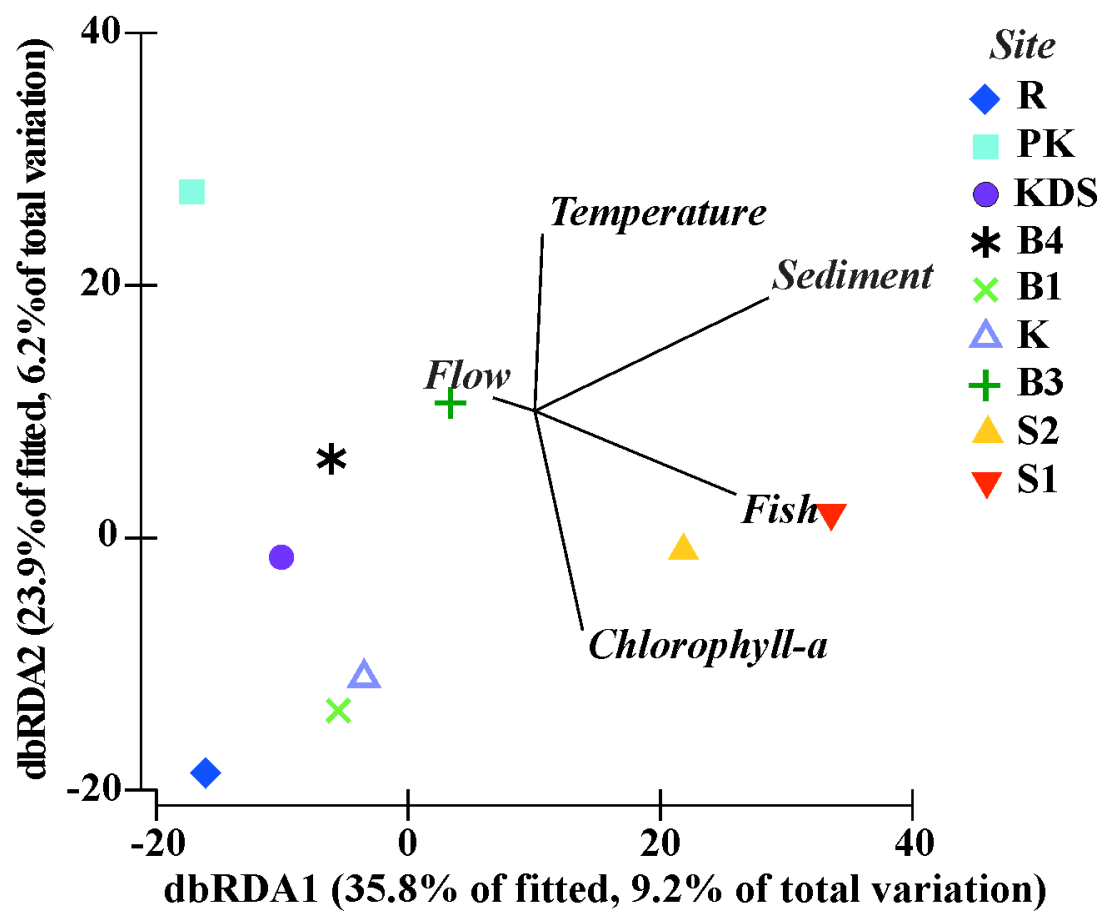

Figure 3.9 Distance based redundancy analysis (DbRDA) plot showing the best model of the multivariate sponge assemblages.

\subsection{Discussion}

The aim of this study was to determine the relative importance of a number of abiotic and biological variables and particularly spongivorous fish abundance on sponge abundance and assemblage composition. Sponges play key functional roles in reef ecosystems and identifying the factors that influence their distributions and abundance is a key step in predicting the effects of anthropogenic impacts on coral reefs. Sponge distributions and abundance are well known to be influenced by a number of abiotic and biological factors, however, few studies have examined the effects of multiple factors and their relative importance. Modelling overall sponge abundance, much of the variation observed across the study sites was unexplained. This was due to contrasting responses to sedimentation of the most abundant species in the study, Lamellodysidea herbacea that was positively correlated with increasing 
sedimentation, while the remaining total sponge abundance was negatively correlated with increasing sedimentation. In contrast, multivariate sponge assemblage patterns were associated with a number of different factors with no one factor dominating.

\subsubsection{Identification of variables correlated with sponge abundance and their relative importance}

Sponge abundance in this study was influenced by a combination of abiotic and biotic factors. Modelling total sponge abundance, only $13 \%$ of the observed variation in sponge abundance across Wakatobi reef slopes was explained by the abiotic and biotic factors I measured. This appears to have been largely due to the presence of one species, Lamellodysidea herbacea that was highly abundant at some sites and was also positively associated with sedimentation, whereas total sponge abundance excluding this species showed a negative association with increasing sedimentation levels. When Lamellodysidea herbacea was excluded from the analysis $34 \%$ of the variation in sponge abundance was explained by the biotic and abiotic factors and the results indicate that sedimentation has the greatest influence on sponge abundance explaining $18 \%$ of the variation in sponge abundance, whereas the other factors each explained less than $12 \%$ of the variation.

Studies in temperate and tropical systems have found that the abundance of some sponge species is correlated with sedimentation levels (e.g. Bell \& Barnes 2000b; Bell \& Smith 2004). In a temperate system, Bell \& Barnes (2000b) found species-specific correlations between sponge abundance and sedimentation levels and found higher abundances of species with arborescent growth forms in sedimented areas. They also found that sedimented sites had high levels of species richness and overall sponge abundance which they attributed to reduced competition with algae. In an earlier study in the Wakatobi, Bell \& Smith (2004) found higher sponge abundance on vertical surfaces at Sampela compared with inclined or horizontal substrates, which they attributed to lower levels of sediment settlement and accumulation on vertical surfaces. There are a number of potential mechanisms that could explain why sedimentation affects sponge abundance. Gerrodette and Flechsig (1979) found that increasing sedimentation levels in aquaria reduced the pumping rate of a tropical sponge. Another study by Roberts et al. (2006a) showed that artificially increasing the sediment levels settling on sponges in situ had a negative effect on sponge growth 


\section{Chapter 3}

rates and reproductive status with sponges subjected to increased silt levels containing lower numbers of spermatocytes than those in control treatments. Sedimentation could also potentially affect sponges during different life stages for instance by affecting larval mortality rates (Maldonaldo 2006). Finally, sedimentation could affect sponge abundance indirectly by reducing competition for space with algae. This could be particularly important for encrusting species and could explain why Lamellodysidea herbacea is so abundant at sedimented sites.

Examining the abundance patterns of the most common sponge in this study, Lamellodysidea herbacea, it was found to be positively correlated with sedimentation. This species was present at all of the surveyed sites, but was particularly abundant at Sampela 1 and Sampela 2. Some sponges have likely evolved specialised adaptations that allow them to exist in environments with high levels of sedimentation such as raised oscula which protrude over the sediment and have the ability to close (e.g. Ilan \& Abelson 1995). It is likely that Lamellodysidea herbacea, which was positively correlated with increasing sedimentation, has adaptations that enable it to live in sedimented environments. In a recent study of the sponge assemblages in the Derawan Islands this species was also found to be one of the most common species (de Voogd et al. 2009). It is surprising that the most abundant sponge at sedimented sites was an encrusting species as this growth form would be expected to intersect more sediment per unit volume than more upright forms. However, encrusting sponges are frequently able to reproduce by fragmentation (Teixidó et al. 2009), which could be an advantage in areas with high levels of sedimentation. Siltation is a known cause of sponge larval mortality (Maldonaldo 2006). If Lamellodysidea herbacea can reproduce by fragmentation this could explain its high abundance at sedimented sites as in these conditions it would be more likely to reproduce successfully than species that rely on sexual reproduction. Alternatively, Lamellodysidea herbacea may have evolved a mechanism to keep its surface free from sediment. Many hard coral species trap sedimentation in a layer of mucus as it settles on their surface that is then sloughed off. This type of mucus production has not been observed in sponges but the sponge Halichondria panacea has been observed to slough off its outer tissue layer in order to prevent biofouling (Barthel \& Wolfrath 1989). Lamellodysidea herbacea could have evolved a similar mechanism to prevent sediment build up. 
The other factors shown to be associated with sponge abundance were spongivorous fish abundance and substrate angle. In general, a positive relationship between surface angle and sponge abundance was observed in this study. This is consistent with Bell $\&$ Smith (2004) who found a similar relationship. Substrate angle may have a direct effect on sponge abundance or an indirect effect through its impact on other factors such as sedimentation or light availability. Spatial competition between sponges and other organisms is also likely to vary with substrate angle as organisms respond differently to light or sediment levels. Bell \& Smith (2004) found higher sponge abundances on vertical compared to inclined or horizontal surfaces at Sampela 1, which they attributed to the lower levels of sedimentation on vertical surfaces. In addition, substrate angle affects light availability with horizontal surfaces experiencing higher light intensity than vertical surfaces. Turon et al. (1998) found that sponge growth rates were higher in an illuminated habitat compared to a shaded one but that sponge mortality rates were also higher in illuminated conditions, which the authors hypothesised may have been due to overgrowth by algae. Another possible explanation for higher sponge abundances with increasing surface angle is the reduction in abundance of spatial competitors such as hard corals and algae. However, given that algae cover was not found to be associated with sponge abundance it is more likely that the effects of substrate angle are due to its interaction with sedimentation or light. This has been found to be the case in a temperate system on the North Atlantic coast of Spain where Preciado \& Maldonado (2005) found that substrate inclination rather than algal abundance explained most of the variation in sponge abundance.

Finally, sponge abundance excluding Lamellodysidea herbacea was negatively correlated with spongivorous fish abundance. It is possible that higher numbers of fish spongivores are keeping sponges at lower abundances at sites such as Sampela 1 and Sampela 2 through predation. There is a growing body of evidence in the Caribbean that fish predation can affect the distribution and abundance of some species (Dunlap \& Pawlik 1998; Pawlik 1998). However, little research has been carried out in the Indo-Pacific and further experimental work is required to show if this is the case as it is possible that this relationship is due to co-variation with one or many other factors. If this is indeed the case then Lamellodysidea herbacea must have evolved a 


\section{Chapter 3}

mechanism which allows it either escape predation or to remain abundant despite it. One possible explanation is that this species is unpalatable to fish predators or alternatively it may have rapid regeneration rates which enable it to counteract the effects of predation.

\subsubsection{Identification of variables associated with sponge assemblages and their relative importance}

The best model for explaining differences in sponge assemblage composition among quadrats included sedimentation, chlorophyll-a, fish spongivore abundance, flow and temperature. Unlike the model for overall sponge abundance, no single factor explained more variation than the others. Overall, the modelling approach explained less variation in sponge assemblages than in the overall patterns of sponge abundance. One of the reasons for this is the high sponge diversity in this area (Bell \& Barnes 2004) that inevitably leads to high variability in sponge assemblages between quadrats. Given that the results indicate that sponge assemblages are related to a number of factors and that each factor explained only a small amount of variation in the sponge assemblage it may be difficult to predict how anthropogenic changes will affect sponge assemblages on reefs in the future. One of the questions that arises from this research is what other factors could be responsible for the remaining unexplained variation in sponge assemblages. Possible areas for investigation that were not included in this study include variation in recruitment success across study sites, light levels and wave exposure as these have all been observed to be associated with changes in sponge abundance in other studies (e.g. Bell \& Barnes 2000b; Bell \& Carballo 2008; deVoogd \& Cleary 2007).

There are a number of ways that the factors selected in the model could be influencing sponge assemblage composition. The amount of chlorophyll- $a$ at a study site may be a reflection of the amount or type of food available to sponges. Lesser (2006) found that food supply affected the distribution of sponges in reef habitats in the Caribbean. He found that food availability increased with depth up to $30 \mathrm{~m}$ and that this was positively correlated with sponge growth and feeding rates. It is possible that variation in food availability at these study sites is affecting sponge assemblages. However, it is worth noting that chlorophyll- $a$ is only a proxy for potential sponge food sources as they mainly feed on cyanobacterial picoplankton that have different types of 


\section{Chapter 3}

chlorophyll. This could explain why only a weak association between sponge assemblage composition and chlorophyll-a was observed. In agreement with previous studies, flow rate was also observed to be correlated with differences in sponge assemblages (Bell \& Barnes 2000a, 2003; Ginn et al. 2000). There are a number of possible explanations why sponge assemblages may vary with flow rates. Sponge species with certain morphologies may be less suited to high flow areas. Those which exhibit, erect or branching growth forms maybe more susceptible to damage and thus may not be able to survive in high flow environments (Wulff 1995). In contrast, other species have been shown to grow better in high flow areas (Wilkinson \& Vacelet 1979; Duckworth et al. 2004) and subsequently are likely to dominate sites that experience high flow rates. Studies have also shown that increased flow can increase the amount of food available to sponges and reduce the energy required by sponges to feed (Vogel 1974, 1977). However, it is not known whether this is true for all species or morphologies. If sponges vary in their capacity to take advantage of flow 'facilitated' feeding then the ones that are able to do so would be expected to be more abundant at higher flow sites.

The major limitation of this study is the fact that data were collected over a relatively short time period. The climate in the Wakatobi is characterised by a dry season from June to October and a rainy season from November to March. My surveys were carried out during the dry season and thus only provide a 'snapshot' of the predictor variables that were measured. I found that variation sedimentation across the study sites was most highly correlated with sponge diversity and abundance but surveys carried out during the rainy season might have highlighted the importance of other factors that vary throughout the year. In addition, the short timescale of the study could also have affected my measurements of sponge abundance and diversity at the study sites. Sponge assemblages are dynamic and seasonal changes in sponge abundance and diversity have been documented in temperate and tropical systems (Carballo et al. 2008, McMurray et al. 2010, Wulff 2006). Further surveys across seasons would be necessary to determine whether the sponge abundances and diversity that I recorded were truly representative of the study sites. Finally, changes to the methods used to measure a number of the abiotic factors would have improved the estimates obtained for these variables. For instance, if resources had allowed it would have been better to deploy a CTD logger at each of the study sites for the 


\section{Chapter 3}

duration of the study rather than carry out limited deployments at each site. The use of sediment traps has also been highly scrutinised (Storlazzi et al. 2011) and can at best provide a relative indication of sponges exposure to suspended sediment. Future studies would benefit from analysis of the grain size of collected sediments as previous studies have indicated that sediment composition not just the quantity of sediment can affect the distribution of filter feeding invertbrates (Fabricius 2005).

To conclude, modelling sponge assemblages across a gradient of habitat degradation showed that sponge abundance and assemblage composition were not strongly associated with spongivorous fish abundance. Sponge aseemblages were correlated with a number of biotic and abiotic factors with no one factor explaining the majority of the variation. This supports the findings of other studies and is also perhaps not unexpected in an area of such high sponge species diversity (Bell \& Smith 2004). However, most of the explained variation in sponge abundance was due to sedimentation effects. In addition, although highly sedimented sites had high sponge abundance they also had the lowest species diversity and were dominated by one encrusting species Lamellodysidea herbacea. This has important implications for the conservation of the highly biodiverse reefs of the WMNP. Increased sedimentation levels on reefs as a result of activities such as coral mining and mangrove felling could have a negative impact on future sponge diversity. Although overall sponge numbers might remain relatively stable sponge assemblages may become dominated by a few species such as Lamellodysidea herbacea which is able to thrive in sedimented conditions. 
Chapter 3 


\section{The effects of predator exclusion on Indo-Pacific sponge assemblages}

\subsection{Abstract}

Predation is an important factor known to influence the distribution, abundance and behaviour of species. In coral reef ecosystems predation has been shown to affect numerous taxa, although little research has focused directly on sponges, a functionally important component of reef communities. Fish predation has been shown to influence sponge distribution patterns and abundance on Caribbean coral reefs but its role in structuring sponge assemblages in the Indo-Pacific are unknown. This study aimed to uncover the possible effects of fish spongivores on sponge assemblages on an Indonesian reef system. A caging experiment was performed to investigate the effects of excluding fish predators on sponge assemblage composition and abundance on the reef slopes of two sites in the Wakatobi Marine National Park, Indonesia. Comparing sponge abundances through time in caging versus control plots revealed that there was no statistically significant effect of excluding fish spongivores (caging treatment effect, $\mathrm{df}=1, \mathrm{~F}=0.001, \mathrm{p}=0.976$ ). In studies where no significant differences are detected, it can be difficult to conclude whether the lack of an observed effect is real or whether the experimental design was inadequate for detecting the difference. A subsequent retrospective power analysis was therefore performed to assess the capacity of the experimental design to detect a range of effect sizes. Although the experimental design had low power to detect weak effects, it had high power to detect larger effects, such as a doubling of sponge abundance in caged plots, which are within the levels of natural variability in the study site over the time period examined. As a result fish predation is unlikely to be a major driver of spatial and temporal variation in sponge assemblages on the reef slopes in the Wakatobi. However, given the experiment was unable to detect small, marginal or sub-lethal effects, there remains the possibility that fish predation is able to affect sponge abundances to some degree. 


\subsection{Introduction}

Elucidating the processes and mechanisms responsible for maintaining species diversity and abundance patterns has long been a central theme in ecology (Hutchinson 1959; Connell 1978; Gaston 2000). Biological communities are influenced by both physical and biological factors, operating at a range of spatial and temporal scales (Menge \& Olson 1990). One of the most important biological processes known to influence marine species distributions on a local level (scale of 1-100s m) is predation (Paine 1969; Holt 1984; Chase 2002; Sih et al. 1985). Predation can have a major impact on marine communities both directly through its effects on prey densities and behavior, and indirectly by mediating the outcomes of competitive interactions between prey (Chase et al. 2002). In coral reef ecosystems many previous studies have focused on understanding the effects of predation on corals (Cox 1994; Cole et al. 2008; Rotjan \& Lewis 2008; Jayewardene et al. 2009). However, recent evidence indicates that predation could be a major factor influencing other important groups of reef organisms, particularly sponges, which are a less well known, but a functionally important component of reef communities (Dunlap \& Pawilk 1996; Pawlik 1998; Wulff 2000).

Sponge distribution and abundance patterns are influenced by abiotic factors including sedimentation, flow and substrate angle (e.g. Gerrodette \& Fleishig 1979; Ginn 2000; Bell \& Smith 2004; Bell 2008). The role of biological factors is less well understood, but research in the Caribbean has shown that fish predation can have a major influence on the distribution and abundance of certain sponge species. For example, transplantation and caging experiments have shown that some mangrove and lagoon sponges are excluded from reef habitats by fish spongivory (Dunlap \& Pawlik 1996; Pawlik 1998; Dunlap \& Pawlik 1998; Wulff 2000; Hill \& Hill 2002). There is also evidence that fish predation can affect sponge morphologies restricting some sponges to cryptic habitats within the reef framework (Wulff 1997; Pawlik 1998). Increased spicule concentrations have also been observed in sponges exposed to artificial predation events (Hill \& Hill 2002). In addition to these direct predation effects, other studies have also found that fish predation can influence the outcome of competitive interactions between sponges and corals (Hill 1998). 


\section{Chapter 4}

Despite the importance of fish predation in driving sponge abundance patterns it is still unclear how sponges are influenced by predation in the Indo-Pacific, where diversity is much higher than in Caribbean reef systems where the majority of previous studies have been carried out. Sponges perform a number of important functional roles on coral reefs, such as bio-erosion, facilitating primary production, nutrient recycling and reef consolidation (Wulff \& Buss 1979; Hutchings 1986; Bell 2008). As a result, changes in sponge assemblages, such as increases or decreases in their abundance could have significant impacts on overall reef ecosystem functioning. If fish predation has a strong impact on the distribution and abundance of sponges, a decline in fish abundance as a result of anthropogenic activities could result in an increase in sponges with subsequent large-scale ecosystem wide impacts.

Cages and predator exclusion/inclusion have been widely adopted to examine the effects of predation in terrestrial, freshwater and marine environments (e.g. Keough \& Butler 1979; Russ 1980; Wulff 1997; Hill 1998; Miller \& Hay 1998; Swearingen \& Pawlik 1998). Caging can provide valuable information on predation effects, but may be limited by artefacts caused by the experimental design. One criticism of caging experiments is that it can be difficult to differentiate between effects caused by predation from those caused by the physical presence of the cage itself, such as reduced flow or increased algal growth inside cages (Sih et al. 1985). One of the ways this issue can be addressed is through the use of partial cages, which are designed to mimic the caging effects while allowing predation to occur. In addition, in cases where no significant difference is detected between caged and non-caged plots it can be difficult to conclude whether the lack of an observed effect is real or whether the experimental design was inadequate for detecting the difference. In these situations retrospective power analysis can be used to assess the capacity of a study to detect a biologically meaningful pattern (Thomas 1997) and to place bounds on the size of the effect (given that there is one) that the study would have been able to detect.

The primary aim of this study was to examine the effects of predation on sponge assemblages on reef slopes in the Wakatobi Marine National Park (WMNP), Southeast Sulawesi, Indonesia. A caging experiment was established to examine the effects of excluding fish on sponge assemblages over a six-month period. Preliminary fish surveys showed that fish assemblages varied across reef slopes both in terms of fish abundance and diversity. Consequently the experiment was replicated at two sites 


\section{Chapter 4}

with contrasting fish assemblages and levels of habitat degradation (see Chapter 3). Finally, retrospective power analyses were performed to examine the capacity of the experimental design to detect predation effects on sponge abundances (Thomas \& Juanes 1996; Steidl et al. 1997; Thomas 1997). I hypothesised that sponge abundance would be higher in caged plots than partial or control plots at the end of the study period due to protection from fish predation. I further hypothesised that the effects of predator exclusion would be greatest at the site with the highest fish abundance due to higher levels of predation.

\subsection{Materials and methods}

\subsubsection{Study Sites}

This experiment was carried out at four sites within two reef systems in the WMNP (two replicate sites within each reef system) (see Figure 4.1). Two sites, Sampela 1 and Sampela 2 were located on the fringing reef that surrounds Kaledupa Island. These sites were considered representative of a degraded reef system with a mean percentage hard coral cover of approximately $10 \%$ and high levels of sedimentation (Salinas-de-León et al. 2011). The reef slope at these sites descended at approximately 45 degrees to sand flats at 11-14 m depth. The two other sites Buoy 3 and Buoy 4 were located on the fringing reef on the western side of Hoga Island. These had relatively high levels of hard coral cover (approximately 40\%), low sedimentation rates and were characterised by walls, overhangs and caves (Salinasde-León et al. 2011). 


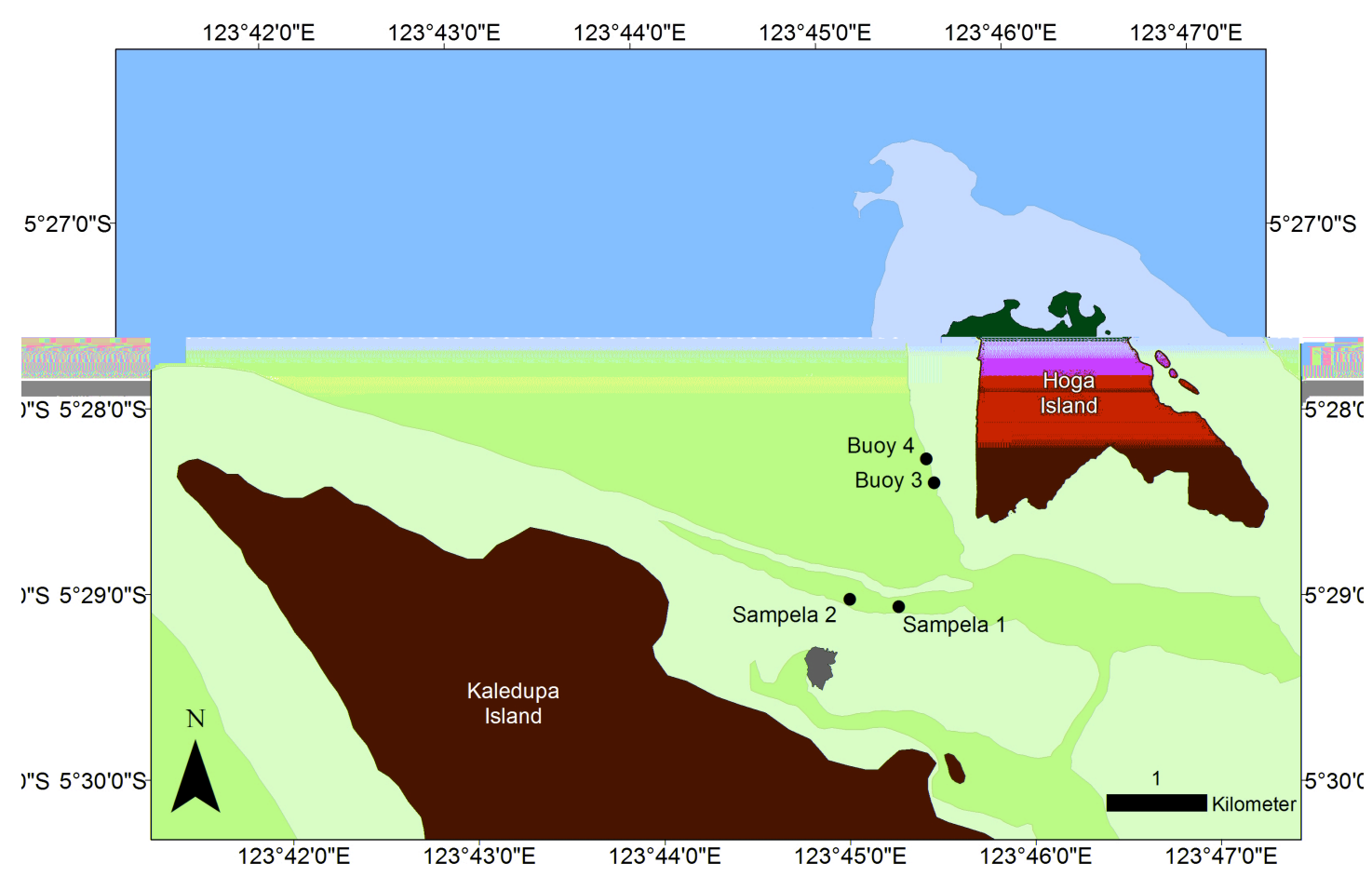

Figure 4.1 Map showing the location of the study sites. Two replicate sites Sampela 1 and Sampela 2 were located on a degraded section of fringing reef off Kaledupa Island and were representative of a degraded reef system. Buoy 3 and Buoy 4 were located in the higher coral cover fringing reef system off Hoga Island.

\subsubsection{Experimental design}

Surveys were carried out at each site in 12 randomly selected plots on vertical surfaces at a depth of $10 \mathrm{~m}$ using a $25 \times 15 \mathrm{~cm}$ quadrat. Each plot was tagged and randomly assigned one of three different treatments: full cage, partial cage or no-cage control (see Figure 4.2). The full cages were made from plastic $1.5 \times 1.5 \mathrm{~cm}$ mesh. The size of the mesh was selected to be small enough to exclude most adult spongivorous fish. The no-cage plots were used as controls against which to measure the effects of excluding predators. In order to separate the effects of predator exclusion from caging artefacts caused by the physical presence of the cage, partial cages that had the top removed were also deployed to mimic the presence of the cage while still allowing predation to occur. Stainless steel metal fencing staples were used to anchor the full and partial cages to the substrate. The cages were attached to the staples with cable ties so that they could be easily removed for cleaning. Four replicates of each treatment were established at each site. Abundances of individual 
sponge species were recorded along with total sponge abundance within all the study plots at the beginning of the experiment in March 2009 and again after 6 months in August 2009 to assess for any caging effects. The duration of the experiment was limited to six months as logistical constraints meant that consistent cleaning of the cages to prevent bio-fouling was only possibly during this time.
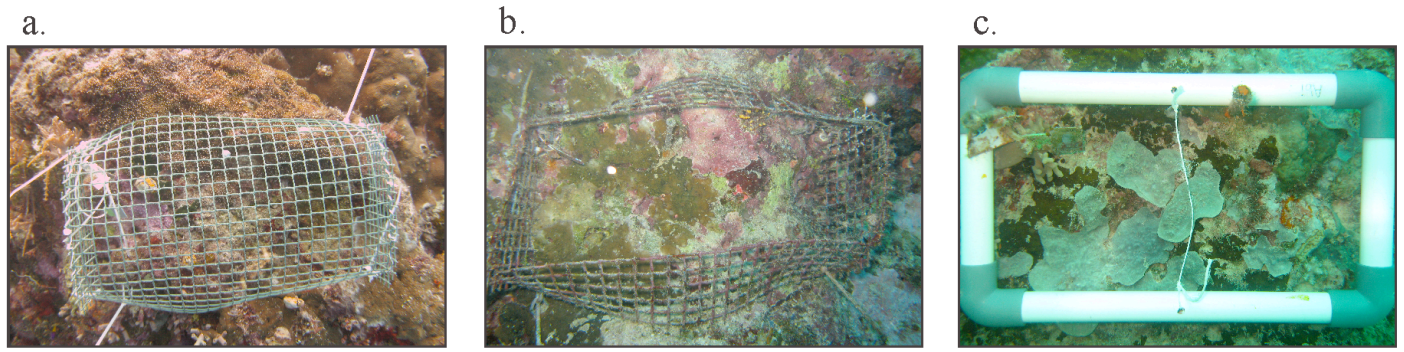

Figure 4.2 Photographs showing the three caging treatments used in the experiment a) full cage b) partial cage c) no cage control.

\subsubsection{Fish surveys}

Fish were surveyed along six transects on reef slopes at a depth of $10 \mathrm{~m}$ at each study site. All fish species present in a virtual tunnel $50 \mathrm{~m}$ long, $5 \mathrm{~m}$ wide and $5 \mathrm{~m}$ above the benthos were identified to species level and recorded. Spongivorous fish present were identified using the information obtained in Chapter 2 and spongivourous fish abundance at the study sites was compared. One additional species was included as a spongivore, Pomacanthus xanthometopon (yellow masked angelfish) because this species was observed feeding on sponges during this study.

\subsubsection{Data analysis}

\subsubsection{Caging effects on sponge abundance}

Sponge abundance in the experimental plots was measured in March and August and the change in sponge abundance in the plots was calculated as the final (August) minus the intial (March) sponge abundances. The resulting change in sponge abundance was the response variable in the following statistical analyses. 


\section{Chapter 4}

Observations from replicate sites on the degraded reef (Sampela 1 and Sampela 2) and the higher quality reef (Buoy 3 and Buoy 4) were pooled in order to increase our statistical power. The assumptions of ANOVA (normality and homogeneity of variance) were tested using Shapiro-Wilk's tests for normality (Shapiro \& Wilk 1965) and Levene's test for homogeneity of varience. These tests revealed that the null hypothesis of normally distributed data could only be rejected (at the $5 \%$ significance level) for one treatment group: partial cages at Sampela. However, all other groups were adequately described by normal distributions, and so all further analyses were performed assuming normally distributed data (see Appendix 6). Levene's tests showed that variences were significantly different between Hoga and Sampela but were not significantly different within sites. Consequently further analyses were performed separately for Sampela and Hoga (Appendix 6). A 1-factor ANOVA with fixed effect of treatment ( 3 levels: no cage, cage, partial cage) was used to for differences between experimental treatments.

\subsubsection{Exploratory power analysis}

A retrospective power analysis was performed to estimate the power of the experimental design to detect pre-defined effect sizes. The power analyses were carried out on square root transformed data using the program $\mathrm{G}^{*}$ power ver. 3.1. Power analyses were carried out to identify the power of a repeated measures ANOVA to detect increases in sponge abundance in caged plots over time ('treatment' effect). Due to the lack of information in the literature regarding the size of predation effects on sponges, power was calculated for a range of effect sizes representing mean increases in the number of sponges in caged plots of $10-100 \%$.

Standard effect sizes were calculated using the formula for Cohen's $d$, which is the difference between the treatment means divided by the standard deviation of either group.

$$
d=\frac{\left(m_{\max }-m_{\min }\right)}{\sigma}
$$

For $m_{\min }$ the mean sponge abundance in caged plots in March was used. To examine the relationship between the power of the experiment and effect size, a range of $m_{\max }$ 


\section{Chapter 4}

values, representing percentage increases in mean sponge abundance of $10-100 \%$ in caged plots, were used (this represents a maximum of a doubling of sponge abundance in caged plots). The standard deviation of sponge abundance in caged plots in March was used to represent $\sigma$. To calculate power, $\mathrm{d}$ values were converted to a primary effect size index f (see table 8.2.1 in Cohen 1977) and entered into G*power 3.1 with a total sample size of $n=16$ with two treatment groups as per the experimental design.

\subsubsection{Caging effects on sponge assemblage structure}

Multivariate analyses were carried out using the statistical package PRIMER-E v6 (Plymouth Routines in Multivariate Ecological Research). Analyses were based on similarity matrices calculated using Bray-Curtis coefficients. An unconstrained nonmetric Multi Dimensional Scaling (MDS) plot was used to graphically represent differences in the sponge assemblages at Sampela and Hoga scaled to two dimensions. A three-factor permutational multivariate analysis of variance (PERMANOVA) was used to determine whether caging treatment had an effect on sponge assemblages over time at the study sites. The PERMANOVA incorporated the following factors: (1) Site (fixed factor with 2 levels), (2) Treatment (fixed factor with 3 levels) and (3) Time (fixed factor with 2 levels).

\subsection{Results}

\subsubsection{Caging effects on sponge abundance}

Mean sponge abundance per quadrat was higher at the Hoga site than at Sampela at the start of the experiment with a mean sponge abundance of $15( \pm 14,1 \mathrm{SD})$ sponges per plot compared with $7( \pm 4)$ at Sampela. Over the course of the experiment sponge abundance increased in all treatments at both sites (see Figure 4.3). No significant differences were detected between treatments at Hoga (Table 4.1) or Sampela (Table $4.2)$. 

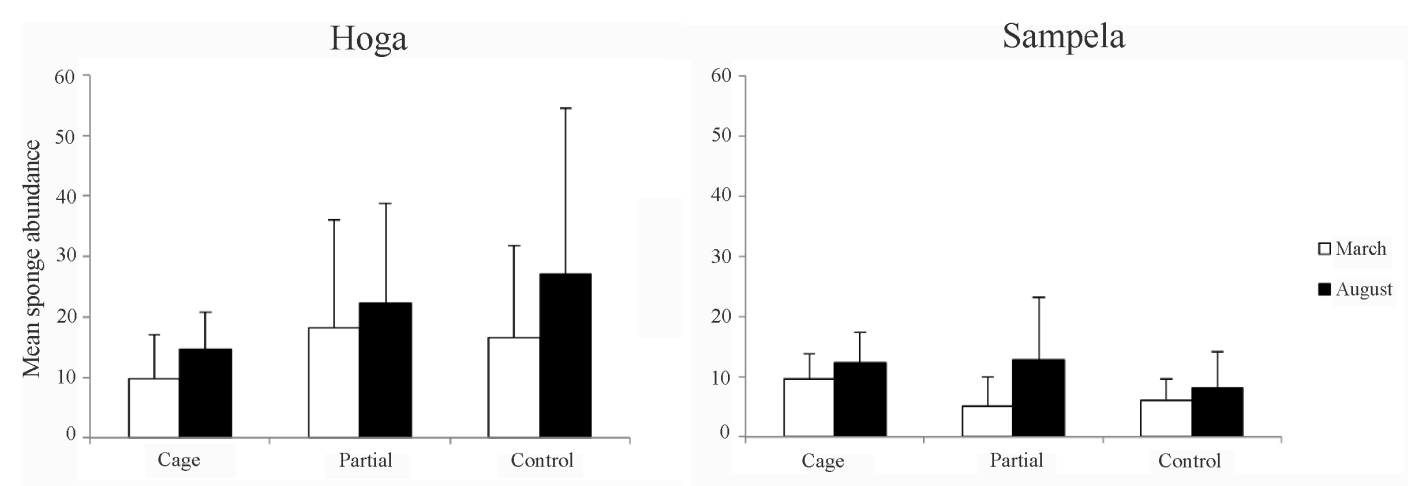

Figure 4.3 Sponge abundance plotted for caging treatments in March and August at the Hoga and Sampela study sites.

Table 4.1 Results of the 1-way ANOVA test for differences in sponge abundance between treatments at Hoga.

\begin{tabular}{lrrrrr}
\hline & Df & \multicolumn{1}{c}{ Sum Sq } & Mean Sq & F-value & $\operatorname{Pr}(>\mathrm{F})$ \\
\hline Factor (Treatment) & & 207.25 & 103.62 & 0.7461 & 0.4864 \\
Residuals & 21 & 2916.75 & 138.89 & & \\
\hline
\end{tabular}

Table 4.2 Results of the 1-way ANOVA test for differences in sponge abundance between treatments at Sampela.

\begin{tabular}{|c|c|c|c|c|c|}
\hline & Df & Sum Sq & Mean Sq & F-value & $\operatorname{Pr}(>\mathrm{F})$ \\
\hline$\overline{\text { Factor (Treatment) }}$ & 2 & 156.33 & 78.167 & 2.5608 & 0.1011 \\
\hline Residuals & 21 & 641 & 30.524 & & \\
\hline
\end{tabular}

\subsubsection{Exploratory power analyses}

The results of the power analyses are summarised in Figure 4.4. Power to detect differences between caged and no-cage control treatments differed at Hoga and Sampela. At Sampela the experiment would have had high power $(80 \%)$ to detect effect sizes representing roughly an $70 \%$ increase in mean sponge abundance in caged treatments. For Hoga the experiment would have only had sufficiently high power to detect larger effects representing a $100 \%$ increase in sponges in caging treatments (Figure 4.4). 


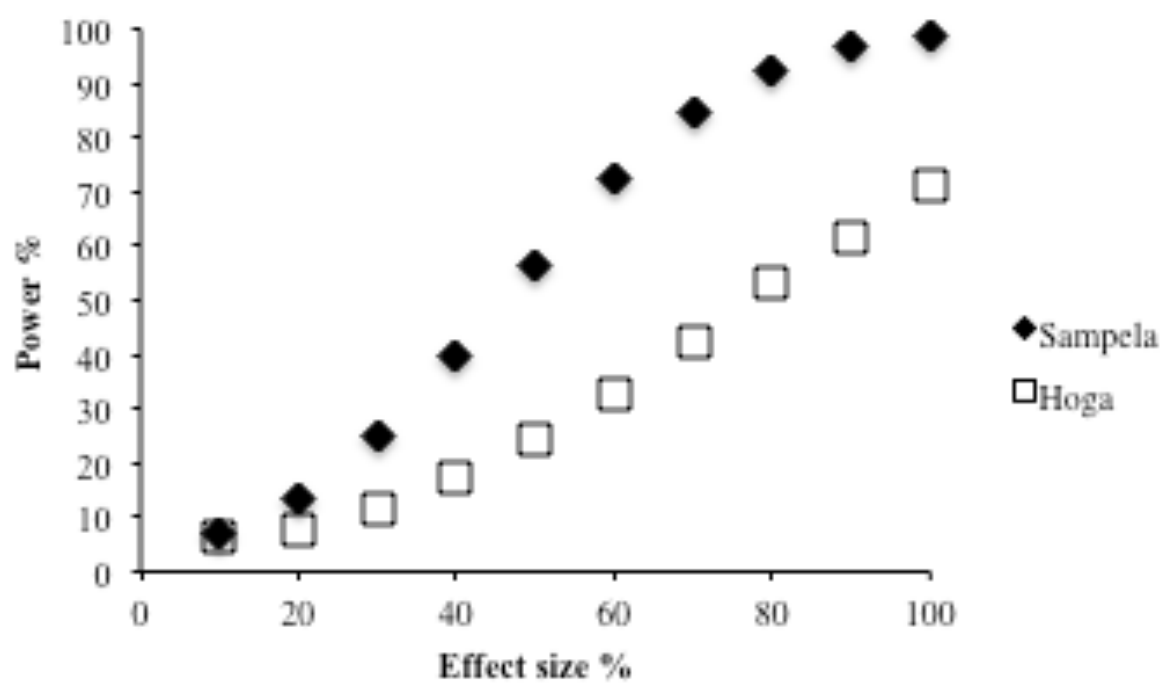

Figure 4.4 Power for rejecting the null hypothesis of no caging effect ( $5 \%$ significance) as a function of hypothetical increases in sponge abundance in caged treatments.

\subsubsection{Caging effects on sponge assemblages}

The results of the multivariate PERMANOVA to test for caging effects on sponge assemblages are summarised in Table 4.3. The only factor that had a significant effect was site reflecting the differences in the sponge assemblages at Hoga and Sampela $(\mathrm{df}=1$, Pseudo- $\mathrm{F}=8.101, \mathrm{p}=0.0001)$. This is further illustrated in the unconstrained non-metric Multi Dimensional Scaling (MDS) plot (Figure 4.5).

Table 4.3 Results of the PERMANOVA examining the effects of caging treatment on sponge assemblages at Hoga and Sampela.

\begin{tabular}{lcccc}
\hline Factors & $\mathrm{df}$ & Pseudo-F & $\mathrm{P}$ & Permutations \\
\hline Site & 1 & 8.101 & 0.0001 & 9931 \\
Treatment & 2 & 1.2896 & 0.1503 & 9894 \\
Time & 1 & 1.1512 & 0.2853 & 9928 \\
Site X Treatment & 2 & 1.5435 & 0.0573 & 9905 \\
Site X Time & 1 & 0.47611 & 0.09521 & 9920 \\
Treatment X Time & 2 & 0.47342 & 0.993 & 9903 \\
Site X Treatment X Time & 2 & 0.59456 & 0.9573 & 9880 \\
\hline
\end{tabular}




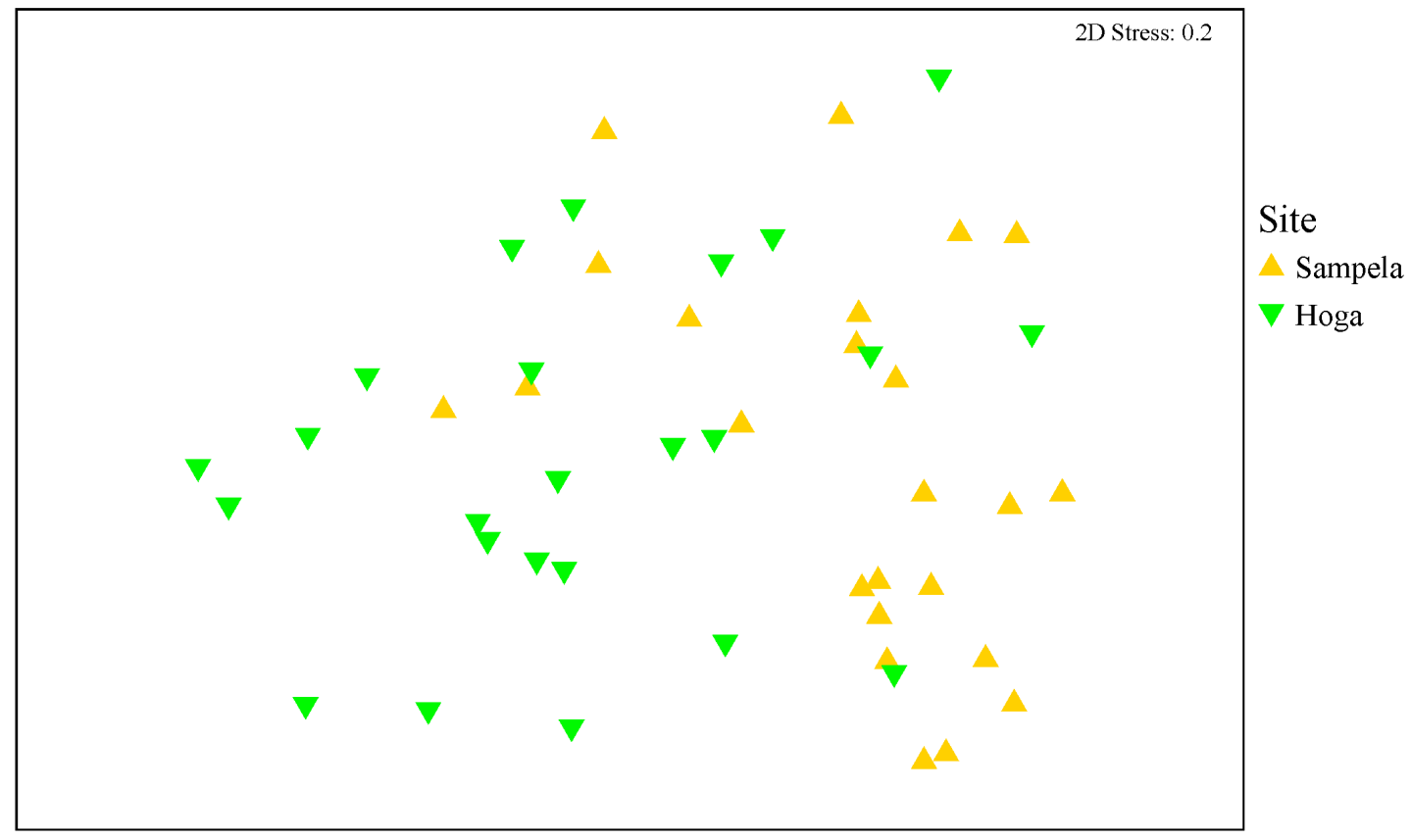

Figure 4.5 Unconstrained non-metric Multi Dimensional Scaling (MDS) plot illustrating the differences (as given by Bray-Curtis coefficients) between sponge assemblages within experimental plots at Hoga and Sampela.

\subsubsection{Fish data analysis}

Mean abundances of 293 (100.82 SD) fish per transect were recorded at Hoga and 279 (35.17SD) at Sampela. Mean spongivore abundance was 20 (8.62 SD) per transect at Hoga and 54 (7.81 SD) per transect at Sampela.

\subsection{Discussion}

Sponge distribution and abundance patterns are influenced by a number of abiotic factors but understanding the role of biological factors like fish predation is particularly important given the potential cascading effects of overfishing. The results presented here suggest that fish predation is not an important factor controlling the abundance and diversity of sponges at these study sites, as excluding fish predators appeared to have no significant effect on sponge assemblages, at least over the timescale of the experiment. Although it is possible to make clear statements about the importance of predation when effects are observed and caging artefacts are ruled out, it is more difficult to interpret experiments where no effects are apparent as the lack 


\section{Chapter 4}

of an effect may be real or the experimental design may be inadequate for detecting what effect is actually occurring. Hall (1990) argued that this has led to an underreporting of weak interactions in marine benthic systems and called for researchers to justify so-called 'negative' results in order to assess the true frequency of weak interactions in benthic systems. In this experiment, two approaches were adopted to investigate how much confidence can be placed in the experimental results; partial cages and statistical power analysis.

Partial cages were used to simulate the physical effects of caging on sponges whilst still allowing predation to occur. If the presence of cages had been affecting sponges there would have been an observable difference in sponge abundances through time between the partial cage and control treatments. This does not appear to have been the case in this study as no significant differences were detected in the change in sponge abundance between any of the treatments at either Sampela or Hoga. Statistical power analysis was used to determine the probability of detecting a predation effect given the experimental design. The results of the power analysis showed that the experiment had higher power to detect effects at Sampela than Hoga. This was due to greater variability in number of sponges in study plots at Hoga than at Sampela. At Sampela the experiment and analysis method had $80 \%$ power to detect a $70 \%$ increase in sponge abundance in the study plots whereas at Hoga this would have only been the case for larger effects representing roughly a doubling (100\% increase) of the mean number of sponges in caging treatments. Although the experiment had low power to detect weak effects at both sites, this analysis reveals that if fish predation is having an effect on the sponge assemblages at the study sites the effect is likely to be small.

My results contrast with previous research suggesting that fish can play an important role in determining sponge abundance and diversity in other reef systems (Pawlik 1998; Dunlap \& Pawlik 1998; Wulff 2000, 2005; Hill \& Hill 2002). One likely explanation for this is that most of the sponge predation research to date has been carried out in the Caribbean and it is possible that fish predation plays a greater role on Caribbean reefs than on Indo-Pacific reefs. While sponges are a high protein food source most sponge species have siliceous or calcareous spicules and produce toxic metabolites that may deter potential predators (Jones et al. 2005). The greater diversity of food sources on Indo-Pacific reefs could also mean that fish feed on less well defended alternatives like hard corals. 


\section{Chapter 4}

It is noteworthy that some of the studies in the Caribbean have involved translocating sponges from other habitats, such as mangroves to reefs and examining predation rates on the translocated sponges (Dunlap \& Pawlik 1996; Dunlap \& Pawlik 1998; Pawlik 1998; Wulff 2000, 2005; Hill \& Hill 2002). In this study, the focus was to identify whether fish influence the abundance and diversity of sponges normally found in reef habitats. It is possible that the sponges that occur on vertical reef walls and are exposed to potential predation have evolved mechanisms to avoid being consumed such as the production of secondary metabolites (Becerro et al. 1997; Green 1977; Swearingen \& Pawlik 1998; Wulff 2006a). Therefore, the results of this study cannot rule out the possibility that fish predation is the factor preventing sponges that commonly occur in mangroves, seagrasses or cryptic habitats in the WMNP from populating coral reef habitats.

The differences in the observed sponge assemblages between Hoga and Sampela are consistent with Bell and Smith (2004) and could have been caused by differences in other biological factors or environment conditions at the study sites (Chapter 3). A further possibility is that invertebrate sponge predators could be having an effect. Studies in the Caribbean have shown that starfish play an important role in limiting the distribution of some sponge species (Wulff 1995, 2006a). However, the results of Chapter 2 suggest that this is unlikely to be the case on the reef slopes of the WMNP as only 2 out of 117 starfish were found on sponges. Another biological factor that could be driving differences in sponge diversity and abundance at Hoga and Sampela is spatial competition with hard corals as these sites have contrasting levels of hard coral cover. However, previous research at these sites has shown that hard coral cover and sponge abundance are only weakly correlated so this seems unlikely to be a major contributor (Powell et al. 2010). Lesser (2006) found that food availability influenced the size, distributions and abundance of sponges on reef slopes in the Caribbean.

Currently, there is no information available on the relative abundance of potential food for sponges at our study sites. The abiotic factors, substrate angle and depth have been shown to influence sponge abundance (Bell \& Barnes 2003; Bell \& Smith 2004; Knapp \& Bell 2010), but the differences observed herein cannot be attributed to these factors as study plots were deliberately placed on vertical surfaces at the same depth to eliminate any possible confounding factors of depth or inclination. One of the most important differences between Sampela and Hoga is the level of sedimentation at 


\section{Chapter 4}

these sites. High levels of sedimentation are associated with reduced hard coral diversity, reduced coral recruitment and lower growth rates (Rogers 1990). Less research has been carried out on the effects of sedimentation on sponges, but researchers have found that some species have special adaptations to sedimented environments (Ilan \& Abelson 1995; Roberts et al. 2006a). The lower sponge abundances that we observed at Sampela compared to Hoga could have been due to the high levels of sedimentation at this site (see Chapter 3 for further discussion).

In addition to differences between the sponge assemblages at Hoga and Sampela there was an observed increase in sponge abundance over time between March and August. There is less information available on the drivers of temporal variability in sponge assemblages compared to spatial variation mainly due to the scarcity of studies that have monitored changes in tropical sponge assemblages over time. Population dynamics of sessile invertebrates are determined by their rates of reproduction, recruitment, growth and mortality (Hall \& Hughes 1996). A number of recent studies have highlighted factors that influence these processes and thus may contribute to temporal variation in sponge populations. McMurray et al. (2010) surveyed the giant barrel sponge Xestospongia muta in the Florida Keys over a six year period and found that population densities increased over the study period due to recruitment pulses. Studies have also shown that the timing of larval release in some sponges is not constant throughout the year but is triggered by environmental cues such as water temperature and therefore is likely to contribute to variability in sponge abundances over time (Maldonaldo 2006). In contrast, a 14 year study of sponge assemblages in Panama documented the steady disappearance of species throughout the study period (Wulff 1991). This trend appears to have been caused by increased sponge mortality due to disease. In a tropical/sub-tropical rocky coast system, Carballo et al. (2008) monitored sponge assemblages off the coast of Mexico for six years and observed short-term fluctuations correlated with seasonal changes in local wind patterns and sediment deposition, nested within large scale annual patterns related to the Southern Oscillation (SOI) and Multivariate ENSO (MEI) indexes. Longer-term monitoring of the sponge assemblages at Hoga and Sampela are necessary in order to determine the cause of the observed increase in sponge abundance and whether these increases are part of a long term trend or short term seasonal fluctuations. 


\section{Chapter 4}

To conclude, predation is unlikely to be a major driver of differences in overall sponge assemblages on reef walls at these study sites as revealed by predator exclusion and subsequent power analyses of the effectiveness of the experimental design. However, the possibility that fish are affecting sponges in some small way cannot be ruled out by this study, due to the low power to detect smaller effects. This study would have been improved by increasing the number of replicates in each treatment and standardizing the initial number of sponges in experimental plots as these would have increased power to detect effects. It would also have been useful to test for non-lethal effects of predation on sponges including increased toxicity and spicule production in un-caged sponges. Direct observations of fish feeding and the effects they may have will be the focus of the following chapter in order to ascertain whether fish may contribute to sub-lethal or marginal effects on sponge growth. However it still remains that environmental conditions, particularly sedimentation, are likely to play a larger structural role in determining spatial distributions of sponge assemblages in the Wakatobi (Chapter 3), although it is still unclear what is driving temporal patterns of variation. 
Chapter 4 


\section{Fish predation on the Indo-Pacific giant barrel sponge, Xestospongia testudinaria}

\subsection{Abstract}

Xestospongia testudinaria is one of the largest and most conspicuous invertebrates on Indo-Pacific coral reefs. Despite its potential to influence reef ecosystem processes, such as nutrient cycling due to its large size and high pumping rate, very little is known about the factors that influence the ecology of $X$. testudinaria. Research in the Caribbean has shown that fish predation can affect the distribution and abundance of the closely related Xestospongia muta, but the extent of spongivory on X. testudinaria is unknown. In this study, video observations were used to quantify spongivory on $X$. testudinaria. Fish predation rates and measurements of barrel sponge regeneration rates were used to simulate fish predation on barrel sponges and to estimate how much material is typically regenerated by sponges in response to predation over a 24 hour period. In addition, the factors that influenced the extent to which individual sponges were fed on were investigated. We found that $X$. testudinaria were regularly consumed by angelfish and one species of butterflyfish. This is in contrast with the Caribbean, where the main predators on $X$. muta were parrotfish. Fish predation intensity was influenced by barrel sponge volume and local habitat complexity. Barrel sponges regenerated quickly from wounds according to an exponential response to wound size, typically regenerating at a rate of -0.1 day $^{-1}$ (equivalent to regeneration of $9.5 \%$ of the wound volume per day, independent of wound volume). By modelling predation on an average sized barrel sponge it was calculated that over a 24 hour period fish predation removed on average $0.46 \%$ of the total sponge volume. These results suggest that the rapid regeneration capacity of $X$. testudinaria may have evolved in response to constant partial predation, and that any changes in fish assemblages on reefs due to anthropogenic activities could affect Indo-Pacific barrel sponges and therefore overall ecosystem functioning. 


\section{Chapter 5}

\subsection{Introduction}

Predation is known to be a major determinant of community structure (Paine 1966, 1969; Menge \& Sutherland 1976) that can affect species in numerous ways both directly through the consumption of prey species and indirectly by altering the behaviour of prey or by affecting other biological processes, such as competition (Chase et al. 2002). In coral reef ecosystems predation can affect reef ecosystem function by influencing the relative abundance of functionally important groups of reef organisms (Adams et al. 2011). An example of the effect of predation on benthic reef assemblages comes from Caribbean reefs where a reduction in herbivorous fish caused by fishing has contributed to phase shifts where previously coral dominated reefs become dominated by algae (Hughes 1994). As a result, a considerable amount of research has focused on the role of herbivory in regulating algal abundance on reefs (McCook 1997; Lefevre \& Bellwood 2011). However, several studies have also shown that predation can impact the distribution and abundance patterns of other reef invertebrates including soft corals, hard corals and sponges (Lasker 1985; Neudecker 1979; Rotjan \& Lewis 2008).

Sponges are preyed upon by a number of vertebrate and invertebrate taxa including sea turtles, nudibranchs and starfish but fish appear to be the most important predators in tropical systems (Meylan 1988; Knowlton \& Highsmith 2005; Dunlap \& Pawlik 1998; Wulff 2008). Based on gut content analysis, Randall and Hartman (1968) concluded that the role of fish predation in influencing sponge distributions and abundance in the Caribbean was likely to be small. However, other research based on feeding observations and experimental approaches suggests that the importance of spongivory may have been underestimated and that it can affect reef sponge assemblages in multiple ways. Transplantation experiments have shown that spongivory affects the distribution and abundance of some tropical sponges restricting them to mangrove and lagoon habitats or to cryptic locations on reefs (Wulff 1997; Dunlap \& Pawlik 1996; Pawlik 1998). These sponges appear to be highly palatable to spongivorous fish and are rapidly consumed when exposed to predation. Other sponges that grow in exposed locations on reefs rather than within the reef framework appear to be exposed to less intense but persistent levels of predation (Dunlap \& Pawlik 1998). This type of partial predation may be analogous to browsing or grazing by herbivores. While the fitness consequences of partial predation have been well- 


\section{Chapter 5}

studied in plants (Belsky 1986; Multikainen 1996; Strauss \& Agrawal 1999; Skarpe \& Hester 2008) there is less information available for benthic marine invertebrates. Many sponges have the ability to regenerate efficiently from damage (Ayling 1983; Bell 2002) so the effects of partial predation may be sub-lethal. Constant predation, however, is likely to affect sponge growth and reproduction due to the allocation of resources to regeneration, and in combination with other stresses, such as disease, could be responsible for regulating sponge abundance and distribution patterns. To date most of the research on fish predation on sponges has been carried out in the Caribbean (Hill \& Hill 2002; Hill 1998; Wulff 1997, 2000, 2005; Dunlap \& Pawlik 1996, 1998; Swearingen \& Pawlik 1998; Pawlik 1998), while little research has been carried out on fish predation on sponges in the Indo-Pacific and as a result its impact is currently unknown.

In this study, I examined the extent and impacts of fish predation on one of the most conspicuous and charismatic sponges on Indo-Pacific reefs, the giant barrel sponge Xestospongia testudinaria (Lamarck 1815). X. testudinaria is a widespread species that occurs from the East African coast to the Australian Great Barrier Reef (Van Soest et al. 2012). It can reach up to $1.5 \mathrm{~m}$ tall and $2 \mathrm{~m}$ in diameter (Fromont 1991; Bell \& Smith 2004) and is thought to be very closely related to Xestospongia muta (Schmidt 1870) the Caribbean giant barrel sponge (Montalvo \& Hill 2011). $X$. testudinaria is an ideal species to study the effects of spongivory for a number of reasons. Firstly, this species hosts large populations of cyanobacteria and could potentially provide a link between primary and secondary production. Secondly, fish predation has been documented on X. muta in the Caribbean (Dunlap \& Pawlik 1998) but to our knowledge there have been no studies of fish predation and this potentially important process in the Indo-Pacific. Comparing the magnitude of these processes on giant barrel sponges between Caribbean and Indo-Pacific reefs may reveal differences in trophic pathways between these two systems, increasing our understanding of the role that spongivory has in a global context. Thirdly, like $X$. muta in the Caribbean, the exceptional size of $X$. testudinaria means that changes in the abundance or health of this species is likely to impact processes such as spatial competition and nutrient cycling on reefs. If fish predation is one of the factors that currently affects $X$. testudinaria distributions and biomass, then changes in fish assemblages due to human activities such as fishing could have subsequent effects on these processes. 


\section{Chapter 5}

Finally, the relative ease with which it can be identified, its abundance and large size make $X$. testudinaria particularly amenable to in-situ studies of feeding behavior.

The primary aims of this study were to measure the extent and intensity of fish predation on $X$. testudinaria in SE Sulawesi, Indonesia. In addition, I examined the potential impacts of spongivory on $X$. testudinaria by measuring the amount of sponge tissue regenerated by this species in response to current levels of fish predation on Indo-Pacific reefs. My objectives were: i) to identify which fish species feed on $X$. testudinaria; ii) to quantify fish feeding rates on $X$. testudinaria; iii) to identify the factors that influence which barrel sponges are consumed; iv) to measure barrel sponge regeneration rates; and v) to use fish feeding rates and barrel sponge regeneration rates to determine how much material barrel sponges must regenerate per day to maintain a constant size or achieve positive growth given current levels of fish predation.

\subsection{Methods}

\subsubsection{Study Sites}

This study was carried out at two replicate sites on the fringing reef that surrounds Kaledupa Island in the Wakatobi Marine National Park (WMNP) in July and August 2011. Sites were located $100 \mathrm{~m}$ apart in close proximity to Sampela Village; site 1 was located approximately $100 \mathrm{~m}$ east of site 2 (see Figure 5.1). The sites are characterised by similar environmental conditions with relatively high sedimentation rates of $20.16 \pm 1.76 \mathrm{~g} \mathrm{~d}$.wt. $\mathrm{m}^{-2} \cdot \mathrm{d}^{-1}$ (Crabbe \& Smith 2002). The mean flow rate at Sampela is $0.063 \pm 0.044 \mathrm{~m} \cdot \mathrm{s}^{-1}$ and water temperatures in July and August are typically between $27-28^{\circ} \mathrm{C}$ (author's unpublished data). The reef slopes are $<45^{\circ}$ leading to a flat sandy bottom at a depth of 10-14 m. 


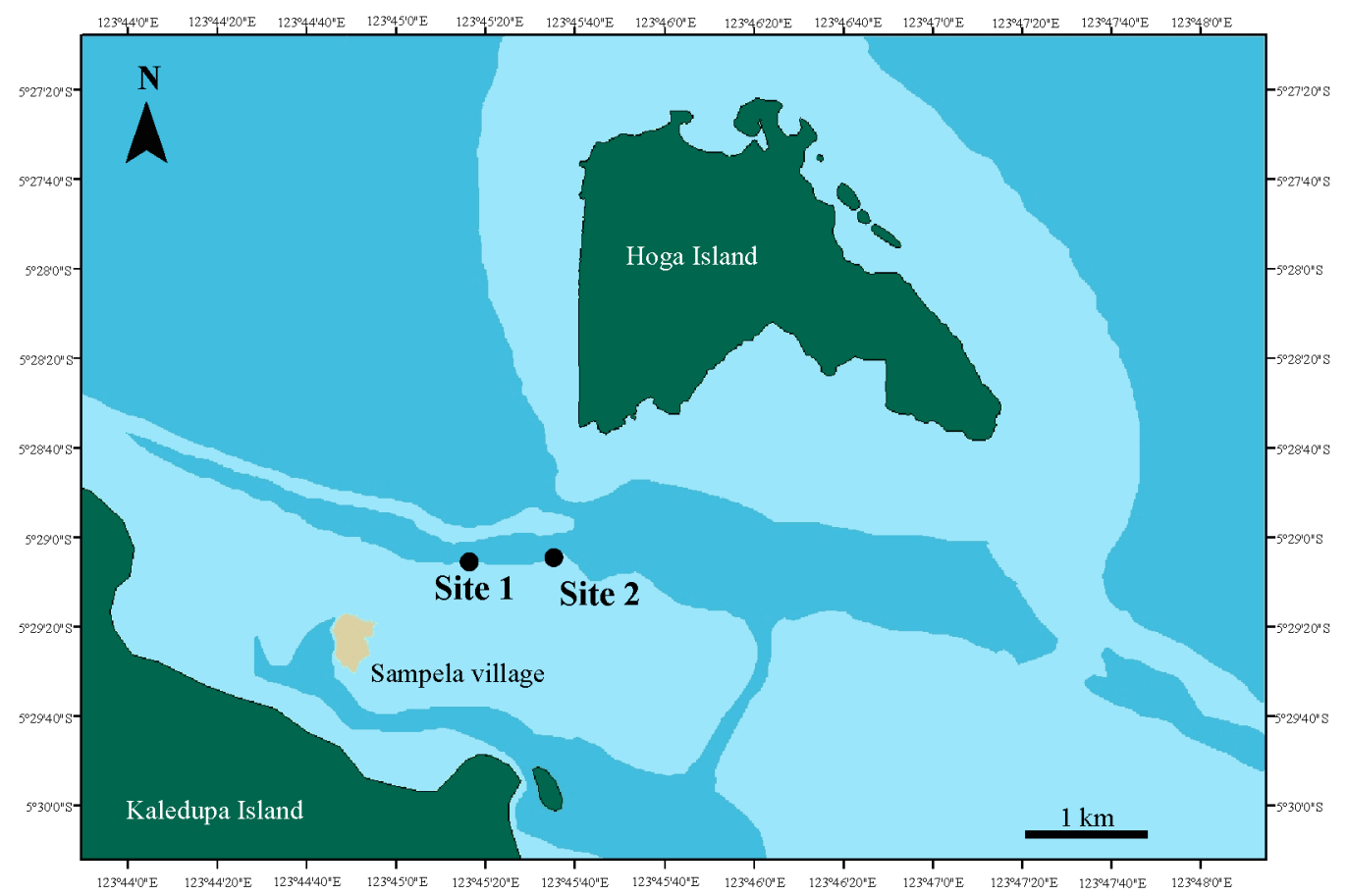

Figure 5.1 Map of the study sites in the context of the Kaledupa-Hoga reef system.

\subsubsection{Species description}

$X$. testudinaria is a distinctive barrel shaped species, with vertical ridges on its outer surface which may be more or less pronounced. It has a firm springy texture and is red-brown in colour (Fromont 1991). This species can reach up to $1.5 \mathrm{~m}$ tall (Fromont 1991) and 1-2 $\mathrm{m}$ in diameter (Bell \& Smith 2004). X. testudinaria are found at turbid inshore reef sites as well as at less turbid sites (Fromont 1991; deVoogd et al. 2009; Bell \& Smith 2004) and occur in shallow and deeper waters. Typically they are gonochoric, and synchronous spawning events have been reported on the Great Barrier Reef (Fromont \& Bergquist 1994). X. testudinaria have been previously recorded at Sampela by Bell \& Smith (2004).

\subsubsection{Barrel sponge densities and fish surveys}

Barrel sponge densities and fish assemblages were surveyed at both study sites as these factors could have influence predation rates. Barrel sponge densities were recorded along three $30 \mathrm{~m}$ transects at each site. Transect tapes were laid on the reef slope at approximately $8 \mathrm{~m}$ depth at each site. A $5 \mathrm{~m}$ gap was left between the end of 


\section{Chapter 5}

one transect and the start of the next. All barrel sponges $2.5 \mathrm{~m}$ either side of the transect line were recorded. A permutational multivariate analysis of variance (PERMANOVA) was carried out to test the hypothesis that there was no difference in barrel sponge abundance between the study sites. The PERMANOVA design included site as a fixed factor with two levels.

Fish surveys were also carried out along $30 \mathrm{~m}$ belt transects but a period of 10 minutes was allowed to elapse before surveys began to try and minimize the effect of disturbance caused by laying the tape. All fish species observed within a virtual 'tunnel' $30 \mathrm{~m}$ long by $5 \mathrm{~m}$ wide and $5 \mathrm{~m}$ high were recorded. A PERMANOVA with site as a fixed factor with two levels was used to test the hypothesis that there was no difference in total fish abundance between the study sites.

\subsubsection{Feeding rates on barrel sponges}

In June 2011 ten barrel sponges were tagged at each site. A Canon S90 camera with underwater housing attached to a weighted GorillaPod tripod was used to record fish feeding behaviour. The camera was deployed facing the sponge at a distance of 1-2 m. A scale bar was held next to the sponge at the start of the video so that the number of fish bites/area sponge visible in the video could be calculated. The camera was left for the maximum time possible given dive constraints ( $\sim 28 \mathrm{~min})$. Each sponge was filmed on three occasions during daylight hours between $9 \mathrm{am}$ and $5 \mathrm{pm}$. The first three minutes of each video was cut in order to account for disturbance caused by installing the camera and the last minute of each video was cut as fish behaviour could have been affected by divers returning to collect the camera. From the videos each fish species that fed on the barrel sponge was identified and the number of bites taken recorded. In addition to numbers of bites, the total number of feeding events on each sponge was also recorded. Feeding events were defined according to the following rules; 1) a feeding event started when a fish took a bite of the sponge, 2) A feeding event came to an end when a fish stopped feeding for over 20 seconds or went out of view. A two factor permutational multivariate analysis of variance (PERMANOVA) was carried out to test whether there were differences in bite rate per $\mathrm{cm}^{2}$ between the study sites. The PERMANOVA design included site as a fixed factor with two levels and sponge as a random factor nested within site. 


\section{Chapter 5}

\subsubsection{Barrel sponge regeneration rates}

In order to calculate barrel sponge regeneration rates tissue was removed from four sponges at each of the two sites and wound regeneration was monitored over 20 days. These sponges were not included in the video observations as the presence of holes could have influenced feeding rates. In order to approximate how a barrel sponge may recover from fish bites, holes were made $2 \mathrm{~cm} 2$ by $3 \mathrm{~mm}$ deep to simulate a moderate sized wound. Three replicate holes were made on each sponge. The area and depth of the holes were measured at 2, 5, 7, 10 and 20 days after the initial wounding $(\mathrm{t}=0)$. The depth of the holes was measured in situ using Vernier Callipers. Three depth measurements taken in random positions were made per hole and used to calculate the average depth for each sampling date. The areas of the holes were obtained in the lab from photos using the software ImageJ (Abramoff et al. 2004). The volume of each hole was plotted over time for each individual sponge.

Two different possible functional forms for the regeneration rates of $\mathrm{X}$. testudinaria were considered. The first assumed that wound volume $V(t)$ was linear through time according to the following relationship,

$V(t)=v_{u}-\beta t$

where $V_{0}$ is the wound volume measured at the time when the wound was instigated $(\mathrm{t}=0)$, and $\beta$ is the rate of change of wound volume through time (units $\mathrm{cm}^{3} \mathrm{~s}^{-1}$ ). The second relationship assumed that wound volume changed according to an exponential decay function,

$V(t)=v_{11} e^{-\gamma t}$

where $\gamma$ is the exponential rate parameter (units s${ }^{-1}$ ). This response is curvilinear and models greater volume regeneration (per unit time) immediately after a wound incident, which slowly declines as the wound ages allowing for an asymptotic recovery back to a fully regenerated state. These were modeled in SPSS by utilising a generalised linear model (assuming normally distributed data) with an identity link function for the linear functional response, and a logarithmic link function for the exponential decay response. In addition no assumptions about the generality of the regeneration rates were made, and so various models were fitted to assess whether regeneration is best described by an overall regeneration rate, or whether regeneration 


\section{Chapter 5}

rates and intercepts are better described by models that allow for varied regeneration rates between different holes on the same sponge. The models investigated for each sponge were therefore: a) linear with main effect: 'time'; b) linear with main effects: 'time', 'hole'; c) linear main effects: 'time', 'hole', 'time*hole' (the interaction between time and hole); d) log link with main effect: 'time'; e) log link with main effects: 'time', 'hole'; and f) log link with main effects: 'time', 'hole', 'time*hole'. Each model can be thought of as a hypothesis of how barrel sponge regeneration occurs. The most complex models with main effects of 'time', 'hole' and 'time*hole' assume that each hole has a different regeneration rate. The models with main effects of 'time' and 'hole' assume that there is a sponge specific rather than hole specific regeneration rate but take into account slight differences in initial hole volume. The simplest models with 'time' as the only effect assume that there is a sponge specific regeneration rate and does not account for differences in initial hole depths. Model fit was evaluated using Akaike's Information Criterion with a second order correction (AICc) (Burnham \& Anderson 2001). For each sponge the Akaike weight of each of the competing models was calculated. Subsequently the Akaike weights for each model type were summed across sponges to determine which model best described the regeneration rates.

\subsubsection{Amount of sponge material consumed by fish}

The amount of material consumed by fish was estimated by measuring the depth and area of 30 visible bite scars on barrel sponges. The depth of the bites was measured in situ using Vernier calipers. The area of the bites was obtained from photographs taken in situ and by using the software ImageJ. Bite volume was calculated from the area and depth measurements using the equation for the volume of a hemisphere.

$$
V=\left(\frac{2}{3}\right) \pi r^{3}
$$

\subsubsection{Regression analysis to determine the factors associated with fish predation on barrel sponges}

Statistical modelling was used in order to identify the factors that might account for differences in fish predation rates on barrel sponges. Distance-based linear modeling (DISTLM) was used to examine associations between the number of bites on sponges 


\section{Chapter 5}

and five predictor variables: depth, habitat complexity, local predatory fish abundance, and barrel sponge volume. These factors were chosen because of their potential to influence the amount of feeding on individual barrel sponges. Depth was included as a predictor variable because many species of reef fish exhibit strong zonation patterns associated with depth (Bean et al. 2002; Freidlander \& Parrish 1998) so the local abundance of spongivorous and consequently the number of bites and feeding events could be different on sponges at different depths. The abundance of piscivorous fish in the immediate vicinity of barrel sponges may also modify the behaviour of spongivorous fish, and therefore may influence their feeding rates (Werner et al. 1983). Habitat complexity can affect fish diversity and abundance (Luckhurst \& Luckhurst 1978; Freidlander \& Parrish 1998) so could affect the number of spongivores in the vicinity of different barrel sponges. We used a simple habitat assessment score (HAS) developed by Gratwicke and Speight (2005) to assess complexity of the substrate around each barrel sponge. The HAS score was a measure that took into account the rugostiy, variety of growth forms, height, refuge size categories, percentage live cover and percentage hard substratum in an area $2.5 \times 2.5$ $\mathrm{m}$ centred on each barrel sponge. Finally, larger barrel sponges could potentially be fed on more than smaller sponges due to their greater visibility to spongivorous fish, and so barrel sponge volume may also be a predictor of fish feeding rates. Barrel volume was calculated using either the formula for the volume of the frustum of a cone or that of a cylinder depending on the overall shape of the sponge. In all cases the volume of the spongoceol, which was calculated using the formula for a cone, was subtracted from the total barrel volume. The dimensions of each sponge were measured in-situ. An information theoretic approach to model selection was adopted using Akaike's Information Criterion corrected for small-sample bias (AICc) to judge between competing models. AICc was computed for models with all possible combinations of predictor variables using the Best procedure in DISTLM. The model with the smallest AICc value was selected as the best representation of the observed data. In addition to the number of bites on sponges, the total number of feeding events observed for each sponge was also subjected to the same statistical modelling procedure.

\subsubsection{Modelling fish predation on $X$. testudinaria}

A numerical stochastic feeding and regeneration model was written and executed in $\mathrm{R}$ 


\section{Chapter 5}

version 2.15.0 (R Development Core Team 2011) to simulate fish predation on a virtual barrel sponge. The full model code is supplied in Appendix 7. The values for each of the parameters used in the model simulations are summarised in Table 5.1. Preliminary observations revealed that some fish species, including a number of surgeonfish, wrasse and damselfish species, did not remove sponge tissue when visibly interacting with the sponge surface and were therefore excluded from model parameter estimation.

Table 5.1 Parameters, parameter values and the method used to obtain these values for the numerical barrel sponge simulation model.

\begin{tabular}{|c|c|c|c|c|}
\hline Parameter & Units & $\begin{array}{c}\text { Measured } \\
\text { mean } \pm 1 \mathrm{SD} \\
\text { (range) }\end{array}$ & $\begin{array}{l}\text { Value used in } \\
\text { model } \\
\text { simulations }\end{array}$ & Measurement method/Source \\
\hline $\begin{array}{l}\text { Sponge } \\
\text { circumference }\end{array}$ & $\mathrm{cm}$ & $\begin{array}{l}56 \pm 29 \\
(25,129) \\
113 \pm 34 \\
(57,173)\end{array}$ & 57 & $\begin{array}{c}\text { All sponge heights and circumferences were } \\
\text { quantified in situ, for all sponges used in the } \\
\text { video analysis }\end{array}$ \\
\hline $\begin{array}{l}\text { Sponge } \\
\text { thickness }\end{array}$ & $\mathrm{cm}$ & & 10 & $\begin{array}{l}\text { This was an estimate of the mean thickness of } \\
\text { the sponge from the outer surface to the } \\
\text { spongocoel. }\end{array}$ \\
\hline $\begin{array}{l}\text { Sponge } \\
\text { regeneration } \\
\text { rate }\end{array}$ & $\mathrm{hr}^{-1}$ & $\begin{array}{c}-0.0033 \pm \\
0.0025 \\
(-0.001,- \\
0.007)\end{array}$ & -0.0033 & $\begin{array}{c}\text { Regeneration rates were obtained from the } \\
\text { regeneration observations of } 8 \text { individual barrel } \\
\text { sponges. }\end{array}$ \\
\hline $\begin{array}{c}\text { Sponge } \\
\text { growth rate }\end{array}$ & & & $\begin{aligned} \mathrm{S}_{\infty} & =66.1213 \\
\mathrm{k} & =0.0388 \\
\mathrm{~d} & =1.8972\end{aligned}$ & $\begin{array}{l}\text { Growth rates were calculated using the } \\
\text { specialised von Bertalanffy growth formula with } \\
\text { parameter estimates obtained from McMurray et } \\
\text { al (2008). }\end{array}$ \\
\hline Bite diameter & $\mathrm{cm}$ & $\begin{array}{r}0.6 \pm 0.2 \\
(0.4,1)\end{array}$ & 0.6 & $\begin{array}{l}\text { Bite diameter was measured from photographs } \\
\text { of } 30 \text { bites using the image analysis software } \\
\text { imageJ. This value was used to determine the } \\
\text { grid size used in the model simulations. }\end{array}$ \\
\hline Bite depth & $\mathrm{cm}$ & $\begin{array}{l}0.2 \pm 0.1 \\
(0.02,0.3)\end{array}$ & $\begin{array}{l}\text { Stochastic } \\
\sim \mathrm{N}(\mu, \sigma)\end{array}$ & $\begin{array}{l}\text { The depth of } 30 \text { bites (all visible bites on } 10 \\
\text { haphazardly selected sponges) was measured in } \\
\text { situ using Vernier Calipers. The depth of each } \\
\text { simulated bite was randomly drawn from a } \\
\text { normal distribution parameterised by the mean } \\
\text { and standard deviation of the recorded bite } \\
\text { depths. }\end{array}$ \\
\hline
\end{tabular}




\begin{tabular}{|c|c|c|c|c|}
\hline $\begin{array}{l}\text { Number of } \\
\text { feeding } \\
\text { events }\end{array}$ & $\mathrm{hr}^{-1}$ & $\begin{array}{c}\mu=0.017 \\
\nu=0.59\end{array}$ & $\begin{array}{l}\text { Stochastic } \\
\sim \mathrm{NB}(\mu, v)\end{array}$ & $\begin{array}{l}\text { The number of feeding events per } 22 \text { minute } \\
\text { period was quantified from the video analysis. A } \\
\text { negative binomial (NB) distribution was fitted to } \\
\text { the distribution of this data to estimate the mean } \\
\mu \text { and variance parameter } v \text { of the expected } \\
\text { number of feeding events. Random numbers of } \\
\text { feeding events per time step were then simulated } \\
\text { from this distribution. }\end{array}$ \\
\hline $\begin{array}{c}\text { Bites per } \\
\text { feeding event }\end{array}$ & & $\begin{array}{c}\mu=8.24 \\
v=0.78\end{array}$ & $\begin{array}{l}\text { Stochastic } \\
\sim \mathrm{NB}(\mu, v)+1\end{array}$ & $\begin{array}{l}\text { The number of bites per feeding event was } \\
\text { quantified from the video analysis. A NB } \\
\text { distribution was fitted to the distribution of this } \\
\text { data. As feeding events are defined only for a } \\
\text { number of bites }>0 \text {, and that the NB distribution } \\
\text { can simulate zero counts, one was subtracted } \\
\text { from the measured number of bites per feeding } \\
\text { event, and the NB distribution was fitted to this } \\
\text { data. The parameters } \mu \text { and } v \text { were then } \\
\text { estimated for this distribution and used to } \\
\text { simulate the number of bites per feeding event. } \\
\text { One was subsequently added to each simulated } \\
\text { number of bites per feeding event to ensure that } \\
\text { each event contained a minimum of one bite. }\end{array}$ \\
\hline Extent & & & 50 & $\begin{array}{l}\text { This parameter represents the area (in terms of } \\
\text { the number of adjacent cells) over which bites in } \\
\text { a feeding event can occur, allowing the } \\
\text { simulation of spatially clustered feeding events. }\end{array}$ \\
\hline $\begin{array}{l}\text { Number of } \\
\text { simulations }\end{array}$ & & & 100 & \\
\hline
\end{tabular}

The virtual barrel sponge was designed to approximate a simple barrel sponge and was shaped like a hollow cylinder opened out to form a rectangular cuboid (see Figure 5.2). The length and width of the rectangle represent the height and diameter of the sponge and the depth represents sponge thickness from the outside to the spongoceol. The surface of the sponge was divided up into an array of small squares or 'cells'. 


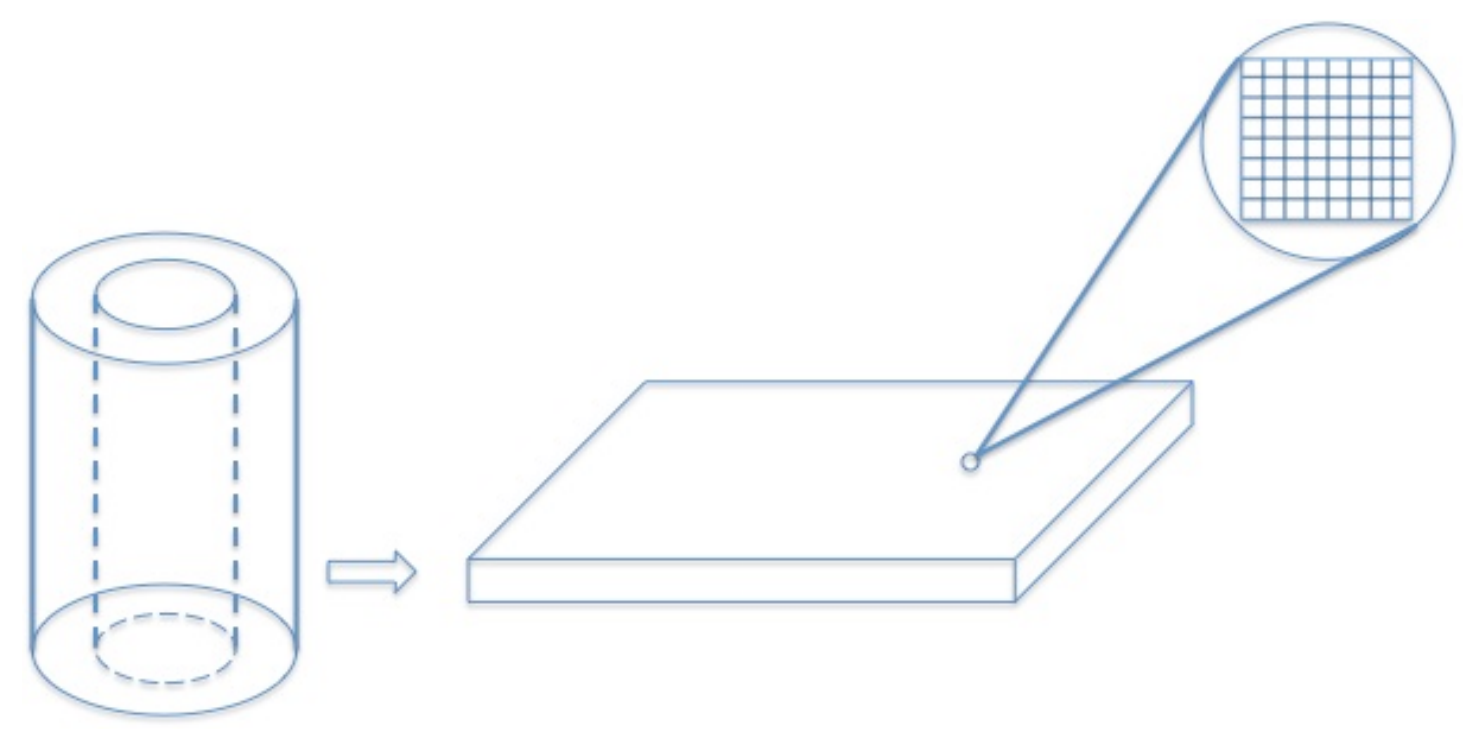

Figure 5.2 Diagram of the idealized barrel sponge used in the regeneration model.

At the start of each time step a number of feeding events is randomly drawn from a negative binomial distribution parameterised by the distribution of feeding events obtained from the video observations. Each of the feeding events is randomly assigned a position on the surface of the virtual sponge. Each feeding event is then assigned a number of bites and each bite is assigned a depth. The number of bites per feeding event is randomly drawn from a negative binomial distribution parameterized by the distribution of the data obtained from the barrel sponge feeding observations. The depth of each bite is randomly drawn from a normal distribution of bite sizes parameterized by our measurements of bite sizes (see Table 5.1). Prior to simulating regeneration of the "wounded" cells, somatic growth across the whole of the sponge is simulated. Finally, regeneration is simulated for all wounded cells according to the rate estimated from the regeneration observations. The process was then iteratively repeated for the length of time desired (Figure 5.3). Fish predation was simulated for a two month period. A certain amount of time needs to pass before equilibrium is reached between the amount of sponge removed and the amount of sponge regenerated (representing current levels of feeding and regeneration). The model was allowed to reach equilibrium and the average volume of tissue being regenerated by the sponge over 24 hours was determined. To account for the inherent variability in the modelling process that aims to account and quantify the stochastic nature of the 


\section{Chapter 5}

processes observed, the simulation was carried out 100 times and results reported represent the average of these simulations.

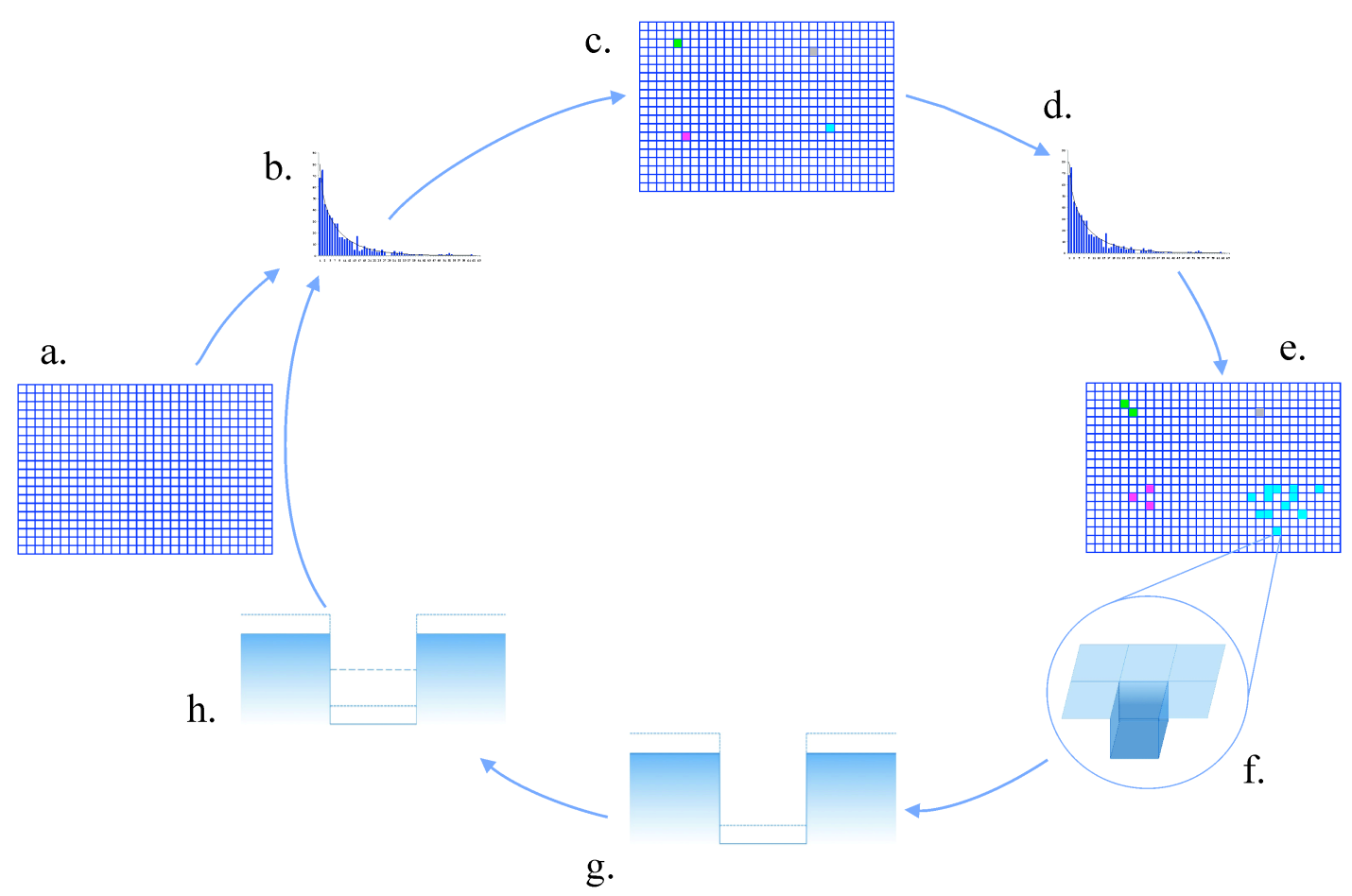

Figure 5.3 Schematic representation of the steps involved in the fish predation model. a) Grid representing the surface of the barrel sponge, b) a random number of feeding events is drawn from a negative binomial distribution, c) each feeding event is given a position on the grid, d) each feeding event is assigned a number of bites drawn from a negative binomial distribution, e) each bite is given a location on the grid centred around the point defined in c), but within a certain distance as defined by the extent model parameter, $\mathrm{f}$ ) each bite is assigned a depth which is randomly drawn from a normal distribution which is then subtracted from the thickness for each of the cells that were identified as being bitten in e), g) this step represents somatic growth which is added equally to every cell in the grid, $h$ ) regeneration is added to any cell which has been previously fed on in any previous step (i.e. if thickness is below the unwounded thickness of the sponge, some regeneration is applied, even if that cell was wounded many time steps before).

\subsection{Results}

\subsubsection{Barrel sponge densities and fish surveys}

Barrel sponge densities at Site 1 were 4 per $100 \mathrm{~m}^{2}( \pm 1.33 \mathrm{SD})$ and 6.67 per $100 \mathrm{~m}^{2}( \pm$ $4 \mathrm{SD}$ ) at Site 2. No significant difference were detected in barrel sponge densities between study sites (PERMANOVA Pseudo-F=1.0588 p=0.4918). Mean fish 
abundance was $235.11( \pm 69.75 \mathrm{SD})$ per $100 \mathrm{~m}^{2}$ at Site 1 and 177.33 fish $( \pm 13.92$ SD) per $100 \mathrm{~m}^{2}$. There was no significant difference in total fish abundance at the study sites (PERMANOVA Pseudo-F=1.6654 p=0.4018).

\subsubsection{Feeding rates on barrel sponges}

In total an average of $1.5 \mathrm{hrs}$ of video was obtained for each of the 20 sponges and 30 hours of footage in total. Video lengths were standardised to 22 minutes prior to analysis. Fifteen species of fish were observed feeding on barrel sponges including, triggerfish, wrasse, butterflyfish, surgeonfish, damselfish and angelfish (see Table $5.2)$.

Table 5.2 List of species observed feeding on the barrel sponges in the videos.

\begin{tabular}{ll}
\hline Species & Common name \\
\hline Acanthurus auranticavus & Blackline surgeonfish \\
Atrosalarias fuscus & Brown coral blenny \\
Acanthurus nigrofuscus & Brown surgeonfish \\
Acanthurus pyroferus & Mimic butterflyfish \\
Balistapus undulatus & Orangelined triggerfish \\
Centropyge bicolor & Bicolor angelfish \\
Ctenochaetus binotatus & Twospot bristletooth \\
Chaetodon kleini & Klein's butterflyfish \\
Chaetodon mertensii & Merten's butterflyfish \\
Centropyge tibicen & Keyhole angelfish \\
Centropyge vroliki & Pearly angelfish \\
Dascyllus trimaculatus & Threespot dascyllus \\
Forcipiger flavissimus & Longnose butterflyfish \\
Cantherhines sp. & Fishfish \\
Hemiglyphidodon plagiometopon & Lagoon damsel \\
Halichoeres prosopeion & Two tone wrasse \\
Pomacentrus amboinensis & Ambon damselfish \\
Pomacentrus bracialis & Charcoal damselfish \\
Pygoplites diacanthus & Regal angelfish \\
Scarus flavipectoralis & Yellowfin parrotfish \\
Thalassoma lunare & Crescent wrasse \\
\hline
\end{tabular}




\section{Chapter 5}

In total 5020 bites on $X$. testudinaria were recorded in the 22 hours of footage. The percentage of the total bites taken by each species is shown in Figure 5.4. The largest number of bites were taken by the surgeonfish, Ctenochaetus binotatus (Two-Spot Surgeon), which took 2095 bites ( $42 \%$ of the total bites), followed by the butterflyfish Chaetodon kleini (Klein's butterflyfish), which took 1099 bites (22\%), and Acanthurus auranticavus (the blackline surgeonfish), which took 675 bites (13\%). There was no significant difference in the overall bite rate between sponges within site or between sites (Table 5.3).

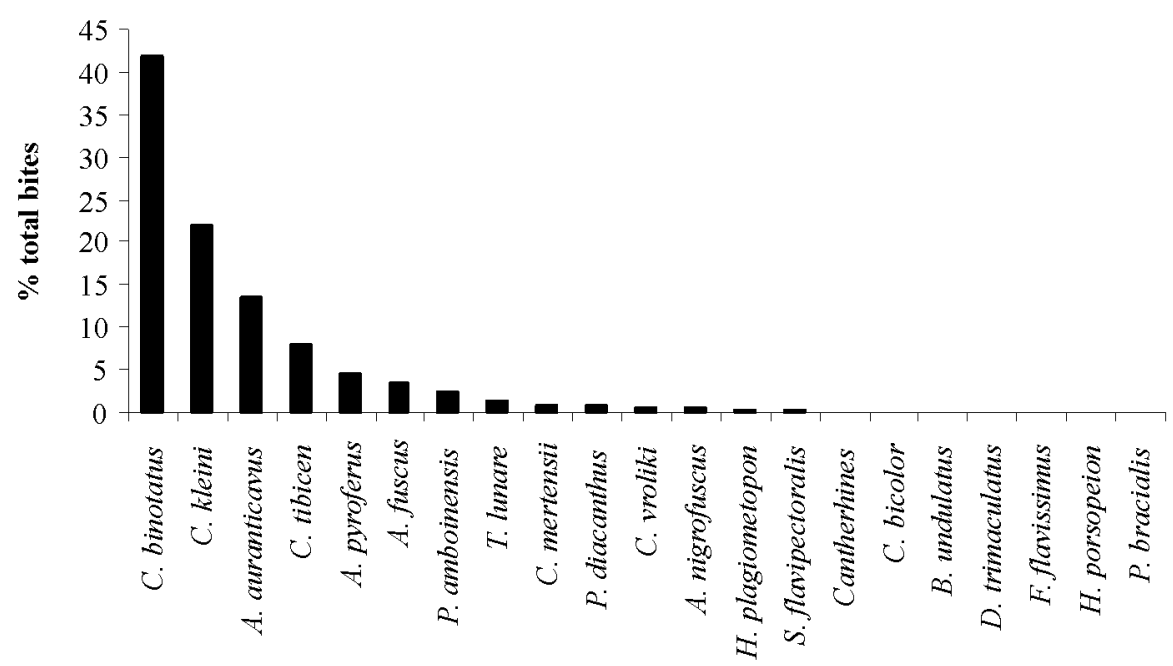

Species

Figure 5.4 Percentage of total bites taken by each species.

Table 5.3 Results of the PERMANOVA to test whether bite rates differed between sites.

\begin{tabular}{llll}
\hline Factor & $\mathrm{df}$ & Pseudo-F & $\mathrm{P}$ \\
\hline Site & 1 & 0.03887 & 0.8666 \\
Sponge (nested within site) & 18 & 1.294 & 0.1982 \\
\hline
\end{tabular}


Chapter 5

\subsubsection{Amount of sponge material consumed by fish}

Mean bite volume $(\mathrm{n}=29)$ was $0.035 \mathrm{~cm}^{3}( \pm 0.033 \mathrm{SD})$. The smallest bite size measured was $0.0035 \mathrm{~cm}^{3}$, while the largest was $0.122 \mathrm{~cm}^{3}$. Most bites were in the smallest size class $0.003-0.023 \mathrm{~cm}^{3}$ (see Figure 5.5).

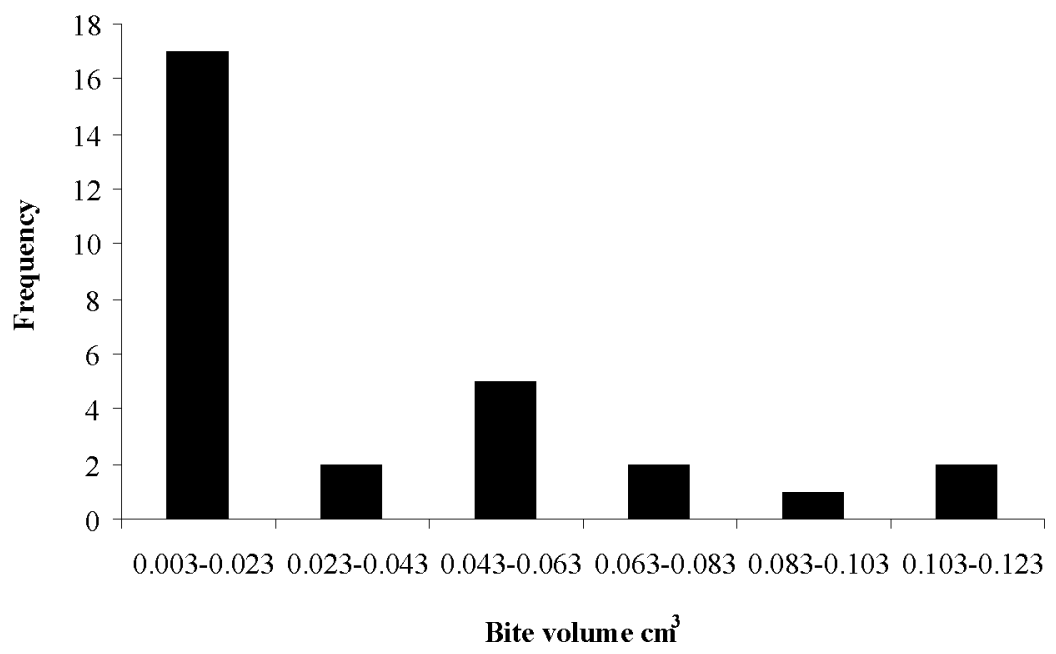

Figure 5.5 Histogram of the volume of the 29 bites measured.

\subsubsection{Barrel sponge regeneration rates}

The summed Akaike weights of the models investigated for regeneration rates are summarised in Table 5.5. The model that best explained barrel sponge regeneration rates was a log link model with main effects of 'hole' and 'time'. This meant that there was an 'overall' regeneration rate for each sponge rather than different rates for each hole, but that each hole had a different starting volume. 
Chapter 5

Table 5.4 Comparison of the summed Akaike weights for the regeneration rate models tested.

\begin{tabular}{ll}
\hline Model & $\begin{array}{l}\text { Standardised Summed } \\
\text { Akaike weights }\end{array}$ \\
\hline Linear (Main effect: Time) & 0.08 \\
Log (Main effect: Time) & 0.11 \\
Linear (Main effects: Hole,Time) & 0.17 \\
Log (Main effects: Hole,Time) & 0.35 \\
Linear (Main effects: Hole, Time, & \\
Hole*Time) & 0.04 \\
Log (Main effects: Hole, Time, Hole*Time) & 0.25 \\
\hline
\end{tabular}

All of the sponges, with the exception of sponge 8 , regenerated over the 20 day period (Figure 5.6). Typical regeneration of one of the artificial wounds is shown in Figure 5.7 .

The depth of the holes in sponge 8 increased, possibly due to fish predation, so the rate obtained for this sponge was omitted when comparing regeneration rates between sponges and sites. In addition, one of the holes in sponge number 4 also increased in volume from day 0 to day 2 so the data from this hole was not included when calculating the regeneration rate of sponge 4 . The mean regeneration rate was -0.1 day ${ }^{-1}$ (equivalent to a $9.5 \%$ decrease in wound volume per day, independent of initial wound volume) and ranged between -0.16 day $^{-1}(14.7 \%$ decrease in wound volume per day - sponge 4$)$ and -0.04 day $^{-1}$ (4\% decrease in wound volume per day - sponge 7). 


\section{Site 1}

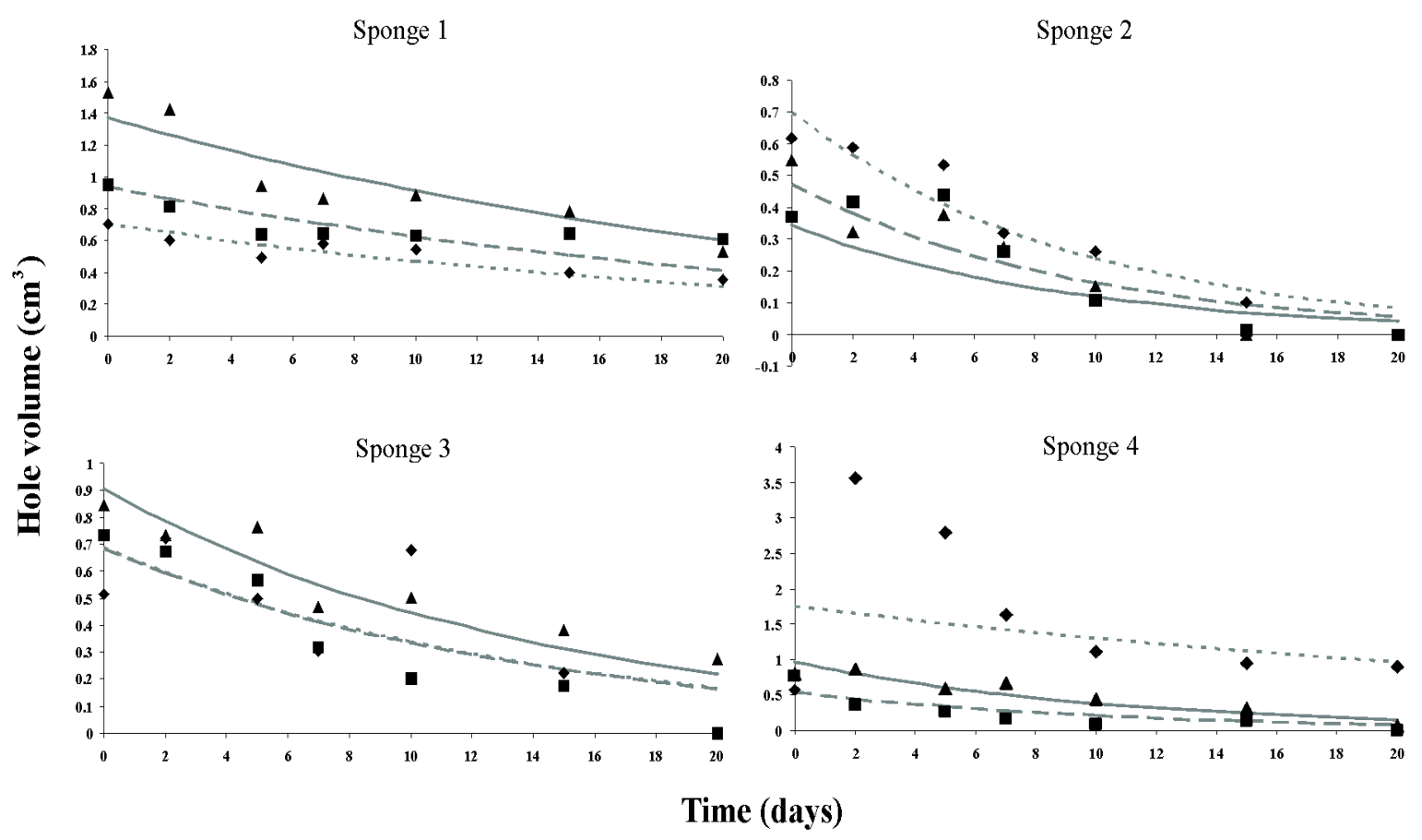

Hole 1 . " . . .

Hole 2 - $-=--$ Hole 3 ^

Site 2
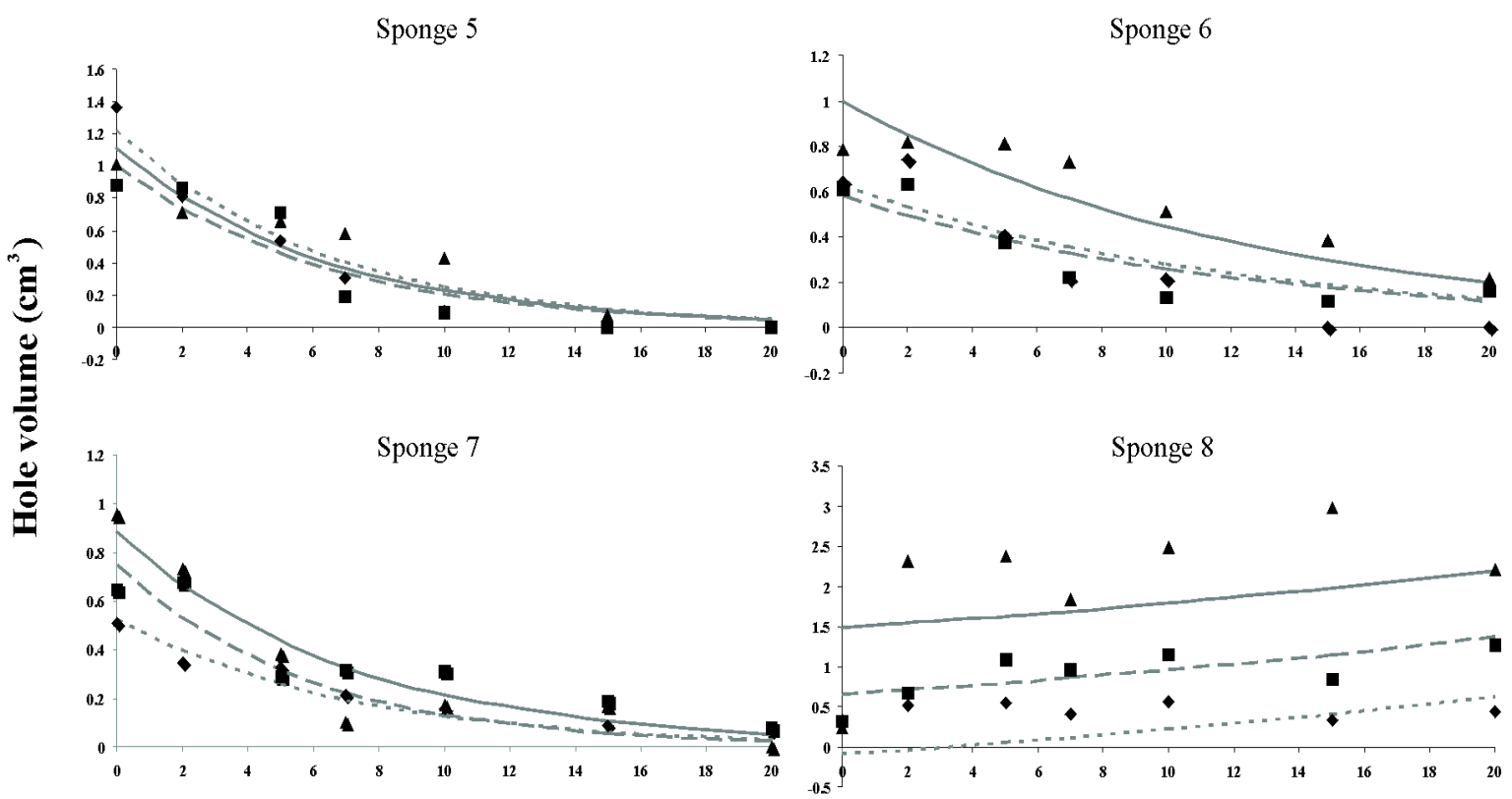

Time (days)

Figure 5.6 Graphs showing the regeneration of the three holes in each sponge. Points represent volume readings taken at each survey. Lines represent the regeneration rate based on a $\log$ relationship estimated from the regression analyses. 
a.

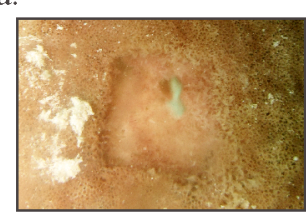

e.

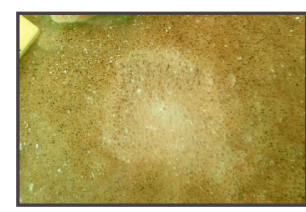

b.

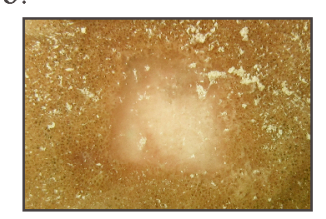

f.

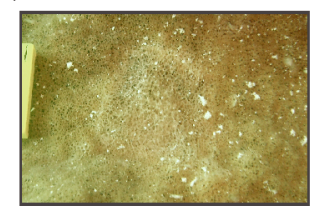

c.

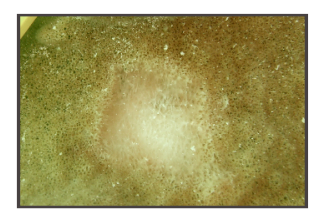

g.

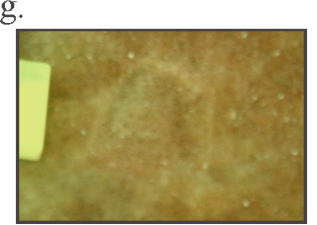

d.

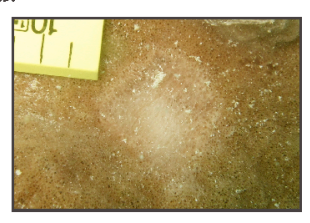

Figure 5.7 Photographs showing the regeneration progression for hole number 1 of Sponge 5: a) day 0, b) day 2, c) day 5 , d) day 7, e) day 10, f) day 15, g) day 20 .

\subsubsection{Regression analysis to determine factors associated with fish predation levels on barrel sponges}

Overall the amount of variation that was explained by the best models for the total number of bites per sponge and number of feeding events per sponge was low. The best model of the total number of bites on barrel sponges contained one variable, the Habitat Assessment Score (HAS), which explained 7\% of the observed variation. The best model of the number of feeding events on barrels sponges also had only one variable, barrel sponge volume, which explained $5 \%$ of the observed variation.

\subsubsection{Modelling fish predation on $X$. testudinaria}

The results from 100 simulations showed that on average $66 \mathrm{~cm}^{3}$ or $0.46 \%$ of the total volume of the sponge was removed from the model barrel sponge over a $24 \mathrm{hr}$ period by the simulated fish predation rates.

\subsection{Discussion}

Understanding the factors that affect the distribution, abundance and survival of functionally important species such as Xestospongia testudinaria is essential in order to predict the impacts of the many threats to coral reefs on reef ecosystem function. 


\section{Chapter 5}

This is the first study to examine the extent and impacts of fish predation on the IndoPacific barrel sponge. Over 22 hours of video footage was recorded and 5020 bites on $X$. testudinaria taken by reef fish in 9 different families were observed. Of these, 2019 bites were taken by species that removed sponge tissue including species of angelfish, butterflyfish, triggerfish, filefish and parrotfish. By modelling predation on a 14,250 $\mathrm{cm}^{3}$ virtual barrel sponge it was calculated that over a 24 hour period fish predation removed on average $66 \mathrm{~cm}^{3}$ of sponge tissue $(0.46 \%$ of total sponge volume). These results show that Indo-Pacific barrel sponges currently have to invest energy into regenerating damage caused by partial predation in order to maintain or increase their current size. Understanding the extent and impact of predation on barrel sponges is particularly important in the light of current anthropogenic impacts on reefs. Notably, fishing has the potential to affect predation intensity on barrel sponges and subsequently barrel sponge health and resilience to other threats such as disease.

\subsubsection{Barrel sponge densities}

The barrel sponge densities recorded in the WMNP are similar to giant barrel sponge densities recorded in previous studies from the Great Barrier Reef and the Caribbean (Table 5.5).

Table 5.5 Reported densities for Xestospongia muta and Xestospongia testudinaria.

\begin{tabular}{llcccl}
\hline Location & Species & $\begin{array}{c}\text { Area surveyed } \\
\mathbf{m}^{2}\end{array}$ & Depth $\mathbf{~ m}$ & $\begin{array}{c}\text { Barrel sponge density } \\
\mathbf{p ~ m}^{2}\end{array}$ & Source \\
\hline WMNP, SE Sulawesi, Indonesia & Xestospongia testudinaria & 900 & $7-13$ & $0.053 \pm 0.031$ & Present study \\
Orpheus Island, Australia & Xestospongia testudinaria & 50 & $4-10$ & $0.24 \pm 0.05$ & Fromont \& Begquist 1994 \\
& & & & & \\
Conch reef, Florida Keys, USA & Xestospongia muta & 603 & 15 & $0.17 \pm 0.045$ & McMurray et al. 2010 \\
Pickles reef, Florida Keys, USA & Xestospongia muta & 603 & 15 & $0.254 \pm 0.017$ & McMurray et al. 2010 \\
Conch reef, Florida Keys, USA & Xestospongia muta & 600 & 15 & 0.2 & Southwell et al. 2008 \\
Upper Florida Keys, USA & Xestospongia muta & 1848 & & $0.023 \pm 0.011$ & Bertin \& Callahan 2008 \\
Middle Florida Keys, USA & Xestospongia muta & 1914 & & $0.051 \pm 0.015$ & Bertin \& Callahan 2009 \\
Lower Florida Keys, USA & Xestospongia muta & 3036 & & $0.046 \pm 0.012$ & Bertin \& Callahan 2010 \\
Curacao & Xestospongia muta & 330 & $5-20$ & 0.009 & Aerts 1998 \\
Colombia & Xestospongia muta & 450 & $5-20$ & 0.17 & Aerts 1998 \\
\hline
\end{tabular}




\subsubsection{Barrel sponge predators}

From the video analysis fish species from five different families were identified as taking bites of $X$. testudinaria. The fish that took the greatest number of bites was a butterflyfish, Cheatodon kleini. Butterflyfish are one of the best studied coral reef fish families and are among the few taxa that are specialised to feed on corals (Reese 1981; Cox 1994; Prachett 2007). Most species of butterflyfish feed primarily on hard coral but there are also generalist species, which feed on a wide range of food items including, algae, hydrozoans, sponges, polychaetes and crustaceans (Nagelkerken et al. 2009). In this study, C. kleini took 1099 bites from barrel sponges during the 22 hours of filming. Nagelkerken et al. (2009) studied the dietary composition of 21 species of butterflyfish on a fringing reef in Kalimantan and also found that C. kleini fed on sponges, accounting for $8 \%$ of its gut contents. Two other butterflyfish species in this study $C$. mertensii and F. flavissimus were also observed feeding on barrel sponges but to a much lesser extent than C. kleini as they took 45 and 1 bites, respectively.

Angelfish have been recorded feeding on sponges in both the Caribbean and the Pacific (Randall \& Hartmann 1968; Hourigan et al. 1989; Padilla Verdin et al. 2010). They are thought to be one of the most recently evolved groups of reef fish and the majority exhibit a 'grab and tear' mode of feeding, with morphological features that enable their jaws to project forwards, close firmly around a food item and then retract, rapidly tearing the food item loose (Konow \& Bellwood 2011). This method of feeding enables angelfish to feed on tough food such as sponges or tunicates (Konow $\&$ Bellwood 2005). Four species of angelfish were observed taking bites from barrel sponges during this study: Pygoplites diacanthus, Centropyge bicolor, Centropyge tibicen and Centropyge vroliki. Pygoplites diacanthus took 35 bites of $X$. testudinaria and was the largest angelfish observed feeding on the barrel sponges. This species has been classified in previous studies as an omnivore that feeds on attached invertebrates including sponges (Masuda \& Allen 1993). C. bicolor, C. tibicen and C. vroliki belong to a group of angelfish referred to as pygmy angelfish. In the present study it was observed that $C$. bicolor took only 3 bites of barrel sponge during 22 hours of filming. This result supports the conclusions of previous studies that sponge does not make up a significant part of the diet of this species (Steene 1978; Masuda \& Allen 1993). C. vroliki was observed taking 26 bites of barrel sponges in the 22 hours of 


\section{Chapter 5}

footage. This supports the findings of Eagle \& Jones (2004), that this species does eat sponge, however, the low number of bites suggests that barrel sponges do not make up a large part of the diet of $C$. vroliki. The final species $C$. tibicen was observed taking 402 bites, which is surprising given that this species has not previously been reported as a potential spongivore.

Bites by triggerfish, filefish and parrotfish only accounted for a small proportion of total recorded bites $(<1 \%)$ in this study. This is in contrast with the Caribbean where parrotfish were the only fish observed feeding on Xestospongia muta by Dunlap \& Pawlik (1998). The only parrotfish observed feeding on $X$. testudinaria in this study was a juvenile Scarus flavipectoralis (yellowfin parrotfish) that took eight bites of one of the sponges during filming. Adult $S$. flavipectoralis feed mainly on algae by scraping algae from the substrate (Bellwood \& Choat 1990). The feeding habits of juvenile parrotfish have been less well studied but the results of this study suggest that sponges might be a food for juvenile $S$. flavipectoralis. One possible explanation for why parrotfish were observed feeding on sponges to a greater extent in the Caribbean than in the WMNP is that all the sponges filmed in the present study were healthy whereas in the Caribbean bleached sponges were also filmed and these individuals were fed on to a much greater extent than un-bleached sponges (Dunlap \& Pawlik 1998)

\subsubsection{Factors that influenced feeding on $X$. testudinaria}

It was not clear from my results which factors affected predation intensity on individual barrel sponges. Neither depth or local abundance of piscivores were associated with the number of bites or feeding events. Habitat Assessment Score (HAS) was the only factor associated with differences in the number of bites on individual sponges. Habitat complexity as measured by HAS explained $7 \%$ of the observed variation in the number of bites on sponges with greater number of bites being taken on sponges in areas with higher habitat complexity. Increased habitat complexity has been associated with increased local fish abundance and diversity so the relationship between HAS and fish bites could be due to higher local abundance of spongivores around sponges with higher HAS scores. Barrel sponge volume was associated with the number of feeding events on sponges explaining $5 \%$ of the variation in the number of feeding events between sponges. Larger sponges are likely 


\section{Chapter 5}

to be more visible to fish and thus make them more likely targets for feeding. However, despite finding that habitat complexity and barrel sponge volume are associated with differences in spongivory, there is still a large amount of unexplained variation. One factor that wasn't investigated in this study is the possibility that there are differences in the chemical defences of individual barrel sponges. The Caribbean giant barrel sponge Xestospongia muta yields chemical extracts that can reduce the photosynthetic potential of the zooxanthellae of hard corals and deter feeding by fish (Pawlik et al. 2007) but high levels of intraspecific variability in these traits have been observed (Pawlik et al. 1995). If the defenses of $X$. testudinaria are similarly variable it could explain why some individuals were fed on more than others.

\subsubsection{Barrel sponge regeneration}

Barrel sponges were able to rapidly regenerate simulated fish predation damage. Barrel sponge regeneration rates were found to be exponential with a mean rate equivalent to a reduction in wound volume of $9.5 \%$ per day, irrespective of wound volume. The amount of material regenerated was greatest during the first few days and nearly all of the experimental wounds were healed after 20 days. The evidence from the video observations that a number of reef fish feed regularly on $X$. testudinaria indicate that this rapid regeneration may have evolved as a mechanism to cope with partial predation. It is difficult to make direct comparisons between the rates quantified here to the results of other studies because of differences in methodology. However, these results are in agreement with previous findings that sponges are able to regenerate rapidly from damage. Ayling (1983) observed the regeneration of 11 encrusting sponge species in New Zealand and recorded regeneration rates 22 to 2900 times faster than natural growth rates. Rapid regeneration has also been recorded for the massive sponge Cliona celata in Ireland (Bell 2002). There is additional evidence that barrel sponges are able to regenerate rapidly following damage. Gilliam et al. (2009) studied the recovery of 180 Xestospongia muta individuals that were accidentally damaged during a dredging operation. These sponges showed a great capacity for recovery with $93 \%$ showing signs of recovery within a few months. Walters and Pawlik (2005) measured the regeneration of smaller wounds in $X$. muta, which were designed to reflect predation damage. They made $2 \mathrm{~cm}^{2}$ holes in each sponge and measured regeneration over 12 days. Two-dimensional regeneration was measured in terms of the area regrown per 


\section{Chapter 5}

day. Regeneration rates varied between $0 \%$ and $8 \%$ per day with a mean of $6 \%$ per day for $X$. muta, which strongly agrees with the results presented in this study.

Despite being geographically separated for 3,000,000 years (Montalvo \& Hill 2011) it seems that $X$. muta and $X$. testudinaria both currently exhibit the ability to regenerate rapidly from partial predation, with markedly similar regeneration rates. This capacity may be one of the factors that has allowed them to survive, and for some individuals to be potentially the longest lived species on reefs (McMurray et al. 2008), despite predation by their respective spongivores in the Caribbean and the Indo-Pacific.

\subsubsection{Modelling predation and regeneration}

The observations of fish feeding on barrel sponges showed that fish predators are constantly removing tissue from barrel sponges. By monitoring levels of predation and measuring regeneration in X. testudinaria a theoretical model of barrel sponge predation and recovery was constructed. Using the model it was found that over a 24 hour period the sponge lost $0.46 \%$ of its total volume through predation. The rapid regeneration capacities of barrel sponges enables them to survive this partial predation, however, constant regeneration is likely to be energetically costly. The allocation of resources to regeneration could reduce the availability of resources for other processes such as growth, reproduction, spatial competition or predator defense (Henry \& Hart 2005). If predation intensity increases in the future then barrel sponge health could be reduced if these processes are adversely affected. Chronic predation by parrotfish on hard corals has been shown to reduce coral fitness and their capacity to recover after bleaching events (Rotjan et al. 2006; Rotjan \& Lewis 2009). In addition, sponges would be unlikely to survive if the amount of material removed by predation frequently exceeded the amount of tissue that can be regenerated by a sponge. On the other hand if fishing reduces spongivore populations then barrel sponges could benefit as predation is reduced.

One of the limitations of this study was that it was difficult to determine how much sponge material was removed by different fish species. On one occasion I directly observed a Moorish Idol (Zanclus cornutus) taking bites of a barrel sponge and measured the depth and size of bites that it took. If more time had been available I would have carried out more in-situ observations of the species recorded taking bites of barrel sponge in the videos to determine their bite sizes. Alternatively, observations 


\section{Chapter 5}

of fish feeding in aquaria might be a more efficient way to obtain this information. In the current barrel sponge regeneration model bite sizes were parameterised by bite sizes that were visible on the surfaces of sponges. This could have biased the assessment of the amount of material removed per bite as only clearly visible bites were recorded.

To conclude, this is the first study to examine fish predation on $X$. testudinaria. Fish species in a number of families appear to feed on barrel sponges. Some of the fish that appeared to take the greatest number of bites did not appear to be removing sponge tissue (surgeonfish). The fish that took the greatest numbers of bites that appeared to be removing tissue were the butterflyfish $C$. kleini and the angelfishes, $C$. tibicen, $C$. vroliki and P. pygoplites. This was also the first study to examine regeneration of small wounds in $X$. testudinaria. Regeneration rates of $X$. testudinaria were rapid and exponential with larger regeneration at earlier wound stages than later. This capacity to regenerate may have evolved as a mechanism for $X$. testudinaria to survive regular partial predation. This research indicates that fishing could impact barrel sponge health by affecting spongivore abundance on reefs and thus predation intensity on barrel sponges. 


\section{General discussion}

The primary aim of my thesis was to examine the role of spongivory in Indo-Pacific coral reef ecosystems. A range of observational and experimental studies were used to identify spongivores, examine the effect of predation on sponge abundance and distribution patterns, and also to investigate potential impacts of sub-lethal predation on sponges. In summary the main findings were: i) fish were the most important group of spongivores in terms of abundance ii) fish predation does not appear to have a strong influence on total sponge abundance or assemblage composition on reef slope sponge assemblages; and iii) Xestospongia testudinaria is exposed to chronic partial predation on Indo-Pacific reefs. Here I discuss my findings with respect to several key questions currently facing sponge ecologists and discuss the implications of this research for coral reef management.

\subsection{Which factors control the distribution and abundance of Indo-Pacific sponges?}

Understanding the factors that control species distributions has long been at the heart of the discipline of ecology. At a time when few ecosystems remain untouched by human activities the need to identify how current changes will affect functionally important species is particularly important. Sponge distribution patterns are known to be associated with a number of abiotic and biotic factors. However, understanding the relative importance of these factors will be crucial to predicting which of the multiple threats currently affecting reef systems have the greatest potential to affect sponge assemblages. Here I place my findings in the wider context of previous research on the ecology of sponges in the Caribbean and the Indo-Pacific and highlight my contributions to sponge ecology and identify important areas for future research.

\subsubsection{Biological factors - Predation}

To date, the vast majority of research into the effects of predation in determining the distribution and abundance of sponges on coral reefs has been carried out in the Caribbean (Randall \& Hartmann 1968; Chanas \& Pawlik 1995; Pawlik et al. 1995; Wulff 2006b). Sponge predators identified from the Caribbean include nudibranchs, starfish, sea turtles and a number of fish species (Randall \& Hartmann 1968; Meylan 1988; Wulff 2006a). In chapter 2 of this thesis I was able to add to our knowledge of 


\section{Chapter 6}

Indo-Pacific spongivores by identifying nudibranch and fish species in a number of families that preferentially fed on sponges. Understanding the impacts of fish predation on sponge distribution and abundance patterns is particularly important given the potential cascading effects of fishing on marine benthic assemblages (Scheffer et al. 2005; Mumby et al. 2006). In the Caribbean there is experimental evidence that fish predation can influence the abundance and distribution of a number of reef sponges (Pawlik 1998; Dunlap \& Pawlik 1996). In the present thesis I used a observational approach in conjunction with an exclusion experiment to determine whether fish predation could influence the distribution and abundance of sponges in the Indo-Pacific. By examining the associations between sponges and a number of environmental and biological 'predictor' variables (chapter 3), I was able to determine how much variation was attributable to variation in spongivore abundance relative to other factors. Spongivore abundance was not associated with total sponge abundance or the abundance of Lamellodysidea herbacea, the most abundant sponge species across my sampling sites. Spongivore abundance, however, was weakly associated with sponge assemblage composition, but the small percentage of variability explained suggested that predation effects were likely to be weak. In addition to adding to our understanding of the role of predation on sponges, this approach also highlighted other factors likely to be influencing sponge assemblages in the WMNP.

While observational approaches can identify possible drivers of variability in sponge assemblages they are based on analyses of correlations between species distributions and predictor variables and thus do not provide evidence of a causal relationship. In my thesis, a caging experiment (chapter 4) provided additional support for the conclusion that fish predation is unlikely to provide strong top-down control on reef sponge populations. Short-term predator exclusion had no effect on total sponge abundance or assemblage composition. The exclusion experiment also revealed that sponge abundance increased in all treatments at both study sites over the course of the experiment, illustrating the temporal variability in reef wall sponge assemblages. The combined results of chapters 3 and 4 provide strong evidence that fish predation is unlikely to have a major influence on the distribution and abundance of sponges on reef slopes in SE Sulawesi and highlight the strength of adopting observational and experimental approaches. 


\subsubsection{Biological factors - Spatial competition}

Another biological factor that has the potential to affect sponge distributions is spatial competition (Suchanek et al. 1983; de Voogd et al. 2004; Gonzalez-Rivero et al. 2011). In Chapter 3 total sponge abundance was found to be associated with hard coral cover. Interestingly, neither algal cover nor soft coral abundance was associated with sponge abundance or assemblage composition. This indicates that, contrary to what might be expected, sponge populations in the Wakatobi do not seem to be affected by spatial competition with these taxa. It also seems unlikely that spatial competition with hard corals drives variation in sponge abundance because hard coral cover was weakly positively associated with total sponge abundance. The environmental conditions that favor high coral abundance at some sites also appears to favor high sponge abundance and diversity. Another explanation for this relationship is that the increased habitat complexity at high coral cover sites provides a greater number of microhabitats for sponges to occupy such as the undersides and bases of corals (Buss \& Jackson 1979; Loh \& Pawlik 2012). To truly understand the nature of spatial competition, however, would require time series observations of competitive interactions between these groups with regard to the rate, mechanisms and outcomes of interactions. As this may vary between areas with different physical stresses, this should be an area of future research in the Wakatobi, and also in the wider Indo-Pacific region, to better understand how the nature of these interactions may change in the future and how they may influence the wider reef ecosystem.

\subsubsection{The role of abiotic factors}

Of the abiotic factors that I examined, sedimentation was most strongly associated with variability in total sponge abundance, sponge assemblage composition and particularly the abundance of Lamellodysidea herbacea. Sedimentation is known to have profound impacts on many reef benthic invertebrates (Rogers 1990) and my results suggest that future experimental work should be carried out to confirm whether sedimentation is causing or simply correlated with the variation that was observed in sponge abundances and assemblage composition. Important areas for investigation include: exploring possible interactions between sedimentation and other variables such as light intensity, flow rate and substrate angle; measuring sediment characteristics (e.g. particle size distribution, ratio of organic to inorganic 


\section{Chapter 6}

content) that can influence the effects of sediment on reef organisms (Fabricius 2005) and the effects of possible seasonal changes in sediment deposition rates (Carballo et al. 2008). Another abiotic factor that was correlated both with total sponge abundance and assemblage composition was cholorophyll- $a$. Increased food availability has been associated with higher sponge growth rates at greater depths on Caribbean reefs (Trussell et al. 2006; Lesser 2006). My results suggest that food availability could also influence local sponge abundance and diversity. Further work assessing differences in food availability between areas and how different food types are utilized by different species (Perea-Blázquez et al. 2010, 2012) may further explain some of the observed variation in sponge abundance and assemblage composition in this reef system.

\subsection{What are the implications of partial predation on reef sponges?}

While spongivory may be less important than abiotic factors such as sedimentation in determining sponge distributions and abundance, my study showed that some reef sponges are exposed to regular partial predation. Partial predation can be considered analogous to herbivory because its effects are generally sub-lethal (Rotjan \& Lewis 2008; Jaywardene et al. 2009). The impacts of herbivory on plant biomass and fitness have been the subject of much research (Strauss \& Agrawal 1999; Skarpe \& Hester 2008; Mutikainen \& Delph 1996; Belsky 2012) but the effects of partial predation on benthic marine invertebrates are much less well studied. A few studies have examined the physiological effects of corallivory on hard corals. For example, Rotjan \& Lewis (2009) showed that partial predation on corals by parrotfish could reduce coral fitness, as predators selectively fed on coral reproductive structures. Another study also showed that parrotfish predation could adversely affect coral recovery after a bleaching event (Rotjan et al. 2006).

One of the potential negative impacts of partial predation on sponges is the reallocation of resources from processes such as growth and reproduction to regenerating damaged tissues and increasing defenses (Henry \& Hart 2005; Wulff 2010). Like plants, many sponges have evolved numerous mechanisms to cope with predation (Pawlik et al. 1995; Bercerro et al. 2003; Hill et al. 2005; Jones et al. 2005; Peters et al. 2009). Some species have structural and chemical defences including spicules (Jones et al. 2005), tough tissues (Chanas \& Pawlik 1995), and unpalatable or 


\section{Chapter 6}

toxic secondary metabolites (Pawlik et al. 1995) that deter predators. Other characteristics such as rapid regeneration can limit the negative impacts of predation on sponges by preventing fouling of exposed skeletal elements and allowing sponges to regain shapes and sizes optimal for feeding (Bell 2002). My measurements of regeneration in Xestospongia testudinaria (Chapter 5) indicate that like Xestospongia muta, this species is able regenerate rapidly from damage. Although the ability to regenerate efficiently is a valuable attribute for a species like $X$. testudinaria, which is exposed to predation, it is also likely to come at a cost. Processes such as growth, reproduction and defence all require energy and the redirection of resources to regeneration after damage could potentially limit other life history processes (Henry \& Hart 2005). In plants, the term 'tolerance' is used to describe the degree to which plant fitness is affected by herbivore damage (Strauss \& Agrawal 1999). Individual plant species differ substantially in their ability to survive and reproduce following herbivory (Marquis 1984; Lehtila \& Strauss 1999). Determining the tolerance of sponges such as $X$. testudinaria will be important if we are to predict the impacts of changing predation levels on these species.

Another potential negative effect of partial predation on Xestospongia testudinaria is that it could potentially affect the ability of sponges to recover from other stressors such as disease or bleaching. Sponge bleaching and subsequent mortality has been recorded throughout the Caribbean since the 1990s (Vicente 1990). Cyclical and fatal bleaching affects giant barrel sponges in the Florida Keys National Marine Sanctuary. Fatal bleaching has been associated with a pathogenic-like condition referred to as 'sponge orange band' (SOB) disease (Cowart et al. 2006). Dunlap and Pawlik (1998) filmed 40 Xestospongia muta individuals and recorded a much greater number of parrotfish bites (527) on bleached sponges than on normally coloured sponges (45). The authors proposed that bleached specimens were fed on more because they were less well chemically defended than non-bleached specimens due to the lack of cyanobacterial symbionts. Not all sponge bleaching is fatal but increased fish predation on bleached sponges is likely to be detrimental to the recovery process. If prevalence of sponge bleaching increases in the future, due to increased water temperatures or disease, then fish predation could exacerbate its effects leading to increased sponge mortality. 
Chapter 6

\subsection{What are the likely effects of reef ecosystem degradation on sponge assemblages?}

One of the aims of this research was to contribute to our understanding of how the current multiple threats to coral reefs would affect sponge assemblages. The finding that sponge diversity and abundance were associated with a number of factors that can potentially be affected by reef degradation has important implications for reef conservation.

\subsubsection{The role of sedimentation}

Increased sedimentation is one of the changes most commonly associated with reef degradation (Fabricius 2005). My findings suggest that increasing sedimentation caused by activities such as deforestation, coastal development, poor agricultural land management, dredging and mining activities could have a profound effect on IndoPacific reef assemblages. Benthic assemblages at degraded, highly sedimented, sites were characterised by sponges rather than any other benthic group (e.g. hard corals or algae). If sedimentation levels on Indo-Pacific reefs increase due to ongoing anthropogenic activities and the projected changes to the marine environment as a result of future climate change are proven true, a similar shift might be expected to occur in other areas. Indonesia is projected to be one of the countries most affected by future sea level rise (Mcleod et al. 2010). This could result in increased coastal flooding and coastal erosion both of which would increase sedimentation on Indonesian coral reefs. It is interesting to note that benthic assemblages at degraded sites in the Wakatobi were dominated by sponges rather than by algae which dominates many degraded reefs in the Caribbean, (Hughes 1994, Rogers \& Miller 2006), Australia (Hatcher 1984) and the eastern Pacific (Hunter \& Evans 1995). One explanation for this is that despite fishing, populations of herbivorous fish in the WMNP are sufficiently high that they limit the growth of macroalgae through grazing. Another possible explanation is that nutrient limitation is preventing the proliferation of algae. Identifying the relative importance of these factors could help to predict whether similar sponge dominated reef ecosystems are likely to become more common in other areas of the Indo-Pacific. 


\subsubsection{Interactions between potential stressors}

The large number of variables associated with differences in sponge assemblages and the weak nature of these associations mean that predicting the impacts of changes in these parameters on sponges will be challenging. While changes in individual variables (e.g. spongivorous fish abundance, hard coral cover or chlorophyll- $a$ ) may have limited effects on sponge distributions or abundance, simultaneous changes in other parameters could have additive, antagonistic or even synergistic effects. For instance, the effects of sedimentation on sponge assemblages could potentially be greater if ambient water flow is reduced. Research on corals has revealed that interactions between stressors such as overfishing and nutrient enrichment have contributed to phase-shifts from coral-dominated to algal dominated reef systems in the Caribbean (Hughes 1994; Scheffer et al. 2001; Pandolfi et al. 2005). Thus, future research should aim to understand how interactions between these factors affect overall sponge abundance and sponge assemblage composition.

\subsubsection{Loss of functional roles}

The low diversity of sponge assemblages at degraded sites has potential implications for sponge functional diversity. Sponges perform a diverse range of functions on coral reefs including facilitating primary production, nutrient cycling, silification, erosion and consolidation of the reef matrix, habitat complexity, bentho-pelagic coupling and the provision of food and microhabitats for other species (Bell 2008). The loss of sponge species at degraded sites could potentially lead to a shift in the functional roles carried out by sponges at these sites or, in extreme cases, the loss of some of these roles. In the present study, the abundance of the encrusting species Lamellodysidea herbacea at degraded sites could lead to a reduction in the overall contribution of sponges to reef habitat complexity, as it coats the underlying reef framework, rather than creating new habitats that would be created by sponges that exhibit more three dimensional growth forms. Another change that might be expected to occur at degraded sites is a reduction in sponge-driven primary production. As a consequence of higher turbidity at degraded sites, the availability and intensity of light may be reduced, leading to a decline in the number of sponges with photosynthetic symbionts. This is likely to decrease the levels of primary production and also may lead to a shift in sponge assemblages that are dominated by heterotrophic, rather than 
Chapter 6

phototrophic sponges. Thus areas of reef may become net energy sinks, rather than sources, leading to a reduction in energy available at higher trophic levels. 

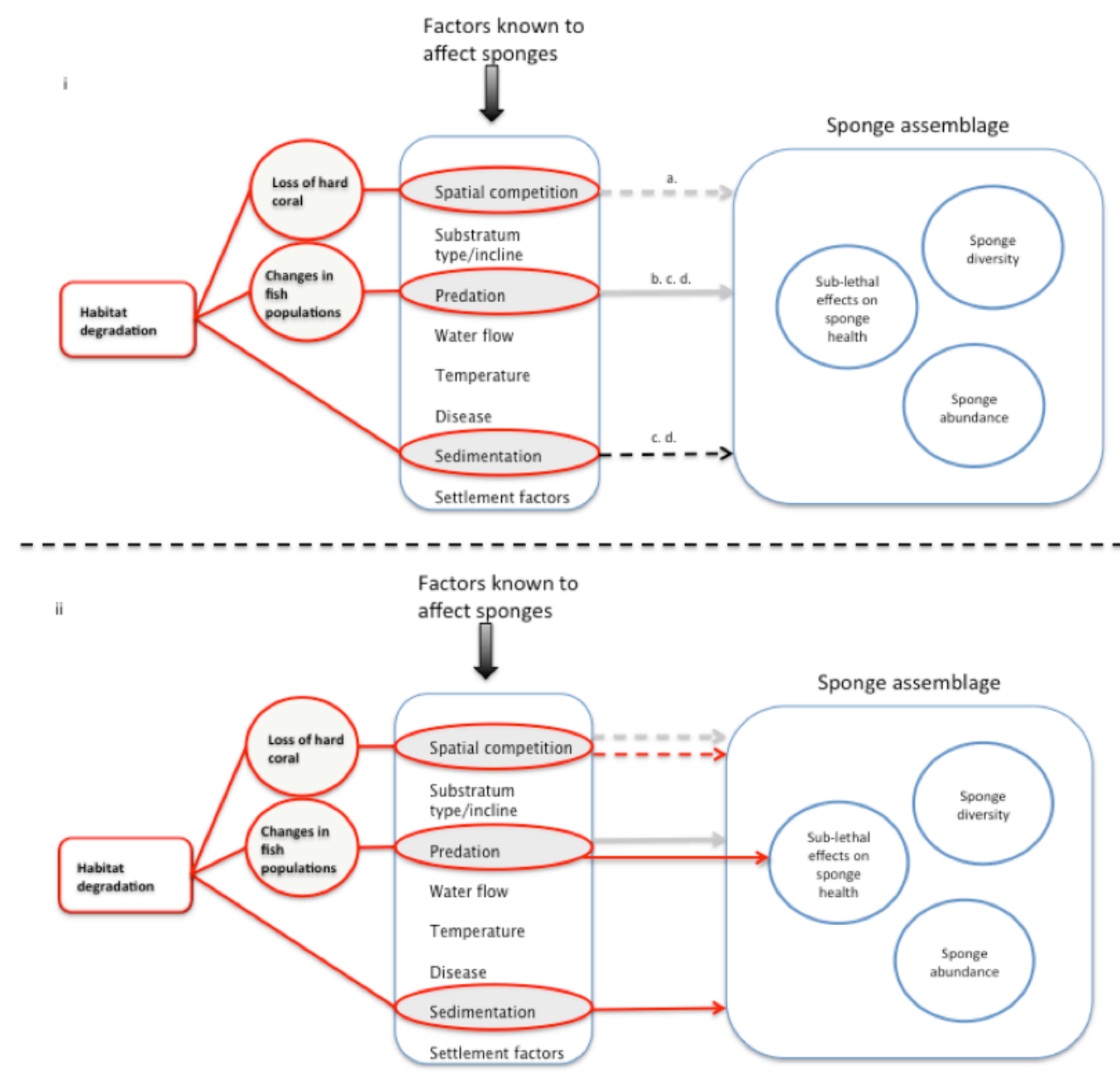

Figure 6.1 Schematic illustrating my contribution to our understanding of Indo-Pacific sponge ecology in terms of the effects of biological and physical factors on sponge assemblages. The top half of the diagram represents what was already known prior to my research. The magnitude of effects is given by the type of arrow, with dashed arrows indicating weak or marginal effects, and full arrows represent stronger structural effects. Grey lines represent what is known from Caribbean reefs and black lines from the Indo-Pacific. Lower case letters refer to the sources of information used a) Aerts \& Soest 1997 b) Pawlik 1998 c) Dunlap \& Pawlik 1996 d) Wulff 2000 e) Bell \& Smith 2004 f) Cleary et al. 2007. In the bottom diagram the red lines represent the findings from this thesis.

\subsection{How can the findings of this thesis inform coral reef management?}

\subsubsection{Managing sedimentation on reefs}




\section{Chapter 6}

This work adds to a significant body of research showing that reef benthic assemblages are associated with differences in sedimentation regimes. Further work is required to confirm whether sedimentation has caused the reduction in sponge diversity that we observed at degraded sites. However, of all the factors examined, sedimentation appears the most likely driver of changes in sponge assemblages. There are a number of practical methods that could be adopted to reduce sedimentation on Wakatobi reefs. One of the major contributors to increased levels of sedimentation near Sampela is the clearing of mangroves for construction and firewood. One practical measure that could be introduced to reduce the impacts of deforestation is to promote the use of coppicing rather than clear cutting mangrove trees. Another activity likely to increase sedimentation at these sites is coral mining by the Bajo (inhabitants of Sampela village) for construction. Giving the Bajo access to rock quarried inland would help alleviate pressure on live corals.

\subsubsection{The need to monitor sponge assemblages}

This research found major differences in sponge distribution patterns across a gradient of habitat degradation. It appears that factors such as increasing sedimentation could result in reef ecosystems dominated by low diversity sponge assemblages. However, there is a real need for temporal data to confirm whether this is the case. Despite a growing awareness of the functional roles of sponges on coral reefs, most monitoring programs currently record them simply as 'sponges' (e.g. Reef Check, RECON, Global Coral Reef Monitoring Network, Mesoamerican Barrier Reef Systems Project Synoptic Monitoring Program). Some of the reasons for this include the lack of sponge identification guides and difficulties in identifying sponges in the field (Wulff 2001). However, by adopting this approach, major changes to sponge assemblages are likely to go undetected. In the WMNP I found that total sponge abundance did not vary consistently across a gradient of habitat degradation. Total sponge abundance was high at some degraded sites like Sampela 1 but also at high coral cover sites like Buoy 4 and Ridge 1. In contrast, species diversity was much lower at the degraded sites than at high coral cover sites. Sponge assemblage shifts from high to low species diversity could have major impacts on reef ecosystem function but would not be detected by monitoring programmes that only recorded sponge abundance. The present study identified one species in particular, Lamellodysidea herbacea, that should be considered for inclusion in future WMNP monitoring programmes. 
Chapter 6

\subsection{Concluding remarks}

To conclude, fish predation does not seem to play a major role in determining the distributions and abundance of coral reef sponges. However, extensive partial predation occurs on some species and future changes in predation intensity are likely to affect sponge fitness. My finding that sedimentation is likely to influence sponge diversity has implications for reef management given that sedimentation is one of the most common effects of habitat degradation. Sponge assemblages in the WMNP are highly variable over a relatively small spatial scale and illustrate the fact that slight changes in environmental conditions can have major impacts on benthic invertebrate assemblages. An important area for future research is to compare the functional roles played by sponges at degraded and higher quality sites. Finally, monitoring sponge assemblages along with potential drivers of sponge variability should be a priority for park managers. 
Chapter 6 


\section{References}

Abramoff MD, Magalhaes PJ, Ram SJ (2004) "Image Processing with ImageJ".

Biophotonics International, 11(7): 36-42.

Adam TC, Schmitt RJ, Holbrook SJ, Brooks AJ, Edmunds PJ, Carpenter RC,

Bernardi G (2011) Herbivory, Connectivity, and Ecosystem Resilience: Response of a Coral Reef to a Large-Scale Perturbation. PLoS ONE 6(8): 1-8.

Aerts LAM (1998) Sponge/coral interactions in Caribbean reefs: analysis of overgrowth patterns in relation to species identity and cover. Marine Ecology Progess Series, 175: 241-249.

Aerts LAM (2000) Dynamics Behind Standoff Interactions in Three Reef Sponge Species and the Coral Montastraea cavernosa. Marine Ecology, 21: 191-204.

Aerts LAM, Soest RWMV (1997) Quantification of sponge/coral interactions in a physically stressed reef community, NE Colombia. Marine Ecology Progress Series, 148: $125-134$.

Allen G, Adrim M (2003) Coral Reef Fishes of Indonesia. Zoological Studies, 42(1), $1-72$.

Allen GR (1991) Damselfishes of the world. Mergus Publishers, Melle, Germany. p 271

Allen GR (2008) Conservation hotspots of biodiversity and endemism for IndoPacific coral reef fishes. Aquatic Conservation: Marine and Freshwater Ecosystems, 18(5): 541-556.

Amesbury SS (1982) Effects of turbidity on shallow-water reef fish assemblages in Truk, Eastern Caroline Islands. In: Gomez ED, Birkeland CE, Buddemeier RW, Johannes RE, Marsh JA, Tsuda RT (eds) Proceedings of the Fourth International Coral Reef Symposium, Vol.1 Marine Science Center, University of the Philippines, Manila, Philippines, p 155-159.

Anderson MJ, Gorley RN, Clarke KR (2008) PERMANOVA+ for PRIMER: Guide to software and Statistical Methods. PRIMER-E: Plymouth, UK. 
Aronson RB, Precht WF, Toscano MA, Koltes KH (2002) The 1998 bleaching event and its aftermath on a coral reef in Belize. Marine Biology, 141(3): 435-447.

Ayling AL (1983) Growth and regeneration rates in thinly encrusting demospongiae from temperate waters. Biological Bulletin, 165: 434-352.

Bannister RJ, Brinkman R, Wolff C, Battershill C, de Nys R (2007) The distribution and abundance of dictyoceratid sponges in relation to hydrodynamic features: identifying candidates and environmental conditions for sponge aquaculture. Marine and Freshwater Research, 58(7): 625-633.

Barthel D, Gutt J, Tendal OS (1991) New information on the biology of Antarctic deep-water sponges derived from underwater photography. Marine Ecology Progess Series, 69: 303-307.

Barthel D, Wolfrath B (1989) Tissue sloughing in the sponge Halichondria panacea: a fouling organism prevents being fouled. Oecologia, 78: 357-360.

Bean K, Jones GP, Caley MJ (2002) Relationships among distribution, abundance and microhabitat specialisation in a guild of coral reef triggerfish (family Balistidae). Marine Ecology Progress Series, 233: 263-272.

Becerro MA, Thacker RW, Turon X, Uriz MJ, Paul VJ (2003) Biogeography of sponge chemical ecology: comparisons of tropical and temperate defenses. Oecologia, 135(1): 91-101.

Becerro MA, Turon X, Uriz MJ (1997) Multiple functions for secondary metabolites in encrusting marine invertebrates. Journal of chemical ecology, 23(6): 1527-1547.

Bell JJ (2002) Regeneration rates of a sublittoral demosponge. Journal of the Marine Biological Association of the UK, 82(01): 169-170.

Bell JJ (2008) The functional roles of marine sponges. Estuarine, Coastal and Shelf Science, 79(3): 341-353.

Bell JJ, Barnes DKA (2000a) A sponge diversity centre within a marine 'island'. Hydrobiologia, 440: 55-64. 
Bell JJ, Barnes DKA (2000b) The distribution and prevalence of sponges in relation to environmental gradients within a temperate sea lough: vertical cliff surfaces. Diversity and Distributions, 6(6): 283-303.

Bell JJ, Barnes DKA (2003) Effect of Disturbance on Assemblages: An Example Using Porifera. Biological Bulletin, 205: 144-159.

Bell JJ, Smith DJ (2004) Ecology of sponge assemblages (Porifera) in the Wakatobi region, south-east Sulawesi, Indonesia: richness and abundance. Journal of the Marine Biological Association of the United Kingdom, 84(3): 581-591.

Bellwood DR, Choat JH (1990) A functional analysis of grazing in parrotfishes (family Scaridae): the ecological implications. Environmental Biology of Fishes, 28 : 189-214.

Belsky AAJ (1986) Does Herbivory Benefit Plants ? A Review of the Evidence. The American Naturalist, 127(6): 870-892.

Bertin M, Callahan (2008) Distribution, abundance and volume of Xestospongia muta at selected sites in the Florida Keys National Marine Sanctuary. Proceedings of the 11th International Coral Reef Symposium, Ft. Lauderdate, Florida, 7-11 July 2008. 2:692-696.

Bjorndal KA (1996) Foraging ecology and nutrition of sea turtles. In: Lutz PL, Musick JA (eds) The Biology of Sea Turtles. CRC Press, Florida, USA, p 199-232.

Bruno JF, Selig ER (2007) Regional Decline of Coral Cover in the Indo-Pacific: Timing, Extent, and Subregional Comparisons. PLoS ONE, 2, e711.

Burke L, Reytar K, Spalding M, Perry A (2011) Reefs at Risk Revisited. World Resources Institute, Washington DC.

Burnham KP, Anderson DR (2001) Kullback-Liebler information as a basis for strong inference in ecological studies. Wildlife Research, 28: 111-119.

Buss LW, Jackson JBC (1979) Competitive networks: nontransitive competitive relationships in cryptic coral reef environments. The American Naturalist, 113(2): 223-234. 
Carballo JL, Nava H (2007) A comparison of sponge assemblage patterns in two adjacent rocky habitats (tropical Pacific Ocean, Mexico). Ecoscience, 14(1): 92-102.

Carballo JL, Vega C, Cruz-Barraza JA, Yáñez B, Nava H, Ávila E, Wilson M (2008) Short- and long-term patterns of sponge diversity on a rocky tropical coast: evidence of large-scale structuring factors. Marine Ecology, 29(2): 216-236.

Chanas B, Pawlik JR (1995) Defenses of Caribbean sponges against predatory reef fish. II. Spicules, tissue toughness, and nutritional quality. Marine Ecology Progress Series, 127: 195-211.

Chase JM, Abrams PA, Grover JP, Diehl S, Chesson P, Holt RD, Richards SA, Nisbet RM, Case TJ (2002) The interaction between predation and competition: a review and synthesis. Ecology Letters, 5(2): 302-315.

Clarke K, Chapman M, Somerfield P, Needham H (2006) Dispersion-based weighting of species counts in assemblage analyses. Marine Ecology Progress Series, 320(1): $11-27$.

Clavico EEG, Muricy G, Da Gama BAP, Batsita D, Ventura CRR, Pereira RC (2006) Ecological roles of natural products from the marine sponge Geodia corticostylifera. Marine Biology, 148: 479-488.

Cleary DFR, de Voogd NJ (2007) Environmental associations of sponges in the Spermonde Archipelago, Indonesia. Journal of the Marine Biological Association of the UK, 87(06): 1669-1676.

Clifton J, Unsworth RKF (2010) Introduction to the Wakatobi National Park. In: Clifton J, Unsworth RKF, Smith DJ (eds) Marine Conservation and Research in the Coral Triangle: The Wakatobi National Park. Nova Publishers, New York, p 1-9.

Cole AJ, Pratchett, MS, Jones GP (2008) Diversity and functional importance of coral-feeding fishes on tropical coral reefs. Fish and Fisheries, 9(3): 286-307.

Connell JH (1978) Diversity in tropical rain forests and coral reefs. Science, 199(4335): 1302-10. 
Cowart JD, Henkel TP, McMurray SE, Pawlik JR (2006) Sponge orange band (SOB): a pathogenic-like condition of the giant barrel sponge, Xestospongia muta. Coral Reefs, 25(4): 513-513.

Cox EF (1994) Resource use by corralivorous butterflyfishes (family Chaetodontidae) in Hawaii. Bulletin of Marine Science, 54(2): 535-545.

Cullen LC (2010) Marine Resource Dependence and Natural Resource Use Patterns in a Small Indo-Pacific Island Community: Implications for Management. In: Clifton J, Unsworth RKF, Smith DJ (eds) Marine Research and Conservation in the Coral Triangle: the Wakatobi Marine National Park. Nova Publishers, New York, p 171191.

Dayton P, Robilliard G, Paine R (1974) Biological accommodation in the benthic community at McMurdo Sound, Antarctica. Ecological Monographs, 44: 105-128.

De Laubenfels MW (1950) An ecological discussion of the sponges of Bermuda. The Transactions of the Zoological Society of London, 27(1): 155-201.

de Voogd N, Becking L, Cleary D (2009) Sponge community composition in the Derawan Islands, NE Kalimantan, Indonesia. Marine Ecology Progress Series, 396: 169-180.

de Voogd NJ, Becking L, Hoeksema B (2004) Sponge interactions with spatial competitors in the Spermonde Archipelago. Bolletino di Museo e Istituto di Biologia dell'Universita di Genova, 68: 253-261.

de Voogd NJ, Cleary DFR (2007) Relating species traits to environmental variables in Indonesian coral reef sponge assemblages. Marine and Freshwater Research, 58: 240249.

de Vos L, Rützler K, Boury-Esnault JV, Donadey C, Vacelet J (1991) Atlas of sponge morphology $=$ Atlas de morphologie des éponges. Smithsonian Institution Press, Washington, $117 \mathrm{pp}$.

Diaz MC, Rützler K (2001) Sponges: An essential component of Caribbean coral reefs. Bulletin of Marine Science, 69: 535-546. 
Disalvo HL, Randall JE, Cea A (2007) Stomach contents and feeding observations of some Easter Island fishes. Atoll Research Bulletin, 548: 1-23.

Duckworth AR (2003) Effect of wound size on the growth and regeneration of two temperate subtidal sponges. Journal of Experimental Marine Biology and Ecology, 287: 139-153.

Duckworth AR, Battershill CN, Bergquist PR (1997) Influence of explant procedures and environmental factors on culture success of three sponges. Aquaculture, 156: 251267.

Duckworth AR, Battershill CN, Schiel DR (2004) Effects of depth and water flow on growth, survival and bioactivity of two temperate sponges cultured in different seasons. Aquaculture, 242(1-4): 237-250.

Dunlap M, Pawlik JR (1996) Video-monitored predation by Caribbean reef fishes on an array of mangrove and reef sponges. Marine Biology, 126: 117-123.

Dunlap M, Pawlik JR (1998) Spongivory by parrotfish in Florida mangrove and reef habitats. Marine Ecology, 19(4): 325-337.

Eagle JV, Jones GP (2004) Mimicry in coral reef fishes: ecological and behavioural responses of a mimic to its model. Journal of Zoology, 264(1): 33-43.

Edinger E, Jamaluddin J, Limmon GV, Widjatmoko W, Risk MJ (1998) Reef degradation and coral biodiversity in Indonesia: Effects of land-based pollution, destructive fishing practices and changes over time. Marine Pollution Bulletin, 36(8): 617-630.

English S, Wilkinson C, Baker V (1997) Survey manual for tropical marine resources. Australian Institute of Marine Science, Townsville, Australia.

Exton D (2010) Nearshore fisheries of the Wakatobi. In: Clifton J, Unsworth RKF, Smith DJ (eds) Marine research and conservation in the Coral Triangle: the Wakatobi National Park. Nova Science Publishers, New York. p 193-207.

Fabricius KE (2005) Effects of terrestrial runoff on the ecology of corals and coral reefs: review and synthesis. Marine Pollution Bulletin, 50(2): 125-46. 
Fitt WK, Brown BE, Warner ME, Dunne RP (2001) Coral bleaching: interpretation of thermal tolerance limits and thermal thresholds in tropical corals. Coral Reefs, 20: 5165.

Fowler AJ (1987) The development of sampling strategies for population studies of coral reef fishes. A case study. Coral Reefs, 6: 49-58.

Fromont J (1991) Descriptions of species of the Petrosida (Porifera: Demospongiae) occurring in the tropical waters of the Great Barrier Reef. The Beagle: Records of the Northern Territory Museum of Arts and Sciences, 8(1): 73-96.

Fromont J, Bergquist P (1994) Reproductive biology of three sponge species of the genus Xestospongia (Porifera: Demospongiae: petrosida) from the Great Barrier Reef. Coral Reefs, 29(2): 71-126.

Friedlander AM, Parrish JD (1998) Habitat characteristics affecting fish assemblages on a Hawaiian coral reef. Journal of Marine Biology and Ecology 224: 1-30.

Ganguly B (1960) The differentiating capacity of dissociated sponges cells.

Development Genes and Evolution, 152: 22-34.

Gaston KJ (2000) Global patterns in biodiversity. Nature, 405(6783): 220-7.

Gemballa S, Schermutzki F (2004) Cytotoxic haplosclerid sponges preferred: a field study on the diet of the dotted sea slug Peltodoris atromaculata (Doridoidea: Nudibranchia). Marine Biology, 144(6): 1213-1222.

Gerrodette T, Flechsig AO (1979) Sediment-induced reduction in the pumping rate of the tropical sponge Verongia lacunosa. Marine Biology, 55(2): 103-110.

Gili JMM, Coma R (1998) Benthic suspension feeders in marine food webs. Trends in Ecology and Evolution, 13: 297-337.

Gilliam DS, Walker BW, Saelens S, Fahy D, Kosmynin VN (2009) Recovery of injured giant barrel sponges, Xestospongia muta, offshore southeast Florida.

Proceedings of the 11th International Coral Reef Symposium, Ft. Lauderdale, Florida, USA. p1230-1234. 
Ginn B (2000) Sponge Ecology on Sublittoral Hard Substrates in a High Current Velocity Area. Estuarine, Coastal and Shelf Science, 50(3): 403-414.

Ginn BK, Logan A, Thomas MLH (2000) Sponge Ecology on Sublittoral Hard Substrates in a High Current Velocity Area. Estuarine, Coastal and Shelf Science, 50: 403-414.

González-Rivero M, Yakob L, Mumby PJ (2011) The role of sponge competition on coral reef alternative steady states. Ecological Modelling, 222(11): 1847-1853.

Grant RE (1826) Observations and experiments on the structure and functions of the sponge. Edinburgh New Philosopical Journal, 14: 336-341.

Gratwicke B, Speight MR (2005) The relationship between fish species richness, abundance and habitat complexity in a range of shallow tropical marine habitats. Journal of Fish Biology, 66: 540-667.

Green G (1977) Ecology of toxicity in marine sponges. Marine Biology, 40(3): 207215.

Hall SJ (1990) Predator-Caging Experiments in Marine Systems: A Reexamination of Their Value. The American Naturalist, 136(5): 657-672.

Hall V, Hughes T (1996) Reproductive strategies of modular organisms: comparative studies of reef-building corals. Ecology, 77: 950-963.

Harrington L, Fabricius K, Eaglesham G, Negri A (2005) Synergistic effects of diuron and sedimentation on photosynthesis and survival of crustose coralline algae. Marine Pollution Bulletin, 51: 415-427.

Hatcher BG (1984) A maritime accident provides evidence for alternative stable states in benthic communities on coral reefs. Coral Reefs, 3(4):199-204.

Hendler G (1984) The association of Ophiothrix lineata and Callyspongia vaginalis : a brittlestar sponge cleaning symbiosis? Marine Ecology, 5(1): 9-27.

Henry LA, Hart M (2005) Regeneration from Injury and Resource Allocation in Sponges and Corals - a Review. International Review of Hydrobiology, 90(2): 125158. 
Hiatt RW, Strasburg DW (1960) Ecological Relationships of the Fish Fauna on Coral Reefs of the Marshall Islands. Ecological Monographs, 30(1): 65-127.

Hill M, Lopez N, Young K (2005) Anti-predator defenses in western North Atlantic sponges with evidence of enhanced defense through interactions between spicules and chemicals. Marine Ecology Progress Series, 291: 93-102.

Hill MS (1998) Spongivory on Caribbean reefs releases corals from competition with sponges. Oecologia, 117(1): 143-150.

Hill MS, Hill AL (2002) Morphological plasticity in the tropical sponge Anthosigmella varians: responses to predators and wave energy. The Biological Bulletin, 202(1): 86-95.

Hobson ES (1974) Feeding relationships of teleostean fishes on coral reefs in Kona, Hawaii. Fishery Bulletin, 72(4): 915-1031.

Hodgeson G, Dixon JA (1988) Logging versus fisheries and tourism in Palawan. Occasional papers of the East-West Environment and Policy Institute, Honolulu. 7: 195.

Hoegh-Guldberg O, Mumby PJ, Hooten AJ, Steneck RS, Greenfield P, Gomez E, Harvell CD, Sale PF, Edwards AJ, Caldeira K, Knowlton N, Eakin CM, IglesiasPrieto R, Muthiga N, Bradbury RH, Dubi A, Hatsiolos ME (2007) Coral reefs under rapid climate change and ocean acidification. Science, 318, 1737-1742.

Holland P (1634) The Historie of the World, commonly called the Naturall Historie of C. Plinius Secundus. Translated into English by Philemon Holland. Printed by Adam Islip, London. Available online (accessed 14/04/13)

http://penelope.uchicago.edu/holland/index.html

Holmes KE (2000) Effects of eutrophication on bioeroding sponge communities with the description of new West Indian sponges, Cliona spp. (Porifera : Hadromerida : Clionidae). Invertebrate Biology, 119: 125-138.

Holt RD (1984) Spatial heterogeneity, indirect interactions, and the coexistence of prey species. The American Naturalist, 124(3): 377-406. 
Hoppe WF (1988) Growth, regeneration and predation in three species of large coral reef sponges. Marine Ecology Progress Series, 50: 117-125.

Hourigan T, Stanton F, Motta P (1989) The feeding ecology of three species of Caribbean angelfishes (family Pomacanthidae). Environmental Biology of Fishes. 24(2):105-116.

Hughes TP (1994) Catastrophes, phase shifts, and large-scale degradation of a Caribbean coral reef. Science, 265: 1547-1551.

Hunter CL, Evans CW (1995) Coral reefs in Kaneohe Bay, Hawaii- two centuries of western influence and two decades of data. Bulletin of Marine Science. 57: 501-515. Hutchings PA (1986) Biological destruction of coral reefs Coral Reefs, 4: 239-252. Hutchinson GE (1959) Homage to Santa Rosalia or Why Are There So Many Kinds of Animals? The American Naturalist, 93(870): 145-159.

Ilan M, Abelson A (1995) The Life of a Sponge in a Sandy Lagoon. Biological Bulletin, 189(3): 363.

Ivlev VS (1961) Experimental ecology of the feeding of fishes. Yale University Press, New Haven, Connecticut, USA.

Jayewardene D, Donahue MJ, Birkeland C (2009) Effects of frequent fish predation on corals in Hawaii. Coral Reefs, 28: 499-506.

Johnson JB, Omland KS (2004) Model selection in ecology and evolution. Trends in Ecology and Evolution, 19(2): 101-8.

Jones A, Blum J, Pawlik J (2005) Testing for defensive synergy in Caribbean sponges: Bad taste or glass spicules? Journal of Experimental Marine Biology and Ecology, 322(1): 67-81.

Kavanagh KD, Olney JE (2006) Ecological correlates of population density and behavior in the circumtropical black triggerfish Melichthys niger (Balistidae). Environmental Biology of Fishes, 76(2-4): 387-398. 
Kelly-Borges MK, Bergquist PR (1988) Success in a shallow reef environment: sponge recruitment by fragmentation through predation. Proceedings of the 6th international Coral Reef Symposium, 2: 757-762.

Keough MJ, Butler, AJ (1979) The role of asteroid predators in the organization of a sessile community on pier pilings. Marine Biology, 51(2): 167-177.

Knapp ISS, Bell JJ (2010) Effect of depth on sponge assemblage structure at Palmyra Atoll, Central Pacific. The Open Marine Biology Journal, 4: 26-30.

Knowlton AL, Highsmith RC (2005) Nudibranch-sponge feeding dynamics: Benefits of symbiont-containing sponge to Archidoris montereyensis (Cooper, 1862) and recovery of nudibranch feeding scars by Halichondria panicea (Pallas, 1766). Journal of Experimental Marine Biology and Ecology, 327(1): 36-46.

Kohler KE, Gill SM (2006) Coral Point Count with Excel extensions (CPCe): A Visual Basic program for the determination of coral and substrate coverage using random point count methodology. Computers \& Geosciences, 32(9): 1259-1269.

Konow N, Bellwood (2005) Prey-capture in Pomacanthus semicirculatus (Teleostei, Pomacanthidae): functional implications of intramandibular joints in marine angelfishes. The Journal of Experimental Biology, 208: 1421-1433.

Konow N, Bellwood DR (2011) Evolution of high trophic diversity based on limited functional disparity in the feeding apparatus of marine angelfishes (f. Pomacanthidae). PloS one, 6(9), e24113.

Lasker H (1985) Prey preferences and browsing pressure of the butterflyfish Chaetodon capistratus on Caribbean gorgonians. Marine Ecology Progress Series, 21, 213-220.

Lefèvre CD, Bellwood DR (2011) Temporal variation in coral reef ecosystem processes: herbivory of macroalgae by fishes. Marine Ecology Progress Series, 422: 239-251.

Lehtila K, Strauss SY (1999) Effects of foliar herbivory on male and female reproductive traits of wild radish, Raphanus raphanistrum. Ecology, 80:116-124. 
León Y, Bjorndal K (2002) Selective feeding in the hawksbill turtle an important predator in coral reef ecosystems. Marine Ecology Progress Series, 245: 249-258.

Lesser MP (2006) Benthic-pelagic coupling on coral reefs: Feeding and growth of Caribbean sponges. Journal of Experimental Marine Biology and Ecology, 328(2): 277-288.

Lesser MP (2007) Coral reef bleaching and global climate change: Can corals survive the next century? Proceedings of the National Academy of Sciences of the United States of America 104: 5259-5260.

Levin SA (1992) The problem of pattern and scale in ecology: the Robert H.

MacArthur award lecture. Ecology, 73(6), 1943-1967.

Li CW, Chen JY, Hua TE (1998) Precambrian Sponges with Cellular Structures. Science, 279: 879-882.

Lirman D (2001) Competition between macroalgae and corals: effects of herbivore exclusion and increased algal biomass on coral survivorship and growth. Coral Reefs, 19(4): 392-399.

Loh T, Pawlik J (2012) Friend or foe? No evidence that association with the sponge Mycale laevis provides a benefit to corals of the genus Montastraea. Marine Ecology Progress Series, 465: 111-117.

López-Legentil S, Song B, McMurray SE, Pawlik JR (2008) Bleaching and stress in coral reef ecosystems: hsp70 expression by the giant barrel sponge Xestospongia muta. Molecular Ecology, 17(7): 1840-9.

Luckhurst BE, Luckhurst K (1978) Analysis of the influence of substrate variables on coral reef fish communities. Marine Biology, 49: 317-323.

Macdonald A, Perry CT (2003) Biological degradation of coral framework in a turbid lagoon environment, Discovery Bay, north Jamaica. Coral Reefs, 22: 523-535.

Maldonado M (2006) The ecology of the sponge larva. Canadian Journal of Zoology, 84(2): 175-194. 
Marquis RJ (1984) Leaf herbivores decrease fitness of a tropical plant. Science, 226: 537-539.

Masuda H, Allen GR (1993) Meeresfische der Welt - Groß-Indopazifische Region. Tetra Verlag, Herrenteich, Melle, p 528

McCook LJ (1997) Effects of herbivory on zonation of Sargassum spp. within fringing reefs of the central Great Barrier Reef. Marine Biology, 129(4): 713-722.

McDonald GR, Nybakken JW (1997) A worldwide review of the food of nudibranch mollusks. I. Introduction and the suborder Arminacea. Veliger 40(2): 157-159.

Mcleod E, Hinkel J, Vafeidis AT, Nicholls RJ, Harvey N, Salm R (2010) Sea-level rise vulnerability in the countries of the Coral Triangle. Sustainability Science, 5: 207-222.

McMellor S, Smith DJ (2010) Coral reefs of the Wakatobi: abundance and biodiversity In: Clifton J, Unsworth RKF, Smith DJ (eds) Marine research and conservation in the Coral Triangle: the Wakatobi National Park. Nova Science Publishers, New York, p 11-26.

McMurray SE, Blum JE, Pawlik JR (2008) Redwood of the reef: growth and age of the giant barrel sponge Xestospongia muta in the Florida Keys. Marine Biology, 155(2): 159-171.

McMurray SE, Henkel TP, Pawlik JR (2010) Demographics of increasing populations of the giant barrel sponge Xestospongia muta in the Florida Keys. Ecology, 91(2): 560-570.

Menge BA, Olson AM (1990) Role of scale and environmental factors in regulation of community structure. Trends in Ecology \& Evolution, 5(2): 52-7.

Menge BA, Sutherland JP (1976) Species diversity gradients: synthesis of the roles of predation, competition, and temporal heterogeneity. American Naturalist, 110(973): 351-369.

Meylan A (1988) Spongivory in Hawksbill turtles: a diet of glass. Science, 239(4838): 393-395. 
Meylan AB, Donnelly M (1999) Status justification for listing the Hawksbill Turtle (Eretmochelys imbricata) as Critically Endangered on the 1996 IUCN Red List of Threatened Animals. Chelonian Conservation and Biology, 3(2): 200-224.

Miller MW, Hay ME (1998) Effects of fish predation and seaweed competition on the survival and growth of corals. Oecologia, 113(2): 231-238.

Montalvo N, Hill R (2011) Sponge-associated bacteria are strictly maintained in two closely related but geographically distant sponge hosts. Applied and Environmental Microbiology, 77(20): 7207-7216.

Mous PJ, Pet JS, Arifin Z, Djohani R, Erdmann MV, Halim A, Knight M, Pet-Soede L, Wiadnya G (2005) Policy needs to improve marine capture fisheries management and to define a role for marine protected areas in Indonesia. Fisheries Management and Ecology, 12(4), 259-268.

Mumby PJ, Dahlgren CP, Harborne AR, Kappel CV, Micheli F, Brumbaugh DR, Holmes KE, Mendes JM, Broad K, Sanchirico JN, Buch K, Box S, Stoffle RW, Gill AB (2006) Fishing, trophic cascades, and the process of grazing on coral reefs. Science, 311(5757): 98-101.

Mutikainen P, Delph LF (1996) Effects of herbivory on male reproductive success in plants. Oikos, 75(3): 353-358.

Nagelkerken I, van der Velde G, Wartenbergh SLJ, Nugues MM, Pratchett MS (2009) Cryptic dietary components reduce dietary overlap among sympatric butterflyfishes (Chaetodontidae). Journal of fish biology, 75(6): 1123-43.

Nava H, Carballo JL (2008) Chemical and mechanical bioerosion of boring sponges from Mexican Pacific coral reefs. Journal of Experimental Biology, 211(17): 28272831.

Neudecker S (2012) Effect of Grazing and Browsing Fishes on the Zonation of Corals in Guam. Ecology, 60(4): 666-672.

Norström A, Nyström M, Lokrantz J, Folke C (2009) Alternative states on coral reefs: beyond coral-macroalgal phase shifts. Marine Ecology Progress Series, 376: 295-306. 
Padilla Verdin CJ, Carballo JL, Camacho ML (2010) A qualitative assessment of sponge-feeding organisms from the Mexican Pacific Coast. The Open Marine Biology Journal, 4: 39-46.

Paine RT (1966) Food web complexity and species diversity. American Naturalist, 100(910): 65-75.

Paine RT (1969) A note on trophic complexity and community stability. The American Naturalist, 103(929): 91-93.

Pandolfi JM, Bradbury RH, Sala E, Hughes TP, Bjorndal KA, Cooke RG, McArdle D, McClenachan L, Newman MJH, Paredes G, Warner RR, Jackson JBC (2003) Global Trajectories of the Long-Term Decline of Coral Reef Ecosystems. Science, 301: 955-958.

Pandolfi JM, Jackson JBC, Baron N, Bradbury RH, Guzman HM, Hughes TP, Kappel C (2005) Are US coral reefs on the slippery slope to slime? Science, 307(5716): 1725.

Pawlik J, Chanas B, Toonen R, Fenical W (1995) Defenses of Caribbean sponges against predatory reef fish. I. Chemical deterrency. Marine Ecology Progress Series, 127: $183-194$

Pawlik JR (1998) Coral reef sponges: Do predatory fishes affect their distribution? Limnology and Oceanography, 43(6): 1396-1399.

Pawlik JR (2008) A Sponge-Eating Worm from Bermuda: Branchiosyllis oculata (Polychaeta, Syllidae). Marine Ecology, 4: 65-79.

Pawlik JR, McMurray SE, Henkel TP (2007a) Abiotic factors control sponge ecology in Florida mangroves. Marine Ecology Progress Series, 339: 93-98.

Pawlik JR, Steindler L, Henkel TP, Beer S, Ilan M (2007b) Chemical warfare on coral reefs : Sponge metabolites differentially affect coral symbiosis in situ. Limnology and oceanography, 52: 907-911.

Pearse AS (1934) Inhabitants of certain sponges at Dry Tortugas. Papers from the Tortugas Lab. Carnegie Institute, 28: 117-124. 
Pearse AS (1950) Notes on the inhabitants of certain sponges at Bimini. Ecology, 31 : $150-151$.

Perea-Blázquez A, Davy SK, Bell JJ (2012) Estimates of Particulate Organic Carbon Flowing from the Pelagic Environment to the Benthos through Sponge Assemblages. PLoS ONE 7(1): e29569.

Perea-Blázquez A, Price K, Davy SK, Bell JJ (2010) Diet Composition of Two Temperate Calcareous Sponges: Leucosolenia echinata and Leucetta sp. from the Wellington South Coast, New Zealand. Open Marine Biology Journal 4: 65-73.

Peters KJ, Amsler CD, McClintock JB, van Soest RWM, Baker BJ (2009) Palatability and chemical defenses of sponges from the western Antarctic Peninsula. Marine Ecology Progress Series, 385: 77-85.

Powell AL, Hepburn LJ, Smith DJ, Bell JJ (2010) Patterns of Sponge Abundance Across a Gradient of Habitat Quality in the Wakatobi Marine National Park, Indonesia. Open Marine Biology Journal, 4: 31-38.

Pratchett MS (2007) Dietary selection by coral-feeding butterflyfishes (Chaetodontidae) on the Great Barrier Reef, Australia. The Raffles Bulletin of Zoology, 14(14): 171-176.

Preciado I, Maldonado M (2005) Reassessing the spatial relationship between sponges and macroalgae in sublittoral rocky bottoms: a descriptive approach. Helgoland Marine Research, 59(2): 141-150.

Przeslawski R, Ahyong S, Byrne M, Wörheide G, Hutchings P (2008) Beyond corals and fish: the effects of climate change on non-coral benthic invertebrates of tropical reefs. Global Change Biology, 14: 2773-2795.

R Development Core Team (2011) R: A Language and Environment for Statistical Computing. Vienna, Austria : the R Foundation for Statistical Computing. ISBN: 3900051-07-0. Available online at http://www.R-project.org/.

Randall J (1955) Fishes of the Gilbert Islands. Atoll Reasearch Bulletin, 47: 1-243. 
Randall J (1980) A survey of ciguatera at Enewetak and Bikini, Marshall Islands, with notes on the systematics and food habits of ciguatoxic fishes. Fishery Bulletin, 78(2): 201-249.

Randall J, Hartman W (1968) Sponge-feeding fishes of the West Indies. Marine Biology, 1(3): 216-225.

Reiswig HM (1971) Particle feeding in natural populations of three marine demosponges. Biological Bulletin, 141: 568-591.

Reese ES (1981) Predation on corals by fishes of the family Chaetodontidae: implications for conservation and management of coral reef ecosystems. Bulletin of Marine Science, 31: 594-604.

Ribeiro SM, Omena EP, Muricy G (2003) Macrofauna associated to Mycale microsigmatosa (Porifera, Demospongiae) in Rio de Janeiro State, SE Brazil. Estuarine, Coastal and Shelf Science, 57: 951-959.

Richter C, Wunsch M, Rasheed M, Kotter I, Badrab MI (2001) Endoscopic exploration of Red Sea coral reefs reveals dense populations of cavity-dwelling sponges. Nature, 413: 726-730.

Riegl B, Branch GM (1995) Effects of sediment on the energy budgets of four scleractinian (Bourne 1990) and five alcyonacean (Lamouroux 1816) corals. Journal of Experimental Marine Biology and Ecology, 186: 259-275.

Roberts CM, McClean CJ, Veron JEN, Hawkins JP, Allen GR, McAllister DE, Mittermeier CG, Schueler FW, Spalding M, Wells F, Vynne C, Werner TB (2002) Marine Biodiversity Hotspots and Conservation Priorities for Tropical Reefs. Science, 295: 1280-1284.

Roberts D, Cummins S, Davis A, Chapman M (2006b) Structure and dynamics of sponge-dominated assemblages on exposed and sheltered temperate reefs. Marine Ecology Progress Series, 321: 19-30.

Roberts DE, Davis AR, Cummins SP (2006a) Experimental manipulation of shade, silt, nutrients and salinity on the temperate reef sponge Cymbastela concentrica. Marine Ecology Progress Series, 307: 143-154. 
Rogers CS (1985) Degradation of Caribbean and Western Atlantic coral reefs and decline of associated fisheries. Proceedings of the fifth International Coral Reef Congress. Tahiti.

Rogers CS (1990) Responses of coral reefs and reef organisms to sedimentation. Marine ecology progress series, 62(1): 185-202.

Rotjan R, Lewis S (2008) Impact of coral predators on tropical reefs. Marine Ecology Progress Series, 367: 73-91.

Rotjan RD, Dimond JL, Thornhill DJ, Leichter JJ, Helmuth B, Kemp DW, Lewis S M (2006) Chronic parrotfish grazing impedes coral recovery after bleaching. Coral Reefs, 25(3): 361-368.

Rotjan RD, Lewis SM (2008) Predators selectively graze reproductive structures in a clonal marine organism. Marine Biology, 156(4): 569-577.

Russ GR (1980) Effects of predation by fishes, competition, and structural complexity of the substratum on the establishment of a marine epifaunal community. Journal of Experimental Marine Biology and Ecology, 42(1): 55-69.

Russ GR, Alcala AC (1996) Marine Reserves : Rates and Patterns of Recovery and Decline of Large Predatory Fish. Ecological Applications, 6(3): 947-961.

Ruzicka R, Gleason D (2008) Latitudinal variation in spongivorous fishes and the effectiveness of sponge chemical defenses. Oecologia, 154: 785-94.

Salinas-de-León, P., Costales-Carrera, A., Zeljkovic, S., Smith, D. J., \& Bell, J. J. (2011). Scleractinian settlement patterns to natural cleared reef substrata and artificial settlement panels on an Indonesian coral reef. Estuarine, Coastal and Shelf Science, 93(1), 80-85.

Sammarco PW, Risk MJ (1990) Large-scale patterns in internal bioerosion of Porites: cross continental shelf trends on the Great Barrier Reef. Marine Ecology Progress Series, 59: 145-156.

Sano M (1989) Feeding habits of Japanese butterflyfishes (Chaetodontidae). Environmental Biology of Fishes. 25(1-3): 195-203. 
Sano M, Shimizu M, Nose Y (1984) Food habits of teleostean reef fishes in Okinawa Island, southern Japan. University of Tokyo Bulletin, 25 University of Tokyo Press, Tokyo, Japan. p 128.

Scheffer M, Carpenter S, Foley JA, Folke C, Walker B (2001) Catastrophic shifts in ecosystems. Nature, 413: 591-596.

Scheffer M, Carpenter S, de Young B (2005) Cascading effects of overfishing marine systems. Trends in ecology \& evolution, 20(11), 577-9.

Schmahl GP (1985) Community structure and ecology of sponges associated with four Southern Florida coral reefs. In: Rutzler K (ed) New perspectives in sponge biology. Smithsonian Inst Press, Washington DC, p 376-383.

Schubauer JP, Burns TP, Richardson TH (1985) Population dynamics of five Demospongiae in Jamaica: variation in time and space. In: Rutzler K (ed) New perspectives in sponge biology. Smithsonian Inst Press, Washington DC, p 443-451.

Shapiro SS, Wilk MB (1965) An analysis of variance test for normality (complete samples). Biometrika, 52: 591-611.

Sih A, Crowley P, McPeek M, Petranka J, Strohmeier K (1985) Predation, Competition, and Prey Communities: A Review of Field Experiments. Annual Review of Ecology and Systematics, 16(1): 269-311.

Skarpe C, Hester A (2008) Plant traits, browsing and grazing herbivores, and vegetation dynamics. In: Gordon IJ, Prins HHT (eds) The Ecology of Browsing and Grazing. Ecological Studies, 195: 217-261.

Southwell MW, Carolina N, Hill C, Weisz JB, Martens CS, Lindquist N (2008) In situ fluxes of dissolved inorganic nitrogen from the sponge community on Conch Reef, Key Largo, Florida. Limnology and Oceanography, 53(3): 986-996.

Stearn CW, Scoffin TP (1977) Carbonate budget of a fringing reef, Barbados. Proceedings of the Third International Coral Reef Symposium. (University of Miami), 471-476.

Steene RC (1978) Butterfly and angelfishes of the world. A.H. \& A.W. Reed Pty Ltd., Australia. vol. 1, p 144. 
Steidl RJ, Hayes JP, Schauber E (1997) Statistical Power Analysis in Wildlife Research. The Journal of Wildlife Management, 61(2): 270.

Strauss S, Agrawal A (1999) The ecology and evolution of plant tolerance to herbivory. Trends in Ecology \& Evolution, 14(5): 179-185.

Stuart-Smith RD, Barrett NS, Crawford CM, Frusher SD, Stevenson DG, Edgar GJ (2008) Spatial patterns in impacts of fishing on temperate rocky reefs: Are fish abundance and mean size related to proximity to fisher access points? Journal of Experimental Marine Biology and Ecology, 365(2): 116-125.

Suchanek TH, Carpenter RC, Witman JD, Harvell CD (1983) Sponges as important space competitors in deep Caribbean coral reef communities. In: Reaka ML (ed) The ecology of deep and shallow coral reefs. Symposia series for undersea research 3(1), NOAA/NURP, Rockville, Maryland. p 55-59.

Swearingen III DC, Pawlik JR (1998) Variability in the chemical defense of the sponge Chondrilla nucula against predatory reef fishes. Marine Biology, 131(4): 619627.

Symonds MRE, Moussalli A (2011) A brief guide to model selection, multimodel inference and model averaging in behavioural ecology using Akaike's information criterion. Behavioral Ecology and Sociobiology, 65(1): 13-21.

Teixidó N, Pineda M, Garrabou J (2009) Decadal demographic trends of a long-lived temperate encrusting sponge. Marine Ecology Progress Series, 375: 113-124.

Thomas TRA, Kavlekar DP, LokaBharathi PA (2010) Marine drugs from spongemicrobe association-a review. Marine Drugs, 8(4): 1417-1468.

Thomas L (1997) Retrospective power analysis. Conservation Biology, 11(1): 276280.

Thomas L, Juanes F (1996) The importance of statistical power analysis: an example from Animal Behaviour. Animal Behaviour, 52(4): 856-859.

Tkachenko KS, Wu BJ, Fang L, Fan T (2007) Dynamics of a coral reef community after mass mortality of branching Acropora corals and an outbreak of anemones. Marine Biology, 151: 185-194. 
Trussell GC, Lesser MP, Patterson MR, Genovese SJ (2006) Depth-specific differences in growth of the reef sponge Callyspongia vaginalis: role of bottom-up effects. Marine Ecology Progress Series, 323: 149-158.

Tsurumi M, Reiswig HM (1997) Sexual versus asexual reproduction in an oviparous rope-form sponge Aplysina cauliformis (Porifera; Verongida). Invertebrate Reproduction and Development, 32: 1-9.

Turon X, Tarjuelo I, Uriz M (1998) Growth dynamics and mortality of the encrusting sponge Crambe crambe (Poecilosclerida) in contrasting habitats: correlation with population structure and investment in defence. Functional Ecology, 12(4): 631-639.

Unsworth RKF, Powell A, Hukom F, Smith DJ (2007) The ecology of Indo-Pacific grouper (Serranidae) species and the effects of a small scale no take area on grouper assemblage, abundance and size frequency distribution. Marine Biology, 152: 243254.

van Soest R (1989) The Indonesian sponge fauna: a status report. Netherlands journal of sea research, 23(2): 223-230.

van Soest R (2012) Xestospongia testudinaria (Lamarck, 1815). In: van Soest RWM, Boury-Esnault N, Hooper JNA, Rützler K, de Voogd NJ, Alvarez de Glasby B, Hajdu E, Pisera AB, Manconi R, Schoenberg C, Janussen D, Tabachnick KR, Klautau M, Picton B, Kelly M, Vacelet J (2012) World Porifera database. Accessed through: van Soest RWM, Boury-Esnault N, Hooper JNA, Rützler K, de Voogd NJ, Alvarez de Glasby B, Hajdu E, Pisera AB, Manconi R, Schoenberg C, Janussen D, Tabachnick KR, Klautau M, Picton B, Kelly M, Vacelet J (2012) World Porifera database at http://www.marinespecies.org/porifera/porifera.php?p=taxdetails\&id=166902 on 2012-05-11

Vicente VP (1990) Response of sponges with autotrophic endosymbionts during the coral-bleaching episode in Puerto Rico. Coral Reefs, 8:199-202.

Vogel S (1977) Current-induced flow through living sponges in nature. Proceeding of the Natural Academy of Sciences, 74: 2069-2071.

Vogel S (1974) Current-induced flow through the sponge, Halichondria. Biological Bulletin. 147: 443-456. 
Wägele H (1989) Diet of some Antarctic nudibranchs (Gastropoda, Opisthobranchia, Nudibranchia). Marine Biology, 100: 439-441.

Walters KD, Pawlik JR (2005) Is there a trade-off between wound-healing and chemical defences among Caribbean reef sponges? Integrative and comparative Biology, 45(2): 352-258.

Werner E, Gilliam, Hall D, Mittelbach G (1983) An experimental test of the effects of predation risk on habitat use in fish. Ecology, 64: 1540-1548.

Wilkinson CR (1978) Microbial association in sponges. I. Ecology, physiology and microbial populations of coral reef sponges. Marine Biology, 49(2): 161-167.

Wilkinson CR (2004) Status of the coral reefs of the world. Australian Institute of Marine Science, Townsville, Australia.

Wilkinson CR, Vacelet J (1979) Transplantation of marine sponges to different conditions of light and current. Journal of Experimental Marine Biology and Ecology, 37: 91-104.

Williams EH, Bartels PJ, Bunkley-Williams L (1999) Predicted disappearance of coral-reef ramparts : a direct result of major ecological disturbances. Global Change Biology, 5: 839-845.

Wood R (1995) The Changing Biology of Reef-Building. PALAIOS, 10: 517-529

Woodland DJ, Randall JE (1979) Siganus puelloides, a new species of rabbitfish from the Indian Ocean. Copeia, 3: 390-393.

Wulff JL (1991) Asexual fragmentation, genotype success, and population dynamics of erect branching sponges. Journal of Experimental Marine Biology and Ecology, 149: 227-247.

Wulff JL (1994) Sponge feeding by Caribbean angelfishes, trunkfishes, and filefishes. In Soest RWMV, Van Kempen TG, Braekman JC (Eds.) Sponge in time and space; Biology, Chemistry, Paleontology. Rotterdam, A.A. Balkema.

Wulff JL (1995) Sponge-feeding by the Caribbean starfish Oreaster reticulatus. Marine Biology, 123: 313-325. 
Wulff JL (1997) Parrotfish predation on cryptic sponges of Caribbean coral reefs. Marine Biology, 129(1): 41-52.

Wulff JL (2000) Sponge predators may determine differences in sponge fauna between two sets of mangrove cays, Belize barrier reef. Atoll Research Bulletin, 477(477): 251-263.

Wulff JL (2001) Assessing and monitoring coral reef sponges: Why and how? Bulletin of Marine Science, 69(2): 831-846.

Wulff JL (2005) Trade-offs in resistance to competitors and predators, and their effects on the diversity of tropical marine sponges. Journal of Animal Ecology, 74(2): $313-321$

Wulff JL (2006a) Ecological interactions of marine sponges. Canadian Journal of Zoology, 84: 146-166.

Wulff JL (2006b) A simple model of growth form-dependent recovery from disease in coral reef sponges, and implications for monitoring. Coral Reefs, 25(3): 419-426.

Wulff JL (2008) Collaboration among sponge species increases sponge diversity and abundance in a seagrass meadow. Marine Ecology, 29(2): 193-204.

Wulff JL, Buss LW (1979) Do sponges help hold coral reefs together? Nature, 281: 474-475.

Yasman (2003) Observation on the feeding of nudibranch Phyllidia varicosa Lamarck, 1801 on the sponge Axinyssa cf. aculeata Wilson, 1925 in coral reefs of Pramuka Island, Thousands Islands National Park, Indonesia. Makara, Sains, 7(1): 1521.

Zea S (2001) Patterns of sponge (porifera, demospongiae) distribution in remote, oceanic reef complexes of the southwestern caribbean. Revista de la Academia Colombiana de Ciencias, 25(97): 579-592.

Zilberberg C, Sole-Cava AM, Klautau M (2006) The extent of asexual reproduction in sponges of the genus Chondrilla (Demospongiae: Chondrosida) from the Caribbean and the Brazilian coasts. Journal of Experimental Marine Biology and Ecology, 336: 211-220. 


\section{Appendix 1}

Powell, A. L., Hepburn, L. J., Smith, D. J. \& Bell, J. J. (2010) Patterns of sponge abundance across a gradient of habitat quality in the Wakatobi Marine National Park, Indonesia. Open Marine Biology Journal, 4, 31-38. 


\title{
Patterns of Sponge Abundance Across a Gradient of Habitat Quality in the
} Wakatobi Marine National Park, Indonesia

\author{
Abigail L. Powell ${ }^{*},{ }^{1}$, Leanne J. Hepburn ${ }^{2}$, David J. Smith ${ }^{2}$ and James J. Bell ${ }^{1}$ \\ 'Centre for Marine Environmental and Economic Research, School of Biological Sciences, Victoria University of \\ Wellington, P.O. Box 600, Wellington 6140, New Zealand \\ ${ }^{2}$ Coral Reof Research Unit, University of Essex, Wivenhoe Park, Colchester CO4 3 SQ. United Kingdom
}

\begin{abstract}
Sponges are important components of reef communities worldwide, fulfilling a mumber of important functional roles. Habitat degradation caused by the loss of hard carals has the potential to cruse increases in sponge abundance and percentage cover as they gain access to resources such as space and food. In this study we compared sponge densities and percentage cover at sites with varying hard coral cover in the Wakatobi Marine National Park, Indonesia (WMNP). We found significant differences in sponge densities at the study sites but no significant difference in sponge densities on different surface angles. Unexpectedly, we also foumd a weak positive comelation between coral cover and sponge density. This indicates that spatial competition is unlikely to be the most important factor determining sponge abundance in the WMNP. In contrast to sponge density dath, we found that sponge percentage cover and hard coral cover were weakly negatively correlated, but found no significant difference in sponge percentage cover between the study sites. Finally. multivariate analysis of the benthic communities at the stady sites indicated that while sites with higher conal cover were characterised by coral (proportionally). lower coral cover sites were characterised by algae and sponges. This suggests that although there was no significant difference in sponge percentage cover between the study sites conditions that led to the loss of hard coral at lower quality sites mean that these sites are characterised by sponges and algae rather than by any other groups of benthic organisms.
\end{abstract}

Keywords: Sponge ecology, sponge distribution patterns, Porifera, Sulawesi, reef invertebrate assemblages, coral reef degradation.

\section{INTRODUCTION}

In addition to their exceptional biodiversity, coral reefs contribute to coastal protection, and are a vital source of income and food for nearly 500 million people worldwide [1]. Coral reefs accoss the globe are currently declining as a result of many threats including overexploitation, habitat destruction, increased sedimentation and murrient levels due to poor land management, and face the potential future threats of ocean acidification and raised sea temperatures as a result of climate change [2-4]. One of the key consequences of habitat degradation is the loss of reef building corals and subsequent reduction in physical complexity. Topographic diversity, a key characteristic of tropical coral reefs, is one of the main drivers of biodiversity and therefore degradation leading to a loss of hard corals will have major and long lasting detrimental impacts on ecosystem diversity and productivity [2,5]. Currently, much research focuses on investigating and mitigating the impacts of hard coral loss on reefs [6-8], however, the vast majority of this research does not talke into account a major component of coral reef communities; sponges.

Sponges are extremely widespread occurring in marine enviromments from polar to tropical regions [9-11]. Porifera,

-Addras corrorpondence to this anthor at the Cantro for Marine Enviroumantal and Economic Research School of Biological Scionces, Victoria University of Wollington, P.O. Box 600 , Wellington 6140 , New Zoaland, Tol: 64 4-4635339; E-mail abigail powol@gvuw.ac.nz

$1874-4506 / 10$ as key spatial competitors, are integral components of tropical coral reef systems and play several functional roles including nutrient cycling, reef consolidation, bio-erosion, facilitating primary production and bentho-pelagic coupling $[12,13]$. Abundance and spatial distribution of sponges are influenced by both physical factors, including substrate angle, offshore distance, depth and sedimentation $[10,14$, 15] and biological factors including competition and predation $[16,17]$. The relative importance of biological and physical factors in driving sponge abundance patterns is still unclear but could have far reaching implications when attempting to predict the impacts of environmental degradation on sponge assemblages. For example, if sponges compete with corals for resources such as space and food, a decline in coral abundance could result in an increase in sponges with subsequent ecosystem function effects. In contrast, if sponge abundance and diversity patterns are primarily driven by physical factors then changes in coral abundance will have little effect on sponges.

Previous studies have shown that sponges are important spatial competitors in temperate and tropical benthic commumities [16, 18]. Most information regarding sponges as spatial competitors on coral reefs comes from the Caribbean where sponges use a number of mechanisms to compete for space inchuding, the production of toxic secondary metabolites $[19,20]$, variable growth rates [21] and variable growth forms [22]. Comparatively, little information is available for other coral reef regions. In Indonesia, de Voogd et al. [23] found that four sponge species use bioactive compounds to 
a.

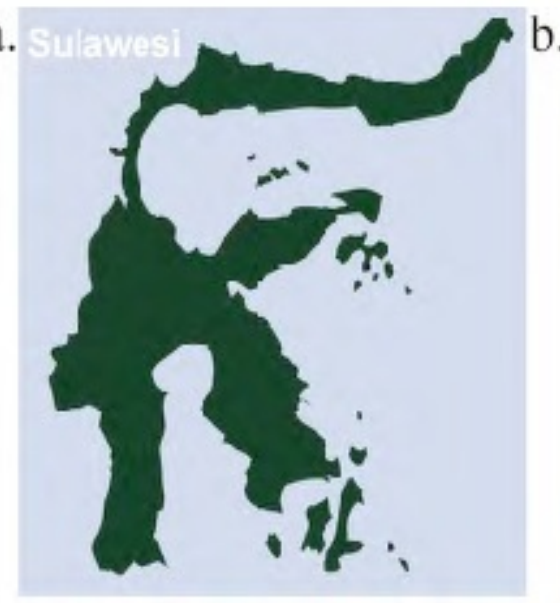

b.

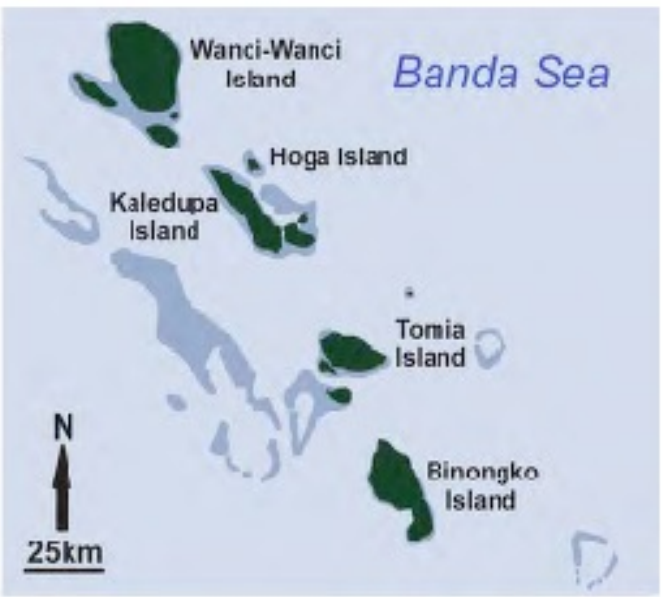

\section{c.}

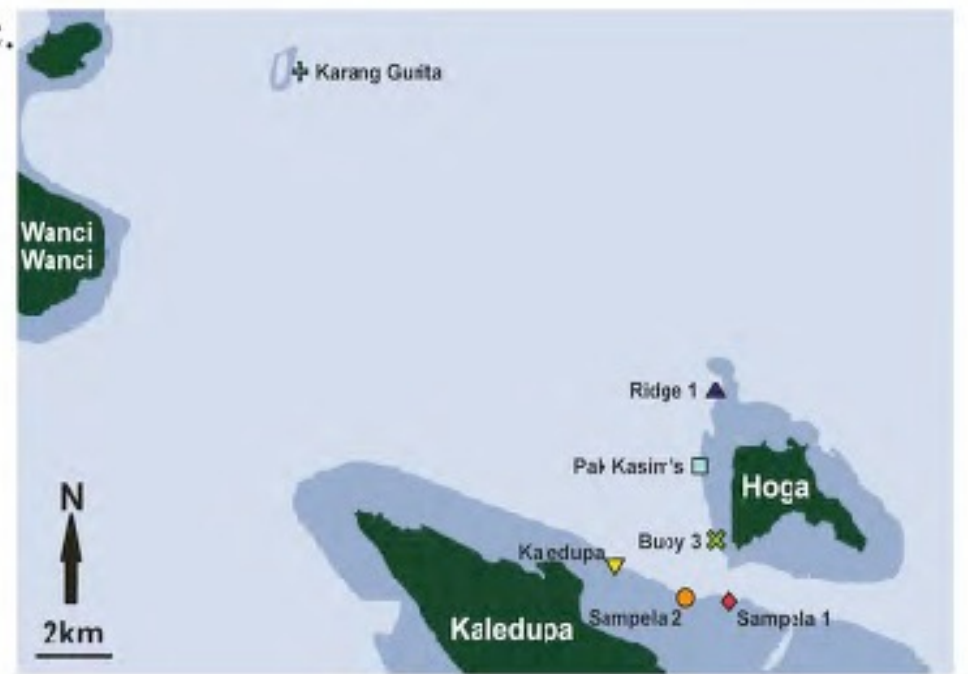

Fig. (1). a) Map of Sulawesi b) The location of Hoga Island in relation to the other main islands of the Walatobi: Wanci-Wanci, Kaledupa, Tomia and Binongko islands c) The location of the seven study sites.

compete with corals in the Spermonde archipelago in Sulawesi.

In this study we attempt to examine spatial relationships between sponges and hard corals to see if competition is likely to be a major factor driving sponge abundance in the Wakatobi Marine National Park (WMNP) SE Sulawesi, Indonesia. Rather than focusing on the competitive abilities of a few species we carried out surveys of sponge abundance at a number of sites with different levels of hard coral cover as a result of habitat destruction. Previous work in the Wakatobi has indicated that surface angle may influence sponge density at some sites so surveys were carried out on flat, inclined and vertical surfaces [14]. We hypothesise that sponge densities and percentage cover will be negatively correlated with coral cover as sponges will be released from spatial competition with hard corals. In addition, we hypo- thesise that sponge densities will be affected by substrate angle with higher sponge densities occurring on vertical, inclined and horizontal surfaces respectively.

\section{MATERIALS AND METHODOLOGY}

\section{Study Sites}

The WMNP comprises four main islands, Wangi-Wangi, Kaledupa, Tomia, Binongko that together with other smaller islands make up the Tukang Besi Archipelago. Surveys were carried out at seven sites near Kaledupa and Hoga islands in July and August 2008 (see Fig. 1). The WMNP is the second largest marine national park in Indonesia and is located within the 'coral triangle' and has exceptional diversity and abundance of scleractinian corals [24]. The WMNP is a suitable location to study the impacts of the loss of hard 
coral on sponge assemblages as it contains some of the most pristine reefs in the world, but also a number of reefs that are heavily degraded as a result of human activities [25]. A rapid ecological assessment carried out in 2003 recorded 396 species of hard coral and 590 species of fish in the park [26], however, there are approximately 90,000 people who inhabit the park and balancing the needs of a growing population with conservation is a major challenge for park authorities and conservation groups.

Site 1 (Buoy 3; $05^{\circ} 28.40 \mathrm{~S}, 123^{\circ} 45.45 \mathrm{E}$ ) is a fringing reef on the Western side of Hoga island. It has a reef flat located between $0-4 \mathrm{~m}$ leading to the reef crest which is located 150 $\mathrm{m}$ offshore at a depth of 2-6 m. The reef slope is characterised by walls, overhangs and caves and descends to a depth of approximately $60 \mathrm{~m}$ before levelling out into sandy habitat. Site 2 (Pak Kasims; 05 27.569S, 123 $45.179 \mathrm{E}$ ) is located $500 \mathrm{~m}$ north of Buoy 3 on the same fringing reef, however, the reef crest is located further offshore $(\sim 200 \mathrm{~m})$ than Buoy 3 and the reef slope is less vertical, descending at an angle of 40-70 degrees leading to gently sloping sand flats at approximately $50 \mathrm{~m}$. Site 3 (Ridge $1 ; 05^{\circ} 26.565 \mathrm{~S}$, $123^{\circ} 45.138 \mathrm{E}$ ) is situated over $1 \mathrm{~km}$ offshore to the north west of Hoga island. The ridge runs from north to south and has a crest between $4-10 \mathrm{~m}$ wide at a depth of $5-10 \mathrm{~m}$. The reef slopes away on either side of the crest at approximately 70 degrees to over $100 \mathrm{~m}$ on the outer slope and slightly shallower on the imer side. Site 4 (Karang Gurita $\left(05^{\circ} 23.48 \mathrm{~S}, 123^{\circ} 40.37 \mathrm{E}\right)$ is a submerged atoll located off to the south east of Wanci Wanci island. The angle of the reef slopes varies between 45-70 degrees. Site 5 (Raledupa; $\left.05^{\circ} 28.22 \mathrm{~S}, 133^{\circ} 43.37 \mathrm{E}\right)$ is a fringing reef off the island of Kaledupa. The reef slopes at an angle of around 50 degrees to approximately $50 \mathrm{~m}$ where it turns into a sandy slope. It has extensive reef flats characterised by coral bommies, boulders and soft corals. Site 6 (Sampela 1; 05 29.6 S, $123^{\circ} 45.26 \mathrm{E}$ ) is located approximately $2 \mathrm{~km}$ south of the Kaledupa study site on the same fringing reef that surrounds Kaledupa island. The reef flat occurs at $2-4 m$ and leads to a crest at $1-3 \mathrm{~m}$. The reef slope descends at approximately 45 degrees to between $11-14 \mathrm{~m}$ where it levels off into sand flats. Sampela 1 is situated near to a Bajo village that is built above the reefs flats approximately $400 \mathrm{~m}$ offshore. This reef is considered to be highly degraded with low hard coral species richness and percentage cover compared to other reefs in the park [25]. The reef at Sampela 1 also experiences high levels of sediment, approximately four times higher than those at the Kaledupa study site [25]. The final site, site 7 , (Sampela 2; $05^{\circ} 29.3 \mathrm{~S}, 123^{\circ} 45.1 \mathrm{E}$ ) is $200 \mathrm{~m}$ north of Sampela 1 on the same stretch of shallow fringing reef. The topography and environmental conditions of this site are very similar to Sampela 1.

\section{Surveys of Sponge Abundance}

The abundance of sponges was quantified at each site using a divided $0.5 \times 0.5 \mathrm{~m}^{2}$ quadrat at a depth of $10 \mathrm{~m}$ An equal number of quadrats were surveyed on flat $(\sim 0)$, inclined $(\sim 45)$ and vertical $(-90)$ surfaces. In total 147 quadrats were surveyed, 21 at each site with 7 on each surface angle. The total number of individual sponge patches was recorded in situ. Photographs were also taken of each quadrat using a Canon $\mathrm{G} 9$ camera with underwater housing.

\section{Photo Quadrats}

Photos were analysed to estimate the percentage cover of sponges relative to other major commonents of the reef benthos. Photos were analysed with Coral Point Count with Excel extensions (CPCe) using a random point count methodology [27]. A matrix of 50 randomly distributed points was overlaid on each quadrat image and the substrate type lying under each was visually identified. The categories used were: sponge, branching hard coral, encrusting hard coral, massive hard coral, sub-massive hard coral, foliose hard coral, tabulate hard coral, free-living hard coral, soft coral, gorgonians, coralline algae (CCA), algae, 'others' (including ascidians, zooanthids, bryozoans, Millepora), recently dead coral (dead coral substrate but the structure is still intact), rock, rubble, and sand.

\section{Data Anabyis}

Kolmogorov-Smimov tests were used to determine whether data were normally distributed. As data were found to be significantly different from normal distributions, nonparametric or semi-parametric tests were used throughout. Univariate and multivariate analyses were carried out using the statistical package PRMMER-E v6 (Plymouth Routines in Multivariate Ecological Research). Analyses were based on similarity matrices calculated using Bray-Curtis coefficients.

A two-factor permutational multivariate analysis of variance (PERMANOVA) [28] was used on the percentage cover data obtained from the photo quadrats to test the null hypothesis that there were no differences in benthic commumity composition between sites or surface angles. The PERMANOVA incorporated the following factors: (1) Site (random factor with seven levels) and (2) Angle (fixed factor with three levels). Unconstrained non-metric Multi Dimensional Scaling (MDS) and constrained Canonical Analysis of Principal coordinates (C.AP) of site percentage cover means were used to graphically represent site differences in two dimensions [29]. Spearman rank correlations of individual benthic components with the resulting CAP axes were used to indicate the benthic groups that characterised the differences among groups from the CAP analysis.

A univariate two-factor PERMANOVA was used to test the null hypothesis that there was no difference in sponge abundance between study sites or surface angles. This test also incorporated the factors (1) Site (random factor with seven levels) and (2) Angle (fixed factor with three levels).

Spearman rank correlations were used to explore the relationship between sponge density and percentage cover and hard coral cover. The mean density of sponges $\left(\mathrm{m}^{-2}\right)$ and the mean hard coral cover (\%) of each of the benthic categories were calculated for site comparisons.

\section{RESULTS}

The benthic assemblages were significantly different between some sites (PERMANOVA, pseudo- $F=5.4966$ p $<0.001$ ). Table 1 summarizes the percentage cover of the major benthic categories at each of the study sites. There was also a significant difference between the benthic communities on different surface angles (PERMANOVA, psoudo$F=2.7773, \mathrm{p}=0.007$ ) and also a sigmificant interaction bet- 
Table 1. Percentage Cover of the Major Benthic Categories at the Study Sites Ranked from Highest to Lowest Coral Cover

\begin{tabular}{|c|c|c|c|c|c|c|c|c|c|c|c|}
\hline \multirow{2}{*}{ Site } & \multicolumn{11}{|c|}{$\%$ Cover } \\
\hline & Coral & Sponges & Soft coral & Gorgomians & Algae & CCA & Others & Dead corsal & Rock & Rabble & Sand \\
\hline Buoy 3 & 51 & 4 & 5 & 0 & 7 & 8 & 3 & 1 & 21 & 0 & 0 \\
\hline Ridgo 1 & 31 & 11 & 9 & 1 & 13 & 8 & 1 & 3 & 21 & 1 & 1 \\
\hline Karang Gurita & 28 & 7 & 9 & 0 & 13 & 15 & 1 & 2 & 17 & 5 & 3 \\
\hline Pak Kanim's & 27 & 3 & 14 & 0 & 11 & 12 & 0 & 4 & 19 & 10 & 0 \\
\hline Sampola 1 & 13 & 8 & 5 & 0 & 22 & 9 & 2 & 4 & 32 & 3 & 2 \\
\hline Kaledepa & 9 & 7 & 23 & 1 & 23 & 8 & 1 & 1 & 24 & 2 & 1 \\
\hline Sampola 2 & 3 & 7 & 6 & 0 & 33 & 14 & 1 & 0 & 27 & 4 & 5 \\
\hline
\end{tabular}

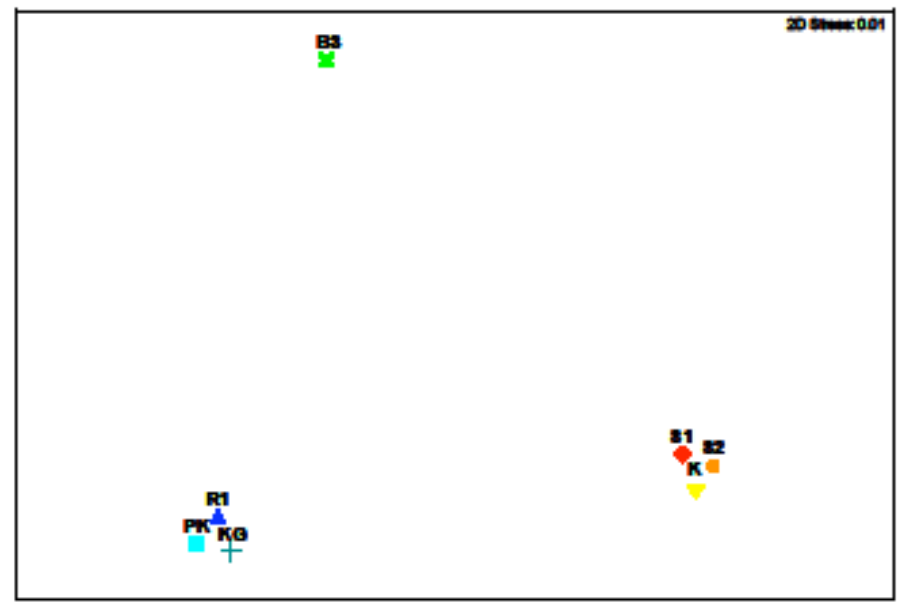

Fig. (2). MDS ordination showing similarities in benthic composition between sites. The ordination is based on a Bray-Curtis similarity matrix of site percentage cover means.

ween site and surface angle (PERMANOVA, psendo$F=1.7593, \mathrm{p}=0.001)$. The unconstrained MDS ordinations showed similarity among assemblages at some sites (Fig. 2). The higher coral cover sites (Pak Kasims, Karang Gurita and Ridge 1) were grouped. The sites with lower hard coral cover (Sampela 1, Sampela 2 and Kaledupa) form another group; Buoy 3 was different from all the other sites. The constrained CAP ordination showed similar grouping of sites to the unconstrained MDS plot. The vectors superimposed on the CAP ordination indicate that Sampela 1, Sampela 2 and Kaledupa are characterised by sponges, rock, algae and sand. Ridge 1, Karang Gurita and Pak Kasims were characterised by hard coral, and particularly by branching, sub-massive, encrusting, foliose, massive and tabulate growth forms. Buoy 3 was characterised by 'others' which mainly consisted of ascidians and high hard coral cover (Fig. 3).

A significant but weak positive correlation was found bet-ween sponge density and percentage coral cover (Spearman's rank correlation $\mathrm{r}=0.184$, d.f $=146, \mathrm{p}=0.026$ ) (Fig. 4). Sponge density varied between the study sites (see Fig. 5) with the highest density ( \pm SE) being reported at Buoy 3 (160 sponges $\mathrm{m}^{-2} \pm 32$ ) and the lowest at Sampela 2 (84 sponges $\mathrm{m}^{-2} \pm 12$ ). The univariate two-factor PERMANOVA indicated that there was a significant difference in sponge density between the sites (pseudo- $F=2.7801, \mathrm{p}=0.002$ ), but there was no significant difference in the number of sponges on different surface angles (psondo- $F=1.3779, \mathrm{p}=0.299$ ). In contrast, we found a weak but significant negative correlation between sponge percentage cover and hard coral cover (Spearman's rank correlation $\mathrm{r}=-0.181$, d.f. $=146, \mathrm{p}=$ 0.028 ). We found no significant difference in the percentage cover of sponges between the study sites.

\section{DISCUSSION}

This study examined how sponge densities and percentage cover varied between seven sites in the WMND in relation to other major benthic organisms and substrate types. The relationship between hard coral cover and sponge abundance is of particular interest due to current concerns 

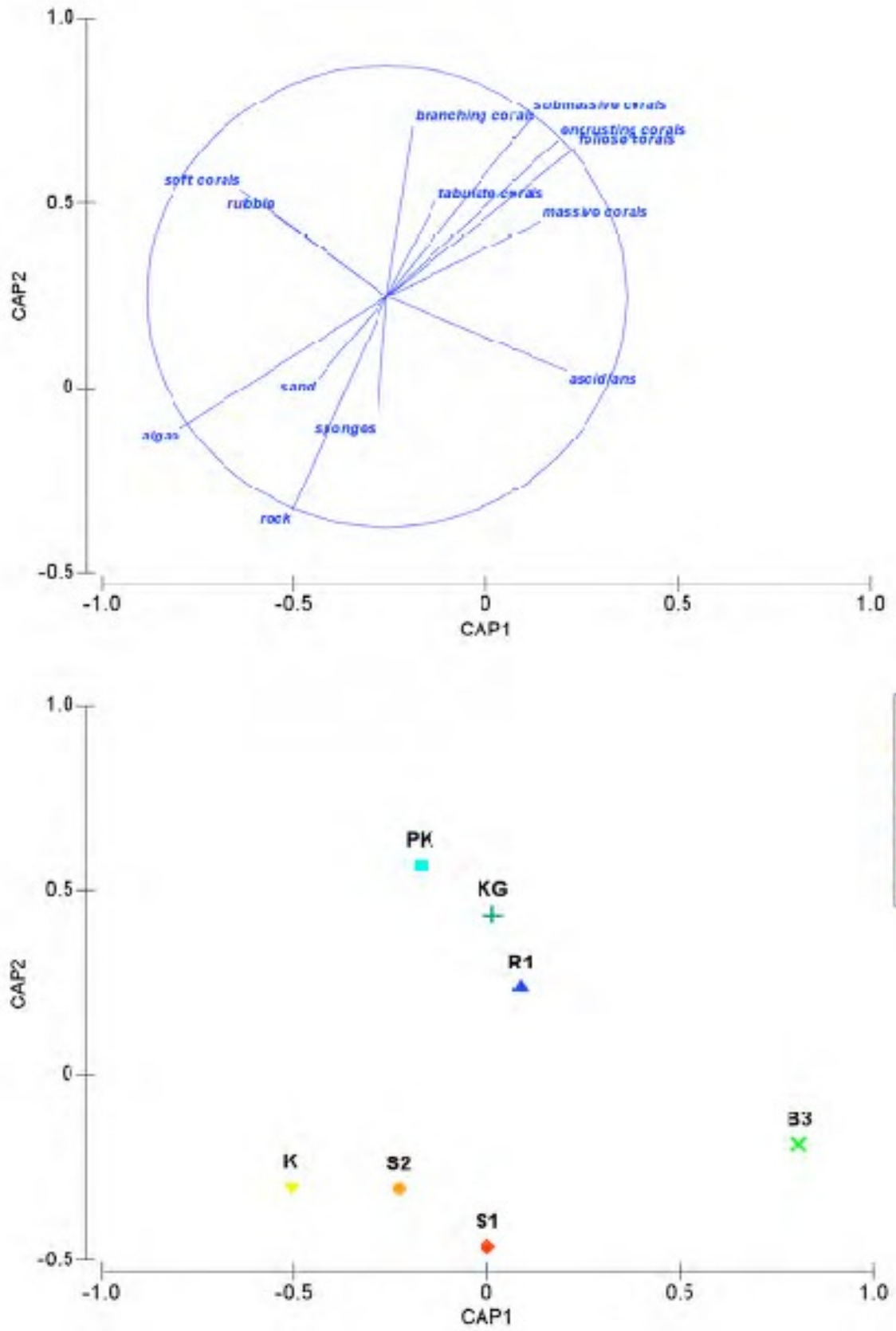

Fig. (3). a) CAP ordination showing similarity between sites. The ordination is based on a Bray-Curtis similarity matrix. b) Vectors represent Spearman rank correlations of individual variables with the CAP axes (restricted to those having lengths $>0.4$ ) indicating which variables characterise the different study sites. 


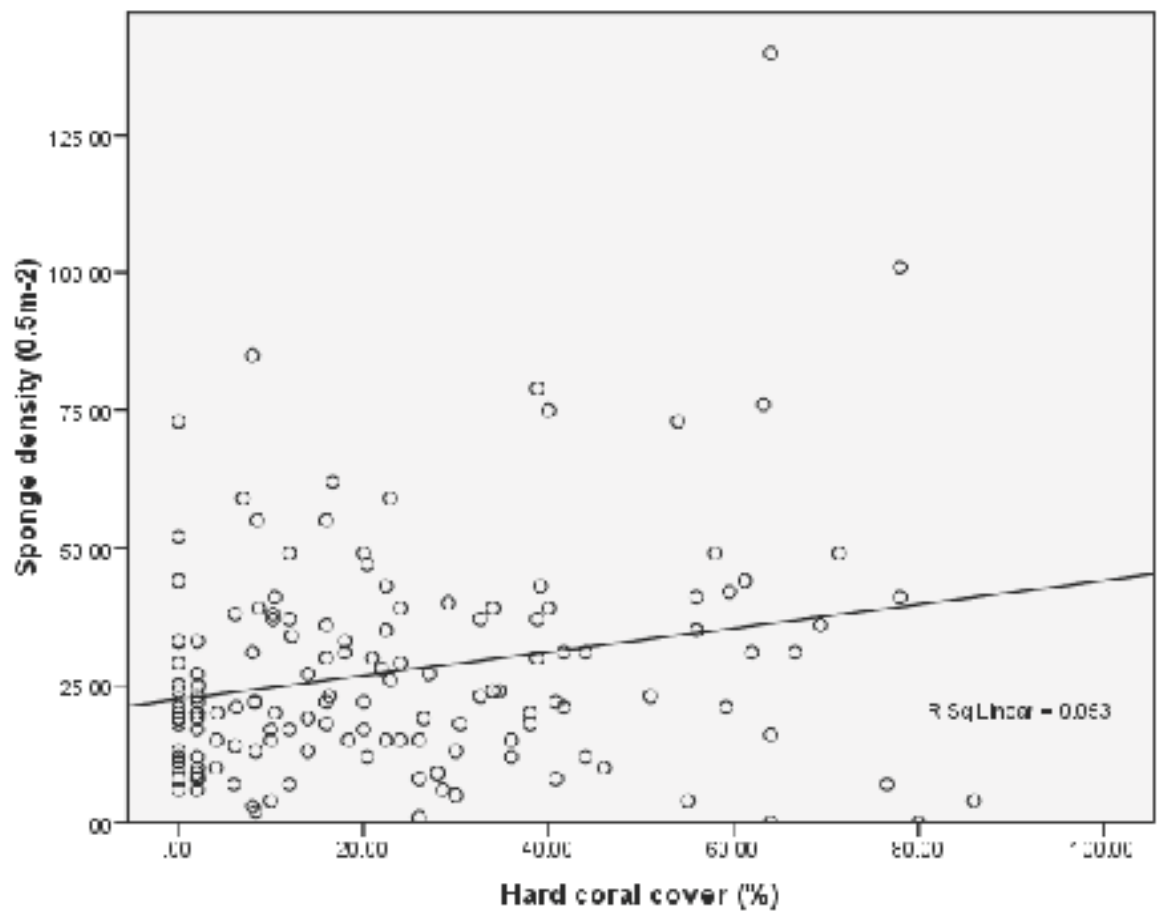

Fig. (4). The relationship between mean sponge density $\left(0.5 \mathrm{~m}^{-2}\right)$ and mean hard coral cover (\%).

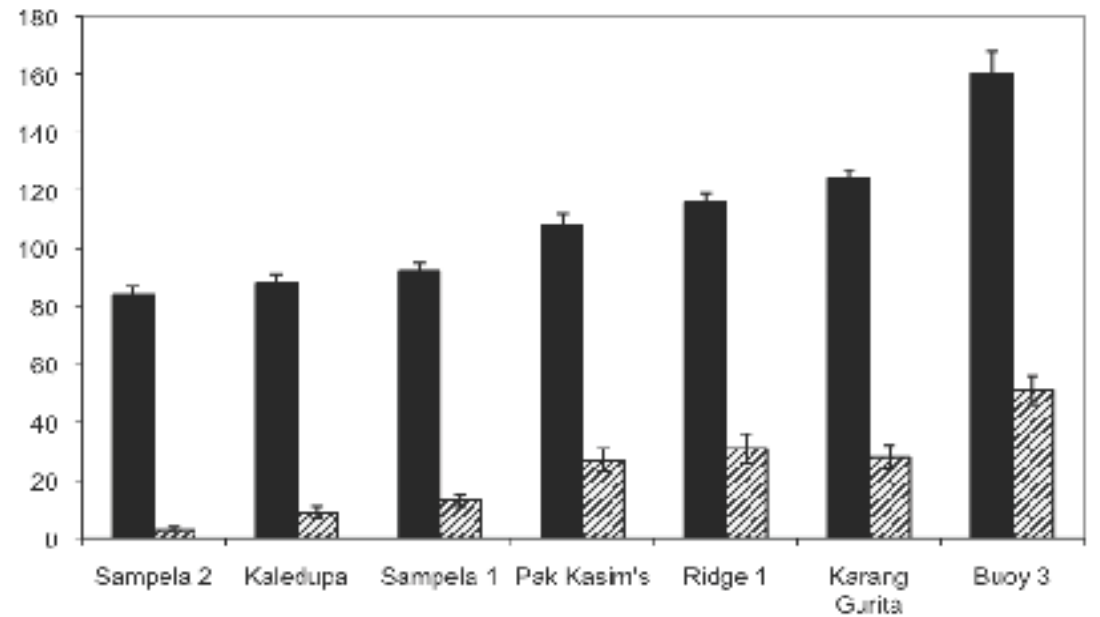

Fig. (5). Mean sponge density $\mathrm{m}^{-2}$ at the seven study sites. $/ 7$ Mean coral cover at the study sites. 
over the loss of hard coral on many Indo-Pacific reefs and how this may influence other organisms. The results of this study contradict our hypothesis that sponge densities would be negatively correlated with hard coral cover as we found a weakly significant positive correlation between sponge abundance and coral cover. We also found a similar patterm when we compared mean sponge densities and mean hard coral cover at the study sites. Sites with higher mean hard coral cover had higher mean sponge densities and conversely sites with lower mean coral cover had lower sponge densities.

One explanation for the relationship between percentage cover of coral and sponge density is that increasing hard coral provides a greater number of micro-habitats for sponges to occupy (eg. amongst the Acropora branches). The majority of the sponges found in the WMNP are small and cryptic, and are found on almost all available substrate types including the undersides of foliose corals and on the skeletons of recently dead corals. Sites with high coral cover had higher levels of recently dead corals than lower coral cover sites (since coral died some time ago), which may also explain our results.

It is also possible that environmental variability between sites may explain the lower sponge densities at some sites. At Sampela 1 and Sampela 2, sedimentation is of particular interest. Both of these sites have low coral cover and also experience high levels of sediment loading. Sedimentation is known to have a number of detrimental effects on corals, but can also have a negative effect on some sponge species [30]. In this study it is difficult to differentiate between the effects of reduced coral cover and sedimentation at Sampela 1 and 2 . It is possible that the lower sponge densities at the Sampela study sites are a result of high levels of sedimentation. rather than lower coral cover.

Alternatively, there may be another factor preventing an increase in sponge densities at low coral cover sites. Despite the fact that some sponges produce toxic secondary metabolites they are known to be an important component of the diet of some reef fish, particularly angelfish [31]. A number of studies have shown that fish predation can affect sponge diversity and abundance on Caribbean reefs [17, 32]. In addition to limiting the distribution of certain species, caging experiments in the Florida Keys have also shown that predation can influence sponge competitive abilities. Excluding predators from naturally occurring sponge-coral interactions resulted in a significant decrease in coral cover compared to uncaged interactions [33]. These results indicate that direct and indirect effects of predation on sponges may have considerable effects on species diversity on Canbbean reefs. Levels of fish predation on sponges in Indonesia are unknown but given its effects in the Canbbean they are likely to have an impact on sponge densities and could be limiting densities at lower coral cover sites in the IndoPacific.

In our study we found that substratum angle had an effect on overall benthic composition, but did not find any effect on sponge densities. Substratum angle is known to influence sponge densities in temperate regions and in 2004 Bell \& Smith found higher numbers of sponges on horizontal, inclined and vertical surfaces respectively at Sampela which they attributed to less sediment settlement on vertical sur- faces. Qualitative observations suggest that increases in the abundance of the encrusting sponge species Dysidea spp. since 2002 may explain why no significant differences were found between surface angles. This sponge was very abundant on horizontal surfaces at Sampela and has photosynthetic symbionts which may explain its abundance on well illuminated hortizontal surfaces despite the sedimentation at this site.

Our results do support our hypothesis that the percentage cover of sponges would be negatively correlated with hard coral cover. This result suggests that although quadrats with lower hard coral cover generally had fewer sponges in them the sponges that did grow there had a greater surface area. Without species information it is impossible to say whether the species that occur in the low coral areas are different to the ones that occur in high coral cover areas. Unlike sponge densities we did not find a significant difference in sponge percentage cover between the study sites due to the high levels of variability.

Multivariate analysis revealed a significant difference in the overall benthic composition between some sites. The results of the CAP ordination showed that the higher quality sites (such as Buoy 3, Karang Gurita and Ridge 1) were characterised by hard corals and that the more degraded sites are characterised by sponges. This was surprising given that we did not find any significant difference between the sponge cover (\%) at the study sites. However, at the degraded sites the proportion of sponge was higher than at the higher quality sites. This finding is significant because it raises the possibility that as a site becomes degraded it may switch from being characterised by hard coral to being characterised by sponges. This can occur even if the percentage cover or number of sponges does not increase when hard coral cover is reduced. A long-term study of shifts in commmity structure of sponges and corals in permanent quadrats on coral reef slopes in the Caribbean found that despite the fact that $78 \%$ of the sponges initially present in 1977 died during the first five years of the study, overall sponge percentage cover and densities remained remarkably stable despite a major reduction in the percentage cover and density of corals due to smothering by macro algae [34].

In contrast, other recent studies have examined temporal changes in tropical sponge assemblages and found changes in sponge abundance over time. A 14 year study of sponges on a shallow reef in Panama revealed a steady disappearance of sponge species over the study period possibily due to sponge disease [35]. The results of a six year study in Mexico found short-term and long term fluctuactions in sponge densities as a result of seasonal changes in wind patterns and large-scale structuring factors such as the $\mathrm{El}$ Niño Southern Oscillation [36]. These contrasting results indicate that the factors controling sponge densities are likely to vary on different reef systems.

In conclusion, we found that sponge densities are weakly positively correlated with hard coral cover whereas sponge percentage cover is wealkly negatively correlated with hard coral cover. These differences may be due to the occurrence large numbers of small sponges in high coral cover areas and lower numbers of larger sponges in low coral cover areas. The weak nature of these correlations suggest that while spatial competition is partially responsible for determining 
sponge densities and percentage cover in the WMNP other factors such as fish predation and other environmental conditions may play a key role and are important areas for future research.

\section{ACKNOWLEDGEMENTS}

Operation Wallacea, Commonwealth Scholarship and Fellowship Plan, Education New Zealand, Singapore Airlines, Matthew Fynes, the staff of Hoga Island Marine Research Station.

\section{REFERENCES}

[1] Wilingon C, Bd Statas of conal reefs of the world Tounsrille: Anatralian Instimts of Marine Science 2004, Vol. 2 .

[2] Hnghes TP. Catastrophes, phase shifts, and lirge-scalo degradation of a Carbbesn coral reof. Science (U.S.) 1994: 265: 1547-51.

[3] Pandolf JM, Bradbury RH, Sala E, et al. Global Trajoctorios of the Long-Term Decline of Coral Reef Econystems. Science 2003; 301 955-8.

[4] Rogen CS. Degradation of Carbbean and Wostenn Atlantic coral reefs and decline of associated fisberios. Proceedings of the fifth Intamational Coral Reef Congress, Tahiti 1985; Vol. 6: po 491-6.

[5] Grabum NAJ, Wilvon SK, Jennings S, Polmin NVC, Bjjoux $\mathbb{P}$, Robinson J. Dynamic frazility of ocosnic coral reof ecorystoms. Robinwon J. Dymamic fragility of oceanic corn

[6] Losser MP. Conal resf blosching and global climato chango: Can conls varvive the nert contury? Proc Natl Acad Sci USÄ 2007 104(13): $5259-60$

71] Thachenko KS, Wh BJ. et al. Dynamics of a coral reef commumity ster man mortality of branching Acropon conls and an outbreal of anemonen. Mar Biol 2007; 15i(1): 185-94.

[B] Fitt WR, Brown BE, Wemer MI, Dume RP. Conal bleaching: interprotation of thermal throsholds in tropical corals. Conl Rees 2001; $20: 31-65$

[9] Bartbel D, Gutt J, Tendal OS. Nerw information on the biology of Antarctic deop-arater sponses derived from underrater photograply. Mrr Ecol Prog Ser 1991; 69(3): 303-7.

[10] Bell JJ, Bumes DKA A sponge diverrity contro within a marine 'ishand. Hydrobiologia 2000; 490: 35-64.

[11] Disx MC, Rutrler K Sponger: An ersential component of Caribbesn coral roefr. Ball Mrr Sci 2001; 69(2): 535-46.

[12] Wulf J. Assossing and monitoring coral roof somgos: Why and how? Bnll Mar Sci 2001; 69(2): 831-46.

[13] Bell JI. The functional roles of marine spongen. Est Coast Shelf Sci 2008; 79(3): 341-53.

[14] Bell JJ, Smith D. Ecology of sponge assemblages (Porifora) in the Wakatobi rogion, south-oast Sulawori, Indonotia: Richnoss and abundance. JMar Biol Assoc UR 2004; 84(3): 581-91.

[15] do Voogd NJ, Cleary DFR Relating species traits to emrirommental variables in Indonenizn coral reef gponge assemblager. Mar Frovhr $\operatorname{Res} 2007 ; 58(3): 240-9$.

[16] Suchenek TH, Carpenter RC, Wimean ID, Harvell CD. Sponges as important space competitorn in deep Carbbesm conal roef communitien. In Reaka ML, Ed. The ecology of deep and ahallow conal reefs \%7 Symposia series for undersea reseurch. Rockvillo, Maryland: NOAA 1983: 55-60.

[17] Wulfi $\pi$. Trade-offs in roistance to conpotiton and prodators, and thair effect on the diverrity of tropical marine sponges. J Anim Bcol 2005; 74(2): 313-21.

[18] Aerts LAM Spongevcoral interactions in Carbbean reefs: amalywis of overgrowth pattems in rolation to specien identity and cover. Mar Ecol Prog Ser 1998; 175: 241-9.

[19] BeIl IJ, Bames DKA. The inportance of competitor identity, morpbology and ranking methodology to outcomes in interforence conspetition between sponger. Mar Biol 2003; 143(3) : 415-26.

[20] Jackson IBC, Buss L. Allolopathy and spatial competition among conl roof invertebnten. Proc Natl Acad Sci USA 1975; 72:5160-3.

[21] Becesto MA, Twrom X, Unix MJ. Maltiplo functions for woondary metabolites in ancrating marine imvertvbratos. J Chem Ecol 1997; 23: 152747 .

[22] Aerts LAM. Dyusmics Behind Standoff Interactions in Throe Reef Sponge Specias and the Coral Moniastraea cavernvesa. Mar Ecol 2000; 21(3-4): 191-204.

[23] do Voogd NJ, Boching IF, Hooksoma BW, Noor A, tran Soost RWWM. Spenge interactions with spatial competitors in the Spermondo Archipelago. Bollotino dai Masei o degli Istituti Biologici della Univerita di Geavon 2004; 68: 253-61.

[24] Hooksoma BW. Delingation of the Indo-Malryzm centre of maximum marine biodiverrity. the coral triangle biogeograply, time, and place: distributions, barriers, and ialnds: Springer. The Notherlands 2007: pp. 117-78.

[25] Crabbe M, Smith DJ. Comparison of two reef sites in the Wabatobi Marine National Park (SE Sularrori, Indomerin) uxing digital image analyvis. Coral Reefs 2002;21(3): 242-4.

[26] Par-Soede I. Frimann M, Eds Rapid Ecologial Assosmont Wabatobi Nationsl Park. Neromber 2003. Report from WWF Indomenia Marine Program, Deoparar, Bali: Iodanevis 2004

[27] Kohlar KF, Gill SM Conl Point Cornt with Excol extenvions (CPCo): A Virul Baxic program for the detarmination of coral and ubbstrto coveraso using rombom point count methodology. Comput Goosci 2006; 32(9): 1259-69.

[28] Andarvon MJ. PERMANOVA: a FORTRAN conputer program for pernumbional maltivariate anabyis of variance. Norr Zesland: Dopartment of Statistick, Univerity of Anckland 2005 .

[29] Andarson MJ, Willis TJ. Camonical malysis of principal coordinaton: a useful method of constrained ordination for ecology. Ecology 2003; 84(2): 511-25.

[30] Gerrodetto T, Flechnig AO. Sediment-induced reduction in the pamping rate of the tropical sponso Verongir-Lacunosa. Mar Biol panping rate of the tro

[31] Randall IR, Hartann WD. Sponge-foeding fishes of the Wort Indien. Mar Biol 1968; 1: 216-25.

[32] Dunlap M, Parril $\mathbb{R}$. Spongivary by partotifish in Florida anerowo and reof habitats. Mar Ecol 1998; 19(4) $325-37$.

[33] Hill MS. Spongivary on Cribbasn roefs roleases conls from conspetition with sponges. Oecologia 1998; $117(1-2): 143-50$.

[34] Hughes TP. Domographic approxches to comnramity dynsmics: a conal roef example. Ecology 1996; $77(7)$ : 2256-60.

[35] Wulff L. Rapid diverrity and abundance decline in a Carbbesn coral roof sponge commumity. Biol Cons 2006; 127: 167-76.

[36] Carballo IL, Voga C, Crur-Baman IA, et al Short- and long-tarm pathems of oponge fivenity on a rock tropical coast: oridence of largo-scalo stucturing factorn. Mar Bcol 2005; 29: 216-36.

\begin{tabular}{lll}
\hline Receivid: Jame 02, 2009 & Revised: Novvember 17, 2009 & Acceptad: January 08, 2010
\end{tabular}

- Pouvll et al.; Licansoo Benham Open.

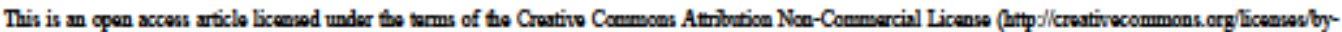
ac/3.0), which pormits umrostrictod, non-commercial use, distribution and roproduction in smy medium, provided the wouk is properly cited. 


\section{Appendix 2}

Detailed description of the methods used to relate the number of bites that fish took on sponges to the availability of sponges in the environment and also to examine whether nudibranchs and starfish were found more frequently on sponges than would be expected given the proportion of sponge in the environment. The following illustrations represent the set up at each site (Sampela 1, Sampela 2, Buoy 3, Buoy 4).

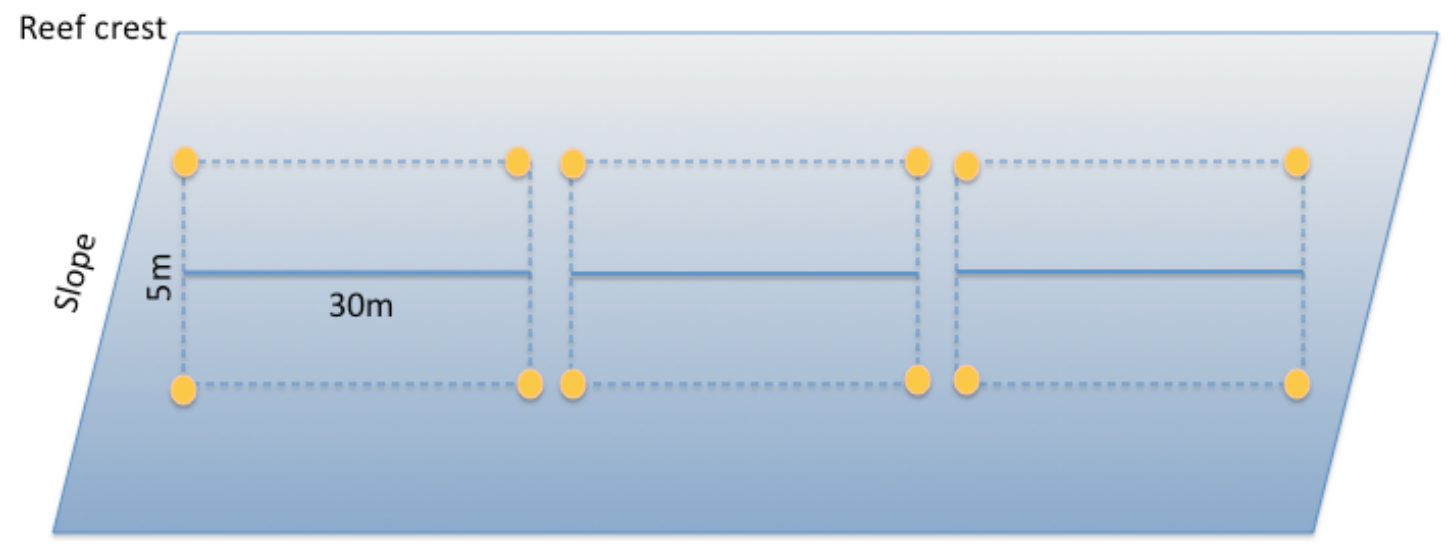

a.

b.

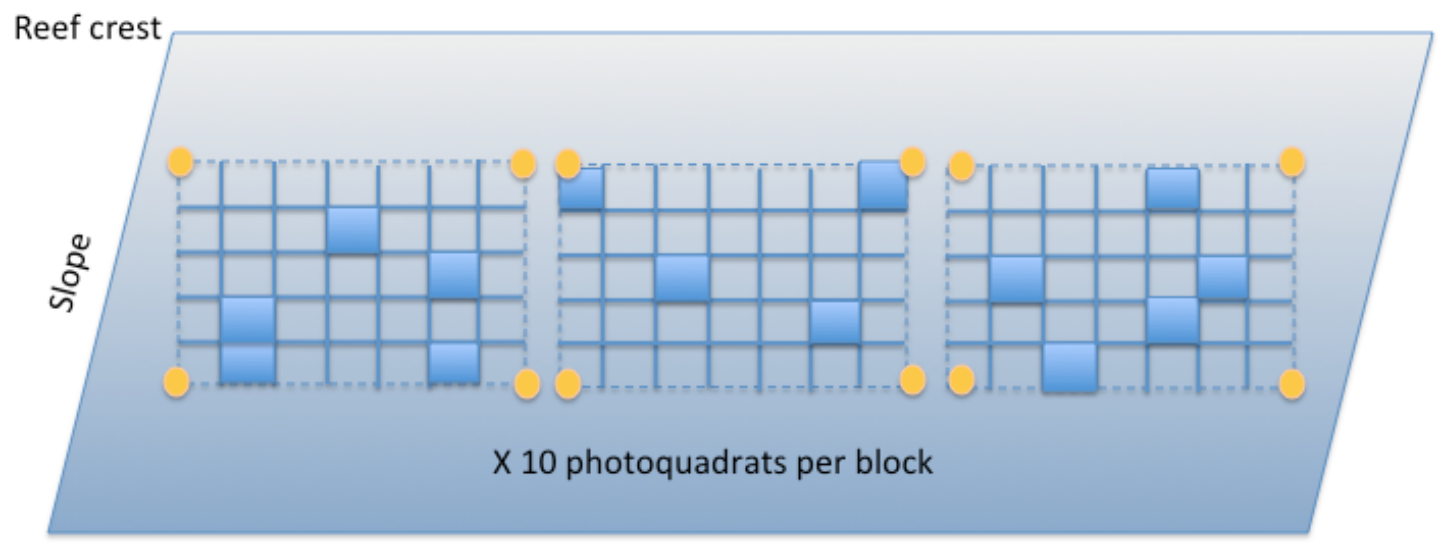

Figure 1

a) A $30 \mathrm{~m}$ transect was laid out parallel to the reef crest at a depth of $10 \mathrm{~m}$. Flagging tape was placed at the ends of the transect $2.5 \mathrm{~m}$ above and below the tape to define a 
$150 \mathrm{~m}^{2}$ area. These plots were surveyed for invertebrates that were identified to species level and the substrates that they were found on recorded (e.g. sponge, rock, algae etc.). Fish observations of feeding behaviour were also carried out within these plots on subsequent dives.

b) Photographs of ten $1 \mathrm{~m}^{2}$ quadrats per plot were used to survey the benthic characteristics at the study sites. The position of the photoquadrats was determined by splitting up the $150 \mathrm{~m}^{2}$ plots into a virtual grid where each $1 \mathrm{~m}^{2}$ cell was assigned a number. A random number generator was then used to select ten positions within each plot, which were photographed and analysed using CPCe. 


\section{Appendix 3}

Table 1. Observed abundances of reef fish observed at the nine sites around Hoga and Kaledupa Islands. Densities are the mean densities observed across three $250 \mathrm{~m}^{2}$ transects and values in parentheses are the standard error.

\begin{tabular}{|c|c|c|c|c|c|c|c|c|c|c|}
\hline \multirow[b]{2}{*}{ Family } & \multirow[b]{2}{*}{ Species } & \multicolumn{9}{|c|}{ Site Density (ind $/ 250 \mathrm{~m}^{2}$ ) } \\
\hline & & $\begin{array}{l}m \\
\overrightarrow{0} \\
\stackrel{0}{0}\end{array}$ & 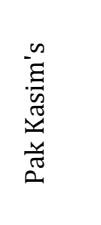 & $\begin{array}{l}\vec{d} \\
\stackrel{\Delta}{0} \\
\overrightarrow{0}\end{array}$ & 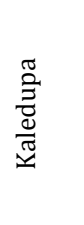 & $\begin{array}{l}\vec{a} \\
\stackrel{\overrightarrow{0}}{0}\end{array}$ & 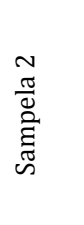 & $\begin{array}{l}\overrightarrow{+} \\
\overrightarrow{0} \\
\stackrel{0}{0}\end{array}$ & 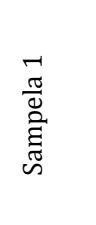 & 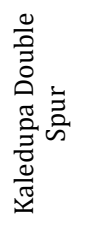 \\
\hline Acanthuridae & $\begin{array}{l}\text { Acanthurus } \\
\text { auranticavus }\end{array}$ & $0(0)$ & $0(0)$ & $0(0)$ & $0(0)$ & $0(0)$ & $0(0)$ & $0(0)$ & $\begin{array}{c}2.3 \\
(1.2)\end{array}$ & $0(0)$ \\
\hline Acanthuridae & $\begin{array}{l}\text { Acanthurus } \\
\text { nigrofuscus }\end{array}$ & $1(1)$ & $3(0.6)$ & $\begin{array}{c}3.3 \\
(0.3)\end{array}$ & $\begin{array}{c}1.7 \\
(0.3)\end{array}$ & $1(0.6)$ & $\begin{array}{c}1.7 \\
(1.7)\end{array}$ & $0(0)$ & $\begin{array}{c}2.7 \\
(1.5)\end{array}$ & $\begin{array}{c}2.7 \\
(1.2)\end{array}$ \\
\hline Acanthuridae & $\begin{array}{l}\text { Acanthurus } \\
\text { pyroferus }\end{array}$ & $\begin{array}{c}1.7 \\
(1.2)\end{array}$ & $\begin{array}{c}5.3 \\
(1.7)\end{array}$ & $\begin{array}{c}7.7 \\
(1.5)\end{array}$ & $\begin{array}{c}5.7 \\
(1.2)\end{array}$ & $\begin{array}{c}3.3 \\
(1.8)\end{array}$ & $\begin{array}{c}2.3 \\
(0.3)\end{array}$ & $\begin{array}{c}1.7 \\
(0.9)\end{array}$ & $6(3.6)$ & $\begin{array}{c}4.3 \\
(1.3)\end{array}$ \\
\hline Acanthuridae & $\begin{array}{l}\text { Acanthus } \\
\text { thompsoni }\end{array}$ & $\begin{array}{c}0.3 \\
(0.3)\end{array}$ & $\begin{array}{c}0.7 \\
(0.7)\end{array}$ & $\begin{array}{c}0.7 \\
(0.7)\end{array}$ & $\begin{array}{c}0.7 \\
(0.7)\end{array}$ & $\begin{array}{c}0.3 \\
(0.3)\end{array}$ & $0(0)$ & $\begin{array}{c}0.3 \\
(0.3)\end{array}$ & $0(0)$ & $\begin{array}{c}0.7 \\
(0.7)\end{array}$ \\
\hline Acanthuridae & $\begin{array}{l}\text { Ctenochaetus } \\
\text { binotatus }\end{array}$ & $\begin{array}{c}0.7 \\
(0.3)\end{array}$ & $1(0.6)$ & $\begin{array}{c}1.3 \\
(0.9)\end{array}$ & $\begin{array}{c}8.7 \\
(1.3)\end{array}$ & $\begin{array}{c}4.7 \\
(1.3)\end{array}$ & $\begin{array}{c}6 \\
(2.1)\end{array}$ & $5.7(2)$ & $\begin{array}{c}7.3 \\
(1.5)\end{array}$ & $10(4)$ \\
\hline Acanthuridae & $\begin{array}{l}\text { Ctenochaetus } \\
\text { striatus }\end{array}$ & $3(1.7)$ & $0(0)$ & $\begin{array}{c}1.7 \\
(1.2)\end{array}$ & $\begin{array}{c}1.3 \\
(0.9)\end{array}$ & $\begin{array}{c}0.7 \\
(0.7)\end{array}$ & $\begin{array}{c}4.7 \\
(1.5)\end{array}$ & $2(0)$ & $7(3.6)$ & $\begin{array}{c}1.3 \\
(0.9)\end{array}$ \\
\hline Acanthuridae & Naso lituratus & $\begin{array}{c}0.3 \\
(0.3)\end{array}$ & $0(0)$ & $\begin{array}{c}0.3 \\
(0.3)\end{array}$ & $0(0)$ & $\begin{array}{c}0.3 \\
(0.3)\end{array}$ & $0(0)$ & $0(0)$ & $0(0)$ & $0(0)$ \\
\hline Acanthuridae & Naso vlamingii & $0(0)$ & $\begin{array}{c}2.3 \\
(1.9)\end{array}$ & $0(0)$ & $0(0)$ & $\begin{array}{c}6.7 \\
(4.1)\end{array}$ & $\begin{array}{c}0.3 \\
(0.3)\end{array}$ & $0(0)$ & $0(0)$ & $\begin{array}{c}0.3 \\
(0.3)\end{array}$ \\
\hline Acanthuridae & Zebrasoma scopas & $\begin{array}{c}0.7 \\
(0.3)\end{array}$ & $3(0)$ & $2(0.6)$ & $\begin{array}{l}10.7 \\
(1.2)\end{array}$ & $3(2)$ & $\begin{array}{c}0.7 \\
(0.7)\end{array}$ & $1(0.6)$ & $\begin{array}{c}5.7 \\
(2.8)\end{array}$ & $5(1)$ \\
\hline Acanthuridae & $\begin{array}{l}\text { Zebrasoma } \\
\text { veliferum }\end{array}$ & $0(0)$ & $0(0)$ & $0(0)$ & $0(0)$ & $\begin{array}{c}0.7 \\
(0.7)\end{array}$ & $0(0)$ & $0(0)$ & $0(0)$ & $0(0)$ \\
\hline Anthinae & $\begin{array}{l}\text { Pseudanthias } \\
\text { huchtii }\end{array}$ & $0(0)$ & $\begin{array}{c}10.3 \\
(10.3)\end{array}$ & $0(0)$ & $0(0)$ & $\begin{array}{c}21.3 \\
(21.3)\end{array}$ & $0(0)$ & $\begin{array}{c}8.3 \\
(6.9)\end{array}$ & $\begin{array}{c}4.7 \\
(4.7)\end{array}$ & $0(0)$ \\
\hline Anthinae & $\begin{array}{l}\text { Pseudanthias } \\
\text { pleurotaenia }\end{array}$ & $\begin{array}{c}3.7 \\
(2.3)\end{array}$ & $0(0)$ & $0(0)$ & $0(0)$ & $0(0)$ & $0(0)$ & $\begin{array}{c}5.3 \\
(5.3)\end{array}$ & $0(0)$ & $0(0)$ \\
\hline Anthinae & $\begin{array}{l}\text { Pseudanthias } \\
\text { squamipinnis }\end{array}$ & $\begin{array}{c}3.7 \\
(1.9)\end{array}$ & $\begin{array}{c}1.7 \\
(1.7)\end{array}$ & $0(0)$ & $0(0)$ & $9(4.7)$ & $0(0)$ & $0(0)$ & $0(0)$ & $0(0)$ \\
\hline Anthinae & Pseudanthias tuka & $0(0)$ & $\begin{array}{c}3.3 \\
(3.3)\end{array}$ & $0(0)$ & $0(0)$ & $0(0)$ & $0(0)$ & $\begin{array}{c}2.3 \\
(2.3)\end{array}$ & $0(0)$ & $0(0)$ \\
\hline Apogonidae & Apogon compresus & $0(0)$ & $0(0)$ & $0(0)$ & $0(0)$ & $0(0)$ & $0(0)$ & $0(0)$ & $0(0)$ & $\begin{array}{c}2.3 \\
(2.3)\end{array}$ \\
\hline Apogonidae & $\begin{array}{c}\text { Apogon } \\
\text { leptocanthus }\end{array}$ & $0(0)$ & $0(0)$ & $0(0)$ & $0(0)$ & $0(0)$ & $0(0)$ & $0(0)$ & $0(0)$ & $\begin{array}{c}10 \\
(10)\end{array}$ \\
\hline
\end{tabular}




\begin{tabular}{|c|c|c|c|c|c|c|c|c|c|c|}
\hline Apogonidae & $\begin{array}{l}\text { Apogon } \\
\text { multilineatus }\end{array}$ & $0(0)$ & $0(0)$ & $0(0)$ & $0(0)$ & $0(0)$ & $0(0)$ & $0(0)$ & $\begin{array}{c}0.7 \\
(0.7)\end{array}$ & $0(0)$ \\
\hline Apogonidae & $\begin{array}{l}\text { Archamia } \\
\text { macroptera }\end{array}$ & $0(0)$ & $0(0)$ & $0(0)$ & $0(0)$ & $\begin{array}{c}0.7 \\
(0.7)\end{array}$ & $0(0)$ & $0(0)$ & $0(0)$ & $0(0)$ \\
\hline Apogonidae & $\begin{array}{l}\text { Cheilodiptherus } \\
\text { macrodon }\end{array}$ & $\begin{array}{c}1.7 \\
(0.3)\end{array}$ & $0(0)$ & $0(0)$ & $\begin{array}{c}0.3 \\
(0.3)\end{array}$ & $0(0)$ & $0(0)$ & $\begin{array}{c}2.3 \\
(1.9)\end{array}$ & $0(0)$ & $\begin{array}{c}0.3 \\
(0.3)\end{array}$ \\
\hline Apogonidae & $\begin{array}{l}\text { Cheilodiptherus } \\
\text { quinquelineatus }\end{array}$ & $0(0)$ & $0(0)$ & $0(0)$ & $0(0)$ & $0(0)$ & $\begin{array}{l}1.3 \\
(0.9)\end{array}$ & $0(0)$ & $0(0)$ & $0(0)$ \\
\hline Aulostomidae & $\begin{array}{l}\text { Aulostomus } \\
\text { chinensis }\end{array}$ & $0(0)$ & $\begin{array}{c}0.3 \\
(0.3)\end{array}$ & $0(0)$ & $\begin{array}{c}0.3 \\
(0.3)\end{array}$ & $\begin{array}{c}0.3 \\
(0.3)\end{array}$ & $0(0)$ & $0(0)$ & $0(0)$ & $\begin{array}{c}0.3 \\
(0.3)\end{array}$ \\
\hline Balistidae & $\begin{array}{l}\text { Balistapus } \\
\text { undulatus }\end{array}$ & $1(0.6)$ & $\begin{array}{c}2.3 \\
(1.2)\end{array}$ & $\begin{array}{c}1.3 \\
(0.9)\end{array}$ & $1(0.6)$ & $\begin{array}{c}0.3 \\
(0.3)\end{array}$ & $\begin{array}{c}1 \\
(0.6)\end{array}$ & $1(0)$ & $\begin{array}{c}0.3 \\
(0.3)\end{array}$ & $\begin{array}{c}0.3 \\
(0.3)\end{array}$ \\
\hline Balistidae & Melichthys vidua & $\begin{array}{c}1.3 \\
(0.3)\end{array}$ & $\begin{array}{c}0.3 \\
(0.3)\end{array}$ & $\begin{array}{c}1.3 \\
(0.7)\end{array}$ & $\begin{array}{c}0.3 \\
(0.3)\end{array}$ & $\begin{array}{c}0.3 \\
(0.3)\end{array}$ & $0(0)$ & $\begin{array}{c}0.7 \\
(0.3)\end{array}$ & $0(0)$ & $0(0)$ \\
\hline Balistidae & Odonus niger & $\begin{array}{l}11.3 \\
(7)\end{array}$ & $7(7)$ & $\begin{array}{l}24.7 \\
(9.3)\end{array}$ & $0(0)$ & $\begin{array}{c}38.3 \\
(14.9)\end{array}$ & $0(0)$ & $\begin{array}{l}20.7 \\
(5.9)\end{array}$ & $0(0)$ & $0(0)$ \\
\hline Balistidae & Sufflamen bursa & $0(0)$ & $0(0)$ & $0(0)$ & $\begin{array}{c}0.3 \\
(0.3)\end{array}$ & $0(0)$ & $\begin{array}{l}1.7 \\
(0.9)\end{array}$ & $0(0)$ & $\begin{array}{c}0.3 \\
(0.3)\end{array}$ & $0(0)$ \\
\hline Blenidae & Ecsenius midas & $\begin{array}{c}0.3 \\
(0.3)\end{array}$ & $\begin{array}{c}0.3 \\
(0.3)\end{array}$ & $0(0)$ & $0(0)$ & $\begin{array}{c}0.7 \\
(0.3)\end{array}$ & $0(0)$ & $0(0)$ & $0(0)$ & $0(0)$ \\
\hline Blenidae & Ecsenius pictus & $0(0)$ & $0(0)$ & $0(0)$ & $\begin{array}{c}0.3 \\
(0.3)\end{array}$ & $0(0)$ & $0(0)$ & $0(0)$ & $0(0)$ & $\begin{array}{c}0.3 \\
(0.3)\end{array}$ \\
\hline Blenidae & $\begin{array}{l}\text { Plagiotremus } \\
\text { rhinorhynchos }\end{array}$ & $0(0)$ & $0(0)$ & $0(0)$ & $0(0)$ & $\begin{array}{c}0.3 \\
(0.3)\end{array}$ & $0(0)$ & $0(0)$ & $0(0)$ & $0(0)$ \\
\hline Caesionidae & Caesio cuning & $0(0)$ & $0(0)$ & $0(0)$ & $0(0)$ & $0(0)$ & $0(0)$ & $0(0)$ & $0(0)$ & $1(1)$ \\
\hline Caesionidae & Caesio teres & $0(0)$ & $0(0)$ & $0(0)$ & $0(0)$ & $0(0)$ & $0(0)$ & $0(0)$ & $0(0)$ & $\begin{array}{c}1.7 \\
(1.7)\end{array}$ \\
\hline Caesionidae & Pterocaesio tile & $0(0)$ & $0(0)$ & $0(0)$ & $\begin{array}{c}43.3 \\
(43.3)\end{array}$ & $\begin{array}{c}33.3 \\
(33.3)\end{array}$ & $0(0)$ & $0(0)$ & $0(0)$ & $0(0)$ \\
\hline Caesionidae & Pterocaesio pisang & $\begin{array}{c}16.7 \\
(16.7)\end{array}$ & $\begin{array}{c}3.3 \\
(3.3)\end{array}$ & $\begin{array}{c}13.3 \\
(13.3)\end{array}$ & $\begin{array}{c}8.7 \\
(5.2)\end{array}$ & $\begin{array}{c}50 \\
(28.9)\end{array}$ & $0(0)$ & $0(0)$ & $0(0)$ & $\begin{array}{c}3.7 \\
(3.7)\end{array}$ \\
\hline Caesionidae & $\begin{array}{l}\text { Pterocaesio } \\
\text { randalli }\end{array}$ & $0(0)$ & $0(0)$ & $0(0)$ & $0(0)$ & $0(0)$ & $0(0)$ & $0(0)$ & $0(0)$ & $\begin{array}{c}16.7 \\
(16.7)\end{array}$ \\
\hline Caesionidae & $\begin{array}{c}\text { Pterocaesio } \\
\text { trilineata }\end{array}$ & $0(0)$ & $0(0)$ & $0(0)$ & $0(0)$ & $\begin{array}{l}123.3 \\
(72.2)\end{array}$ & $0(0)$ & $0(0)$ & $0(0)$ & $0(0)$ \\
\hline Carangidae & $\begin{array}{c}\text { Caranx } \\
\text { melampygus }\end{array}$ & $0(0)$ & $0(0)$ & $\begin{array}{c}0.3 \\
(0.3)\end{array}$ & $0(0)$ & $0(0)$ & $0(0)$ & $0(0)$ & $0(0)$ & $0(0)$ \\
\hline Chaetodontidae & Chaetodon auriga & $0(0)$ & $0(0)$ & $0(0)$ & $\begin{array}{c}0.7 \\
(0.3)\end{array}$ & $0(0)$ & $\begin{array}{c}0.3 \\
(0.3)\end{array}$ & $0(0)$ & $0(0)$ & $0(0)$ \\
\hline Chaetodontidae & $\begin{array}{l}\text { Chaetodon } \\
\text { baronessa }\end{array}$ & $0(0)$ & $\begin{array}{c}0.3 \\
(0.3)\end{array}$ & $0(0)$ & $\begin{array}{c}0.3 \\
(0.3)\end{array}$ & $0(0)$ & $0(0)$ & $\begin{array}{c}0.7 \\
(0.3)\end{array}$ & $1(1)$ & $\begin{array}{c}0.7 \\
(0.7)\end{array}$ \\
\hline Chaetodontidae & $\begin{array}{l}\text { Chaetodon } \\
\text { bennetti }\end{array}$ & $0(0)$ & $\begin{array}{c}0.7 \\
(0.7)\end{array}$ & $0(0)$ & $0(0)$ & $0(0)$ & $0(0)$ & $0(0)$ & $0(0)$ & $0(0)$ \\
\hline Chaetodontidae & Chaetodon kleinii & $\begin{array}{c}0.3 \\
(0.3)\end{array}$ & $1(0.6)$ & $\begin{array}{c}3.3 \\
(0.7)\end{array}$ & $2(2)$ & $2(1)$ & $\begin{array}{l}3.7 \\
(2)\end{array}$ & $\begin{array}{c}2.3 \\
(0.9)\end{array}$ & $4(0)$ & $\begin{array}{c}3.3 \\
(2.4)\end{array}$ \\
\hline Chaetodontidae & $\begin{array}{l}\text { Chaetodon } \\
\text { lineolatus }\end{array}$ & $0(0)$ & $0(0)$ & $0(0)$ & $0(0)$ & $0(0)$ & $0(0)$ & $\begin{array}{c}0.3 \\
(0.3)\end{array}$ & $0(0)$ & $0(0)$ \\
\hline
\end{tabular}




\begin{tabular}{|c|c|c|c|c|c|c|c|c|c|c|}
\hline Chaetodontidae & Chaetodon lunula & $\begin{array}{c}0.3 \\
(0.3)\end{array}$ & $0(0)$ & $0(0)$ & $0(0)$ & $0(0)$ & $\begin{array}{c}0.3 \\
(0.3)\end{array}$ & $0(0)$ & $0(0)$ & $0(0)$ \\
\hline Chaetodontidae & $\begin{array}{c}\text { Chaetodon } \\
\text { lunulatus }\end{array}$ & $0(0)$ & $\begin{array}{c}0.7 \\
(0.7)\end{array}$ & $\begin{array}{c}0.3 \\
(0.3)\end{array}$ & $0(0)$ & $\begin{array}{c}1.3 \\
(0.3)\end{array}$ & $\begin{array}{c}2.3 \\
(1.5)\end{array}$ & $\begin{array}{c}1.7 \\
(0.9)\end{array}$ & $1(1)$ & $3(2.1)$ \\
\hline Chaetodontidae & $\begin{array}{l}\text { Chaetodon } \\
\text { melannotus }\end{array}$ & $0(0)$ & $\begin{array}{c}0.3 \\
(0.3)\end{array}$ & $1(1)$ & $2(1.2)$ & $\begin{array}{c}1.3 \\
(1.3)\end{array}$ & $0(0)$ & $0(0)$ & $0(0)$ & $\begin{array}{c}1.3 \\
(0.9)\end{array}$ \\
\hline Chaetodontidae & $\begin{array}{c}\text { Chaetodon } \\
\text { mertensii }\end{array}$ & $0(0)$ & $0(0)$ & $0(0)$ & $0(0)$ & $0(0)$ & $0(0)$ & $0(0)$ & $\begin{array}{c}0.3 \\
(0.3)\end{array}$ & $0(0)$ \\
\hline Chaetodontidae & Chaetodon meyeri & $\begin{array}{c}0.3 \\
(0.3)\end{array}$ & $0(0)$ & $0(0)$ & $0(0)$ & $0(0)$ & $0(0)$ & $0(0)$ & $\begin{array}{c}0.3 \\
(0.3)\end{array}$ & $\begin{array}{c}0.7 \\
(0.7)\end{array}$ \\
\hline Chaetodontidae & $\begin{array}{l}\text { Chaetodon } \\
\text { ornatissimus }\end{array}$ & $0(0)$ & $\begin{array}{c}0.3 \\
(0.3)\end{array}$ & $\begin{array}{c}0.7 \\
(0.3)\end{array}$ & $\begin{array}{c}0.7 \\
(0.7)\end{array}$ & $0(0)$ & $0(0)$ & $\begin{array}{c}1.3 \\
(0.7)\end{array}$ & $0(0)$ & $0(0)$ \\
\hline Chaetodontidae & $\begin{array}{c}\text { Chaetodon } \\
\text { punctatofasciatus }\end{array}$ & $\begin{array}{c}1.3 \\
(0.9)\end{array}$ & $\begin{array}{c}2.3 \\
(1.9)\end{array}$ & $\begin{array}{c}0.3 \\
(0.3)\end{array}$ & $\begin{array}{c}0.7 \\
(0.7)\end{array}$ & $2(1.2)$ & $0(0)$ & $\begin{array}{c}2.7 \\
(1.2)\end{array}$ & $0(0)$ & $1(1)$ \\
\hline Chaetodontidae & Chaetodon rafflesi & $0(0)$ & $0(0)$ & $0(0)$ & $0(0)$ & $0(0)$ & $0(0)$ & $0(0)$ & $1(1)$ & $0(0)$ \\
\hline Chaetodontidae & $\begin{array}{l}\text { Chaetodon } \\
\text { speculum }\end{array}$ & $0(0)$ & $0(0)$ & $\begin{array}{c}0.3 \\
(0.3)\end{array}$ & $0(0)$ & $0(0)$ & $0(0)$ & $0(0)$ & $0(0)$ & $0(0)$ \\
\hline Chaetodontidae & $\begin{array}{l}\text { Chaetodon } \\
\text { trifascialis }\end{array}$ & $\begin{array}{c}0.7 \\
(0.7)\end{array}$ & $0(0)$ & $0(0)$ & $0(0)$ & $\begin{array}{c}0.3 \\
(0.3)\end{array}$ & $0(0)$ & $0(0)$ & $0(0)$ & $0(0)$ \\
\hline Chaetodontidae & $\begin{array}{l}\text { Chaetodon } \\
\text { ulietensis }\end{array}$ & $0(0)$ & $1(0.6)$ & $\begin{array}{c}0.3 \\
(0.3)\end{array}$ & $0(0)$ & $0(0)$ & $0(0)$ & $1(1)$ & $0(0)$ & $0(0)$ \\
\hline Chaetodontidae & $\begin{array}{l}\text { Chaetodon } \\
\text { unimaculatus }\end{array}$ & $0(0)$ & $\begin{array}{c}0.7 \\
(0.7)\end{array}$ & $\begin{array}{c}0.7 \\
(0.7)\end{array}$ & $0(0)$ & $0(0)$ & $0(0)$ & $0(0)$ & $0(0)$ & $\begin{array}{c}0.3 \\
(0.3)\end{array}$ \\
\hline Chaetodontidae & $\begin{array}{l}\text { Chaetodon } \\
\text { vagabundus }\end{array}$ & $\begin{array}{c}0.7 \\
(0.7)\end{array}$ & $0(0)$ & $\begin{array}{c}0.3 \\
(0.3)\end{array}$ & $\begin{array}{c}0.3 \\
(0.3)\end{array}$ & $\begin{array}{c}0.7 \\
(0.3)\end{array}$ & $\begin{array}{c}1 \\
(0.6)\end{array}$ & $0(0)$ & $2(1.2)$ & $0(0)$ \\
\hline Chaetodontidae & $\begin{array}{l}\text { Chaetodon } \\
\text { xanthurus }\end{array}$ & $0(0)$ & $0(0)$ & $0(0)$ & $0(0)$ & $0(0)$ & $0(0)$ & $0(0)$ & $0(0)$ & $0(0)$ \\
\hline Chaetodontidae & $\begin{array}{l}\text { Forcipiger } \\
\text { flavissimus }\end{array}$ & $\begin{array}{c}4.3 \\
(1.3)\end{array}$ & $\begin{array}{c}5.7 \\
(1.2)\end{array}$ & $\begin{array}{c}2.3 \\
(0.3)\end{array}$ & $\begin{array}{c}1.7 \\
(0.7)\end{array}$ & $3(1)$ & $\begin{array}{c}1.7 \\
(1.7)\end{array}$ & $3.3(2)$ & $1(0.6)$ & $3(1.5)$ \\
\hline Chaetodontidae & $\begin{array}{c}\text { Hemitaurichthys } \\
\text { polylepis }\end{array}$ & $0(0)$ & $0(0)$ & $\begin{array}{c}1.3 \\
(1.3)\end{array}$ & $0(0)$ & $0(0)$ & $0(0)$ & $0(0)$ & $0(0)$ & $\begin{array}{c}20 \\
(19.5)\end{array}$ \\
\hline Chaetodontidae & $\begin{array}{l}\text { Heniochus } \\
\text { acuminatus }\end{array}$ & $0(0)$ & $0(0)$ & $0(0)$ & $0(0)$ & $0(0)$ & $\begin{array}{c}0.3 \\
(0.3)\end{array}$ & $0(0)$ & $0(0)$ & $0(0)$ \\
\hline Chaetodontidae & $\begin{array}{c}\text { Heniochus } \\
\text { chrysostomus }\end{array}$ & $\begin{array}{c}0.7 \\
(0.7)\end{array}$ & $0(0)$ & $0(0)$ & $0(0)$ & $0(0)$ & $\begin{array}{c}0.3 \\
(0.3)\end{array}$ & $\begin{array}{c}0.7 \\
(0.7)\end{array}$ & $0(0)$ & $\begin{array}{c}0.7 \\
(0.7)\end{array}$ \\
\hline Chaetodontidae & Heniochus varius & $\begin{array}{c}1.3 \\
(0.9)\end{array}$ & $\begin{array}{c}0.3 \\
(0.3)\end{array}$ & $\begin{array}{c}0.7 \\
(0.7)\end{array}$ & $0(0)$ & $\begin{array}{c}0.7 \\
(0.3)\end{array}$ & $\begin{array}{c}0.7 \\
(0.7)\end{array}$ & $\begin{array}{c}0.7 \\
(0.7)\end{array}$ & $2(1)$ & $\begin{array}{c}0.3 \\
(0.3)\end{array}$ \\
\hline Cirrhitidae & Cirrhitichthys falco & $\begin{array}{c}0.3 \\
(0.3)\end{array}$ & $0(0)$ & $0(0)$ & $0(0)$ & $0(0)$ & $0(0)$ & $0(0)$ & $0(0)$ & $0(0)$ \\
\hline Cirrhitidae & $\begin{array}{l}\text { Paracirrhites } \\
\text { forsteri }\end{array}$ & $\begin{array}{c}0.3 \\
(0.3)\end{array}$ & $0(0)$ & $0(0)$ & $\begin{array}{c}0.3 \\
(0.3)\end{array}$ & $0(0)$ & $0(0)$ & $0(0)$ & $0(0)$ & $0(0)$ \\
\hline Ephippidae & Platax teira & $0(0)$ & $0(0)$ & $0(0)$ & $0(0)$ & $0(0)$ & $\begin{array}{c}0.3 \\
(0.3)\end{array}$ & $0(0)$ & $0(0)$ & $0(0)$ \\
\hline Gobidae & Exyrias bellisimus & $0(0)$ & $0(0)$ & $0(0)$ & $0(0)$ & $0(0)$ & $\begin{array}{c}1.7 \\
(0.7)\end{array}$ & $0(0)$ & $0(0)$ & $0(0)$ \\
\hline Haemulidae & $\begin{array}{c}\text { Plectorhinchus } \\
\text { vittatus }\end{array}$ & $0(0)$ & $0(0)$ & $\begin{array}{c}0.7 \\
(0.7)\end{array}$ & $0(0)$ & $0(0)$ & $0(0)$ & $0(0)$ & $0(0)$ & $0(0)$ \\
\hline
\end{tabular}




\begin{tabular}{|c|c|c|c|c|c|c|c|c|c|c|}
\hline Holocentridae & $\begin{array}{l}\text { Myripristis } \\
\text { violacea }\end{array}$ & $0(0)$ & $0(0)$ & $0(0)$ & $\begin{array}{c}0.3 \\
(0.3)\end{array}$ & $0(0)$ & $4(4)$ & $0(0)$ & $\begin{array}{c}0.3 \\
(0.3)\end{array}$ & $0(0)$ \\
\hline Holocentridae & $\begin{array}{l}\text { Neoniphon } \\
\text { sammara }\end{array}$ & $3(2.5)$ & $8(5)$ & $\begin{array}{c}0.3 \\
(0.3)\end{array}$ & $\begin{array}{c}0.7 \\
(0.7)\end{array}$ & $\begin{array}{c}0.3 \\
(0.3)\end{array}$ & $1(1)$ & $\begin{array}{c}2.7 \\
(0.9)\end{array}$ & $0(0)$ & $\begin{array}{c}0.7 \\
(0.7)\end{array}$ \\
\hline Holocentridae & $\begin{array}{c}\text { Sargocentron } \\
\text { caudimaculatum }\end{array}$ & $0(0)$ & $\begin{array}{c}0.3 \\
(0.3)\end{array}$ & $\begin{array}{c}1.3 \\
(0.7)\end{array}$ & $0(0)$ & $\begin{array}{c}0.3 \\
(0.3)\end{array}$ & $\begin{array}{c}1 \\
(0.6)\end{array}$ & $0(0)$ & $0(0)$ & $\begin{array}{c}0.7 \\
(0.7)\end{array}$ \\
\hline Holocentridae & $\begin{array}{l}\text { Sargocentron } \\
\text { ittodai }\end{array}$ & $0(0)$ & $0(0)$ & $0(0)$ & $\begin{array}{c}0.7 \\
(0.7)\end{array}$ & $0(0)$ & $\begin{array}{c}4.7 \\
(4.7)\end{array}$ & $0(0)$ & $0(0)$ & $0(0)$ \\
\hline Labridae & Anampses twisti & $0(0)$ & $0(0)$ & $\begin{array}{c}1.3 \\
(0.7)\end{array}$ & $\begin{array}{c}0.7 \\
(0.3)\end{array}$ & $\begin{array}{c}0.3 \\
(0.3)\end{array}$ & $0(0)$ & $0(0)$ & $0(0)$ & $1(0.6)$ \\
\hline Labridae & Bodianus diana & $\begin{array}{c}2.3 \\
(1.5)\end{array}$ & $0(0)$ & $1(0)$ & $0(0)$ & $\begin{array}{c}0.7 \\
(0.3)\end{array}$ & $0(0)$ & $\begin{array}{c}0.7 \\
(0.7)\end{array}$ & $0(0)$ & $0(0)$ \\
\hline Labridae & $\begin{array}{l}\text { Bodianus } \\
\text { mesothorax }\end{array}$ & $0(0)$ & $0(0)$ & $\begin{array}{c}0.3 \\
(0.3)\end{array}$ & $\begin{array}{c}0.7 \\
(0.3)\end{array}$ & $0(0)$ & $0(0)$ & $0(0)$ & $1(0.6)$ & $1(0)$ \\
\hline Labridae & Cheilinus chlorurus & $0(0)$ & $0(0)$ & $0(0)$ & $\begin{array}{c}0.3 \\
(0.3)\end{array}$ & $0(0)$ & $0(0)$ & $0(0)$ & $0(0)$ & $0(0)$ \\
\hline Labridae & Cheilinus fasciatus & $\begin{array}{c}0.7 \\
(0.3)\end{array}$ & $\begin{array}{c}0.7 \\
(0.7)\end{array}$ & $\begin{array}{c}2.3 \\
(0.3)\end{array}$ & $\begin{array}{c}0.7 \\
(0.3)\end{array}$ & $\begin{array}{c}0.3 \\
(0.3)\end{array}$ & $\begin{array}{c}0.3 \\
(0.3)\end{array}$ & $0(0)$ & $\begin{array}{c}0.7 \\
(0.7)\end{array}$ & $\begin{array}{c}0.7 \\
(0.7)\end{array}$ \\
\hline Labridae & $\begin{array}{l}\text { Choerodon } \\
\text { anchorago }\end{array}$ & $0(0)$ & $0(0)$ & $0(0)$ & $0(0)$ & $0(0)$ & $0(0)$ & $0(0)$ & $\begin{array}{c}0.3 \\
(0.3)\end{array}$ & $0(0)$ \\
\hline Labridae & $\begin{array}{l}\text { Cirrhilabrus } \\
\text { cyanopleura }\end{array}$ & $0(0)$ & $\begin{array}{c}25 \\
(22.5)\end{array}$ & $\begin{array}{l}14.7 \\
(8.4)\end{array}$ & $0(0)$ & $1(1)$ & $\begin{array}{c}5.3 \\
(5.3)\end{array}$ & $\begin{array}{c}6.7 \\
(6.7)\end{array}$ & $0(0)$ & $\begin{array}{c}1.3 \\
(1.3)\end{array}$ \\
\hline Labridae & Coris batuensis & $0(0)$ & $\begin{array}{c}0.3 \\
(0.3)\end{array}$ & $0(0)$ & $0(0)$ & $0(0)$ & $0(0)$ & $0(0)$ & $\begin{array}{c}0.7 \\
(0.3)\end{array}$ & $1(1)$ \\
\hline Labridae & Epibulus insidiator & $\begin{array}{c}0.3 \\
(0.3)\end{array}$ & $\begin{array}{c}0.3 \\
(0.3)\end{array}$ & $1(0.6)$ & $\begin{array}{c}1.3 \\
(0.9)\end{array}$ & $0(0)$ & $\begin{array}{c}0.3 \\
(0.3)\end{array}$ & $0(0)$ & $\begin{array}{c}0.3 \\
(0.3)\end{array}$ & $1(0.6)$ \\
\hline Labridae & Gomphosus varius & $0(0)$ & $0(0)$ & $0(0)$ & $0(0)$ & $0(0)$ & $0(0)$ & $0(0)$ & $0(0)$ & $1(1)$ \\
\hline Labridae & $\begin{array}{l}\text { Halichoeres } \\
\text { hortulanus }\end{array}$ & $0(0)$ & $\begin{array}{c}0.3 \\
(0.3)\end{array}$ & $0(0)$ & $0(0)$ & $0(0)$ & $0(0)$ & $0(0)$ & $0(0)$ & $\begin{array}{c}0.3 \\
(0.3)\end{array}$ \\
\hline Labridae & $\begin{array}{l}\text { Halichoeres } \\
\text { melanurus }\end{array}$ & $0(0)$ & $0(0)$ & $0(0)$ & $0(0)$ & $0(0)$ & $0(0)$ & $0(0)$ & $\begin{array}{c}0.3 \\
(0.3)\end{array}$ & $0(0)$ \\
\hline Labridae & $\begin{array}{l}\text { Halichoeres } \\
\text { porsopeion }\end{array}$ & $\begin{array}{l}1.7 \\
(0.9)\end{array}$ & $\begin{array}{c}2.7 \\
(1.5)\end{array}$ & $4(0)$ & $\begin{array}{c}3.7 \\
(1.7)\end{array}$ & $4(0.6)$ & $\begin{array}{c}1.3 \\
(0.7)\end{array}$ & $\begin{array}{c}5.7 \\
(1.2)\end{array}$ & $1(0.6)$ & $\begin{array}{c}2.3 \\
(1.5)\end{array}$ \\
\hline Labridae & $\begin{array}{l}\text { Hemigymnus } \\
\text { fasciatus }\end{array}$ & $0(0)$ & $\begin{array}{c}0.7 \\
(0.7)\end{array}$ & $0(0)$ & $0(0)$ & $2(1.2)$ & $0(0)$ & $0(0)$ & $0(0)$ & $0(0)$ \\
\hline Labridae & $\begin{array}{l}\text { Hemigymnus } \\
\text { melapterus }\end{array}$ & $0(0)$ & $0(0)$ & $0(0)$ & $\begin{array}{c}0.7 \\
(0.7)\end{array}$ & $0(0)$ & $0(0)$ & $0(0)$ & $0(0)$ & $0(0)$ \\
\hline Labridae & Labriodes bicolor & $\begin{array}{c}0.3 \\
(0.3)\end{array}$ & $0(0)$ & $0(0)$ & $0(0)$ & $0(0)$ & $\begin{array}{c}0.3 \\
(0.3)\end{array}$ & $0(0)$ & $\begin{array}{c}1.3 \\
(1.3)\end{array}$ & $\begin{array}{c}0.3 \\
(0.3)\end{array}$ \\
\hline Labridae & $\begin{array}{l}\text { Labriodes } \\
\text { pectoralis }\end{array}$ & $0(0)$ & $\begin{array}{c}0.3 \\
(0.3)\end{array}$ & $0(0)$ & $1(0.6)$ & $0(0)$ & $0(0)$ & $\begin{array}{c}0.3 \\
(0.3)\end{array}$ & $1(1)$ & $\begin{array}{c}2.7 \\
(2.2)\end{array}$ \\
\hline Labridae & $\begin{array}{l}\text { Labroides } \\
\text { dimidiatus }\end{array}$ & $\begin{array}{c}3.7 \\
(0.9)\end{array}$ & $7(1)$ & $\begin{array}{c}5.3 \\
(0.9)\end{array}$ & $\begin{array}{c}3.7 \\
(1.9)\end{array}$ & $\begin{array}{c}5.3 \\
(1.7)\end{array}$ & $\begin{array}{c}4 \\
(1.5)\end{array}$ & $\begin{array}{c}3.7 \\
(1.3)\end{array}$ & $\begin{array}{c}5.3 \\
(1.5)\end{array}$ & $\begin{array}{c}2.7 \\
(1.8)\end{array}$ \\
\hline Labridae & $\begin{array}{l}\text { Oxycheilinus } \\
\text { celebicus }\end{array}$ & $0(0)$ & $\begin{array}{c}0.3 \\
(0.3)\end{array}$ & $0(0)$ & $\begin{array}{c}0.3 \\
(0.3)\end{array}$ & $0(0)$ & $0(0)$ & $0(0)$ & $0(0)$ & $0(0)$ \\
\hline Labridae & $\begin{array}{l}\text { Oxycheilinus } \\
\text { digrammus }\end{array}$ & $0(0)$ & $\begin{array}{c}0.3 \\
(0.3)\end{array}$ & $2(0.6)$ & $\begin{array}{c}1.3 \\
(0.7)\end{array}$ & $1(0)$ & $1(1)$ & $\begin{array}{c}0.7 \\
(0.3)\end{array}$ & $\begin{array}{c}0.7 \\
(0.3)\end{array}$ & $\begin{array}{c}0.3 \\
(0.3)\end{array}$ \\
\hline
\end{tabular}




\begin{tabular}{|c|c|c|c|c|c|c|c|c|c|c|}
\hline Labridae & $\begin{array}{l}\text { Pseudodax } \\
\text { moluccanus }\end{array}$ & $0(0)$ & $0(0)$ & $0(0)$ & $\begin{array}{c}0.3 \\
(0.3)\end{array}$ & $0(0)$ & $0(0)$ & $0(0)$ & $0(0)$ & $0(0)$ \\
\hline Labridae & $\begin{array}{c}\text { Thalasomma } \\
\text { amblycephalum }\end{array}$ & $0(0)$ & $0(0)$ & $\begin{array}{c}6.3 \\
(3.2)\end{array}$ & $\begin{array}{c}0.7 \\
(0.7)\end{array}$ & $0(0)$ & $0(0)$ & $0(0)$ & $0(0)$ & $\begin{array}{c}3.3 \\
(3.3)\end{array}$ \\
\hline Labridae & Thalassoma lunare & $\begin{array}{c}0.3 \\
(0.3)\end{array}$ & $\begin{array}{c}1.3 \\
(0.9)\end{array}$ & $1(1)$ & $0(0)$ & $4(1)$ & $1(0)$ & $\begin{array}{c}0.7 \\
(0.7)\end{array}$ & $\begin{array}{c}4.3 \\
(2.8)\end{array}$ & $\begin{array}{c}0.3 \\
(0.3)\end{array}$ \\
\hline Lutjanidae & $\begin{array}{l}\text { Lutjanus } \\
\text { biguttatus }\end{array}$ & $0(0)$ & $\begin{array}{c}0.7 \\
(0.7)\end{array}$ & $0(0)$ & $0(0)$ & $0(0)$ & $0(0)$ & $0(0)$ & $0(0)$ & $0(0)$ \\
\hline Lutjanidae & $\begin{array}{c}\text { Lutjanus } \\
\text { decussatus }\end{array}$ & $\begin{array}{c}0.7 \\
(0.3)\end{array}$ & $\begin{array}{c}0.3 \\
(0.3)\end{array}$ & $0(0)$ & $0(0)$ & $0(0)$ & $0(0)$ & $0(0)$ & $0(0)$ & $\begin{array}{c}0.3 \\
(0.3)\end{array}$ \\
\hline Lutjanidae & Macolor macularis & $1(1)$ & $\begin{array}{c}1.3 \\
(1.3)\end{array}$ & $0(0)$ & $\begin{array}{c}0.7 \\
(0.7)\end{array}$ & $0(0)$ & $\begin{array}{c}0.3 \\
(0.3)\end{array}$ & $\begin{array}{c}0.3 \\
(0.3)\end{array}$ & $\begin{array}{c}0.7 \\
(0.7)\end{array}$ & $\begin{array}{c}0.3 \\
(0.3)\end{array}$ \\
\hline Mullidae & $\begin{array}{c}\text { Mulloidichthys } \\
\text { vanicolensis }\end{array}$ & $0(0)$ & $0(0)$ & $0(0)$ & $0(0)$ & $3(2.1)$ & $0(0)$ & $0(0)$ & $0(0)$ & $0(0)$ \\
\hline Mullidae & $\begin{array}{c}\text { Parupeneus } \\
\text { barberinus }\end{array}$ & $0(0)$ & $\begin{array}{c}0.3 \\
(0.3)\end{array}$ & $\begin{array}{c}0.3 \\
(0.3)\end{array}$ & $0(0)$ & $0(0)$ & $\begin{array}{c}0.3 \\
(0.3)\end{array}$ & $0(0)$ & $\begin{array}{c}0.7 \\
(0.7)\end{array}$ & $0(0)$ \\
\hline Mullidae & $\begin{array}{l}\text { Parupeneus } \\
\text { crassilabris }\end{array}$ & $0(0)$ & $0(0)$ & $\begin{array}{c}0.7 \\
(0.7)\end{array}$ & $\begin{array}{c}0.3 \\
(0.3)\end{array}$ & $\begin{array}{c}0.7 \\
(0.3)\end{array}$ & $\begin{array}{c}0.3 \\
(0.3)\end{array}$ & $\begin{array}{c}0.3 \\
(0.3)\end{array}$ & $0(0)$ & $0(0)$ \\
\hline Mullidae & $\begin{array}{l}\text { Parupeneus } \\
\text { cyclostomus }\end{array}$ & $0(0)$ & $\begin{array}{c}0.3 \\
(0.3)\end{array}$ & $0(0)$ & $0(0)$ & $0(0)$ & $0(0)$ & $0(0)$ & $0(0)$ & $0(0)$ \\
\hline Mullidae & $\begin{array}{l}\text { Parupeneus } \\
\text { multifasciatus }\end{array}$ & $\begin{array}{c}0.3 \\
(0.3)\end{array}$ & $1(0.6)$ & $\begin{array}{c}0.7 \\
(0.7)\end{array}$ & $1(0)$ & $\begin{array}{c}0.3 \\
(0.3)\end{array}$ & $\begin{array}{c}0.3 \\
(0.3)\end{array}$ & $\begin{array}{c}0.7 \\
(0.3)\end{array}$ & $\begin{array}{c}1.3 \\
(0.9)\end{array}$ & $0(0)$ \\
\hline Mullidae & Upeneus tragula & $0(0)$ & $0(0)$ & $0(0)$ & $0(0)$ & $0(0)$ & $\begin{array}{c}0.3 \\
(0.3)\end{array}$ & $0(0)$ & $2(1.5)$ & $0(0)$ \\
\hline Nemipteridae & Scolopsis bilineata & $0(0)$ & $\begin{array}{c}0.7 \\
(0.3)\end{array}$ & $\begin{array}{c}0.7 \\
(0.7)\end{array}$ & $\begin{array}{c}0.3 \\
(0.3)\end{array}$ & $1(1)$ & $\begin{array}{c}0.7 \\
(0.3)\end{array}$ & $0(0)$ & $\begin{array}{c}1.7 \\
(0.9)\end{array}$ & $0(0)$ \\
\hline Nemipteridae & Scolopsis ciliata & $0(0)$ & $0(0)$ & $0(0)$ & $0(0)$ & $0(0)$ & $9(1)$ & $0(0)$ & $3(1.7)$ & $0(0)$ \\
\hline Nemipteridae & $\begin{array}{c}\text { Scolopsis } \\
\text { margaritifera }\end{array}$ & $\begin{array}{c}0.3 \\
(0.3)\end{array}$ & $0(0)$ & $0(0)$ & $0(0)$ & $0(0)$ & $0(0)$ & $0(0)$ & $\begin{array}{c}0.7 \\
(0.7)\end{array}$ & $0(0)$ \\
\hline Plesiopidae & $\begin{array}{l}\text { Calloplesiops } \\
\text { altivelis }\end{array}$ & $0(0)$ & $0(0)$ & $0(0)$ & $0(0)$ & $0(0)$ & $\begin{array}{c}0.3 \\
(0.3)\end{array}$ & $0(0)$ & $0(0)$ & $0(0)$ \\
\hline Pomacanthidae & Centropyge bicolor & $0(0)$ & $0(0)$ & $0(0)$ & $0(0)$ & $0(0)$ & $\begin{array}{c}3.3 \\
(0.9)\end{array}$ & $0(0)$ & $\begin{array}{c}3.7 \\
(1.8)\end{array}$ & $\begin{array}{c}0.7 \\
(0.7)\end{array}$ \\
\hline Pomacanthidae & $\begin{array}{c}\text { Centropyge } \\
\text { bispinosus }\end{array}$ & $0(0)$ & $\begin{array}{c}3.3 \\
(1.8)\end{array}$ & $1(0)$ & $\begin{array}{c}0.3 \\
(0.3)\end{array}$ & $0(0)$ & $0(0)$ & $0(0)$ & $0(0)$ & $\begin{array}{c}0.3 \\
(0.3)\end{array}$ \\
\hline Pomacanthidae & $\begin{array}{l}\text { Centropyge } \\
\text { multifasciata }\end{array}$ & $\begin{array}{c}1.7 \\
(1.7)\end{array}$ & $\begin{array}{c}0.3 \\
(0.3)\end{array}$ & $0(0)$ & $\begin{array}{c}0.3 \\
(0.3)\end{array}$ & $\begin{array}{c}0.3 \\
(0.3)\end{array}$ & $0(0)$ & $\begin{array}{c}1.3 \\
(0.9)\end{array}$ & $0(0)$ & $0(0)$ \\
\hline Pomacanthidae & Centropyge nox & $\begin{array}{c}2.3 \\
(0.9)\end{array}$ & $3(1)$ & $\begin{array}{c}0.3 \\
(0.3)\end{array}$ & $1(0.6)$ & $\begin{array}{c}0.3 \\
(0.3)\end{array}$ & $\begin{array}{c}1.3 \\
(1.3)\end{array}$ & $\begin{array}{c}2.7 \\
(0.7)\end{array}$ & $\begin{array}{c}0.7 \\
(0.7)\end{array}$ & $0(0)$ \\
\hline Pomacanthidae & Centropyge tibicen & $0(0)$ & $\begin{array}{c}1.3 \\
(0.9)\end{array}$ & $\begin{array}{c}0.7 \\
(0.7)\end{array}$ & $\begin{array}{c}1.7 \\
(1.2)\end{array}$ & $\begin{array}{c}0.3 \\
(0.3)\end{array}$ & $\begin{array}{c}4 \\
(2.1)\end{array}$ & $\begin{array}{c}0.3 \\
(0.3)\end{array}$ & $\begin{array}{c}3.3 \\
(1.2)\end{array}$ & $0(0)$ \\
\hline Pomacanthidae & Centropyge vroliki & $1(0.6)$ & $0(0)$ & $\begin{array}{c}0.3 \\
(0.3)\end{array}$ & $0(0)$ & $\begin{array}{c}0.7 \\
(0.7)\end{array}$ & $\begin{array}{c}1 \\
(0.6)\end{array}$ & $0(0)$ & $\begin{array}{c}1.7 \\
(1.2)\end{array}$ & $\begin{array}{c}1.3 \\
(1.3)\end{array}$ \\
\hline Pomacanthidae & $\begin{array}{l}\text { Pomacanthus } \\
\text { imperator }\end{array}$ & $0(0)$ & $0(0)$ & $0(0)$ & $0(0)$ & $0(0)$ & $0(0)$ & $\begin{array}{c}0.3 \\
(0.3)\end{array}$ & $0(0)$ & $0(0)$ \\
\hline Pomacanthidae & $\begin{array}{l}\text { Pomacanthus } \\
\text { navarchus }\end{array}$ & $\begin{array}{c}0.3 \\
(0.3)\end{array}$ & $0(0)$ & $0(0)$ & $\begin{array}{c}0.3 \\
(0.3)\end{array}$ & $0(0)$ & $0(0)$ & $0(0)$ & $0(0)$ & $0(0)$ \\
\hline
\end{tabular}




\begin{tabular}{|c|c|c|c|c|c|c|c|c|c|c|}
\hline Pomacanthidae & $\begin{array}{l}\text { Pomacanthus } \\
\text { xanthometopon }\end{array}$ & $\begin{array}{c}0.3 \\
(0.3)\end{array}$ & $0(0)$ & $0(0)$ & $0(0)$ & $0(0)$ & $0(0)$ & $0(0)$ & $\begin{array}{c}0.3 \\
(0.3)\end{array}$ & $0(0)$ \\
\hline Pomacanthidae & $\begin{array}{l}\text { Pygoplites } \\
\text { diacanthus }\end{array}$ & $\begin{array}{c}2.7 \\
(0.9)\end{array}$ & $2(1)$ & $3(0.6)$ & $\begin{array}{c}1.3 \\
(0.3)\end{array}$ & $2(1.2)$ & $\begin{array}{c}0.3 \\
(0.3)\end{array}$ & $\begin{array}{c}0.7 \\
(0.7)\end{array}$ & $\begin{array}{c}1.3 \\
(0.9)\end{array}$ & $\begin{array}{c}5.3 \\
(3.9)\end{array}$ \\
\hline Pomacentridae & $\begin{array}{l}\text { Acanthochromis } \\
\text { polycanthus }\end{array}$ & $0(0)$ & $\begin{array}{c}0.3 \\
(0.3)\end{array}$ & $0(0)$ & $0(0)$ & $0(0)$ & $0(0)$ & $0(0)$ & $0(0)$ & $0(0)$ \\
\hline Pomacentridae & $\begin{array}{c}\text { Amblyglyphidodon } \\
\text { aureus }\end{array}$ & $8(7)$ & $0(0)$ & $\begin{array}{c}3.3 \\
(0.9)\end{array}$ & $\begin{array}{c}0.7 \\
(0.7)\end{array}$ & $4(1)$ & $0(0)$ & $\begin{array}{c}0.7 \\
(0.3)\end{array}$ & $0(0)$ & $\begin{array}{c}0.7 \\
(0.7)\end{array}$ \\
\hline Pomacentridae & $\begin{array}{c}\text { Amblyglyphidodon } \\
\text { curacao }\end{array}$ & $\begin{array}{c}2.7 \\
(2.7)\end{array}$ & $3(1.7)$ & $0(0)$ & $\begin{array}{c}0.3 \\
(0.3)\end{array}$ & $0(0)$ & $2(1)$ & $0(0)$ & $\begin{array}{l}19.3 \\
(7.5)\end{array}$ & $0(0)$ \\
\hline Pomacentridae & $\begin{array}{c}\text { Amblyglyphidodon } \\
\text { leucogaster }\end{array}$ & $\begin{array}{c}3.3 \\
(1.8)\end{array}$ & $\begin{array}{c}40.3 \\
(14.3)\end{array}$ & $\begin{array}{l}14.3 \\
(4.8)\end{array}$ & $\begin{array}{l}24.3 \\
(3.8)\end{array}$ & $\begin{array}{c}8.7 \\
(1.5)\end{array}$ & $0(0)$ & $7(2)$ & $\begin{array}{c}3.7 \\
(3.7)\end{array}$ & $\begin{array}{c}22 \\
(9.5)\end{array}$ \\
\hline Pomacentridae & Amphiprion clarkii & $0(0)$ & $\begin{array}{c}2.3 \\
(1.9)\end{array}$ & $\begin{array}{c}0.7 \\
(0.7)\end{array}$ & $\begin{array}{c}2.3 \\
(2.3)\end{array}$ & $0(0)$ & $0(0)$ & $0(0)$ & $0(0)$ & $3(2.1)$ \\
\hline Pomacentridae & $\begin{array}{l}\text { Amphirion } \\
\text { perideraion }\end{array}$ & $0(0)$ & $2(2)$ & $1(1)$ & $0(0)$ & $0(0)$ & $\begin{array}{c}0.3 \\
(0.3)\end{array}$ & $0(0)$ & $0(0)$ & $\begin{array}{c}0.7 \\
(0.7)\end{array}$ \\
\hline Pomacentridae & Chromis alpha & $\begin{array}{c}2.3 \\
(1.2)\end{array}$ & $\begin{array}{c}6.7 \\
(3.7)\end{array}$ & $\begin{array}{c}0.3 \\
(0.3)\end{array}$ & $\begin{array}{c}0.3 \\
(0.3)\end{array}$ & $0(0)$ & $0(0)$ & $\begin{array}{c}8.3 \\
(6.4)\end{array}$ & $0(0)$ & $\begin{array}{c}2.3 \\
(1.2)\end{array}$ \\
\hline Pomacentridae & $\begin{array}{c}\text { Chromis } \\
\text { amboinensis }\end{array}$ & $\begin{array}{l}12.7 \\
(4.1)\end{array}$ & $\begin{array}{c}31.3 \\
(25.1)\end{array}$ & $\begin{array}{c}9.7 \\
(8.7)\end{array}$ & $\begin{array}{l}21.3 \\
(13)\end{array}$ & $\begin{array}{c}3.3 \\
(1.9)\end{array}$ & $0(0)$ & $\begin{array}{l}27.7 \\
(9.1)\end{array}$ & $\begin{array}{c}7.7 \\
(6.2)\end{array}$ & $\begin{array}{l}13.3 \\
(4.8)\end{array}$ \\
\hline Pomacentridae & Chromis analis & $\begin{array}{l}15.3 \\
(9.9)\end{array}$ & $\begin{array}{c}2.3 \\
(2.3)\end{array}$ & $\begin{array}{c}34.7 \\
(19.1)\end{array}$ & $4(1)$ & $3(1)$ & $0(0)$ & $\begin{array}{l}11.3 \\
(2.9)\end{array}$ & $0(0)$ & $3.3(2)$ \\
\hline Pomacentridae & Chromis atripes & $0(0)$ & $4.3(2)$ & $\begin{array}{l}24.3 \\
(4.1)\end{array}$ & $\begin{array}{l}14.3 \\
(4.3)\end{array}$ & $3(2.5)$ & $\begin{array}{c}0.3 \\
(0.3)\end{array}$ & $3(0.6)$ & $0(0)$ & $\begin{array}{l}16.3 \\
(2.9)\end{array}$ \\
\hline Pomacentridae & Chromis caudalis & $\begin{array}{c}2.7 \\
(2.7)\end{array}$ & $\begin{array}{c}7.7 \\
(3.7)\end{array}$ & $\begin{array}{l}13.7 \\
(2.7)\end{array}$ & $6(2.1)$ & $0(0)$ & $0(0)$ & $\begin{array}{c}1.7 \\
(0.9)\end{array}$ & $0(0)$ & $\begin{array}{c}0.7 \\
(0.7)\end{array}$ \\
\hline Pomacentridae & Chromis delta & $\begin{array}{c}0.3 \\
(0.3)\end{array}$ & $0(0)$ & $0(0)$ & $0(0)$ & $0(0)$ & $0(0)$ & $0(0)$ & $0(0)$ & $\begin{array}{c}1.3 \\
(1.3)\end{array}$ \\
\hline Pomacentridae & Chromis eleare & $\begin{array}{c}4.7 \\
(4.7)\end{array}$ & $0(0)$ & $0(0)$ & $0(0)$ & $0(0)$ & $0(0)$ & $\begin{array}{c}0.3 \\
(0.3)\end{array}$ & $0(0)$ & $0(0)$ \\
\hline Pomacentridae & Chromis lepidolepis & $11(5)$ & $\begin{array}{c}4.3 \\
(2.2)\end{array}$ & $3(3)$ & $2(2)$ & $\begin{array}{c}50 \\
(13.2)\end{array}$ & $\begin{array}{c}4.3 \\
(2.2)\end{array}$ & $5.7(3)$ & $\begin{array}{c}47.7 \\
(22.1)\end{array}$ & $\begin{array}{c}1.7 \\
(0.9)\end{array}$ \\
\hline Pomacentridae & $\begin{array}{c}\text { Chromis } \\
\text { margaritifer }\end{array}$ & $0(0)$ & $\begin{array}{c}2.3 \\
(1.9)\end{array}$ & $\begin{array}{l}14.3 \\
(2.6)\end{array}$ & $0(0)$ & $\begin{array}{c}0.3 \\
(0.3)\end{array}$ & $0(0)$ & $\begin{array}{c}0.3 \\
(0.3)\end{array}$ & $\begin{array}{c}0.7 \\
(0.7)\end{array}$ & $0(0)$ \\
\hline Pomacentridae & $\begin{array}{c}\text { Chromis } \\
\text { retrofasciata }\end{array}$ & $\begin{array}{c}0.7 \\
(0.7)\end{array}$ & $\begin{array}{l}12.7 \\
(1.3)\end{array}$ & $7.7(5)$ & $\begin{array}{c}6.3 \\
(1.2)\end{array}$ & $4(1.2)$ & $\begin{array}{c}0.3 \\
(0.3)\end{array}$ & $\begin{array}{c}12.7 \\
(7)\end{array}$ & $0(0)$ & $\begin{array}{c}2.7 \\
(1.3)\end{array}$ \\
\hline Pomacentridae & $\begin{array}{c}\text { Chromis } \\
\text { ternatensis }\end{array}$ & $\begin{array}{c}3.3 \\
(3.3)\end{array}$ & $\begin{array}{l}53.7 \\
(8.3)\end{array}$ & $\begin{array}{c}15.3 \\
(11.6)\end{array}$ & $\begin{array}{c}5.7 \\
(5.7)\end{array}$ & $9.7(5)$ & $0(0)$ & $\begin{array}{c}31.7 \\
(22.4)\end{array}$ & $\begin{array}{c}18.7 \\
(18.7)\end{array}$ & $\begin{array}{c}40 \\
(30.6)\end{array}$ \\
\hline Pomacentridae & Chromis viridis & $0(0)$ & $0(0)$ & $0(0)$ & $0(0)$ & $0(0)$ & $0(0)$ & $\begin{array}{c}15 \\
(15)\end{array}$ & $0(0)$ & $0(0)$ \\
\hline Pomacentridae & Chromis weberi & $0(0)$ & $0(0)$ & $0(0)$ & $0(0)$ & $0(0)$ & $\begin{array}{c}5 \\
(2.5)\end{array}$ & $3(3)$ & $\begin{array}{c}2.7 \\
(1.7)\end{array}$ & $\begin{array}{c}2.7 \\
(2.7)\end{array}$ \\
\hline Pomacentridae & Chromis xanthura & $0(0)$ & $0(0)$ & $\begin{array}{c}0.3 \\
(0.3)\end{array}$ & $1(0.6)$ & $\begin{array}{c}1.7 \\
(0.9)\end{array}$ & $0(0)$ & $0(0)$ & $0(0)$ & $\begin{array}{c}0.3 \\
(0.3)\end{array}$ \\
\hline Pomacentridae & Chrysiptera rex & $0(0)$ & $0(0)$ & $0(0)$ & $0(0)$ & $0(0)$ & $0(0)$ & $0(0)$ & $\begin{array}{c}0.3 \\
(0.3)\end{array}$ & $0(0)$ \\
\hline Pomacentridae & $\begin{array}{c}\text { Chrysiptera } \\
\text { rollandi }\end{array}$ & $8(0.6)$ & $\begin{array}{c}16 \\
(6.2)\end{array}$ & $\begin{array}{c}3.3 \\
(0.3)\end{array}$ & $11(4)$ & $7.3(3)$ & $\begin{array}{c}9.7 \\
(4.2)\end{array}$ & $\begin{array}{l}16.7 \\
(8.5)\end{array}$ & $\begin{array}{c}10 \\
(3.2)\end{array}$ & $\begin{array}{c}5.3 \\
(1.9)\end{array}$ \\
\hline
\end{tabular}




\begin{tabular}{|c|c|c|c|c|c|c|c|c|c|c|}
\hline Pomacentridae & $\begin{array}{c}\text { Chrysiptera } \\
\text { talbotti }\end{array}$ & $\begin{array}{l}12.3 \\
(4.1)\end{array}$ & $\begin{array}{l}14.3 \\
(3.8)\end{array}$ & $\begin{array}{c}16 \\
(2.5)\end{array}$ & $\begin{array}{c}25 \\
(3.1)\end{array}$ & $\begin{array}{l}11.3 \\
(1.2)\end{array}$ & $\begin{array}{c}1.7 \\
(1.7)\end{array}$ & $\begin{array}{c}26 \\
(0.6)\end{array}$ & $1(1)$ & $\begin{array}{l}20.3 \\
(5.8)\end{array}$ \\
\hline Pomacentridae & $\begin{array}{l}\text { Dascylus } \\
\text { reticulatus }\end{array}$ & $\begin{array}{c}0.3 \\
(0.3)\end{array}$ & $\begin{array}{c}14.7 \\
(12.3)\end{array}$ & $\begin{array}{c}37 \\
(11.8)\end{array}$ & $\begin{array}{c}6.7 \\
(6.7)\end{array}$ & $\begin{array}{c}6.3 \\
(4.8)\end{array}$ & $\begin{array}{c}3.7 \\
(2.7)\end{array}$ & $\begin{array}{c}55.3 \\
(30.9)\end{array}$ & $\begin{array}{c}49.3 \\
(10.5)\end{array}$ & $\begin{array}{c}41 \\
(18.1)\end{array}$ \\
\hline Pomacentridae & $\begin{array}{l}\text { Dascylus } \\
\text { trimaculatus }\end{array}$ & $0(0)$ & $0(0)$ & $0(0)$ & $0(0)$ & $\begin{array}{c}0.3 \\
(0.3)\end{array}$ & $\begin{array}{l}14.7 \\
(8.4)\end{array}$ & $\begin{array}{c}0.3 \\
(0.3)\end{array}$ & $3.3(2)$ & $\begin{array}{c}1.3 \\
(1.3)\end{array}$ \\
\hline Pomacentridae & $\begin{array}{l}\text { Neoglyphidodon } \\
\text { melas }\end{array}$ & $1(1)$ & $\begin{array}{c}0.3 \\
(0.3)\end{array}$ & $0(0)$ & $\begin{array}{c}0.7 \\
(0.7)\end{array}$ & $0(0)$ & $0(0)$ & $0(0)$ & $0(0)$ & $\begin{array}{c}0.3 \\
(0.3)\end{array}$ \\
\hline Pomacentridae & $\begin{array}{c}\text { Neoglyphidodon } \\
\text { nigroris }\end{array}$ & $\begin{array}{c}9.3 \\
(0.3)\end{array}$ & $\begin{array}{l}35.3 \\
(6.6)\end{array}$ & $\begin{array}{l}46.3 \\
(3.2)\end{array}$ & $\begin{array}{l}34.7 \\
(6.7)\end{array}$ & $\begin{array}{l}10.7 \\
(1.2)\end{array}$ & $0(0)$ & $\begin{array}{l}11.7 \\
(5.5)\end{array}$ & $\begin{array}{c}3.3 \\
(2.8)\end{array}$ & $\begin{array}{c}21.3 \\
(12.7)\end{array}$ \\
\hline Pomacentridae & $\begin{array}{l}\text { Neopomacentrus } \\
\text { violascens }\end{array}$ & $0(0)$ & $0(0)$ & $0(0)$ & $\begin{array}{c}2.7 \\
(1.8)\end{array}$ & $3.3(2)$ & $\begin{array}{c}4 \\
(1.7)\end{array}$ & $\begin{array}{c}0.3 \\
(0.3)\end{array}$ & $\begin{array}{c}2.3 \\
(0.7)\end{array}$ & $\begin{array}{c}0.3 \\
(0.3)\end{array}$ \\
\hline Pomacentridae & $\begin{array}{l}\text { Plectroglyphidodon } \\
\text { lacrymatus }\end{array}$ & $0(0)$ & $0(0)$ & $0(0)$ & $\begin{array}{c}0.7 \\
(0.7)\end{array}$ & $0(0)$ & $0(0)$ & $0(0)$ & $0(0)$ & $0(0)$ \\
\hline Pomacentridae & $\begin{array}{l}\text { Pomacentrus } \\
\text { adelus }\end{array}$ & $0(0)$ & $0(0)$ & $0(0)$ & $0(0)$ & $0(0)$ & $\begin{array}{c}0.7 \\
(0.3)\end{array}$ & $0(0)$ & $\begin{array}{c}0.3 \\
(0.3)\end{array}$ & $0(0)$ \\
\hline Pomacentridae & $\begin{array}{l}\text { Pomacentrus } \\
\text { alexanderae }\end{array}$ & $0(0)$ & $\begin{array}{c}0.3 \\
(0.3)\end{array}$ & $0(0)$ & $0(0)$ & $0(0)$ & $\begin{array}{l}11.3 \\
(3.5)\end{array}$ & $0(0)$ & $\begin{array}{c}3.3 \\
(2.4)\end{array}$ & $0(0)$ \\
\hline Pomacentridae & $\begin{array}{l}\text { Pomacentrus } \\
\text { amboinensis }\end{array}$ & $0(0)$ & $4.3(3)$ & $0(0)$ & $\begin{array}{c}2.3 \\
(2.3)\end{array}$ & $0(0)$ & $\begin{array}{c}12 \\
(3.5)\end{array}$ & $1(1)$ & $\begin{array}{l}12.7 \\
(1.5)\end{array}$ & $2(2)$ \\
\hline Pomacentridae & $\begin{array}{l}\text { Pomacentrus } \\
\text { bankanensis }\end{array}$ & $0(0)$ & $\begin{array}{c}0.3 \\
(0.3)\end{array}$ & $0(0)$ & $0(0)$ & $0(0)$ & $0(0)$ & $0(0)$ & $0(0)$ & $0(0)$ \\
\hline Pomacentridae & $\begin{array}{l}\text { Pomacentrus } \\
\text { brachialis }\end{array}$ & $4(1.2)$ & $\begin{array}{l}11.3 \\
(2.9)\end{array}$ & $\begin{array}{l}20.3 \\
(5.8)\end{array}$ & $\begin{array}{l}17.7 \\
(7.3)\end{array}$ & $7(5.6)$ & $\begin{array}{c}4.7 \\
(1.8)\end{array}$ & $\begin{array}{c}5.7 \\
(0.3)\end{array}$ & $31(4)$ & $\begin{array}{c}24 \\
(10.2)\end{array}$ \\
\hline Pomacentridae & $\begin{array}{l}\text { Pomacentrus } \\
\text { coelestis }\end{array}$ & $0(0)$ & $0(0)$ & $\begin{array}{c}1.3 \\
(1.3)\end{array}$ & $0(0)$ & $\begin{array}{c}0.3 \\
(0.3)\end{array}$ & $0(0)$ & $1(1)$ & $0(0)$ & $\begin{array}{c}0.7 \\
(0.7)\end{array}$ \\
\hline Pomacentridae & $\begin{array}{c}\text { Pomacentrus } \\
\text { lepidogenys }\end{array}$ & $0(0)$ & $\begin{array}{c}16.7 \\
(16.7)\end{array}$ & $\begin{array}{c}1.7 \\
(1.7)\end{array}$ & $0(0)$ & $0(0)$ & $\begin{array}{c}0.3 \\
(0.3)\end{array}$ & $\begin{array}{c}14 \\
(14)\end{array}$ & $\begin{array}{c}21 \\
(21)\end{array}$ & $\begin{array}{c}7.3 \\
(7.3)\end{array}$ \\
\hline Pomacentridae & $\begin{array}{c}\text { Pomacentrus } \\
\text { moluccensis }\end{array}$ & $0(0)$ & $4(3.5)$ & $0(0)$ & $\begin{array}{c}2.7 \\
(1.5)\end{array}$ & $0(0)$ & $0(0)$ & $\begin{array}{c}0.3 \\
(0.3)\end{array}$ & $\begin{array}{c}12 \\
(11)\end{array}$ & $3(2.5)$ \\
\hline Pomacentridae & $\begin{array}{l}\text { Pomacentrus } \\
\text { nigromanus }\end{array}$ & $0(0)$ & $\begin{array}{c}1.3 \\
(1.3)\end{array}$ & $0(0)$ & $0(0)$ & $0(0)$ & $\begin{array}{c}0.7 \\
(0.7)\end{array}$ & $0(0)$ & $0(0)$ & $0(0)$ \\
\hline Pomacentridae & $\begin{array}{c}\text { Pomacentrus } \\
\text { nigromarginatus }\end{array}$ & $\begin{array}{c}9.7 \\
(1.3)\end{array}$ & $\begin{array}{c}0.3 \\
(0.3)\end{array}$ & $0(0)$ & $1(1)$ & $\begin{array}{c}7.7 \\
(4.2)\end{array}$ & $0(0)$ & $\begin{array}{c}11 \\
(0.6)\end{array}$ & $0(0)$ & $0(0)$ \\
\hline Pomacentridae & Pomacentrus reidi & $4(1.2)$ & $\begin{array}{c}8.7 \\
(5.9)\end{array}$ & $\begin{array}{c}6.7 \\
(2.6)\end{array}$ & $3.7(2)$ & $\begin{array}{c}2.7 \\
(0.3)\end{array}$ & $\begin{array}{c}1.3 \\
(0.3)\end{array}$ & $\begin{array}{c}5.7 \\
(1.7)\end{array}$ & $0(0)$ & $5(1)$ \\
\hline Pomacentridae & Pomacentrus vauli & $0(0)$ & $0(0)$ & $0(0)$ & $\begin{array}{c}0.7 \\
(0.7)\end{array}$ & $0(0)$ & $0(0)$ & $0(0)$ & $0(0)$ & $0(0)$ \\
\hline Pomacentridae & $\begin{array}{c}\text { Premnas } \\
\text { biaculeatus }\end{array}$ & $0(0)$ & $1(1)$ & $0(0)$ & $0(0)$ & $0(0)$ & $0(0)$ & $0(0)$ & $0(0)$ & $0(0)$ \\
\hline Pseudochromidae & $\begin{array}{c}\text { Labracinus } \\
\text { cyclopthalmus }\end{array}$ & $0(0)$ & $1(0.6)$ & $0(0)$ & $1(1)$ & $0(0)$ & $\begin{array}{c}0.7 \\
(0.3)\end{array}$ & $\begin{array}{c}1.3 \\
(0.9)\end{array}$ & $\begin{array}{c}0.7 \\
(0.7)\end{array}$ & $0(0)$ \\
\hline Pseudochromidae & $\begin{array}{l}\text { Manonichthys } \\
\text { splendens }\end{array}$ & $\begin{array}{c}0.3 \\
(0.3)\end{array}$ & $\begin{array}{c}0.7 \\
(0.3)\end{array}$ & $\begin{array}{c}1.3 \\
(0.3)\end{array}$ & $\begin{array}{c}0.3 \\
(0.3)\end{array}$ & $\begin{array}{c}0.7 \\
(0.7)\end{array}$ & $0(0)$ & $1(0)$ & $0(0)$ & $0(0)$ \\
\hline Pseudochromidae & $\begin{array}{l}\text { Picitichromis } \\
\text { paccagnellae }\end{array}$ & $\begin{array}{c}50.7 \\
(25.4)\end{array}$ & $\begin{array}{l}20.7 \\
(4.6)\end{array}$ & $\begin{array}{l}44.3 \\
(6.6)\end{array}$ & $\begin{array}{c}27 \\
(18.7)\end{array}$ & $\begin{array}{c}84.7 \\
(16.9)\end{array}$ & $\begin{array}{c}2.3 \\
(1.2)\end{array}$ & $\begin{array}{l}87.3 \\
(6.2)\end{array}$ & $1(1)$ & $9(2.6)$ \\
\hline Ptereleotridae & $\begin{array}{l}\text { Nemateleotris } \\
\text { magnifica }\end{array}$ & $0(0)$ & $\begin{array}{c}0.3 \\
(0.3)\end{array}$ & $\begin{array}{c}0.7 \\
(0.7)\end{array}$ & $0(0)$ & $\begin{array}{c}0.7 \\
(0.7)\end{array}$ & $0(0)$ & $0(0)$ & $0(0)$ & $0(0)$ \\
\hline
\end{tabular}




\begin{tabular}{|c|c|c|c|c|c|c|c|c|c|c|}
\hline Scaridae & $\begin{array}{l}\text { Bolbometopon } \\
\text { muricatum }\end{array}$ & $0(0)$ & $\begin{array}{c}3.7 \\
(3.7)\end{array}$ & $0(0)$ & $0(0)$ & $\begin{array}{c}0.3 \\
(0.3)\end{array}$ & $0(0)$ & $0(0)$ & $0(0)$ & $0(0)$ \\
\hline Scaridae & Cetoscarus bicolor & $0(0)$ & $0(0)$ & $0(0)$ & $0(0)$ & $\begin{array}{c}0.3 \\
(0.3)\end{array}$ & $\begin{array}{c}0.3 \\
(0.3)\end{array}$ & $0(0)$ & $0(0)$ & $0(0)$ \\
\hline Scaridae & Chlorurus bleekeri & $0(0)$ & $\begin{array}{c}0.7 \\
(0.7)\end{array}$ & $\begin{array}{c}0.3 \\
(0.3)\end{array}$ & $0(0)$ & $\begin{array}{c}0.3 \\
(0.3)\end{array}$ & $0(0)$ & $0(0)$ & $0(0)$ & $0(0)$ \\
\hline Scaridae & Chlorurus sordidus & $0(0)$ & $2(1)$ & $\begin{array}{c}2.3 \\
(1.3)\end{array}$ & $1(0.6)$ & $0(0)$ & $0(0)$ & $\begin{array}{c}0.7 \\
(0.3)\end{array}$ & $\begin{array}{c}0.7 \\
(0.7)\end{array}$ & $2(1.2)$ \\
\hline Scaridae & $\begin{array}{c}\text { Scarus } \\
\text { flavipectoralis }\end{array}$ & $\begin{array}{c}0.7 \\
(0.3)\end{array}$ & $\begin{array}{c}0.7 \\
(0.3)\end{array}$ & $0(0)$ & $2(1.2)$ & $\begin{array}{c}0.7 \\
(0.7)\end{array}$ & $\begin{array}{c}0.7 \\
(0.7)\end{array}$ & $\begin{array}{c}0.3 \\
(0.3)\end{array}$ & $\begin{array}{c}1.7 \\
(0.9)\end{array}$ & $\begin{array}{l}1.7 \\
(0.9)\end{array}$ \\
\hline Scaridae & Scarus ghobban & $0(0)$ & $0(0)$ & $0(0)$ & $0(0)$ & $0(0)$ & $0(0)$ & $0(0)$ & $\begin{array}{c}0.3 \\
(0.3)\end{array}$ & $0(0)$ \\
\hline Scaridae & Scarus niger & $0(0)$ & $3(1)$ & $\begin{array}{c}1.7 \\
(1.2)\end{array}$ & $1(1)$ & $\begin{array}{c}0.7 \\
(0.7)\end{array}$ & $0(0)$ & $\begin{array}{c}0.3 \\
(0.3)\end{array}$ & $0(0)$ & $\begin{array}{c}0.7 \\
(0.7)\end{array}$ \\
\hline Scaridae & Scarus psittacus & $0(0)$ & $3(1.7)$ & $\begin{array}{c}0.3 \\
(0.3)\end{array}$ & $0(0)$ & $0(0)$ & $0(0)$ & $0(0)$ & $0(0)$ & $\begin{array}{c}1.7 \\
(0.9)\end{array}$ \\
\hline Scorpaenidae & Pterois antennata & $0(0)$ & $0(0)$ & $0(0)$ & $0(0)$ & $0(0)$ & $\begin{array}{c}0.3 \\
(0.3)\end{array}$ & $0(0)$ & $\begin{array}{c}0.3 \\
(0.3)\end{array}$ & $0(0)$ \\
\hline Serranidae & $\begin{array}{l}\text { Aethaloperca } \\
\text { rogaa }\end{array}$ & $0(0)$ & $\begin{array}{c}0.3 \\
(0.3)\end{array}$ & $0(0)$ & $0(0)$ & $\begin{array}{c}0.3 \\
(0.3)\end{array}$ & $0(0)$ & $0(0)$ & $\begin{array}{c}0.7 \\
(0.3)\end{array}$ & $0(0)$ \\
\hline Serranidae & $\begin{array}{c}\text { Anyperodon } \\
\text { leucogrammicus }\end{array}$ & $0(0)$ & $0(0)$ & $0(0)$ & $0(0)$ & $0(0)$ & $0(0)$ & $\begin{array}{c}0.3 \\
(0.3)\end{array}$ & $\begin{array}{c}0.3 \\
(0.3)\end{array}$ & $0(0)$ \\
\hline Serranidae & $\begin{array}{l}\text { Cephalopholis } \\
\text { argus }\end{array}$ & $0(0)$ & $0(0)$ & $0(0)$ & $0(0)$ & $0(0)$ & $0(0)$ & $\begin{array}{c}0.3 \\
(0.3)\end{array}$ & $0(0)$ & $\begin{array}{c}0.3 \\
(0.3)\end{array}$ \\
\hline Serranidae & $\begin{array}{l}\text { Cephalopholis } \\
\text { cyanostigma }\end{array}$ & $0(0)$ & $0(0)$ & $0(0)$ & $0(0)$ & $0(0)$ & $0(0)$ & $0(0)$ & $0(0)$ & $\begin{array}{c}0.3 \\
(0.3)\end{array}$ \\
\hline Serranidae & $\begin{array}{l}\text { Cephalopholis } \\
\text { leopardus }\end{array}$ & $0(0)$ & $0(0)$ & $\begin{array}{c}0.7 \\
(0.7)\end{array}$ & $0(0)$ & $0(0)$ & $\begin{array}{c}0.3 \\
(0.3)\end{array}$ & $0(0)$ & $0(0)$ & $0(0)$ \\
\hline Serranidae & $\begin{array}{l}\text { Cephalopholis } \\
\text { miniata }\end{array}$ & $0(0)$ & $0(0)$ & $0(0)$ & $0(0)$ & $0(0)$ & $\begin{array}{c}0.3 \\
(0.3)\end{array}$ & $0(0)$ & $0(0)$ & $0(0)$ \\
\hline Serranidae & $\begin{array}{l}\text { Cephalopholis } \\
\text { sexmaculata }\end{array}$ & $\begin{array}{c}0.3 \\
(0.3)\end{array}$ & $0(0)$ & $0(0)$ & $0(0)$ & $0(0)$ & $0(0)$ & $\begin{array}{c}0.3 \\
(0.3)\end{array}$ & $0(0)$ & $0(0)$ \\
\hline Serranidae & $\begin{array}{l}\text { Cephalopholis } \\
\text { spiloparaea }\end{array}$ & $\begin{array}{c}3.3 \\
(1.3)\end{array}$ & $\begin{array}{c}0.7 \\
(0.3)\end{array}$ & $\begin{array}{c}0.7 \\
(0.7)\end{array}$ & $\begin{array}{c}0.3 \\
(0.3)\end{array}$ & $\begin{array}{c}1.7 \\
(0.3)\end{array}$ & $0(0)$ & $\begin{array}{c}3.3 \\
(0.3)\end{array}$ & $0(0)$ & $0(0)$ \\
\hline Serranidae & $\begin{array}{l}\text { Cephalopholis } \\
\text { urodeta }\end{array}$ & $1(0.6)$ & $0(0)$ & $0(0)$ & $0(0)$ & $0(0)$ & $0(0)$ & $\begin{array}{c}0.7 \\
(0.3)\end{array}$ & $0(0)$ & $0(0)$ \\
\hline Serranidae & $\begin{array}{c}\text { Epinephelus } \\
\text { coeruleopunctatus }\end{array}$ & $0(0)$ & $0(0)$ & $0(0)$ & $0(0)$ & $0(0)$ & $0(0)$ & $0(0)$ & $0(0)$ & $\begin{array}{c}0.3 \\
(0.3)\end{array}$ \\
\hline Serranidae & $\begin{array}{c}\text { Gracila } \\
\text { albomarginata }\end{array}$ & $\begin{array}{c}0.3 \\
(0.3)\end{array}$ & $0(0)$ & $0(0)$ & $0(0)$ & $0(0)$ & $0(0)$ & $\begin{array}{c}0.3 \\
(0.3)\end{array}$ & $0(0)$ & $0(0)$ \\
\hline Siganidae & Siganus guttatus & $0(0)$ & $\begin{array}{c}0.3 \\
(0.3)\end{array}$ & $0(0)$ & $0(0)$ & $0(0)$ & $0(0)$ & $0(0)$ & $0(0)$ & $0(0)$ \\
\hline Siganidae & Siganus puellus & $0(0)$ & $0(0)$ & $\begin{array}{c}0.7 \\
(0.7)\end{array}$ & $0(0)$ & $0(0)$ & $0(0)$ & $0(0)$ & $0(0)$ & $0(0)$ \\
\hline Siganidae & $\begin{array}{c}\text { Siganus } \\
\text { canaliculatus }\end{array}$ & $0(0)$ & $0(0)$ & $0(0)$ & $0(0)$ & $0(0)$ & $0(0)$ & $0(0)$ & $2(2)$ & $0(0)$ \\
\hline Synodontidae & Synodus variegatus & $0(0)$ & $\begin{array}{c}0.7 \\
(0.3)\end{array}$ & $0(0)$ & $\begin{array}{c}0.3 \\
(0.3)\end{array}$ & $0(0)$ & $\begin{array}{c}0.3 \\
(0.3)\end{array}$ & $0(0)$ & $\begin{array}{c}0.3 \\
(0.3)\end{array}$ & $0(0)$ \\
\hline
\end{tabular}




\begin{tabular}{|c|c|c|c|c|c|c|c|c|c|c|}
\hline Tetradontidae & $\begin{array}{c}\text { Arothron } \\
\text { nigropunctatus }\end{array}$ & $0(0)$ & $0(0)$ & $0(0)$ & $\begin{array}{c}0.3 \\
(0.3)\end{array}$ & $0(0)$ & $0(0)$ & $0(0)$ & $0(0)$ & $\begin{array}{c}0.3 \\
(0.3)\end{array}$ \\
\hline Tetradontidae & $\begin{array}{c}\text { Canthigaster } \\
\text { papua }\end{array}$ & $\begin{array}{c}1.3 \\
(0.9)\end{array}$ & $\begin{array}{c}0.3 \\
(0.3)\end{array}$ & $0(0)$ & $\begin{array}{c}2.3 \\
(1.2)\end{array}$ & $\begin{array}{c}0.3 \\
(0.3)\end{array}$ & $\begin{array}{c}1 \\
(0.6)\end{array}$ & $\begin{array}{c}1.3 \\
(0.3)\end{array}$ & $\begin{array}{c}1.7 \\
(0.9)\end{array}$ & $1(0)$ \\
\hline Tetradontidae & $\begin{array}{c}\text { Canthigaster } \\
\text { valentini }\end{array}$ & $0(0)$ & $\begin{array}{c}0.3 \\
(0.3)\end{array}$ & $0(0)$ & $0(0)$ & $0(0)$ & $0(0)$ & $1(0.6)$ & $0(0)$ & $\begin{array}{c}0.7 \\
(0.7)\end{array}$ \\
\hline Zanclidae & Zanclus comutus & $\begin{array}{c}1.7 \\
(1.7)\end{array}$ & $1(0.6)$ & $3(1.5)$ & $\begin{array}{c}0.7 \\
(0.3)\end{array}$ & $\begin{array}{c}1.3 \\
(1.3)\end{array}$ & $\begin{array}{c}2.7 \\
(0.3)\end{array}$ & $0(0)$ & $4(1.7)$ & $\begin{array}{c}1.7 \\
(1.2)\end{array}$ \\
\hline
\end{tabular}




\section{Appendix 4}

Fish Gut Contents pilot study

In 2009 a pilot study was carried out to examine the feasibility of large-scale fish gut content survey and to determine whether this approach could be used to identify which fish were feeding on sponges, the relative contribution of sponges to the diets of spongivorous fish and which sponge species were being fed on. Fish were bought from local fisherman, their gut contents removed and dissolved in bleach and examined under a microscope for the presence of spicules. A number of difficulties were encountered with this approach. Firstly, it was difficult to obtain some of the potentially spongivorous fish (e.g. angelfish) as they are not commonly targeted by fisherman. Secondly, although I had hoped that gut content analysis could be used to confirm whether certain species such as the mimic surgeonfish were feeding on sponge tissue or consuming detritus on the surfaces of sponges I found that the evidence from analyzing their gut contents was inconclusive. Some surgeonfish including mimic surgeons have a muscular, gizzard-like stomach that pulverizes their food so although broken spicules were visible in the bleached gut content samples it was not clear whether consumption was intentional (see fig. 1). Thirdly, identification of sponge species from the gut contents was very difficult as in most cases only spicules were present so it was impossible to tell whether they originated from a single or multiple sponge species.

Figure 1

a)
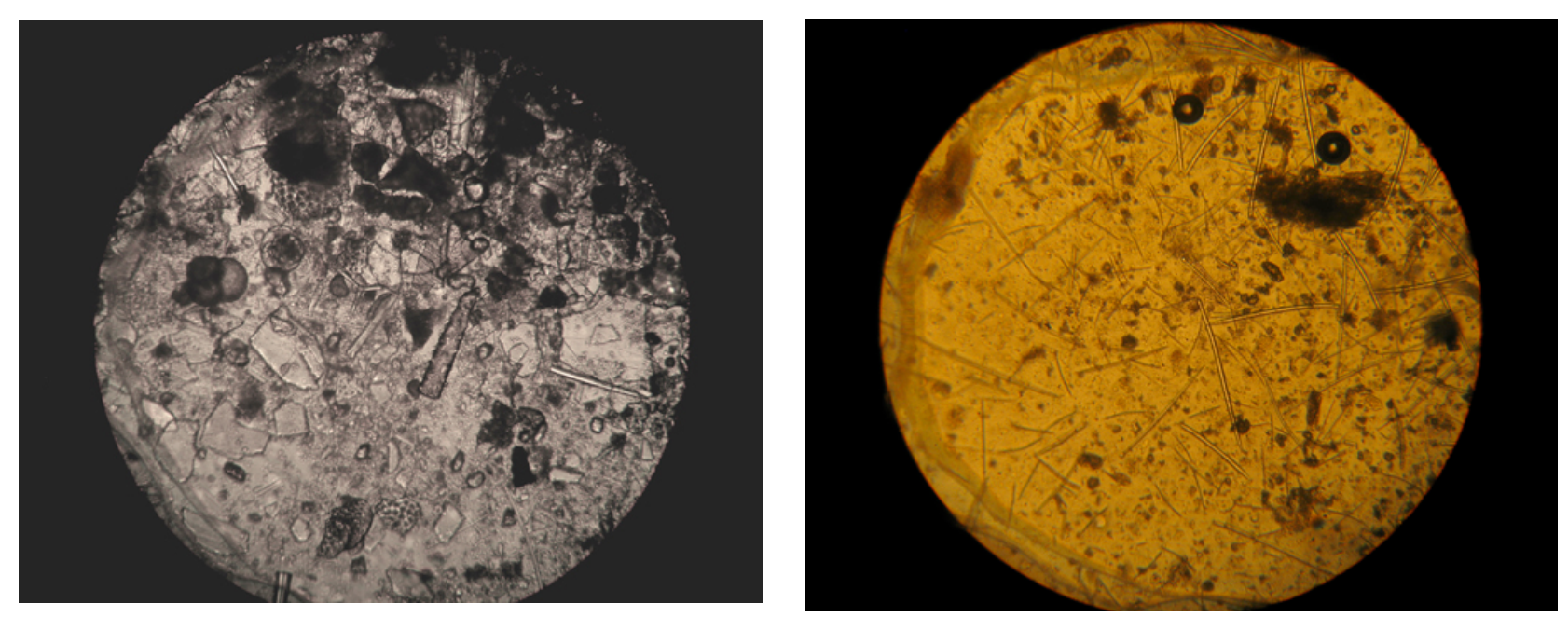

Fig. 1) a) Bleached gut contents of a Regal Angelfish (Pygoplites diacanthus) with visible spicules b) Bleached gut contents of a species with a gizzard the Mimic surgeonfish (Acanthurus pyroferus) where broken spicules are visible. 


\section{Appendix 5}

List of species and Operational Taxonomic Units:

\begin{tabular}{|c|c|c|c|}
\hline \multicolumn{2}{|c|}{ Species } & \multicolumn{2}{|c|}{ Species } \\
\hline 1. & Sycon sp. & 43. & Callyspongia (Euplacella) biru (de \\
\hline 2. & Aaptos sp. & 44 & Stylissa carteri (Dendy 1889) \\
\hline 3. & Topsentia sp. & 44. & \\
\hline 4. & Liosina c.f. gramularis (Kelly Borges \& & 45. & $\begin{array}{l}\text { Petrosia (Petrosia) hoeksemai } \\
\text { Clathria (Thalusias) reinwardti }\end{array}$ \\
\hline 5. & Bergquist, 1988) & & (Vosmaer, 1880) \\
\hline 6. & $\begin{array}{l}\text { Challmula sp. } \\
\text { Dysidea sp. } 17\end{array}$ & 47. & Axinyssa aff. variabilis \\
\hline 7. & Chelonaplysilla sp. & 48. & OTU 1 \\
\hline 8. & Dendrilla $s p$. & 49. & OTU 2 \\
\hline 9. & Haplosclerina Sub order sp. undet. & 50. & OTU 3 \\
\hline 10. & Monanchora unguiculata (Dendy, 1922) & 51. & OTU 4 \\
\hline 11. & Cinachyrella sp. & 52. & OTU 5 \\
\hline 12. & Niphates sp. c.f. 4514 & 53. & OTU 6 \\
\hline 13. & Haliclona sp. & 54. & OTU 7 \\
\hline 14. & Cribochalina sp. & 55. & OTU 8 \\
\hline 15 . & Chalinula milnei (de Laubenfels, 1954) & 56. & OTU 9 \\
\hline 16. & Axinyssa sp. & 57. & OTU 10 \\
\hline 17. & Clathria (Microciona) mima (de & 58. & OTU 11 \\
\hline & Laubenfels, 1954) & 59. & OTU 12 \\
\hline 18. & Cliona orientalis (Thiele, 1900) & 60. & OTU 13 \\
\hline 19. & Pericharax $s p$ & 61. & OTU 14 \\
\hline 20. & Chalinula nematifera (de Laubenfels, & 62. & OTU 15 \\
\hline & 1954) & 63. & OTU 16 \\
\hline 22. & Jaspis splendens & 64. & OTU 17 \\
\hline 23. & Agelas sp. & 65. & OTU 18 \\
\hline 24. & Acanthella sp. & 66. & OTU 19 \\
\hline 25 . & Niphates sp. & 67. & OTU 20 \\
\hline 26. & $\begin{array}{l}\text { Nipnates sp. } \\
\text { Jaspis sp. }\end{array}$ & 68. & OTU 21 \\
\hline 27. & Cribochalina sp. & 69. & OTU 22 \\
\hline 28 . & Clathria (Thalysias) sp. c.f 2322 & 70. & OTU 23 \\
\hline 29. & 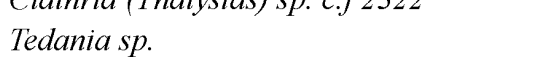 & 71. & OTU 24 \\
\hline 30 . & $\begin{array}{l}\text { Ieacinia sp. } \\
\text { Iotrochota } s p .\end{array}$ & 72. & $\begin{array}{l}\text { OTU } 24 \\
\text { OTU } 25\end{array}$ \\
\hline 31. & $\begin{array}{l}\text { lotrochota } s p . \\
\text { Protosuherites on }\end{array}$ & 73 & $\begin{array}{l}\text { OTU } 25 \\
\text { OTU } 26\end{array}$ \\
\hline 32 . & Protosuberites sp. & 74 & $\begin{array}{l}\text { OTU } 26 \\
\text { OTU } 27\end{array}$ \\
\hline 32. & Desmacella sp. & 74 & OTU 27 \\
\hline 33. & Lamellodysidea herbacea (Keller, 1889) & 75. & \\
\hline 34. & Aaptos suberitoides (Brondsted, 1934) & 76. & OTU 29 \\
\hline 35 . & Hyrtios erectus (Keller, 1889) & 77. & OTU 30 \\
\hline 36. & Niphates olemda (de Laubenfels, 1954) & 78. & OTU 31 \\
\hline 37. & Xestospongia testudinaria (Lamarck, & 79. & OTU 32 \\
\hline & 1815) & 80. & OTU 33 \\
\hline 38 . & Stelletta clavosa (Ridley, 1884) & 81. & OTU 34 \\
\hline 39. & Dactylospongia elegans (Thiele, 1899) & 82 & OTU 35 \\
\hline 40 . & Theonella swinhoei (Gray, 1868) & & \\
\hline 41. & $\begin{array}{l}\text { Callyspongia schulzei (Kieschnick, } \\
\text { 1900) }\end{array}$ & & \\
\hline 42. & Melophlus sarasinorum (Thiele, 1899) & & \\
\hline
\end{tabular}


OTU 1

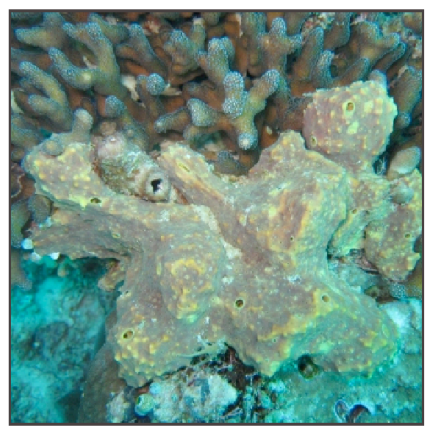

OTU 2

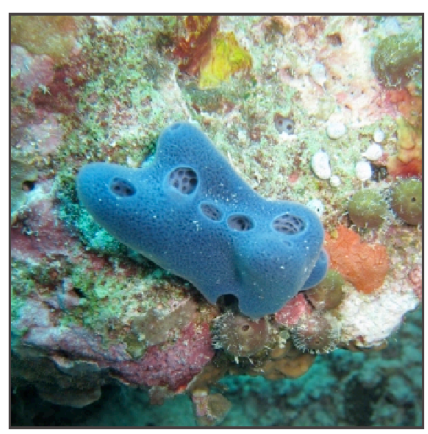

OTU 3

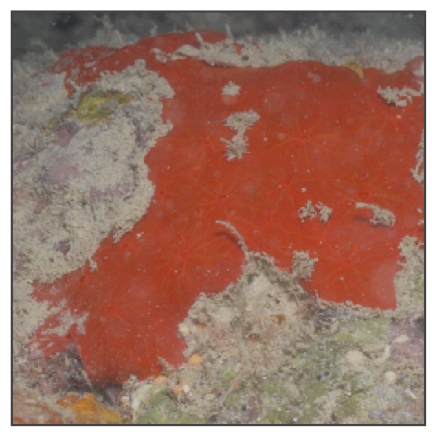

OTU 4

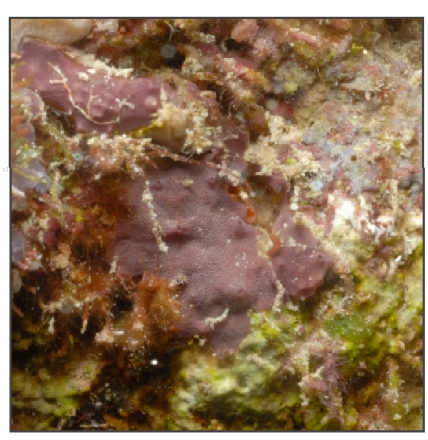

OTU 5

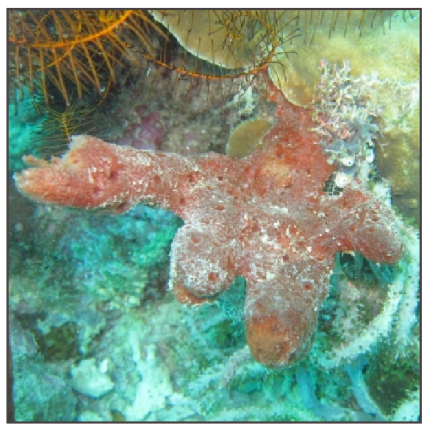

OTU 6

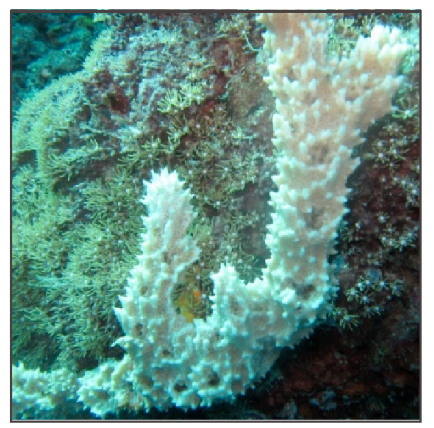

OTU 7

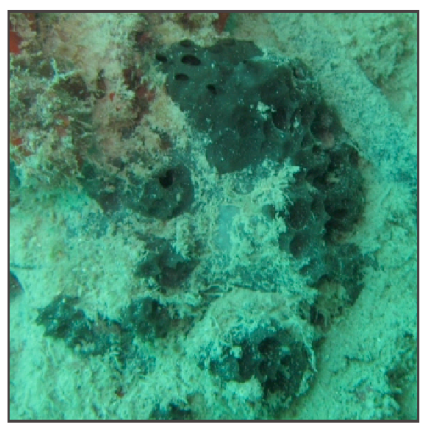

OTU 8

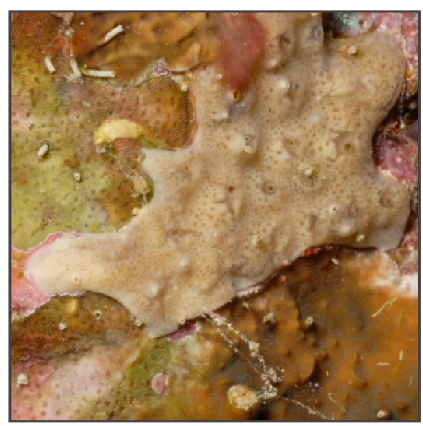

OTU 9

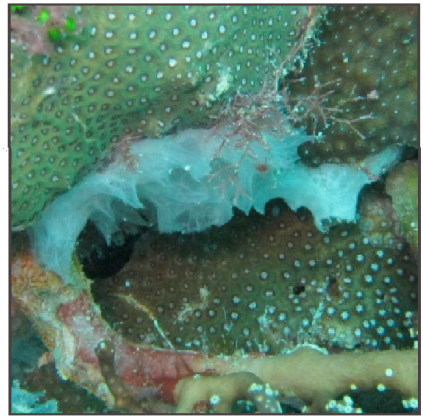

OTU 10

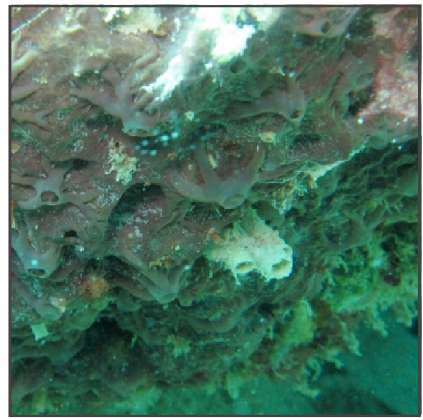



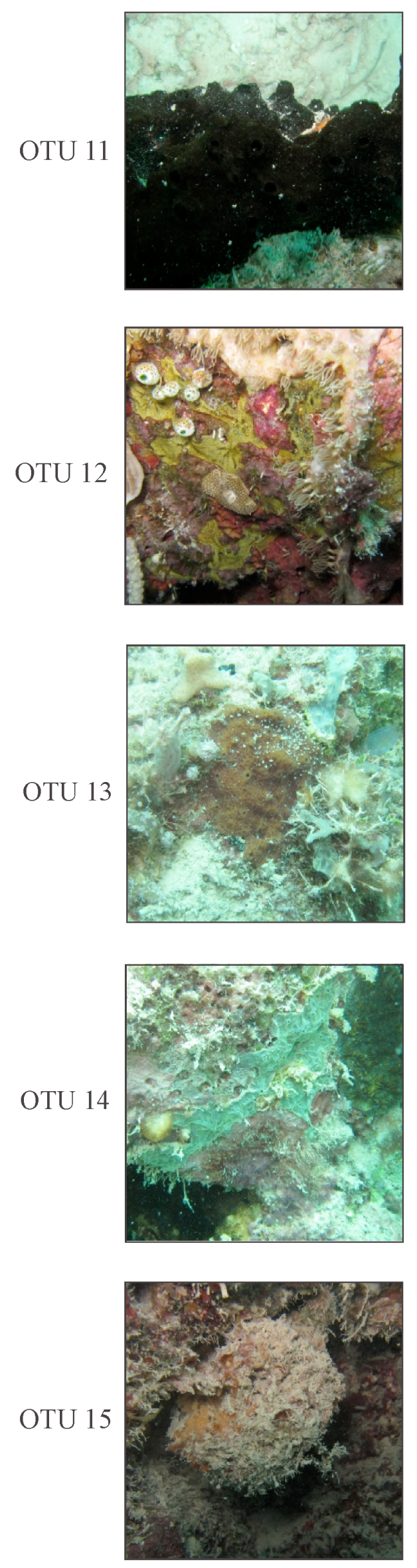

OTU 16

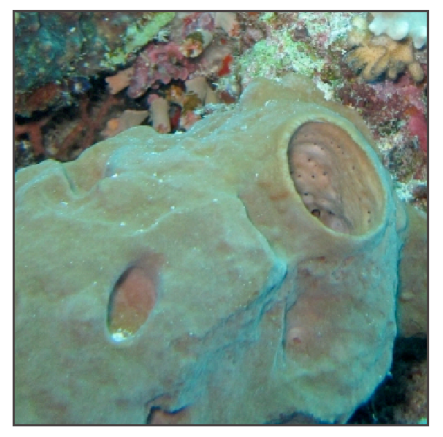

OTU 17

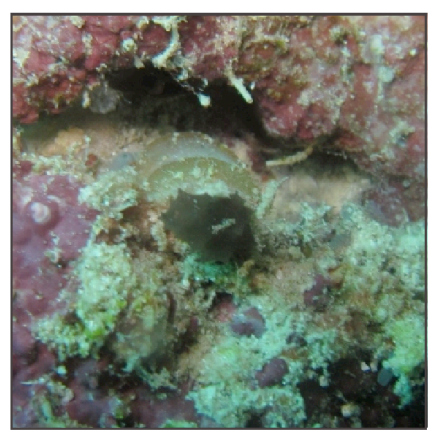

OTU 18

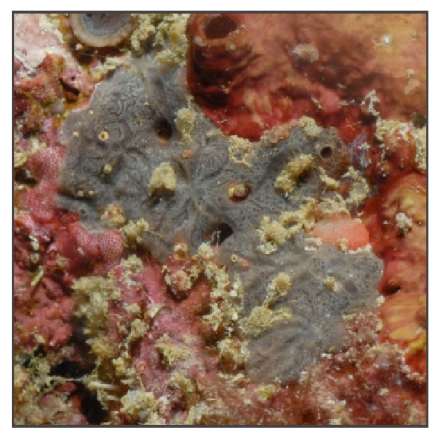

OTU 19

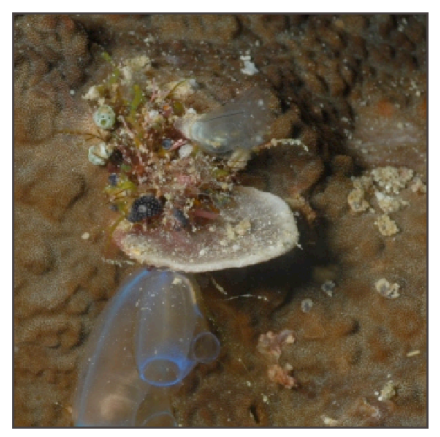

OTU 20

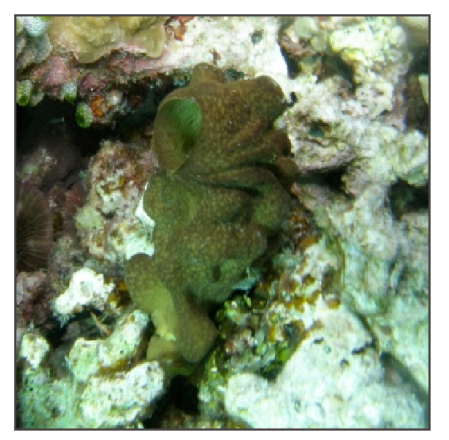



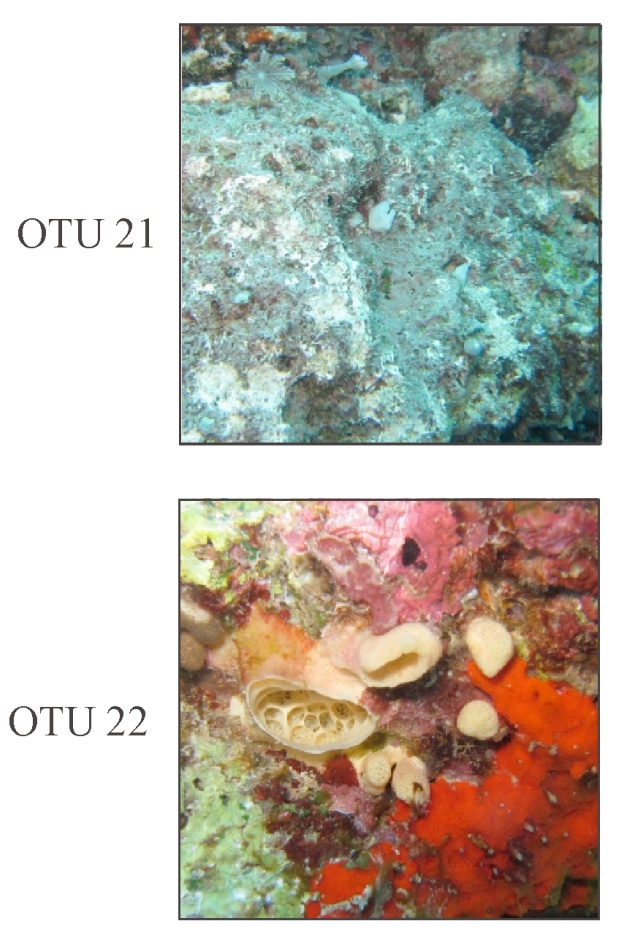

OTU 23

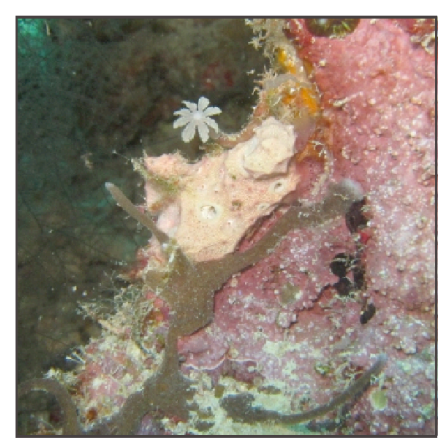

OTU 24

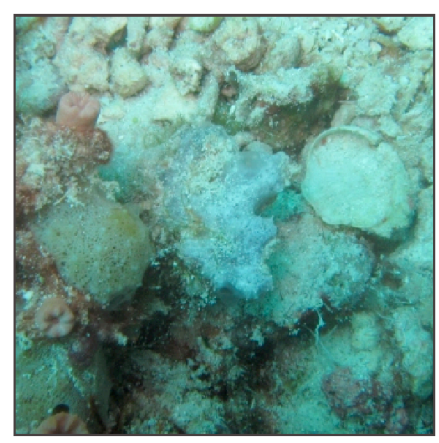

OTU 25

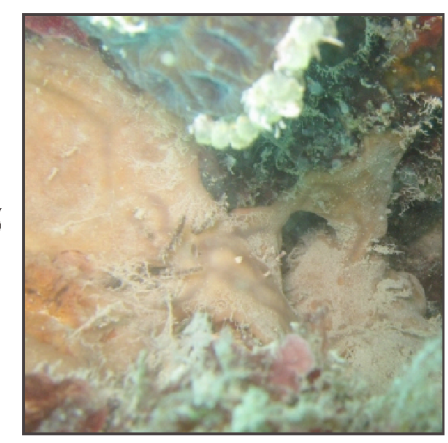

OTU 26

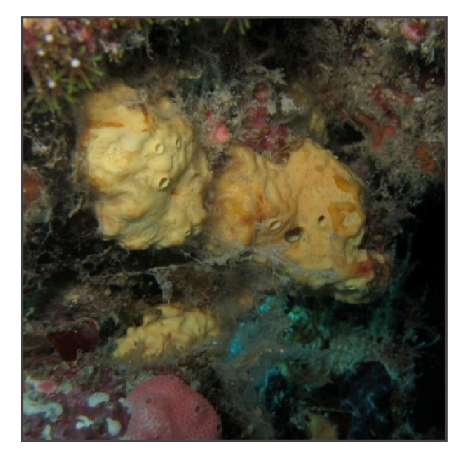

OTU 27

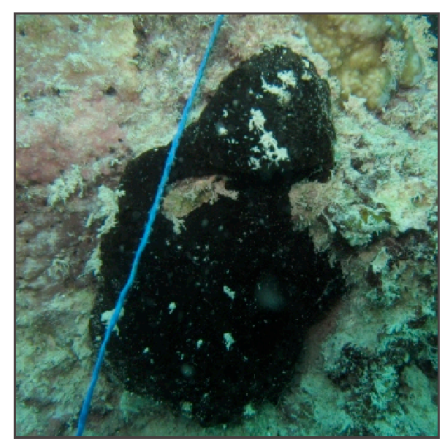

OTU 28

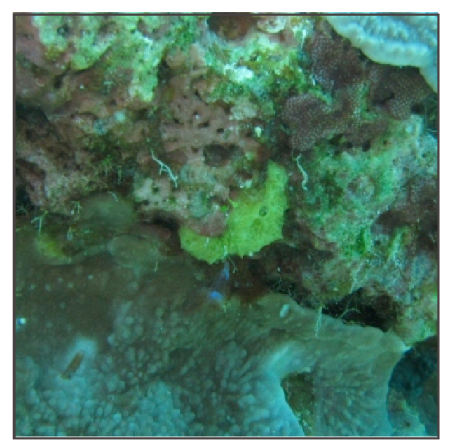

OTU 29

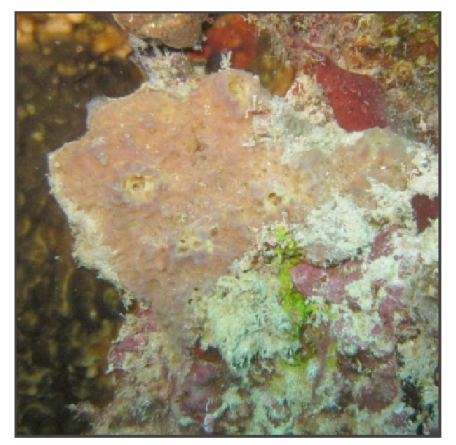

OTU 30

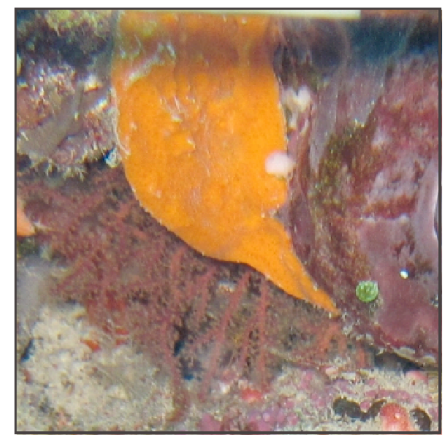



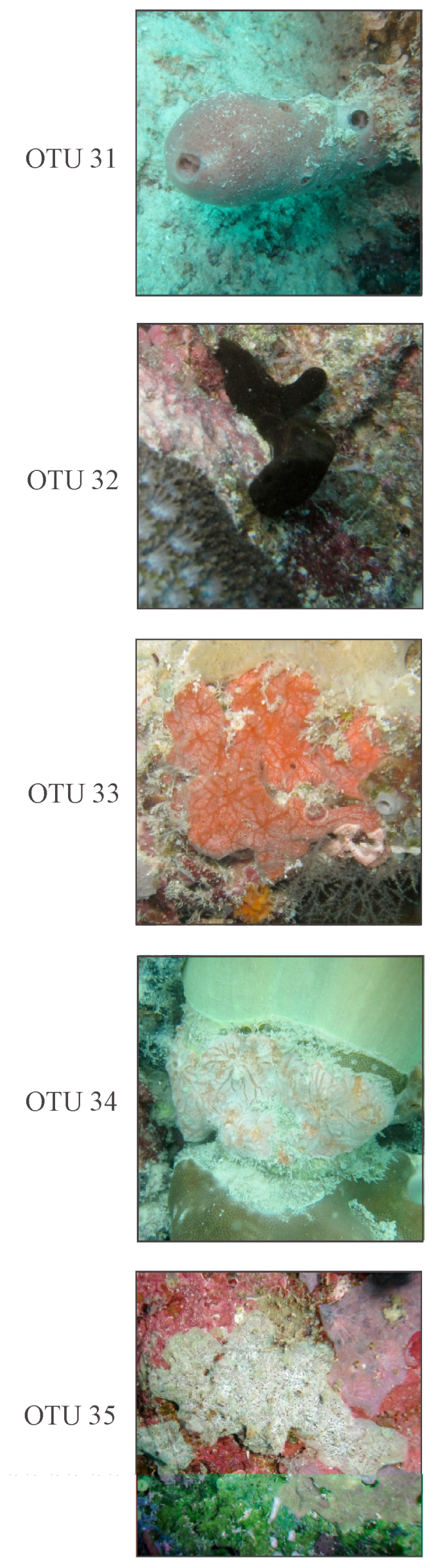


\section{Appendix 6}

To test for effects of excluding predators and possible cage artefact effects, the change in sponge abundance between March and August sampling periods were examined.

\section{Assumption of Normality}

Shapiro-Wilks tests were performed on replicate data from each treatment and site to test for normality of data. These tests revealed that the null hypothesis of normally distributed data could only be rejected (at the $5 \%$ significance level) for one site:Treatment groups, for partial cages at Sampela. However all other groups were adequately described by normal distributions, and so all further analyses are performed assuming normally distributed data (Table 1)

Table 1. Shapiro-Wilks results

\begin{tabular}{llr}
\hline Site & Group & p-value \\
\hline Sampela & Control & 0.8554 \\
& Partial & 0.03888 \\
& Cage & 0.2057 \\
Hoga & Control & 0.629 \\
& Partial & 0.7377 \\
& Cage & 0.3604 \\
\hline \hline
\end{tabular}

\section{Assumption of Homogeneity of Variance}

Homogeneity of variance was examined among all Treatment:Site groups using levenes test. This revealed that variances were significantly different among all experimental levels (Table 2).

Table 2. Results of levenes test for homogeneity of variance 


\begin{tabular}{|c|c|c|c|}
\hline & Df & F value & $\operatorname{Pr}(>F)$ \\
\hline \multirow[t]{2}{*}{ group } & 5 & 3.8239 & 0.006052 \\
\hline & 42 & & \\
\hline
\end{tabular}

Consequently Levenes test was performed between sites to identify whether the assumption of homogeneity of variance was met for among site differences. This revealed that variances were significantly different among sites (Table 3).

Table 3. Levenes test for homogeneity of variances among sites

\begin{tabular}{lrrrr}
\hline & Df & & F value & $\operatorname{Pr}(>\mathrm{F})$ \\
\hline group & & 1 & 5.5275 & 0.02306 \\
& 46 & & \\
& & & & \\
\hline \hline
\end{tabular}

Levenes test was then performed testing for differences among treatment levels, but for each site separately (Table $4 \& 5$ )

Table 4. Levenes test for homogeneity of variances among treatments at Sampela

\begin{tabular}{lcccc}
\hline & Df & & F value & $\operatorname{Pr}(>\mathrm{F})$ \\
\hline group & & & & \\
& & 2 & 2.7553 & 0.08657 \\
& 21 & & \\
& & & & \\
\hline \hline
\end{tabular}

Table 5. Levenes test for homogeneity of variances among treatments at Hoga

\begin{tabular}{lcccc}
\hline & Df & & F value & $\operatorname{Pr}(>\mathrm{F})$ \\
\hline group & & 2 & 2.6597 & 0.09341 \\
& & & \\
& & 21 & & \\
\hline \hline
\end{tabular}

There were no significant differences in variance among treatment levels at Sampela or Hoga, and therefore further analyses were performed separately for Sampela and Hoga testing for Treatment effects using ANOVA. 


\section{Appendix 7}

Barrel sponge predation and regeneration simulation code written by Timothy Jones (2012).

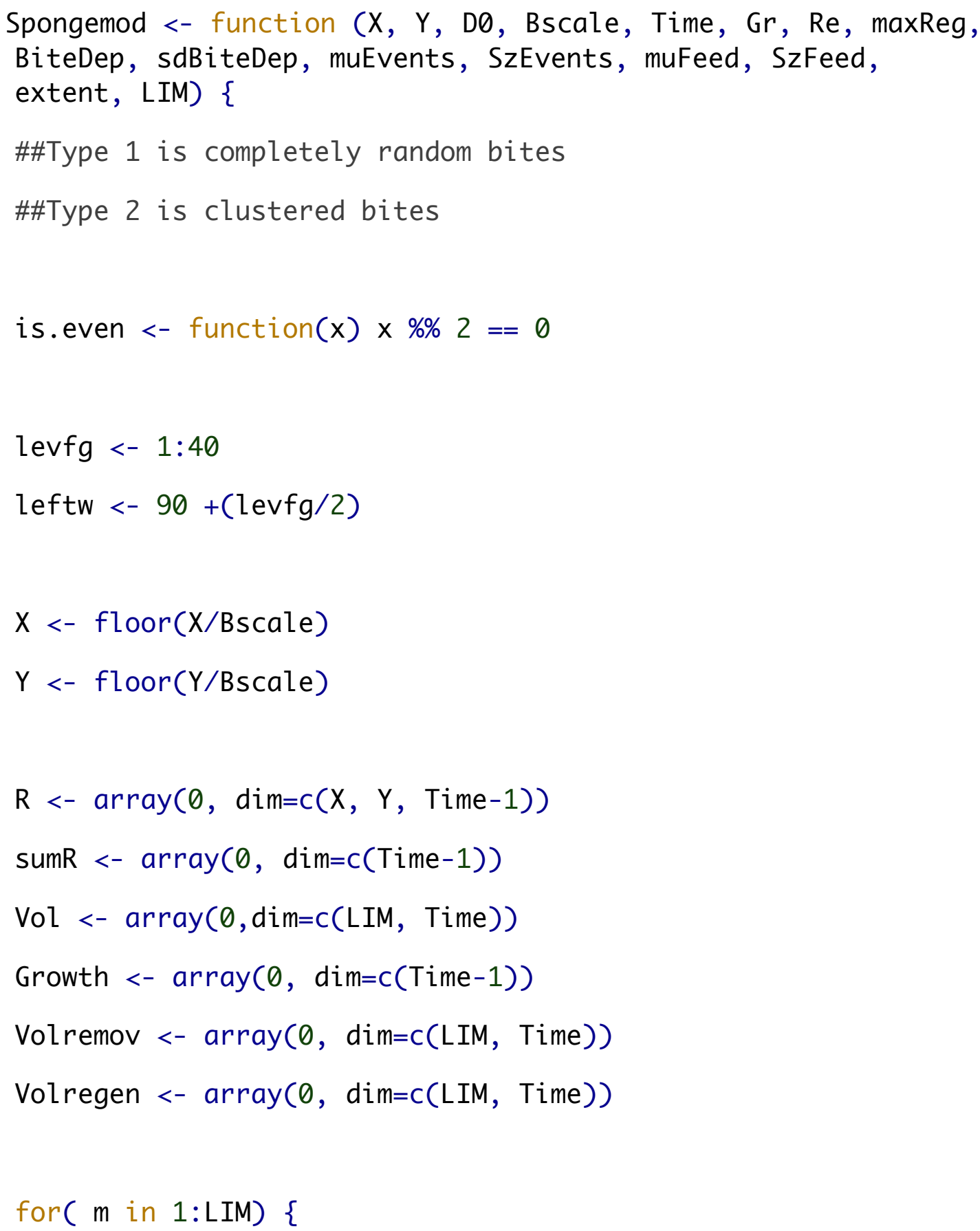




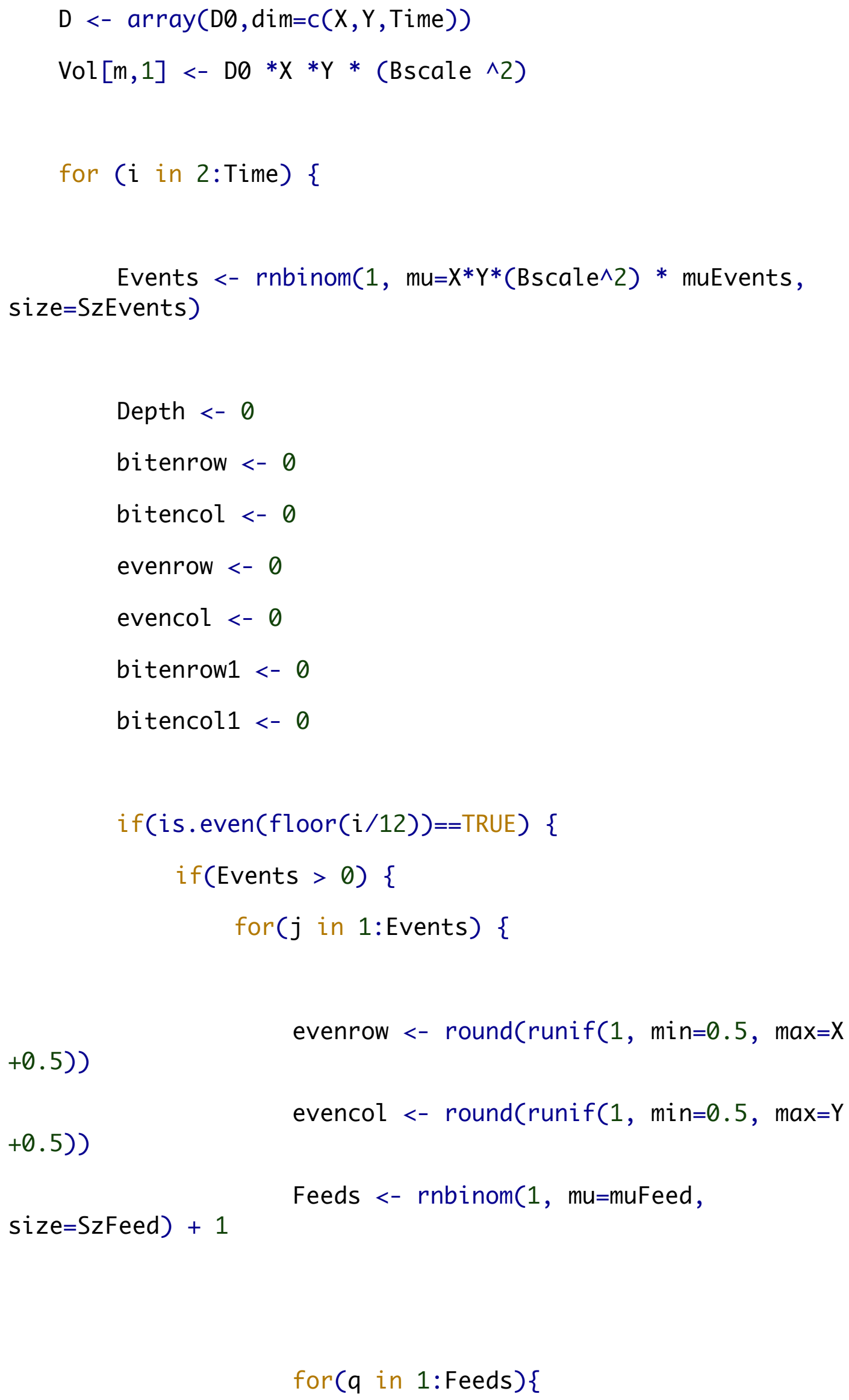

for(q in 1:Feeds) \{ 


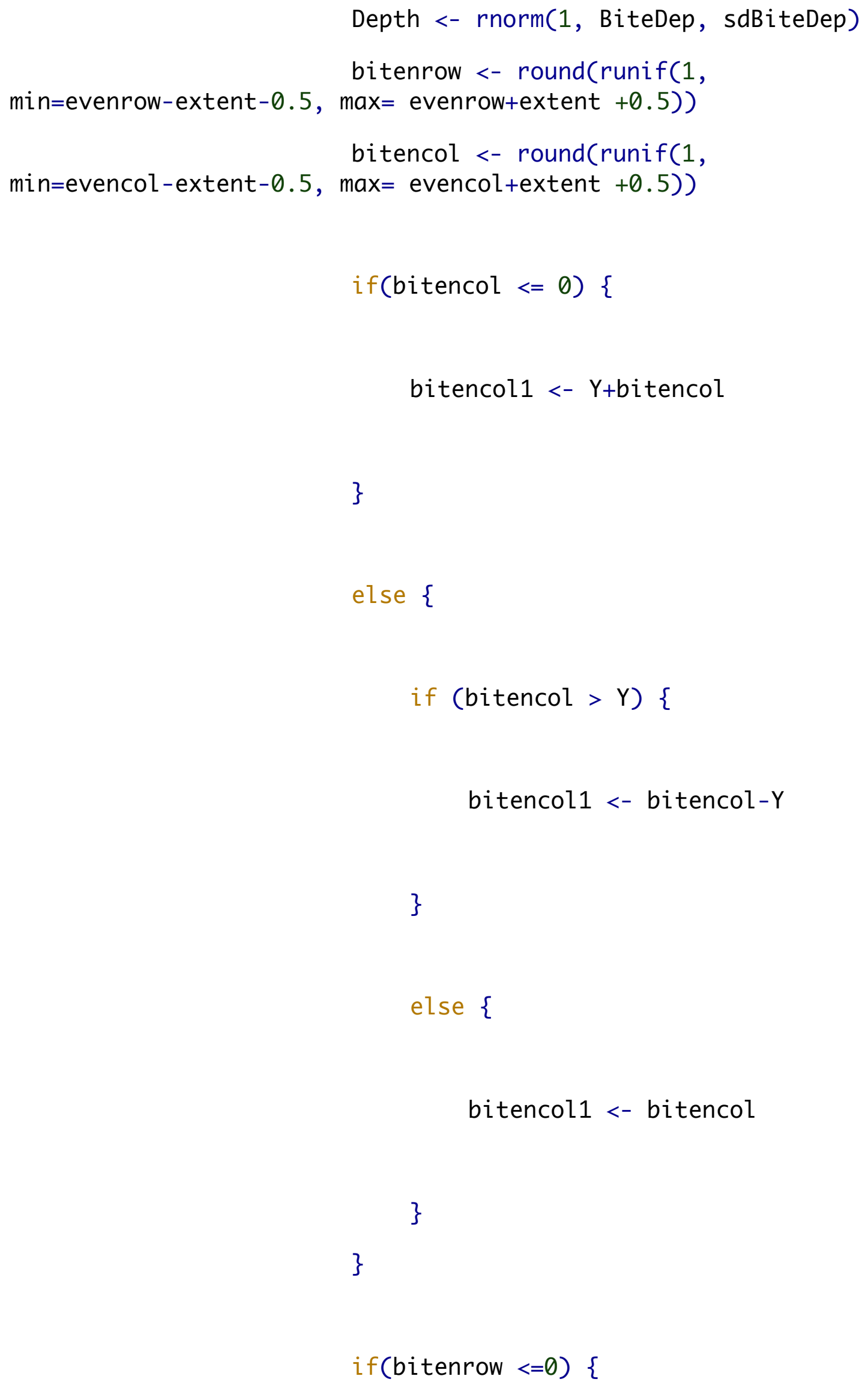


bitenrow1 <- X+bitenrow

\}

else \{

if (bitenrow $>X)\{$

bitenrow1 <- bitenrow-X

\}

else \{

bitenrow1 <- bitenrow

\}

\}

D[bitenrow1, bitencol1, i-1]<D[bitenrow1, bitencol1, i-1] - Depth

Depth

$\operatorname{Volremov}[m, i]<-\operatorname{Volremov}[m, i]+$ 
\}

Volinit $<-\operatorname{sum}(D[,, i-1]) *(B s c a l e \wedge 2)$

LinSize $<-$ Volinit^(1/3)

Age <- $-(1 /(0.0388)) * \log (1-(L i n S i z e / 66.1211))$

LinSize2 $<-66.1211 *(1-\exp (-0.0388 *($ Age $+(1 / 8760))))$

Volinit2 <- LinSize2^3

if $(G r==1)\{$

^2))

Growth $[\mathrm{i}-1]<-($ Volinit2 - Volinit)/(X*Y* (Bscale 


\section{else \{}

Growth $[i-1]<-0$

\}

for $(k$ in $1: X)\{$

for $(\mathrm{l}$ in $1: \mathrm{Y})\{$

Dbar $<-D 0+\operatorname{sum}($ Growth)

Growth $[i-1])) * \exp (\operatorname{Re})$

$$
R[k, l, i-1]<-D[k, l, i]-D[k, l, i-1]
$$

\}

\}

$\operatorname{sum} R[i-1]<-\operatorname{sum}(R[,, i-1]) *\left(B^{\prime} c a l e \wedge 2\right)$

for $(k$ in $1: x)\{$

for $(1$ in $1: Y)\{$ 


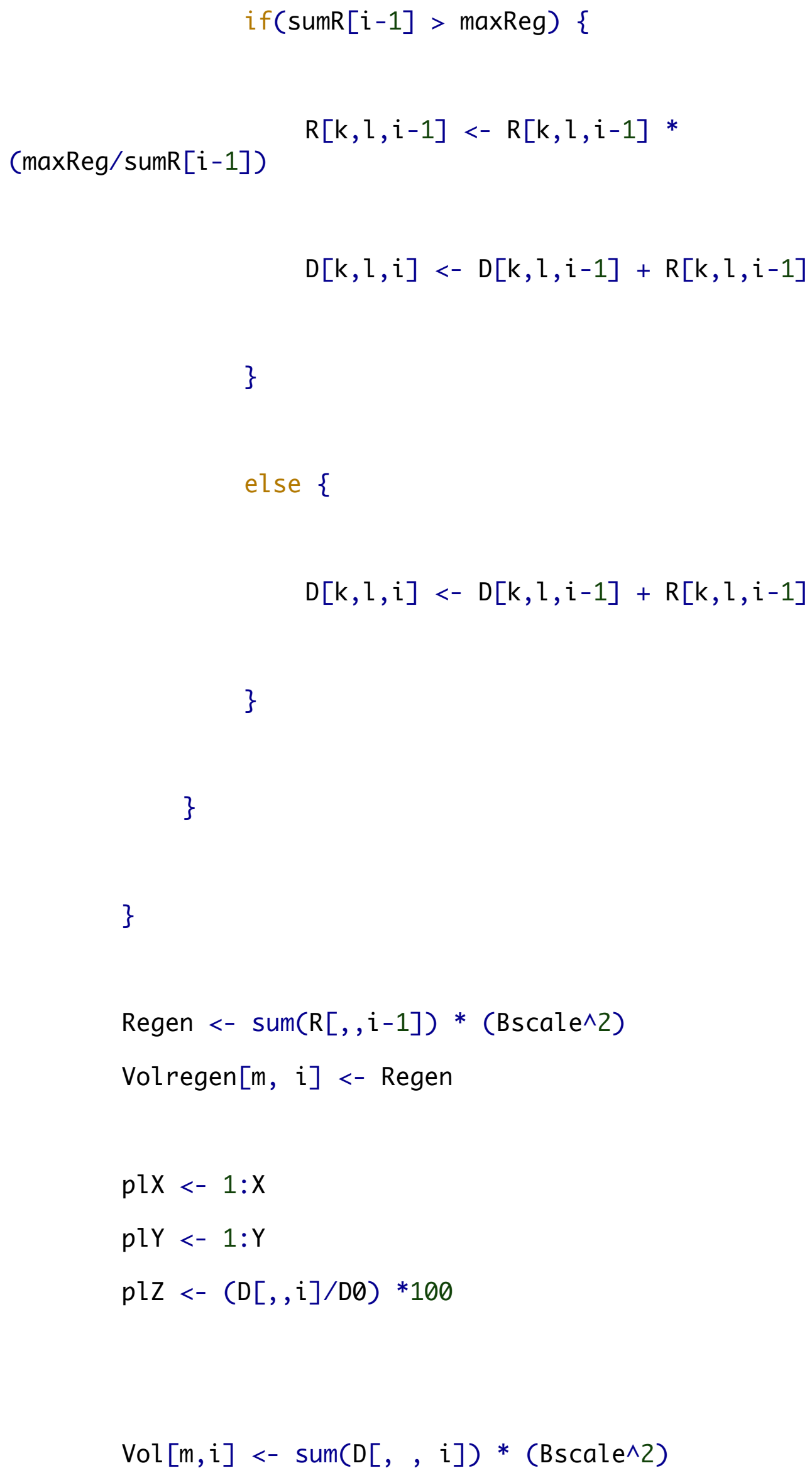




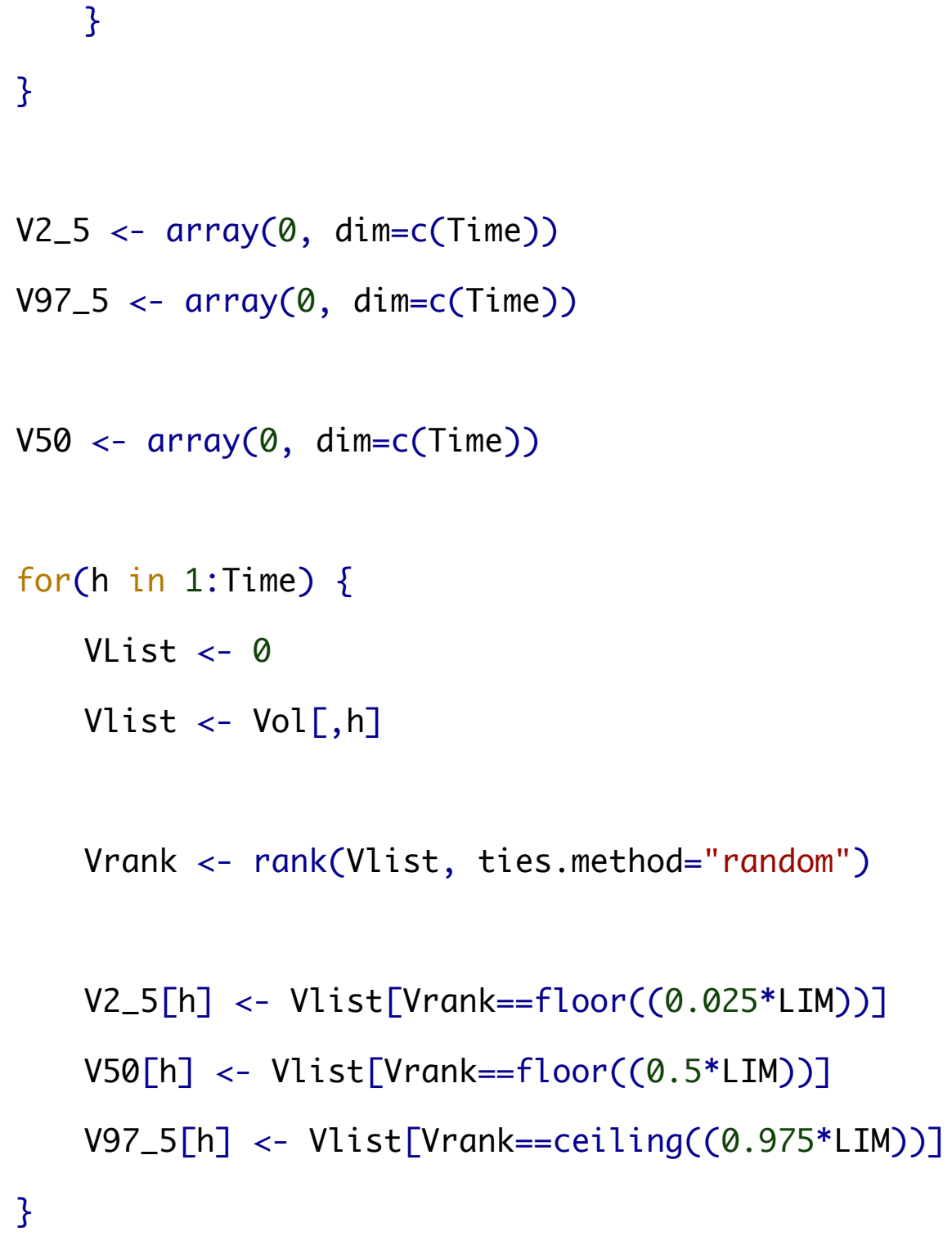


for (j in 1:TimeLim) \{

$$
\begin{aligned}
& \text { Confremov }[K]<-\operatorname{sum}(\operatorname{Volremov}[\mathrm{i},(((j-1) * 24)+1):(j * 24)]) \\
& \text { Confregen }[K]<-\operatorname{sum}(\operatorname{Vol} r e g e n[i,(((j-1) * 24)+1):(j * 24)]) \\
& K<-K+1
\end{aligned}
$$

ConfremovU <- Confremov[rank(Confremov, ties.method="random") $==\operatorname{ceiling}((0.975 *$ LIM*TimeLim) $)]$

ConfremovL <- Confremov[rank(Confremov, ties.method="random") $==\operatorname{floor}((0.025 * \mathrm{LIM} *$ TimeLim $))]$

ConfremovM <- Confremov[rank(Confremov, ties.method="random") $==\operatorname{floor}((0.5 *$ LIM*TimeLim $))]$

ConfregenU <- Confregen[rank(Confregen, ties.method="random") $==\operatorname{ceiling}((0.975 *$ LIM*TimeLim) $)]$

ConfregenL <- Confregen[rank(Confregen, ties.method="random") $==\operatorname{floor}((0.025 * \mathrm{LIM} *$ TimeLim $))]$

ConfregenM <- Confregen[rank(Confregen, ties.method="random") $==\operatorname{floor}((0.5 * \operatorname{LIM} *$ TimeLim) $)]$

print("Volume removed in 24 hour period")

print(ConfremovM)

print("With 95\% confidence interval")

print(paste("(", ConfremovL, ",", ConfremovU, ")")) 
print("Volume regenerated in 24 hour period")

print(ConfregenM)

print("With 95\% confidence interval")

print(paste("(", Confregent, ",", ConfregenU, ")"))

write.csv(D[, ,Time], file="Abi_barrel.csv")

write.csv(Vol, file="Output_Barrel_mod.csv")

write.csv(Volremov, file="VolumeRemov.csv")

write.csv(Volregen, file="VolumeRegen.csv")

Vconf <- data.frame(V2_5, V50, V97_5)

write.csv(Vconf, file="Barrel_Confidence.csv")

\}

Spongemod $(1,1,2,0.2,26,0,-0.05,1000,0.15,0.03,0.2$, $1,9,1,5,1000)$

Spongemod (X, Y, D0, Bscale, Time, Gr, Re, maxReg, BiteDep, sdBiteDep, muEvents, SzEvents, muFeed, SzFeed, extent, LIM) 
Spongemod $(1,1,2,0.1,720,0,-0.00346,1000,0.15,0.03$, $0.002,1,9,1,5,10)$ 